\title{
Under the skin of truancy in Aotearoa (New Zealand): A grounded theory study of young people's perspectives
}

By

\section{Delia Baskerville}

A thesis submitted to the Victoria University of Wellington in fulfilment of the requirements of the degree of

Doctor of Philosophy in Education

2019

Citation: Baskerville, D. J. (PhD thesis). Under the skin of truancy in Aotearoa (New Zealand): A grounded theory study of young people's perspectives.

Wellington: Victoria University of Wellington, New Zealand. 


\begin{abstract}
Truancy is a longstanding, unresolved educational issue in countries where there are compulsory attendance policies. Taking time out from class without permission is illegal and negatively influences future functioning for students who truant in regards to employment, family and community. Truancy represents a long-term cost to society in expenditure on health, well-being and incarceration.

Previous research has focused on key demographic variables related to truancy, causal factors, and a variety of viewpoints. However, there has been a paucity of evidence about truancy from student perspectives. Therefore, the purpose of this research was twofold; (1) to investigate how secondary school students who truant constructed meaning about their experiences, and (2) to develop a substantive theory that identified how participants constructed the processes involved in truanting. This thesis used a grounded theory approach, concurrently gathering and analysing data generated through interviews with 13 young people from three schools and an activity centre.
\end{abstract}

Students in the study referred to truanting as wagging. In respect of this, the study presents a process theory of wagging which identifies four stages: Wagging-inclass; leaving; awakening, and reincluding. The study contributes to truancy scholarship in several ways, which include the experiences and challenges occurring in class and in their personal lives that contribute to youth truanting; how youth reposition themselves when they truant; the nature of their interactions and the group they truant with; what causes them to realise there is no future value in truanting; the conditions that support them to reintegrate in class after truanting; and why they are able to return and attend school regularly after truanting.

Further findings indicate that teacher intentional behaviours and student willingness to change are necessary to support the further development of inclusive practices in schools required to address truancy. The recommendations made for school leaders, teachers, counsellors, teacher educators and policy makers include four suggestions: (1) building teacher-student rapport, links with whānau, and school connectedness; (2) more proactive, sustained and consistent monitoring of student attendance; (3) reviewing school systems to foster inclusiveness and student attendance; and (4) providing a strong focus on inclusiveness within teacher education and professional development programmes. Future research and development opportunities are also identified, for example, the design of an ethnodrama to disseminate the results of this study and to heighten awareness of the dangers of wagging to students and the 
community. The intention is also to research the audience reactions and responses to the ethnodrama. This thesis also draws attention to the need for further studies to replicate the design features of the present study in other contexts so as to confirm, modify, extend or challenge the process theory of wagging that has emerged from this research.

Key words: truancy, wagging, student perspectives, process theory, teacher-student relationships, teacher intentionality 


\section{ACKNOWLEDGEMENTS}

Thanks to the many people who have supported me during this doctoral process. First, thanks are due to those who participated in the interviews - the young people who truanted. Thank you for the privilege of meeting with you and for trusting me with your stories. Without your assistance, and the valuable information you provided, this research would not have been possible. Thanks also to the participating schools (boards of trustee members, principal, and management teams) for granting me access to your schools and consequently supporting me to conduct this research. To all my past and current students - primary, secondary, and tertiary - thank you for the privilege of teaching you all, for the learning, the challenges I have experienced, the insights I have gained, and for the inspiration you gave me to want to investigate this topic.

I wish to extend my sincere thanks and gratitude to my supervisors who assisted me through this journey: Dr. Judith Loveridge, Dr. Kay de Vires and Emeritus Professor Cedric Hall. I truly appreciate your expertise, wise guidance, many conversations, feedback, and commitment to my work. Thanks to Victoria University for study leave, my head of school, Dr. Caroline Tait, and school colleagues - especially Liz Melchior for support with workload and encouragement during this journey.

My wonderful family, I love you and thank you for the patience you have shown regarding my "absence" in your lives in order to complete this significant task. My special friends - Chris Bowden, Bernadette Hall, Suanne Gibson, Cath Growcott, Perry Piercy, Tricia McGuinness, Diana Mardon and Jude Parrett - I love you for your patience, encouragement, generosity, and unwavering support. Thank you all for believing in me.

I dedicate this doctorate to my late father, Don Baskerville. Thank you Dad for your vision to give us a better life in New Zealand, for prioritising my education, and for guiding and protecting me. I miss your South East London accent, humour, resilience, support, and guidance. I am sorry you are not here to see me realise your immigrant dream. 


\title{
GLOSSARY OF TERMS
}

\section{RELATING TO THE PROCESS THEORY OF WAGGING}

\begin{abstract}
Absconding is a term that refers to the action of youth to leave class without permission. The motives of students who abscond include getting away from teachers, peers, and perceived problems in class and the need for time to be alone to deal with personal, family, and school negative experiences. Absconding identifies the negative experiences that "push" students to leave class. (See also "leaving" and "mattering".)

Accommodating is the nature of teacher and peer interactions that provide the social structures and acceptance that youth who truant need to alleviate vulnerability in the classroom, stop truanting, feel included, be psychologically present, and participate in learning.
\end{abstract}

Awakening is a term used to explain defining moments, times when participants came to the realisation that there was no future in wagging. This positioning evoked significant change in their behaviour and attitudes and these changes reshaped participants' future directions.

Detaching refers to the process of intellectual, social and emotional withdrawal which students, who subsequently truant, experience when they feel excluded by teachers or less important or inferior to other students in class, as a consequence of perceived negative actions and behaviour of teachers and other students. Students may detach from teachers, peers, learning, or all of these:

Detaching from teachers is a response to perceived teachers' prioritisation of other students, sensed unjust treatment, and recognised inadequate support.

Detaching from peers represents the disconnectedness of youth who truant from peers that causes exclusion from activities, evokes a sense of unworthiness, and creates isolation in the classroom environment.

Detaching from learning refers to the obstacles (e.g., material that is too difficult or boring) that youth who truant experience that inhibit their ability to focus and increase their disconnection from the social and academic aspects of class.

Exiting is the term used to explain circumstances when participants lacked sufficient support to change attitudes and behaviours towards attendance. Consequently, they were following a pathway of leaving school. Exiting occurs at a later stage in the "process theory of wagging" than "leaving" (see next).

Leaving describes students' explicit choice to remove themselves from class involving the "push" and "pull" forces of absconding and mattering. The first focuses on the negative school and/or family experiences that youth seek to avoid, the latter on the positive experience of acceptance and enjoyment that students feel when they are with their "outsider" peers. 
Mattering is the enjoyable shared experience that provides opportunities for youth who truant to form close relationships, to feel wanted and accepted, to develop a sense of community, and to receive the support they need to overcome the restlessness and obstacles they experience in classrooms.

Process theory of wagging is the name given to the grounded theory of truancy that is presented here as emergent from youth's perceptions of truancy and the motives or factors that led to their truancy. The theory incorporates all the terms described in this glossary.

Reincluding highlights the restorative approaches, circumstances and social and academic support required to assist youth who truant to turn back to school, attend regularly again, and experience successful outcomes. Reincluding comprises two components: "accommodating" (see earlier) and "willing". The first focuses on the accommodating actions of teachers and peers that are positively received by the youth, the latter on the readiness, desire, and determination of the youth to overcome the challenges faced in reintegrating to school.

Turning is a term used to describe the events and behaviours (applied consistently and with fairness) that happen when other people in youths' lives apply interventions or act in ways that signal to youth who truant that their behaviour is intolerable and that change is expected.

Wagging-in-class is a state of being representing the responses of youth to negative aspects of the classroom environment that lead them to detach (switch off) from class participation and learning. Wagging-in-class is a response to negative classroom dynamics involving the youth with teachers and peers that create or exacerbate obstacles affecting learning.

Willing is student readiness, desire and determination to overcome previous challenges and the underlying factors that provide the impetus to find pathways forward, envision success, attend class again, and stop truanting. 


\section{TABLE OF CONTENTS}

Abstract i

Acknowledgements iii

Glossary of terms relating to the process theory of wagging iv

Table of contents vi

List of tables $\quad$ ix

List of figures $\quad$ ix

Chapter 1: Research background and context 1

1.1 The significance of truancy and the research aim 1

1.2 Defining truancy 3

1.3 The New Zealand context 6

1.4 New Zealand law 10

$\begin{array}{lll}1.5 & \text { Researcher background } & 12\end{array}$

1.6 Thesis organisation 14

$\begin{array}{ll}\text { Chapter 2: } \text { Literature review } & 16\end{array}$

2.1 Introduction 16

2.2 Historical development of truancy scholarship 17

2.2.1 Historical attribution of blame 17

2.2.2 Truancy: Analysis of causal factors 20

2.2.3 Truancy trends in New Zealand 29

2.2.4 Key demographic variables related to truancy 34

2.3 Second literature review $\quad 39$

2.3.1 Positioning of youth 40

2.3.2 Youth perceptions of causes of truancy 45

2.3.3 Youth perceptions of factors that support change 48

2.4 Literature review: Summary 54

Chapter 3: Methodology

3.1 Introduction $\quad 59$

3.2 Research aim and question $\quad 59$

3.3 Justification of research design 60

$\begin{array}{lll}3.4 & \text { Personal subjectivity } & 61\end{array}$

3.5 Grounded theory methodology 62

3.5.1 The history of grounded theory 63

3.5.2 Grounded Theory's relevance to privileging student voice 68

$\begin{array}{lll}3.5 .2 & \text { Approach taken for this study } & 70\end{array}$ 
3.6.1 Initial objectives of the pilot study 72

3.6.2 Contribution of pilot to main study 73

3.7 Selection of schools and recruiting participants $\quad 75$

3.8 Concurrent data collection and analysis $\quad 82$

3.8.1 Strategies, tools and instruments 82

3.8.2 Sorting and ordering the data 86

3.9 Ensuring the trustworthiness/validity of the research findings 96

3.10 Ethical considerations 102

$\begin{array}{lll}3.11 \text { Limitations } & 104\end{array}$

$\begin{array}{ll}3.12 \text { Conclusion } & 105\end{array}$

Chapter 4: Findings and discussion $\quad 106$

$\begin{array}{lll}4.1 \text { Introduction } & 106\end{array}$

4.2 The nature of wagging 106

4.2.1 Wagging as a common term for truancy 106

4.2.2 Wagging as habit 108

4.2.3 Wagging as response to perceived disrespect in class $\quad 110$

4.2.4 Wagging as an attraction to be with friends 111

4.2.5 Wagging as a time to be alone 113

4.2.6 Summary of students' perspectives on wagging 114

4.3 A process theory of wagging: Overview 115

4.4 Process theory of wagging: Stage 1 - Wagging-in-class 116

4.4.1 Introduction to wagging-in-class 116

4.4.2 Detaching from teachers 118

$\begin{array}{lll}\text { 4.4.3 Detaching from peers } & 122\end{array}$

$\begin{array}{lll}\text { 4.4.4 Detaching from learning } & 127\end{array}$

4.4.5 Wagging-in-class: Summary 129

4.5 Process theory of wagging: Stage 2 - Leaving 130

4.5.1 Introduction to leaving 130

4.5.2 Absconding 131

$\begin{array}{lll}4.5 .3 & \text { Mattering } & 135\end{array}$

4.5.4 Leaving: Summary 141

4.6 Process theory of wagging: Stage 3-Awakening 141

4.6.1 Introduction to awakening 141

4.6.2 Turning 143

$\begin{array}{lll}\text { 4.6.3 Exiting } & 153\end{array}$ 
4.7 Process theory of wagging: Stage 4-Reincluding 158

4.7.1 Introduction to reincluding 158

4.7.2 Accommodating 159

$\begin{array}{lll}4.7 .3 & \text { Willing } & 164\end{array}$

4.7.4 Reincluding: Summary 169

$\begin{array}{lll}4.8 & \text { Chapter summary } & 169\end{array}$

Chapter 5: Conclusion: Contribution, methodological reflections, 171 and implications

$\begin{array}{lll}5.1 & \text { Introduction } & 171\end{array}$

$\begin{array}{lll}5.2 & \text { Contribution to knowledge } & 171\end{array}$

5.2.1 Nature of wagging 172

$\begin{array}{lll}\text { 5.2.2 Causes } & 172\end{array}$

5.2.3 Relationship pedagogy 173

5.2.4 Repositioning 176

5.2.5 Mattering and its implications 177

5.2.6 Reintegrating into class after wagging 178

$\begin{array}{lll}5.3 & \text { Methodological reflections } & 179\end{array}$

5.3.1 Summary of strengths 181

$\begin{array}{lll}\text { 5.3.2 Limitations } & 181\end{array}$

5.4 Implications of the findings for policy and practice 182

5.4.1 Build teacher-student rapport and school connectiveness 183

5.4.2 Monitor student attendance 184

5.4.3 Review school systems to foster inclusiveness and attendance 186

5.44 Recommendations for teacher professional learning 188

5.5 Recommendations for future research 189

$\begin{array}{lll}5.6 \text { Conclusion } & 191\end{array}$

References $\quad 193$

$\begin{array}{ll}\text { Appendices } & 221\end{array}$ 


\section{LIST OF TABLES}

$\begin{array}{lll}\text { Table 3.1 Recruitment sequence } & 77\end{array}$

Table 3.2 Participants in the study 81

$\begin{array}{lll}\text { Table } 3.3 & \text { Sorting and ordering the data } & 87\end{array}$

Table 3.4 Data analysis grid $\quad 89$

Table 3.5 Questioning analysis grid 91

Table 3.6 Category development: Constant comparison involving 93 another sweep of the data, November 2013

Table 3.7 Abstracting ideas towards theory development 95

\section{LIST OF FIGURES}

Figure 2.1 Positioning of students who truant 57

Figure 4.1 A process theory of wagging 116 


\section{CHAPTER 1}

\section{RESEARCH BACKGROUND AND CONTEXT}

\subsection{The significance of truancy and the research aim}

Truancy is a long-standing and serious educational issue in countries where there are compulsory attendance requirements. Across all OECD countries, principals report that school attendance is a critical problem that hinders student learning (OECD, 2015). When students do not attend school, they do not have access to the curriculum, therefore do not engage in school learning (Ministry of Education, 2018) and are at an increased risk of alienation from the education system (Education Counts, 2017). Being absent from classes not only impacts negatively on students who truant, but also other students may suffer due to diminished learning time and disruption to the flow of instruction when students who have been absent obtain assistance to catch up previously missed curriculum (OECD, 2015).

Regular attendance at school is important because it links to school achievement and future career prospects (Malcolm, Wilson, Davidson, \& Kirk, 2003). Absence from class without reason is illegal (Claes, Hooghe, \& Reeskens, 2009) and a lifetime of potential problems have been associated with truancy (Garry, 1996; McCray, 2006). International research, for example, indicates an association between truancy and underachievement (Malcolm et al., 2003), less parental involvement (Vaughn, Maynard, Salas-Wright, Perron, \& Abdon, 2013), unemployment and reduced future learning capacity (Garry, 1996), delinquency, drug involvement, and criminal activity (Baker, Sigmon, \& Nugent, 2001; Strickland, 1999), and poor academic outcomes, school dropout, and incarceration (Catalano, Hawkins, Wells, Miller, \& Brewer, 1991).

Similarly, truancy in New Zealand is a serious problem with evidence that truancy rates have reached their highest level during the last decade. For example, the Ministry of Education (2018), which conducts an annual survey covering attendance data in term two, 
report an increase in non-attendance between 2016 and 2017. The Ministry uses as the criterion for "regular" attendance, a student who is present at school on more than 90 per cent of all half days. However, in 2017 due in part to increased absences because of medical reasons, only $63 \%$ of students attended school regularly in term two, a decrease of 4\% from 2016 (Education Counts, 2018). In 2017 over 280,000 students - more than a third - were absent from schools (Redmond, 2018). In relation to unjustified absences, which are generally attributed to truancy, the rate of absence increased from $1.8 \%$ in 2016 to $2.0 \%$ in 2017 . There was also a sharp increase towards the end of term two in the amount of time students missed classes due to truancy and family holidays taken in term time (Education Counts, 2018).

In New Zealand, students who leave school without qualifications are at increased risk of adverse outcomes, such as developing nicotine dependence, substance use, juvenile offending, receiving a benefit, and engaging in no tertiary training (Fergusson, Swain, Campbell, \& Horwood, 2002). Not surprisingly, evidence exists that truancy negatively affects future functioning, such as later academic achievement, employment, and family and community functioning (Denny et al., 2011). In addition, links exist between truancy and crime, giving cause for concern (Education Counts, 2018). For example, Clark et al. (2010) conducted a study of the behaviour of an extremely high-risk group of youth in alternative education and their health-jeopardising activities. These students report high rates of unprotected sex and pregnancies, not wearing seat belts, and driving dangerously. Clearly, truancy represents a long-term cost to societies (e.g., expenditure on health, well-being, and incarceration), both nationally and internationally. Consequently, greater understanding of truancy and the signals that indicate a problem exists in schools and communities is a worthwhile focus for educational analysis. 


\section{Research aim}

This research focused on the voices of students who did not attend school and their experiences in mainstream education, thus acknowledging some of the vulnerable young people in the school system. The aim of the research was to learn about how a sample of 13 students experienced their world of truancy and how they interpreted the social aspects of their personal, educational, and home circumstances. I wanted to understand their behaviours and construct a theory about the basic social process that accounted for most of the similarities and variations in the reported behaviour. The overarching question was: How do secondary school students in New Zealand construct meaning from their experiences of truancy? This research has the potential to support educators to develop further understanding of factors that influence truancy and uncover the progression of truancy in relation to its characteristic patterns. Furthermore, it is possible that this study has the capacity to identify when intervention is likely to be effective in reducing both incidents of truancy and the long-term cost to our society.

\subsection{Defining truancy}

Although both research and policy contribute to the different ways school absenteeism and truancy are framed, definitions of truancy differ in academic literature. For example, Tyerman (1968) interpreted the word truancy to refer to when students initiate their absence from school without parental consent. However, the Ministry of Education (MoE), 2010 states that the term truancy applies when a student is absent from school without explanation, or satisfactory explanation, to the principal. Students who truanted were interviewed in a study by Wilson, Malcom, Edward and Davidson (2008) and indicated that their absence required permission from teachers. In other words, while agreement exists that truancy refers to students being absent without permission, different views exist on whose permission is required. Other perspectives also exist in the literature. For example, Reynolds and Murgatroyd (1977) suggest that whatever the 
reason, every child who is absent from school without permission should be categorised as truant. Likewise, Gase, Defossest, Perry, and Kuo (2016) define school truancy as "any intentional, unauthorized or illegal absence from school" (p. 299). In a similar vein, Veenstra, Lindenberg, Tinga, and Ormel (2010) suggest truancy occurs when "a child was absent one day or more from school without a valid reason" (p. 304). These three definitions or descriptions of truancy avoid specifying the authority relating to permission, although the reference to "illegal absence" in the definition by Gase et al. (2016) identifies that a legal basis generally exists.

A study of non-attendance by Malcolm et al. (2003) highlights further the complications underlying a common understanding of absence. They identified three distinctions in the use of the concept of non-attendance: they defined truancy as "absences which pupils themselves indicated would be unacceptable to teachers"; unacceptable absences as "absences which were unacceptable to teacher and local authorities but not recognised as such to pupils"; and parental condoned absences as non-attendance "related to parents/caregivers keeping pupils away from school" (p. 4). However, as noted by Reid (2010), other researchers might consider that not all three of these definitions constitute truancy, whereas others would suggest that they did.

The notion of "unexplained absence" is the most commonly accepted element of a definition of truancy but this is problematic due to inconsistencies between schools in the way they record and report absence. In other words, the coding and reliability of unexplained absence data across schools is questionable either because of different interpretations of truancy (Zhang, 2003) or because of the degree of (in) consistency of daily record-keeping (Heilbrunn, 2007). Zhang (2003) notes that different authors are referring to different aspects of truancy and he suggests that the old system of marking students present or absent would simplify this problem.

The debate about what constitutes truancy is clearly complex. As pointed out by Wilson, Edward, and Davidson (2008), the concept of truancy represents different things 
to different researchers. The challenge involves the recognition of different kinds of school absenteeism. For example, absenteeism covers absence without legal authority (truancy), parentally condoned absence (illegal or not), absence from specific classes or lessons, psychologically or medically recognised absence, and school refusal or school phobia on the part of students. Because students being absent without good reason is often equated to truancy regardless of the cause, it is essential to clarify and understand what truancy means (Reid, 2010).

One area within which there appears to be greater consensus relates to the distinction between truancy described as school avoidance behaviour associated with anti-social tendencies and school refusal described as a psychological disorder with anxiety symptoms (Kearney, 2002). The latter may sometimes be related to parental emotional distress that leads to parental-condoned absence (Dembo, Wareham, Schmeidler, Briones-Robinson, \& Winters, 2016). With such complexity and historical definitional inconsistency, it is difficult to ascertain the extent of the truancy phenomenon as evidenced in either the lack of, or inconsistent truancy statistics across districts (National Centre for School Engagement, 2007). Even though Coldman (1995) concluded that a major reason for truancy was curriculum due to lesson-truancy being more prevalent than whole-day truancy, statistical recording and analysis is problematic because the application of definitions to practice is complicated.

As a definition provides the parameters for managing truancy, a universal definition is the first step in the facilitation of better comparisons (Gentle-Genitty, Karikari, Chen, Wilka, \& Kim, 2015). These researchers embarked on synthesising literature, as well as conducting focus group interviews with truancy experts in an attempt to establish a universal definition. Truancy was defined as "a student's act of non-attendance evidenced in missing part or all of the school-day without it being legitimately excused by school or per state law" (p. 78). This definition addresses previous complications. Although these authors provided well-defined parameters that 
apply to the New Zealand context, researchers and professional voices dominate this definitional debate, hence further exploration of student perspectives, those closest to truancy, will add to further understanding of how truancy is defined.

\subsection{The New Zealand context}

Aotearoa New Zealand is a Commonwealth democracy situated in the South Pacific. It is a small country with approximately 4.8 million inhabitants who are increasing in diversity. New Zealand's nationhood was established with the signing of the Treaty of Waitangi in 1840 by Māori as the indigenous people and the British Crown (e.g., Berryman, Eley, \& Copeland, 2017; Tawhai \& Gray-Sharp, 2011; Wang, 2018); the Treaty remains central to New Zealand law and society today.

The Ministry of Education (hereafter referred to as the Ministry) is the major presiding body overseeing New Zealand education. The New Zealand education system is a five-tiered model structured according to age: early childhood (pre-school); primary (Years 1-6); intermediate (Years 7-8); secondary (Years 9-13); and tertiary education. (Note: In some contexts, primary schools cover both the primary and intermediate years). The Ministry's website, (Education Government New Zealand, n.d.), lists its main functions in relation to school level education as including: implementation of government policy in education; strategic leadership (e.g., policy advice and development, and monitoring of sector needs and performance); support and resources for education providers including funding, administration of legislation, and monitoring the performance of providers; and interventions for target student groups. The latter includes students with special educational needs; arguably, the latter category includes students who truant regularly or who are absent for long periods without justifiable reasons.

Other important educational bodies for school level education include the New Zealand Qualifications Authority, which administers senior secondary school 
examinations and assessment, and the Education Review Office which conducts periodic evaluations of schools and early childhood services in relation to the education and care they provide. The latter agency is responsible for monitoring the procedures that schools use for recording and acting on truancy.

The Ministry, the key educational body in relation to the research undertaken for this thesis, is committed to building a fully inclusive education system where every school demonstrates inclusive practices, where teachers are supported and confident, and where children and young people are engaged (Ministry of Education, 2014). The Ministry identifies four key dimensions to inclusive education that foster effective practices in New Zealand schools: (1) building an inclusive school culture; (2) developing inclusive processes and systems; (3) addressing the needs of diverse learners; and (4) enhancing relationships. The role of the school leader, according to the Ministry (Ministry of Education, 2014), is to show manākitanga (leading with a moral purpose), ako (being a learner), and awhinatanga (providing guidance and support).

Within the New Zealand educational system, governance of schools has been decentralised to individual schools through each school's Board of Trustees. Hall (2005) argues that the system of school management adopted by the New Zealand government falls within an "outcomes-based" model of educational accountability. In its simplest form, this system involves three steps. The first step describes the objectives or standards that must be met by the different processes or systems that a school is required to provide. These objectives/standards may be centrally defined (e.g., legislation related to health and safety) or locally declared but centrally approved. The focus of these objectives and standards includes the maintenance of school buildings, implementation of the curriculum, reporting of student achievement, professional development and staff appraisal, and implementation of inclusive education. The second step recognises the autonomy of schools to design their own programmes to meet the declared or centrally specified objectives. The third step refers to the processes by which schools are monitored and held 
accountable centrally for meeting the educational outcomes as defined in the declared/prescribed requirements.

The Ministry provides oversight of the operation of schools in various ways, for example, through evaluations by the Education Review Office and reports from Boards of Trustees on indicators that are periodically collected. Under this system, schools have the responsibility for developing a programme that prevents, or at least minimises, truancy behaviour, while both the Ministry (nationally) and individual schools (locally) have responsibility for recording and monitoring students' attendance at school (see also Section 1.4).

There are four main classifications of school in New Zealand: State, state integrated, Kura Kaupapa Māori and private. The first three are state funded and teach the national curriculum (i.e., the New Zealand curriculum for English medium school or the Te Mautauranga Māori for Māori medium schools). Private schools are not funded by the government but do receive government subsidies, they charge fees and are not required to follow the national curriculum. Eighty five percent of school-aged children attend state schools in New Zealand (New Zealand Government, n.d.). State integrated schools provide education through their "special character", which reflects their own particular values, and possibly teach a specific philosophy (e.g., Steiner) or religion (e.g., Catholic). Eleven percent of school-aged children attend New Zealand state integrated schools (New Zealand Government, n.d.), which integrated into the state system post legislative changes in 1975. Four percent of school-aged children attend private schools in New Zealand (New Zealand Government, n.d.).

This study concerns students involved in mainstream secondary schooling and an activity centre. Activity centres in New Zealand provide a specialised learning programme for referred secondary students at risk of disengaging from school or achieving poor educational, social, and vocational outcomes (Education Government New Zealand, n.d.). Class sizes are smaller in activity centres and staff usually work to 
transition students back to mainstream classrooms. The official stance is that mainstream education focuses on the New Zealand curriculum and places individual young people at the heart of education in New Zealand. This positioning prioritises them as enterprising so that they make informed and good choices, become confident, connected learners who seize opportunities that contribute to becoming life-long learners (Ministry of Education, 2007).

However, the rapid and far-reaching social and technological changes that have taken place over the past three decades have placed considerable pressure on the education system to ensure that all students are able to achieve success. Change has been a constant in recent times in New Zealand, evident by the altered nature of the family structure, children's increased vulnerability, and the challenges schools face (Galloway, 2007). Families also experience difficulties and challenges due to older parents, fewer marriages, increased divorce rates, fewer resident fathers, and increases in solo-parent families and the economic pressures that they face (Education Government New Zealand, n.d.). Children are more vulnerable than in the past, and many students are absent from school. Along with the impact of education reform, self-governance and school management by Boards of Trustees, and teachers' management of regular changes in content and delivery of the curriculum, New Zealand schools face challenges (Galloway, 2007). Internationally, teachers battle with a broadening curriculum, increasing accountability, assessment and paperwork, reduced resourcing, and impaired health and well-being (Nilsson, Ejlertsoon, Andersson, \& Blomqvist, 2015). In New Zealand, current issues in education relate to an aging teacher workforce, teachers' unwillingness to take on leadership roles, retention of new teachers, teacher supply, and teacher specialist content knowledge (Education Government New Zealand, n.d.).

New Zealand has also become the country in the Programme for International Student Assessment (PISA) with the greatest disparity between rich and poor (OECD, 
2015). In the current political climate, there is a commitment to looking after the most vulnerable in our society. One focus of the newly elected New Zealand coalition government is to alleviate poverty; of significance is that the Prime Minister, Jacinda Ardern, has taken responsibility for the portfolio of Minister of Child Poverty Reduction. The Children's Commissioner's (2018a) report recommends a focus on the vulnerable in the school system; the report urges politicians and educators to listen to the voices of students who do not attend school so that their perspectives inform educators and contribute to educational policy changes that are necessary for improving educational outcomes for these students.

\subsection{New Zealand law}

According to Sommer (1985), truancy was the driving factor for the formation of compulsory school attendance. Enforcing legislation has attempted to change the management of school non-attendance with three education acts being of particular significance: The 1877 Education Act; the 1914 Education Act; and the 1989 Education Act.

The 1877 Education Act made school attendance in New Zealand a political issue by legalising the requirement for compulsory primary school attendance for children between the ages of 7 and 13 (Kerslake, Lange, \& Bennie, 1997). Before this act, family financial circumstances contributed to school attendance. Those who attended either originated from affluent families (who could afford fees) or lived in close proximity to schools run by religious organisations or provincial governments, which meant urban children had better access to schools than rural families (TeAra, n.d.). Even after 1877, school attendance was not universal. From 1875, children under the age of 14 were prohibited from night shift work, and from 1877 children were required to be over 12 to work in factories. Consequently, from 1877 compulsory schooling significantly affected the demands of the labour force, although rural children continued 
to complete farm work before and after school tasks (TERA, n.d. www.teara.govt.nz/en/childhood/4). It appears that these reforms were aimed at reducing inequalities and enhancing social mobility.

Secondary schooling around 1900 was not free so generally the wealthy elite benefitted. However, the 1914 Education Act required secondary schools to offer free education to children who received a Certificate of Proficiency (Education Government New Zealand, n.d.), which became the major determinant of jobs and career opportunities. However, this exam was abolished in 1936 due to the growing expectation for a longer and more comprehensive educational programme for every child regardless of ability, location and economic status (NZ History, https://nzhistory.govt.nz/). Social reforms implemented from 1944 by Labour governments made secondary schooling free and compulsory until 15 years old; consequently, school rolls doubled between 1945 and 1960 (NZ History, https://nzhistory.govt.nz/). These educational provisions appeared to be influenced in part by fears related to juvenile delinquency arising from a believed lack of discipline in the home (N.Z. History, https://nzhistory.govt.nz/).

The school leaving age was raised from 15 to 16 in 1989 (Education Government New Zealand, n. d.). The 1989 Education Act, the basis of primary and secondary educational reform, required parents and Boards of Trustees to have dual responsibility for student attendance (Ministry of Education, 2005). Parents were required to enrol their children at school and ensure that they attended. Boards of Trustees were instructed to take appropriate actions to make sure that the students who were enrolled at their school attended. The 1989 legislation was also implemented to reduce educational expenditure (N.Z. History, https://nzhistory.govt.nz/).

Truancy was prevalent throughout New Zealand in 1995 when the Education and Science Select Committee Inquiry investigated children at risk through truancy and behavioural problems (New Zealand House of Representatives, 1995). These state interventions have still not resolved the problem of truancy in New Zealand. 


\subsection{Researcher background}

I conducted this research within what Cohen, Manion, and Morrison (2000) refer to as an "interpretive" (qualitative) research paradigm. It was a grounded theory (GT) study of students' truancy behaviour, and how they interpreted it. In keeping with GT, I designed this study to construct a theory about the basic social process that accounted for most of the similarities and differences in the reported participant behaviour. The focus was on the collective experience, not the individual. The research focused on students' perspectives to understand their truancy experiences in the New Zealand social and educational context.

As noted by Creswell (1994), a basic premise of qualitative research is that researchers should position themselves and their motivations for conducting the research. My family immigrated to New Zealand from England when I was ten months old. My parents had high expectations that I would eventually proceed to tertiary level education; my father told me that a major reason for coming to New Zealand was the opportunity I would receive for advancing my education beyond school. However, during my school years, I received elocution lessons to diminish my South-East London accent because I was frequently mocked and marginalised at school. This experience had a profound effect on my schooling and has contributed to my desire to work with, and support the education of students who experience marginalisation at school.

In early adult life, I lived on a state benefit for eight years as a single parent supporting my two sons. However, I have also undertaken tertiary education, gaining qualifications in teacher education and drama. I have ten years' experience as a secondary school educator, teaching mainly drama to students from a wide range of social and cultural backgrounds (see below). Over the past decade, I have been a university lecturer in the field of teacher education. I describe myself as a middle class, middle-aged educator whose Christian beliefs help guide my personal and professional interactions with adults, youth and children. 
I acknowledge that my attitudes, values, beliefs and all my experiences influence the frames through which I view the world; these frames have clearly impacted on the way I have shaped my inquiry, interpreted the data, and reached conclusions. I am aware that I notice equity issues, that I want to make a difference, and that I view life through a social justice lens.

My own experiences of marginalisation lead me to be aware of those on the edges of groups, of those who feel that they do not belong. According to Felman (1993, cited in Berlak, 1996), our unconscious precludes us from fully recognising our stories as all efforts to write our stories are so severely prejudiced by the language that influences not only what we say, but how we say it. Because I wanted these (at times unconscious) aspects of my thinking to be made explicit, I noted and recorded my emotions (thoughts, speculations, and responses to situations) as field notes throughout the process of this project.

In addition to these personal reflections, a range of professional incidents, as an educator, also informed the development of this project and have further influenced the lens by which I view events in schools. I am an experienced drama teacher. Prior to my position at Victoria University of Wellington, I taught Year 9 - 13 drama in a multicultural, inner city, co-educational, secondary school. I co-constructed, produced and directed over twenty plays based on life challenges that students wanted to investigate. Positive relationships, student autonomy, and meaningful contexts for learning were important aspects of our classroom experiences.

Whilst on professional development leave from secondary teaching, I spent three months living on a marae (congregational place) working voluntarily as a cook for a Māori theatre company. The learning process within this mahi (work) operated "through the sense-making processes and the knowledge" that these players brought to the interaction (Bishop \& Glynn, 1999, p. 177). During this time I gained insights into the te ao Māori worldview and mārae restorative justice; I embraced mistakes, and 
absorbed Māori protocols, processes, and rituals that influenced my worldview (Baskerville, 2009a). I learnt how different living in a Māori community context was from school and our mainstream community.

Years later, after a New Zealand residential youth justice school project (Baskerville, 2009b), I was left wondering what earlier intervention for our mainstream youth at risk in their learning would prevent their entrance into a youth prison. This research indicated implications for mainstream students and stirred my interest in researching the social reality of truancy.

I write from the understanding gained through all of these lived experiences and in recognition of the power, interests and complexities in my present (and past) everyday life.

\subsection{Thesis organisation}

This thesis is a grounded theory analysis of truancy from a student perspective, with the aim of producing a substantive theory to explain the experiences that characterise the decisions of youth to truant and later either re-enter or exit school. By discovering how different youth interpreted their situations, actions and occurring events, I intend to contribute to knowledge and understanding of a particular group of students who have experienced living in the margins of New Zealand school education.

This thesis contains five chapters that explain the complexities and outcomes of the research project. This first chapter introduces the reader to the New Zealand context, the problem of truancy, and the researcher background. Chapter 2 examines truancy research and identifies the gaps in knowledge of how young people construct experiences of truancy. The literature is presented in two parts: historical development of truancy scholarship and literature contributing to theory development. Chapter 3 describes the methodological approach adopted for this research, namely GT. It describes in detail the research design, the selection of schools, and the recruitment of 
participants. It sets out the selection of data gathering strategies and the techniques involved in data analysis. It also considers the trustworthiness of the data and conclusions, and describes the ethical considerations that influenced the conduct of the research. Chapter 4 presents the findings and discussion in the form of a process theory. The findings begin with a description of the nature of truancy, then proceed to describe four stages that characterise the truancy process. Finally, Chapter 5 concludes this thesis, acknowledges contributions the theory makes to truancy scholarship, identifies implications for policy and practice, and considers possibilities for further research. 


\section{CHAPTER 2}

\section{LITERATURE REVIEW}

\subsection{Introduction}

Truancy is a long-standing, complex field of scholarship. Initially, quantitative studies using statistical analysis to examine determinants of truancy dominated this field and only minimal consideration was apportioned to youths' perspectives and experiences. Grounded theory is a useful method where there is not a lot previously presented from a particular perspective. When this project began, research presented mainly adults' views, thus the selection of grounded theory supported the construction of theory about issues in the lives of students (McCallin, 2006; Mills, Bonner \& Francis, 2006) who truanted in schools.

In keeping with grounded theory (Glaser, 1998), I conducted two distinctive literature reviews for this research: firstly, an initial, preliminary reading of the literature for the development of a research proposal, and secondly, an on-going review during and after the theory generation development. The literature is presented in two parts: an update of the initial review (section 2.2), and findings driven literature (Section 2.3). The timing of the second literature review, delayed and conducted after data analysis, minimised the influence of pre-existing literature infiltrating the coding and development of categories (Glaser, 1998). This timing resulted in full conceptual integration of the literature into the emerging theory (Andrew, 2006). In keeping with the presentation of a grounded theory study, the literature and findings are integrated in Chapter 4.

It is important to note here that historically there have also been many interventions to address truancy; these studies are too extensive for this review and lie outside the primary focus of this research. However, truancy in schools is still 
problematic, both nationally and internationally, in relation to countries with compulsory school attendance policies (Davies \& Lee, 2006).

\subsection{Historical development of truancy scholarship}

This section of the literature review, as previously mentioned, provides an update of the initial review, conducted for the research proposal as well as discerning a gap in truancy scholarship worthy of investigation.

\subsubsection{Historical attribution of blame}

Contention regarding attribution of blame has historically complicated truancy scholarship, perhaps adding complexity and inhibiting earlier understanding and reduction of truancy. The story of the truant child began pre-World War 1. Broadwin (1932) was the first to attribute truancy to personality difficulties. Evidence gathered by Broadwin in his medical practice, specifically the study of six patients, two in depth, all truanting school, identified truancy as symptomatic and part of personality difficulties, obsessions, and anxiety rationalised by the child as fears related to maternal safety (Broadwin, 1932). Although an opinion piece, with neither reference to academic literature nor research methodology, through the close study of a thirteen-year-old boy and a nine-year-old girl, Broadwin was the first to recommend early detection of this form of parental condoned truancy in order to help the child's growth of independence.

By the early 1940s truancy was recognised as a symptom associated with a range of causal factors requiring diagnosis and treatment (Geiger, 1941). Truant children were positioned as "phobic". In the US by the 1960s, personality abnormalities related to phobias or neurosis were suggested as a cause of truancy (Kahn \& Nursten, 1962) and by the late seventies perceived abnormalities were scrutinised closely. Although only a small number of students who truanted were identified at that time as experiencing psychological difficulties, the number of students with noticeable emotional problems 
was increasing (Reid, 2008). Children who truant were located in discussions associated with disorders and maladjustment, which identified the individual child as flawed.

Historically, the use of deficit labelling identified children who truant as: "incorrigibles", "abnormal boy", "recalcitrant lads" (Trustees of Boston University, 1907, p. 348); “chronically troublesome”, "delinquent” (Richman, 1906, p. 237); "bad”, "stubborn", "contrary" (Williams, 1927, p. 284); "unadjusted" (Brown, 1934); and “difficult", "awful" and "dull” (Norton, 1934, respectively pp. 435, 439, \& 444). Young people who truanted were identified as failures with "peculiar mental characteristics" (Williams, 1927, p. 284), implying some form of psychological disorder. Similarly, doctors and researchers labelled peers of truant children as "vicarious associates" (Richman, 1906, p. 238), “idle wanderers” (p. 239), "bad companions” (Williams, 1927, p. 285) and "bad associates" (Broadwin, 1932, p. 253). Children who truanted were also described as youth who associated with "loafers and juvenile criminals" involved in "vice and crime" (Kuser, 1916, p. 366). In addition, psychological examinations of 110 truancy court cases heard between 1929 and 1930 identified half of the truants as being borderline in intelligence and showing "grade retardation" (McElwee, 1931, p. 210).

The categorising of children in this way had several limitations. It associated the individual problems of students who truanted with an identifiable group of wayward children, it stigmatised these children as less valuable than their attending peers, and it attributed failure to individual weaknesses and deficiencies within the child, which identified and demeaned them as the problem. Adults assigned blame for the behaviour of children to the children themselves, an attribution that remained largely unchallenged during the late twentieth century (Gleeson, 1996). The underlying assumption here supposed that school structures were socially just, were appropriate for all students, and did not require change.

Over time, this view was challenged and scrutiny of the use of deficit terms began. Fine and Rosenberg (1983) conducted a study using tests, surveys, and 
interviews to investigate established beliefs of high-school dropouts as "losers". Their sample comprised 88, 14-21 year-old Black and Hispanic dropouts. The data focused on the participants' critique of schools in South Bronx, US. Findings suggest that these students were aware that dropping out decreased employment opportunities, and therefore these researchers urged that dropping out be viewed as "an act of resistance" (p. 267). Davies and Lee (2006), in their comparative study of students with severe attendance problems and students who attended despite having trouble at school, identified through interviews that "self-withdrawal" (p. 208) was a solution to students' critique of the school and the problems they experienced. In her discursive conceptualisation, rather than outlawing truancy as a "deviant behaviour" (p. 375) requiring punitive measures, McIntyre-Bhatty (2008) suggested that truants' behaviour be considered as a rational act voicing discontent with school. These social justice perceptions of youth as school resistors warranted an on-going examination of other school-based causal factors, as well as the motivational aspirations of resistors, which positioned young people (hereafter referred to as youth) as acting on their disillusionment with school. Such a response to an unfriendly environment suggests that the way schools are structured may not suit youth who truant.

More recently, assigned labels stereotyped youth who truant in different ways: typical (that is, behaviour in common with others), psychological, and institutional (Gentle-Genitty et al., 2015; Jonasson, 2011); occasional truants, characterised by intermittent truant behaviour (Keppens \& Spruyt, 2016); and academically disengaged, chronic skippers (Maynard, Salas-Wright, Vaughn, \& Peters, 2012). Although these categorisations by researchers acknowledge difficult home backgrounds, anxiety towards school, and school related behaviours as indicators of truancy, it is clear that "truant" is a deficit label that positions children who truant in a negative light. In New Zealand, Bishop and Berryman (2006) support this claim based on their analysis of the narratives of Year 9-10 Māori students, teachers, principals and whānau members. 
Māori students reported that when they felt exposed to negative stereotyping and singled out as troublemakers, they "voted with their feet" (p. 255) and selectively absented themselves from class. They made these conscious decisions to escape unfairness, being singled out, and "untenable relationships in particular classes" (p. 255).

What is clear from the above literature is that historically the blame was mainly attributed to children who truant. Other contributors to the problem of truancy (i.e., the home, the school, and students' peers) were assigned limited blame by comparison. The next subsection shifts the discussion to other causal factors.

\subsubsection{Truancy: Analysis of causal factors}

The discussion here is presented under four subheadings: contrasting perspectives of administrators, teachers and parents; school-based factors; individual causes of truancy; and home-based factors.

\section{Contrasting perspectives of administrators, teachers and parents}

Although numerous reasons for truancy have been proposed, and the nature and organisational grouping of these has changed over time, few systematic studies of causes were conducted prior to the 1950s (Kahn, 1951). In addition, irrespective of geographical location, the nature of causal factors identified across countries has been largely the same (Davies \& Lee, 2006). It is evident that considerable time, money, and resourcing have been invested in determining causal factors of truancy (McIntyreBhatty, 2008) and, as noted, over the last two to three decades, the identification of causal factors has changed and developed complexity (Reid, 2010). However, it is also evident that researchers have reached consensus regarding the broad categorisation of factors, namely individual, home, and school (e.g., Malcolm et al., 2003; Reid, 2008), although disagreement exists as to the relative importance of these categories and the specific influences within each category. These differences reflect to some extent the perspectives of administrators/officials, teachers, and parents. 
In case-based research of 27 schools (13 primary and 14 secondary) located across seven Local Education Authorities (LEAs) in various parts of England, representatives from LEAs and teachers were reported to have disagreed with parents and students regarding causes of student absences (Malcolm et al., 2003). Parents and students claimed that school-based factors, such as, boredom, bullying, and dislike of teachers, were the main cause. In contrast, most LEA representatives and school staff believed that parental attitudes and home environment (e.g., inadequate parenting and disorganised life styles) were the most influential factors. Much earlier, Tyerman (1958) suggested that although student voices might be valid, the tendency for students to blame teachers was largely self-deception. However, other researchers suggested rebellion was a normal reaction to unsatisfactory environments within schools (e.g., Reynolds \& Murgatroyd, 1977). In addition, Reid (1985) argued that a combination of social-psychological and school-based factors explained school absenteeism, and more children missed school in the United Kingdom for school-based reasons than for socialpsychological or home-background factors. These disagreements between researchers and/or commentators regarding the causes of truancy, highlighted the tensions between parental, student, and professional perspectives, and suggested that truancy is complex, with many root causes. In New Zealand, Donn, Bennie, and Kerslake (1993) agreed; they acknowledged that the combination of factors varies in each student and made managing the truancy problem very complex.

Two further studies (Dalziel \& Henthorne, 2005; Reid, 2006) provided additional insight into these contrasting perspectives about causes of truancy. I will take the latter study first because of its greater scope. Reid (2006) carried out focus group interviews with 160 secondary school pastoral-care staff (40 head teachers, deputy principals, deputy heads, middle managers, and form teachers). In his evaluation of their perceptions of school attendance issues, evident discontent amongst staff was reported. Management of attendance issues was both challenging and counterproductive for 
several reasons. The disproportionate amount of pastoral staff time spent on persistent absence did not appear to influence outcomes; staff perceived chronic truants' behaviour as unlikely to change. The staff were also frustrated with the perceived unfairness of having to deal with challenging circumstances beyond their control. For example, insufficient allowance was made for school location and typology of student intake, which disadvantaged schools from low-socioeconomic areas (Reid, 2006). In addition, parental-condoned absences were recorded as non-attendance; this included incidences of parents removing children from school for term-time holidays and staffs' inability to remove travellers' children from the roll, even though they were located in the area for only a few weeks and marked absent for the entire year. Reid concluded that early intervention was rare and strategies for successful reintegration and return to school were lacking at that time.

Reid (2006) also argued that school staff required more support to manage truancy. Lack of specific training, social problems and increasing numbers of dysfunctional families, disillusionment with current court outcomes, the rigidity of the curriculum, and overemphasis on testing were identified by secondary pastoral staff as causal factors for persistent non-attendance. Reid noted that school staff were not sympathetic towards children with attendance problems, as they perceived it to be a parental duty to ensure children attend school regularly. It is evident from Reid's research that although teachers were able to identify external causal factors, they did not take responsibility for the ways they might have contributed to student truancy.

In the study by Dalziel and Henthorne (2005), the parents/caregivers of (a) regular and (b) persistent poor attenders were interviewed to examine and compare their attitudes towards their children's attendance. Both parents'/caregivers' groups valued education, recognised the importance of a good education, had similar views regarding the nature of acceptable and unacceptable reasons for child attendance, and accepted they were responsible for their child's attendance at school. However, like the teachers 
in Reid's study, parents/caregivers reported that they required further support to address their children's truancy. They cited inadequate early communication with schools and lack of support from schools and other agencies as factors that contributed to early attendance problems, including their detection. Parents wanted to be better informed about their children's early non-attendance. They also wanted a sensitive, closer examination of the individual circumstances that related to poor attendance, and they wanted school staff to play a larger role to ensure children attended. Parents also felt the need for greater provision of necessary support to maintain children's attendance at school (Dalziel \& Henthorne, 2005).

It is evident, then, that although both parents and school pastoral care staff experience challenges getting and keeping children at school, neither group acknowledged or gave sufficient recognition to their own personal contributions to causal factors. The inability of these groups to focus on others' perspectives not only inhibited effective communication between home and school, but also prevented understanding of the combined effect of students' lives and school worlds. Both the studies of Reid (2006) and Dalziel and Henthorne (2005) indicate that further exploration of youths' perspectives is necessary to understand their personal circumstances and school worlds and how these challenges influence young people's choices to truant school.

In summary, the studies reviewed in this sub-section identify that different perspectives on truancy exist between school administrators, teachers, and parents. It is apparent also, that insufficient attention has been given to the experiences of students, their reasons why they truant, and what that means to them. It is the latter focus that lies at the heart of this doctoral research.

\section{School-based factors}

School-based causal factors of truancy have been reported for over one hundred years, and although changing in nature, they have not yet been resolved. Reid (1985) was the 
first to report that institutional (school-based) attention focused initially on nonattendance and then expanded to include rising levels of absence, including students who become persistent truants. This suggests that truancy generates further truancy. Over time, school-based factors have been identified as: ineffective and inconsistently implemented attendance policies (Bell, Rosen, \& Dynlacht, 1994); the use of unqualified teachers (Dougherty, 1999); unsuitable academic placement of students in classes (Jones, Harris, \& Finnegan, 2002); and poor teaching, unacceptable school cultures, anti-social behaviour, a lack of long-term vocational direction, and safety problems (Reid, 2008). More recently, meaningless learning context, stress due to fast instructional pace, low workload, and under-achievement have also been identified (Salzer, Trautwein, Ludtke, \& Stamm, 2012). It should be noted that 20-30 years ago, difficulties such as cyber bullying or eating disorders either did not exist or were much less common (Reid, 2008). It is evident that newly emerging causes of both schoolbased and home-based truancy have created a bigger challenge for schools and teachers who are faced with managing rapid change.

An earlier collaborative research project between students and university researchers, conducted in two large urban public schools in two different US cities, highlights the relevance of acknowledging student voice for analysing truant behaviour (Fallis \& Opotow, 2003). Over four years, data were gathered from 160 students, initially in individual interviews, then focus group interviews. Students "cut" class as a reaction, a way to cope with alienation and boredom resulting from slow-paced learning, unchallenging and uninteresting curriculum, inadequate resourcing, uninviting, sterile school environments, and unaddressed conflicts. Staff attitudes, behaviours, and treatment of students, such as negative labelling, contributed to student isolation and consequent class cutting. Students perceived teachers as insensitive to their needs and goals, thus highlighting that teachers did indeed play a role in students cutting class. 
This suggests that students need schoolwork that is meaningful, environments that are welcoming and stimulating, and teachers who respect them.

A study of 88 youth in the UK, aged between 15 and 25, who participated in biographical interviews (MacDonald \& Marsh, 2004), reported school-based factors as causal factors that broaden our understanding of school-based factors contributing to student truancy. These included discouraging teachers, pointless curriculum, bullying, peer sanctions against engagement, and perceptions of not being an "educational priority" (p. 157). Another study conducted by Davies and Lees (2006), provided an insider-view of two schools within one LEA. Thirteen secondary students with severe attendance problems, their parents, school and management staff, Education Welfare Officers (EWOs), and 35 Year 9 and 10 low-achieving regular attendees, were interviewed to elicit their views about truancy. The perspectives of these different groups also varied. Whilst professionals problematised the content and rigidity of the curriculum, students and parents disagreed and identified relationships with teachers as the main causal factor (Davies \& Lee, 2006). Bullying and intimidation was another problem and often preceded the non-attending students' decision not to attend. Parents were eager for their children to attend and experience success at school and reported that schools needed to address bullying more effectively.

The regular low-achieving attenders in this study provided different perspectives. They did not perceive teachers as the problem; they did not reject core subjects but wanted a vocationally orientated curriculum. Despite difficulties with bullying, good attendees thought themselves sufficiently mature not to be intimidated by peer pressure and felt sufficiently safe to make their own decisions. These students recognised that school attendance affected their future lives, especially in securing work, and was relevant to their future aspirations (Davies \& Lee, 2006). They wanted choice rather than the school imposed "universal curriculum" (p. 209). Those who did attend 
did so because they enjoyed the social value of school and the later support that regular attendance and consequent achievement provided for them to engage with society.

One of the first New Zealand studies to report on unjustified absences (Donn et al., 1993) involved stakeholders from 11 primary and 12 secondary schools; principals, Board of Trustee representatives, staff responsible for monitoring attendance, attendance officers or visiting teachers, and community group members were interviewed. District Liaison Officers identified schools that were effective in monitoring attendance. They all agreed that school climate was important; a caring approach was more effective in encouraging than a punitive one, and good student-teacher relationships and cooperative, sharing and supportive classroom atmospheres encouraged attendance. They offered advice to other schools about effective strategies for monitoring attendance. This study highlighted the serious time and resource challenges schools faced in dealing with a few truant students to the detriment of regularly attending ones. Again, student voice was absent in the study.

What is clear from the above literature is that there is a paucity of studies representing student perspectives and insufficient detail about the circumstances surrounding the causes of truancy. Further research is required to provide deeper understanding, not just examples of youths' deviant behaviours, but rather their perspectives of the world around them, and the challenges they face. If we delve to the heart of the problem and examine the circumstances, and how these affect individuals, we are likely to deepen our understanding of the collective experiences of youth.

\section{Individual causal factors of truancy}

As indicated earlier, an individualistic approach to truancy developed historically and led to a focus on the deviant behaviour of the truant child (Claes et al., 2009), leading to the criminalising and pathologising of truancy (McIntyre-Bhatty, 2008). Consequently, students who truant were stereotyped to the extent that even the students perceived themselves as having lower academic ability and self-esteem (Reid, 1985, 1999). In 
contrast, according to Capps (2003), youth who truant often perceive the world around them as unstable and confusing.

A study conducted by Reid (2008) of three distinct groups of 391 professionals with responsibility for improving attendance in their school, involved all groups attending professional development workshops where they participated in a rotating carousel to brainstorm the reasons for students' non-attendance. Participants recognised that non-attendance was the result of a combination of social, psychological, and institutional factors. They considered that students disliked coming to school because they had few friends and felt unsafe. Professionals reported that pupils perceived themselves as being "cool" when they skipped school, lacking career options, and suffering from low self-esteem. However, the study did not include student voices to confirm the opinions of the professionals. Instead, action plans to manage future truancy were to be considered.

Whatever the position taken by adults, and explanations made by youth who truant, causes assigned to individual factors for truancy in the literature highlight the challenges these children face predominantly from an adult perspective. Not only has the assumption been prevalent that truant youth should adjust, secondary student voices in New Zealand have not been given a strong focus in the literature at the time of this initial review and consequently are identified here as a gap in the truancy literature.

\section{Home-based factors}

Factors related to adverse home circumstances have also been explored over time. Several studies have identified addressing issues including: marital discord and unemployed parents (Farrington, 1980); chaotic family life (Donn et al., 1993; Rohrman, 1993); breakup of families and working mothers (Blackburn, 1993); parental need (Galloway, 1995); and poor parenting practices (Little \& Thompson, 1983; Nielsen \& Gerber, 1979). Other researchers have identified multiple children (Fogelman, Tibbenham, \& Lambert, 1980); crowded living conditions (Fogelman et al., 1980); 
child-parent relationship conflict, home responsibilities (Teasley, 2004), and family history of truancy, unemployment, lack of parental supervision, and vacant houses during day-time that provide a place to truant (Donn et al., 1993) as important homebased factors. During the next decade, parental disregard of, or contribution to, truancy was identified (Reid, 2008). In support, Education Welfare Officers (EWOs) identified a range of home circumstances such as economic and social deprivation, substance misuse, and illness, as significant causal factors. More experienced EWOs took a compassionate approach and focused on the welfare of non-attenders whereas newer officers held the legalistic view that parental court punishment was an effective way to manage truancy. School attendance officers identified some families as holding a “culture of non-attendance" (Davies \& Lees, 2006, p. 6).

Parents persisting in condoning truancy even when this lead to parental prosecution, highlights that the parents' role is particularly important. The position taken is that parents are liable for getting their children to school. However, the effectiveness of parental prosecution for their child's unauthorised absence from school is questionable. Surveys of prosecutions conducted in 43 LEAs in England and Wales over three years provided the number of parental prosecutions imposed and the change in truancy rates (Zhang, 2003). Findings suggested that secondary students' attendance improved in association with prosecution rates but primary students' attendance did not. Overall, the results suggested that prosecution did not have an immediate meaningful or long-term impact on truancy. McIntyre-Bhatty (2008) lent support to the findings of Zhang, suggesting that past attempts involving coercion or legal action to reduce truancy proved unsuccessful. Zhang (2003) and McIntyre-Bhatty (2008) challenged the legitimacy of parental prosecution and they suggested that alternative approaches require consideration. In New Zealand, the stance of parental prosecution was taken in response to "Tomorrow's Schools" when School Boards of Trustees were legally required to take reasonable steps to ensure that all children between the ages of 6 and 16 attended school 
(Education Act, 1989), and costly, time-consuming, ineffective monitoring of children who truant was not prioritised (Donn et al., 1993). Boards of Trustees wanted an outside agency to investigate and prosecute truancy because of potential damage to school community relationships (Donn et al., 1993).

A further problem relating to the assumption that prosecuting parents was a solution to truancy was that such action assumed that there were no contributing circumstances to truancy other than home-based factors. The previous discussion of the categorisation of individual, home and school-based causes, contradicts this claim. Again, the discussion in this subsection points to the need to investigate students' school experiences to ascertain the characteristics of contributing interactions that influence their choices to truant, the different stages at which truancy develops, the related outcomes of these, and the change that is required both at an individual and school level. Such research, designed to elucidate understanding, will add to truancy scholarship.

\subsubsection{Truancy trends in New Zealand}

As this study is situated in New Zealand, and New Zealand truancy research seldom features in comparative international truancy studies, this section focuses on truancy trends in the New Zealand context. The discussion is presented under two areas: monitoring truancy in the New Zealand context, and key factors of truancy. The majority of authors cited in this section are authoring for the School Analysis Unit of the Ministry of Education (the Ministry).

\section{Monitoring truancy in the New Zealand context}

Over time, educational legislation and the Ministry policy impacted on schools' management of truancy in New Zealand schools. For example, the 1877 Education Act politicised attendance in New Zealand (Kerslake \& Lang, 1998) by the government taking control of education, establishing twelve regional boards and making education compulsory for children in New Zealand to year eight. Much later, truancy was 
recognised as widespread and in 1995 there was a national education inquiry focussing on children at risk through truancy and problem behaviours (New Zealand House of Representatives, 1995). Although the Ministry provided funding and resources to support schools' management of truancy, at times these were perceived by school staff as inadequate (Kerslake, Lang, \& Bennie, 1997). A national focus on improving school attendance began during 1992 and 1993, and from 1994, the New Zealand Government allocated budget funding for truancy programmes. For example, Rotorua Māori Wardens were funded to develop a programme designed to reduce truancy, implemented by people who had intimate knowledge and close connection to their community. The nationwide District Truancy Service eventually replaced this service in 1997 (Kerslake \& Lang, 1998).

Like international research, quantitative studies initially dominated this field. Since 1996, at first biannually but more recently annually, all state and state-integrated schools were invited to participate voluntarily in national school attendance surveys (Kerslake \& Lang, 1998). The 1966 survey, conducted by the then Department of Education, examined absence in New Zealand for one day (Kerslake \& Lang, 1998). Absences that were deemed to be for "unsatisfactory" reasons were counted across the country. The counts provided truancy rates of $0.47 \%$ and $0.49 \%$ for primary and secondary schools respectively, suggesting that limited truancy was occurring in New Zealand. However, later analysis of the 1966 survey data (Jenson, 1967, 1968a,b) challenged this finding, suggesting closer examination of the small truancy rate should be undertaken because of the likely serious truancy level of Māori, specific regions, and particular schools. This supposition was confirmed when form four students from eight secondary schools in New Zealand self-reported their absences in a questionnaire (Bobillier, 1976). Youth referred to absence from classes as "wagging". Thirteen percent of 2000 students reported "wagging" persistently (16 days and over); 17\% "wagged" frequently (6-15 days), and approximately a third of students reported "wagging" 
between a half and five days so far that year. Bobillier's (1976) research identified that the highest truancy rates occurred in the poorest communities with the lowest socioeconomic groups.

The Truancy Action Survey undertaken in 169 primary and 450 Year 7-13 schools (Kerslake et al., 1997) reported the concerns of school staff about truancy. Truancy was not a universal problem; some New Zealand schools reported that truancy was not an issue for them due to effective school systems, supportive parents, and good communication between school and home. However, schools where truancy was a problem reported experiencing inadequate resourcing. These schools noted that a specific person was required to follow up on non-attending children. However, the truancy protocol, despite three reviews, was not an effective truancy back-up service for schools. In addition, school staff interpreted the slow action by the Child, Youth and Family Service (CYFS) Workers as reluctance to become involved and follow through on truancy issues (Kerslake et al., 1997). School staff perceived truancy as "a symptom of a larger problem" (p. 26) and reported that although they had effective systems to support the return of children who truant to school, they cited the existence of alternative problems (for example, parent condoned truancy, peer pressure and petty crime) and the lack of resources and time to change truant students into good learners (Kerslake et al., 1997).

On-going Ministry funded research (Mallari \& Loader, 2013) examined relationships between "school level factors (e.g., school type, region, and decile) or student factors (e.g., gender, ethnicity, year level)" (p. 4) and provided useful reference points, for example, when and where higher truancy rates occurred (which will be discussed more fully in Section 2.2.4). All state and state-integrated schools were invited to respond to surveys conducted by the research division of the Ministry. Typically, $80 \%$ or higher yearly response rates were obtained. Despite this, the actual extent of truancy in New Zealand could not be identified because absences were based on the number of 
absent events, not the number of students (Ryan \& Loader, 2012). In addition, the survey data collection methods changed over time. In 1998, 2002, 2004 and 2006 paper forms were used. Absences were counted and categorised in three ways: (1) justified absences (JA) - a satisfactorily explained absence; (2) unjustified absences (UA) unsatisfactorily explained absence; and (3) intermittent unjustified absence (IUA) student absence for part of day or period that is unjustified ( $\mathrm{Ng}, 2007)$.

Although clear instructions were given for data collection and recording, the possibility of human error could not be discounted. In 2009, the use of electronic data collection began and only a representative sample of schools participated as a trial that year. However, data were not identified in a form that provided details of how many students were absent on particular days during the survey week and how many students were persistent truants. Since 2011, surveys have been collected annually, but have excluded data from schools for teenage parents from 2012 onwards (Mallari \& Loader, 2013). As surveys were either paper-based or involved electronic submission, another complexity occurred; schools making paper submissions may have interpreted data differently to schools using electronic forms (Loader, 2014). In 2014, only schools using electronic attendance registers (eAR) were able to participate in the survey (Schooling Analysis Unit, 2015).

In 2015, a new student attendance measure that focused on calculating individual half-day attendance rates was introduced, and term-time holidays were coded as unjustifiable absences for the first time (Schooling Analysis Unit, 2016). The Ministry attendance and truancy guideline statement and the data recording code list, comprising school code, classroom, reason, explanations, truancy code, and half day calculation, were introduced to improve future analysis of eAR data and provide consistently interpreted data from participating schools (Schooling Analysis Education, 2016). This will support understanding of the extent of the truancy problem in state and state-integrated schools in New Zealand, and accurately identify regions and specific 
schools with high truancy rates that require further assistance to solve the problem. However, at the time of this review, results from the first round of this new approach to recording data were yet to be reported.

A previous "Wanganui Truancy Service" study (Kilmister \& Baxter, 2002) highlighted the benefits of collecting and recording data in a form that allowed trends and meaningful analysis to be interpreted. Data were collected regarding the occurrences of contact between Attendance and Youth Aid Officers and intermediate-age (11-12 year old) truant children, labelled as "recidivist truants" (p. 6). Attendance improved due to interventions. Three case histories were compiled to identify common risk factors, protective factors, and early interventions, and the impact of these on future school attendance. Interventions included customised family-focused solutions that involved schools, Youth Aid Officers, and Community Agencies. These solutions broke the emerging truancy patterns of over half the intermediate-aged truant children and transitioned them back to school (Kilmister \& Baxter, 2002). Unfortunately, the earlier disestablishment of the District Truancy Services, as a consequence of the Education Act (1989), placed schools in a position to monitor their own truancy occurrences, placing pressure on time and funding resources.

The preceding discussion highlighted the need for consistent procedures in data collection and entering for obtaining useful information. This includes the use of codes or categories that teachers and schools understand so that the validity and the reliability of the data are assured. The earlier research reported in this subsection highlights that truancy is a complex problem in New Zealand schools that requires greater targeting of resources and effort for achieving resolutions and providing effective follow-up. Collaboration between schools, families and external agency workers implementing a customised, family-focused intervention that targets risk factors appears to support children who truant returning to school (Kilmister \& Baxter, 2002). Resources are also required for targeted schools. The evidence from the above discussion suggests that 
some schools require a full-time person to interpret absentee coded data to provide an immediate response, such as informing parents/caregivers of their child's absence. Such a person is also needed to organise and allocate home visits to relevant staff and to build rapport with both the children concerned and their families to make explicit the reasons why attendance at school every day matters.

\subsubsection{Key demographic variables related to truancy}

The previously mentioned the Ministry Survey (Mallari \& Loader, 2013) identified three key variables associated with truancy: school typology, ethnicity, and gender.

\section{School typology}

The nature of schools matters in relation to truancy. The most significant trend within the truancy data relates to a decile level of school (Mallari \& Loader, 2013). As noted earlier, school decile (1 to 10 ) refers to the extent that a school draws its students from low socio-economic communities and the funding that is provided to support such a school to overcome barriers to learning. The lower the decile, the more funding a school receives. According to Mallari and Loader, Decile 1 and 2 schools provided the highest unexplained absence rates in their 2012 survey. Similarly, low decile schools also had higher rates of "frequent" truants when compared to higher decile schools (Mallari \& Loader, 2013; Schooling Analysis Unit, 2015). Frequent truants were defined as students who were unjustifiably absent at least three times during the survey week in 2015 (Schooling Analysis Unit, 2016). The question that arises from these findings is whether lower decile schools are disadvantaged even though they receive more funding than higher decile schools, because they have to cope with higher levels of truancy within their budgets.

Another finding from the New Zealand literature worthy of mention is that truancy appears to be linked to school type (Mallari \& Loader, 2013). In New Zealand, education is provided in different ways; schools are organised into year levels of 
attending students, and school character changes according to these groupings. For example, there are single-sex and co-educational schools; primary schools that offer education to Year 1-6 students; intermediate schools for Year 7-8 students; secondary schools for Year 9-13 students; and composite schools that cover the full Year 1-13 range. In New Zealand then, school type results provide findings according to student gender and different year levels. Even though secondary schools report a higher rate of frequent truancy (frequent truancy refers to students unjustifiably absent for three or four days during the survey week) than primary schools (Ryan \& Loader, 2012), these vary according to school year level: composite Year 1-13, 2.3\%; secondary Year 9-13, 1.7\%; secondary Year 7-13, 1.3\%; primary 1.1\%; and intermediate 1.1\% (Schooling Analysis Unit, 2015). These percentages may be perceived as low but it is important to note that the data that contributed to these percentages only accounts for student attendance during one week of the year. Also of relevance is the fact that secondary school students interact with many teachers in a day whereas primary children have the opportunity to bond with one teacher in particular. This suggests that student-teacher relationships for primary students have a greater opportunity to foster a "pastoral care" interaction, which is likely to be a protective factor against truancy. The examination of secondary school teacher-student relationships, as a risk factor in truancy, warrants exploration.

\section{Ethnicity}

Ethnicity is also a key factor with regard to truancy in Ministry surveys. Available data show that Māori and Pasifika students have double the truancy rate of their New Zealand European and Asian peers (e.g., Loader \& Ryan, 2010; Ministry of Education, 2005; Ng, 2007). In 2012, in relation to ethnicity, Year 9 and 10 Māori students had the highest "frequent truancy" rates in all Ministry regions apart from the Southern region. For the Southern Region, Pasifika Year 9 and 10 students had the highest rate of frequent truants (Mallari \& Loader, 2013). Although reduction in Year 9 and 10 student truancy rates is a stated performance target of the Ministry, the frequent truant rate for both Māori and 
Pasifika students increased in 2014, and was the highest rate for data collected since 2009 (Schooling Analysis Unit, 2015). Amongst Māori and Pasifika students, Year 13 students had the highest truancy rates, whilst primary schools had the lowest. These were higher than the frequent truancy rates for non-Māori and non-Pasifika students (Schooling Analysis Unit, 2016).

It is of interest to note that a 2006 survey conducted by $\mathrm{Ng}$ (2007) compared attendance rates for Māori students in Kura and other immersion schools, with Māori in mainstream schools. The data showed higher truancy rates for Māori students in mainstream schools than in Kura and other immersion schools. This suggests that cultural context in relation to learning appears to be a protective factor against truancy in New Zealand. Three studies in particular provide insights to support this claim.

Bishop and Berryman (2006) concluded that the key to solving the problems facing Māori students lies in the quality of relationship between teachers and students and the acknowledgement of students' cultural experiences and understandings. In New Zealand, concern about underachievement for Māori and Pasifika in relation to other students is a matter of high priority for the Ministry. An on-going initiative funded by the Ministry that is proving to be successful in raising success for Māori (Sleeter, Bishop, \& Meyer, 2011) in terms of academic, attendance, and school retention is "Te Kotahitanga" (Bishop, Berryman, Tiakiwai, \& Richardson, 2003). The concept of "Te Kotahitanga" refers to a collaborative response towards a commonly held vision, goal or other such purpose or outcome. Associated with the initiative was a belief in "culturally responsive pedagogy of relations" (Bishop, 2011, p. 29) that takes as its focus the importance of the relationship between teachers and students in classrooms with a fundamental belief that Māori students should be encouraged by teachers to bring who they are into the classroom. As Year 9 and Year 10 Māori students are at greatest risk of school dropout, this initiative should support teachers to build trustworthy, reciprocal learning relationships in order for them to learn from their students (Cavanagh, 
Macfarlane, Glynn, \& Macfarlane, 2012). A lesson learned from the "Te Kotahitanga" initiative (Bishop et al., 2003), which is relevant to the present research, is the importance of students finding their own voices in classrooms, specifically about their perceptions of teacher-student interactions that influence learning and their choice to attend school. Gathering these stories may provide insights into the circumstances and impact of such interactions on students' choices not to attend school.

To ascertain the causes of truancy, Baleinakorodawa (2009) investigated the perspectives of 15 Pasifika students with a reputation for truanting, who formerly attended mainstream education institutions. At the time of interviewing, these students attended an alternative school. According to Baleinakorodawa, because Pasifika students' approach to learning is influenced by the behaviour of teachers, schools should employ empathetic teachers who understand Pasifika students' cultural circumstances. They should also provide programmes that are seen by these students to be relevant and accommodate their academic needs.

Ng (2007), Bishop et al. (2003), and Baleinakorodawa (2009) have taken some of their guiding principles from Māori and Pasifika students' own perceptions of what helps and hinders them in classrooms and in schools generally. This suggests that students' perceptions provide insights to help schools address attendance problems.

As is evident from the New Zealand research to date, truancy is a complex phenomenon because of, for example, the clear association between ethnicity and the socio-economic backgrounds of students and their families. As early as 1993, Donn et al. reported that some families who lacked money had limited resources for clothing, school uniforms, food and transport, and were too embarrassed to send their children to school. This complexity is further compounded by gender and factors related to school type. 


\section{Gender}

The third key factor with regard to truancy in the Ministry surveys is gender. Available data since 2011 identified the percentage of students arriving late to class without a reason, which schools record as an "intermittent unjustified absence" (Schooling Analysis Unit, 2015, p. 31). In relation to gender, girls arrived late to more classes in Years 1-6, whilst boys were late more often in Years 7 onwards (Mallari \& Loader, 2013). However, when the truancy rate is examined in relation to gender and school level concurrently, a different pattern emerges. Both girls and boys had higher truancy rates in Year 13 compared to girls and boys in Year 1 (Mallari \& Loader, 2013). That truancy rates are higher at Year 13 than Year 1 is not surprising, but the interaction between year level and gender indicates that other factors may be in operation. For example, Year 13 is not a typical year at secondary school. Some students experience more relaxed school policies because they have reached leaving age, which may bring perceptions of earned freedom rather than actually truanting classes. Given that school typology is another key factor in truancy, these findings may also have been influenced by the structural differences in schools. Primary children in New Zealand have the same classroom for most subjects whereas, because they "travel" between classes, secondary students may be more inclined to truant class.

A further finding from these surveys worthy of mention, and which may affirm the previous supposition, is the complex relationships between gender and the types of schools that students attend. Males attending co-educational schools had a higher overall absence rate than males and girls in single-sex schools (Ng, 2007). Girls attending Year 9-13 single-sex schools had the lowest truancy rate compared to other groups $(\mathrm{Ng}$, 2007).

Internationally, over the last three decades there have been reported differences in truancy in regards to gender. For example, in the United Kingdom, Morris and Rutt (2004) and Smith (2004) suggest that more girls than boys are absent from school, but 
according to Reid (2008), boys more often than girls are inexplicably absent from school. However, in New Zealand, Loader and Ryan (2010) report that European and Māori females were absent from school more frequently than their male peers, whereas the situation was reversed for Pacific and Asian students. The data from New Zealand suggest that when gender is examined in relation to cultural identity, differences exist across cultural groups.

If geographical regions in New Zealand are examined, the data show that $12.3 \%$ of students from Tai Tokerau (Northland) and 10.2\% from Hawkes Bay had attended less than $75 \%$ of all half-days in the survey week (Schooling Analysis Unit, 2015). The unjustified absence rates in these areas were well above the 2014 national average. This suggests that truancy is a geographical regional problem, or at least that region and socio-economic status interact. Students at schools in particular locations are at increased risk of truancy, dependent on various factors such as school decile, school size, age, and ethnicity.

In summary, in New Zealand truancy rates increase as children progress through school year levels if they attend co-educational schools, and if they are educated in particular geographical regions. Geographical locations, ethnicity, and socio-economic status of students and families in relation to school decile all appear to influence truancy behaviour. Similarly, the nature of schools (e.g., single sex and full-immersion schools) also appears to relate to truancy levels.

\subsection{Second literature review}

As pointed out in the introduction to this chapter, this section of the literature review focuses on studies identified in response to the theoretical concepts and categories emerging from the analysis of data. This approach, moving from data to related literature, is consistent with the use of grounded theory that gives initial primacy to the code "speaking" to the researcher from the data gathered (Allan, 2003; Glaser \& Strauss, 
1967). However, grounded theory is also conducted iteratively by analysing and collecting data simultaneously (Glaser \& Strauss, 1967; Suddaby, 2006). During this process, literature is also considered as data (Alvita, 2006; Glaser, 1998; Martin, 2006; McCallin, 2006) and is integrated with the emerging theory (Alvita, 2006; Andrew, 2006). The placement of this literature prior to the findings should not be considered as a pre-emption of the research results (Walker \& Myrick, 2006).

In this section, I structure the literature into three main areas: (1) positioning of youth, (2) youth perceptions of causes of truancy, and (3) youth perceptions of factors that support change. Whilst there is an overlap between the content under these three headings, I argue this is in part due to their interrelationships, and an underlying progression that makes sense of the findings of this study.

\subsubsection{Positioning of youth}

The term "positioning of youth" refers to the perceptions of youth who truant - how they are identified and consequently situated to fail. Youth who truant are attributed blame for their failure to meet adult expectations. The perceived use of adult deficit labelling identified them as variously called "bad students" (Freire, Carvalho, Freire, Azevedo, \& Oliveiro, 2009, p. 83), "failures" (Aaltonen, 2012, p. 225), "school refusers", "delinquents", “criminals" (Bottrell, 2007, p. 69), and "troublemaker" (DaCosta, 2006, p. 55). These "labels" imply that adults perceive youth who truant as deviant with a flawed, defiant identity that positions them as susceptible to failure.

This reputation and stereotyping affects the identity of youth who truant (Bottrell, 2007). A Swedish study (Pless, 2014), involving three rounds of student interviews, reported that truant youth struggle to cope with the requirements of school life. The aim of this study was to ascertain how the setting helped frame their present and future identities, and how youth dealt with and understood their marginal positioning at school. These youth felt that they were delegated responsibility for their failures. Two further studies endorse this claim (Aaltonen, 2012; Freire et al., 2009). 
Firstly, 32 15-17 year-old students from Finland (Aaltonen, 2012) report in biographical interviews that teachers distinguished them as problematic because they were incapable of adapting to school rules, "messed up" their careers, and lacked the motivation and sense of responsibility to achieve. Secondly, many of the 20 13-18 year-old interviewed participants in the study of Freire et al. (2009), who had a history of truancy and failure, were perceived by their teachers as students who misbehaved in class, who had no desire to learn, and who were a bad influence on classmates. The stereotyping of youth who truant fosters a reputation of students who are problematic, unmotivated, and incapable of learning.

In a US study (Edinburgh, Garcia, \& Saewycs, 2013) of 11 vulnerable 13-16 year-old Asian immigrant youth in the first three months of a runaway prevention programme, the researchers examined reoccurring runaway patterns gathered from clinical charts, reports, and descriptive video diaries. Parental expectations imposed an identity that girls in the study did not accept. They did not want to be "good Asian girls" who stayed home, cooked, looked after siblings, and learnt to be a good future wife. They did not want to conform to these traditional parental norms and ran away from home (and schooling) to avoid such positioning. This study suggests that when labelling threatened girls' perceptions of their reputation - that is, girls felt they were not accepted for who they wanted to be - an identity struggle took place and they adopted the stance of "rebel" in line with the positioning that they felt had been assigned to them by adults. However, not all adults position girls who truant in a negative light; in a different study, some parents acknowledged their daughters as "good kids" (Bottrell, 2007, p. 608).

\section{The impact of imposed positioning}

The term "the impact of imposed positioning" refers to the impact of teachers' positioning of students, in particular the consequent risks to students' current and future learning. Various researchers indicate that labelling and stereotyping compromise youths' well-being. For example, McHugh, Horner, Colditz, and Wallace (2013) 
undertook a comprehensive study of the perceptions of 78 youth (aged between 14 and 20) of their interactions with teachers using focus group interviews as a major source of data. Students reported generally feeling uncared for and misunderstood by teachers, and identified perceived teacher stereotyping of students and inattention to their needs as barriers to positive relationships in classrooms. Similarly, Strand (2014) reports that students felt like outcasts from the labelling and stereotyping that they experienced (Strand's research is reported in more detail shortly). In a previously mentioned study, Friere et al. (2009) reported that youth, when labelled, experience restricted involvement in class, reduced significant teacher interactions, and compromised ability to achieve academically. Along similar lines, Pless (2014) argues that this subordinate positioning produces disappointment, disaffection, diminished self-worth, and a sense of being marginalised. On a different tack, research in Australia investigated youths' perceptions of exclusion from class (Lewis, Romi, \& Roach, 2012). This study involved analysis of 302 exclusion questionnaires administered to youth. The study identified that the majority of exclusions $(71 \%)$ were characterised by students as involving teacher anger; the students reported the experience of feeling hated and picked on (45\%). In the majority of cases (60-70\%), students also reported an absence of prior punishments or warnings, along with a feeling of being suddenly rejected.

All of these studies (Friere et al., 2009; Lewis Romi, and Roache, 2012; McHugh et al., 2013; Strand, 2014) suggest that when students notice their unfavourable positioning, they feel marginalised in their time with teachers, in their ability to achieve, and in their feelings of self-worth, safety, and well-being. These factors appear to contribute to a sense of imposed subordinate positioning, consequently risking youths' current and future learning.

\section{Youth behaviours in response to imposed positioning}

The term "youth behaviours in response to imposed positioning" refers to the strategies youth implemented in order to avoid entrenched stereotyping and the sense of exclusion 
from participation in school. For example, Bottrell (2007) conducted a study involving twelve 13-24 year-old, mainly Aboriginal and Anglo-Australian girls, in Australia. The study took place over a twelve-month period and involved participant observations in and around the public housing estate's youth centre, which had 300 clients. Bottrell reported that the school system failed to address the entrenched stereotyping, which was at the heart of truancy, and girls adopted a youth culture as a "viable" alternative to schooling. These girls claimed that they did not enjoy being labelled and did not want to experience stereotyping. Truanting and participation in a local youth network were strategies that they used to resist the negativity and marginalisation of school. Girls perceived participation in the local youth network as "time out" to deal with issues and to regroup within community support systems. They proudly belonged to "their" people and claimed the margins when they stuck together in friendships in their youth network. The sense of belonging through claiming and "being owned" by one's people provided self-esteem, status and solidarity. They wanted to be safe, enjoy their chosen identity, experience social status, and belong. This suggests that deficit thinking, in terms of labelling and stereotyping, inhibited youth belonging in Bottrell's study. The girls resisted, connected with others, and positioned themselves in an accepting alternative youth culture.

In a US study, DaCosta (2006) gathered data from 22, predominately black, high school students over two years, which involved focus group interviews, semistructured interviews, and observations of the students' compliance to the school's uniform policy. The data also included students' academic performance reports. While the study did not address truancy as such, the findings have relevance to the discussion here. Findings indicate that, when feeling motivated to maintain self-respect and manage their provoked hostility, youth either adapted or challenged in some way the school's uniform policy. While some youth worked within policy constraints, others attempted defiance, but conformed under pressure. Another, less subversive group, tested the 
policy in order to exercise a sense of freedom and gain a sense of control. Another group of youth rebelled; they did not wear the required school uniform. It is evident from the study that these students expressed the desire for consultation before change of the kind instituted by the school was imposed. In other words, some students appear to have felt provoked into defiance or reluctant acceptance by the positioning invoked by the school's policy. This mirrors the behavioural reactions to imposed authority of some of the students in Bottrell's research; that is, students resisted the negativity and marginalisation they experienced at school, which inhibits their sense of belonging, and subsequently adopted the alternative "norms" of their peer group.

In both Bottrell's (2007) and DaCosta's (2006) studies, students reacted and showed their disapproval when experiencing perceived unfairness and consequent identity struggles related to "rebelling" against school norms. These impositions appear to have affected students' identity, inhibiting their self-expression regarding who they wanted to be.

DaCosta's findings are echoed more dramatically in the US study (cited earlier) by Edinburgh et al. (2013) that focused on the experiences of Asian immigrant (Hmong) girls who resisted traditional family norms. Whilst on the run, these girls experienced diminished well-being. Variously, girls reported gang rape, prostitution, sexually transmitted diseases, multiple sexual partners, and unprotected sex. Subsequently, girls endured anxiety, depression, self-harm, post-traumatic stress, and suicidal tendencies (Edinburgh et al., 2013). These reactions indicate that when youth resist what they perceive as unwelcomed identity and marginalisation, they become vulnerable to various forms of harm.

The research in this section suggests that youth exposed to entrenched stereotyping experience exclusion from participation in school. They resist this marginalisation by connecting with others in an alternative space and participate in an 
accepting youth culture. However, what occurs and the outcomes of participation in the youth culture are unknown. This identified gap requires further investigation.

\subsubsection{Youth perceptions of causes of truancy}

Various circumstances within the school environment contribute to youth being truant. For example, Pless (2014) argued that youth perceive school as a place of turbulent times associated with periods of truancy, school fatigue, poor academic skills, social rejection, feelings of inadequacy, doubt and uncertainty, fewer post-compulsory education opportunities, detours, dropouts, and dead ends. In another study, Strand (2014) claims that most youth dislike school and blame their truancy on school conflict, social exclusion, and school atmosphere. In interviews with fifteen 7-16 year-old boys from two secondary schools, Strand noted circumstances within the school environment that students felt impaired their attendance. These included a lack of social relationships between students and their teachers, peer pressure, bullying, school-weariness, diminished motivation to attend, boredom, and a lack of challenges in relation to learning. Youth in this study variously could not cope with noisy classrooms, loneliness, sport, inadequate sports equipment, studying, poor study instructions, not understanding what to do in the classroom, and the consequent achievement pressure they experienced. In Strand's study, the only alternatives to school-based factors given by students to explain their truancy behaviour were sunny weather and parental health. However, on a different tack, interviews conducted by Dahl (2016) with 34 emerging adults described as "truant youth", identified that the influence of peers was a major contribution to their skipping class. Youth perceived that two circumstances - a need to gain peer acceptance and reassurance that they did not miss something important outside of class - governed this behaviour.

Taken together, the three studies above (Dahl, 2016; Pless, 2014; Strand, 2014) suggest that youth who truant struggle to attend class due to multiple "exclusionary" 
causes: the perception that they are socially unacceptable to others; negative influence from peers; and class circumstances that inhibit their participation in the curriculum.

Disrespect may also contribute to exclusionary circumstances in the classroom. For example, a previously mentioned US study (McHugh et al., 2013) conducted across three urban sites, gives support to this conclusion. This study, designed to elicit understanding about youth perspectives of their interactions with teachers, involved 70 14-20 year-old youth in 13 focus group interviews. Many students reported feeling uncared for and misunderstood by teachers; they identified perceived teacher stereotyping of youth, and inattention to their needs as barriers to positive relationships in classrooms. The disrespect that emerged from perceived impaired relationships in classrooms contributed to student exclusion.

Teaching approaches were also identified as contributing to truancy in research conducted by Reid and McCallum (2014). Youth perceived that old-style methods, such as requiring students to copy writing from the board or learn difficult concepts directly from a textbook, were unhelpful; such learning was unconnected to their lives and aspirations. There appeared to be an absence of respect (whether intended or not) for students' prior knowledge and cultural capital. In another study, Syrjalainen, Jukarainen, Varri, and Kaupinmaki (2015) reported that perceived lack of safety and trust between youth and others in the classroom contributed to their insecurity. Some youth found teacher control and supervision unpleasant. Again, it seems that in this classroom study, teacher behaviour and student insecurity contributed to students' perceived experience of disrespect. However, Murphy-Graham and Lample (2014) conducted a cross-national study, involving research teams in four sites in Honduras and three sites in Uganda, to investigate how education can foster trust. They identified, through interviews and extensive field notes, that students attending an alternative secondary school (described as offering a social action programme) learnt to build trust through small group activities in a space where all opinions were respected. These researchers claim that trust is a 
learnt capacity that provides opportunities for students and teachers to reduce discriminatory behaviour, share values, work together, and build cooperation.

Taken together, the studies of Reid and McCallum (2014), Syrjäläinen et al. (2015), and Murphy-Graham and Lample (2014) suggest that truant youth disconnect from learning due to inattention arising from teaching approaches, and lack of trust and personal insecurity. The latter study suggests strongly that building trust in classrooms between teachers and youth, and youth and youth, is an important strategy for helping alleviate labelling and stereotyping.

In addition, insights into classroom tensions are gained by noting youths' reactions to unfairness. Of relevance are the findings from an ethnographic study involving field notes and individual interviews of twelve 15-18 year-old runaway boys (Raval, 2012). Their interactions with peers (e.g., moving on as if a conflict that arose did not happen) reflect an underlying cultural discourse of collectivism and interpersonal harmony in their relationships with peers. However, conflict with adults developed when the boys in the study perceived teachers' actions as unfair. The boys expressed their feelings in the form of righteous anger, evident in their withdrawal from activities, as a correct action in the circumstances. Similarly, in a previously cited study (DaCosta, 2006), youth perceived the stringently enforced uniform policy, a reform implemented to restrict gang affiliation and associated violence, as an exclusionary punishment that inhibited their freedom of expression. These two studies indicate that when youth perceive teacher practices as exclusionary, they feel that they have been placed in a subordinate position. The students find this unacceptable, compromising, and affecting their freedom of expression.

In summary, this section indicates that lack of social relationships with teachers and peers, school policy, and circumstances within the classroom (e.g., meaningless learning, loneliness, mistrust, and being uncared for) diminish youth autonomy and 
potential to participate in learning and achieve. The research also suggests that trust is a protective factor against disrespect in the classroom.

\subsubsection{Youth perceptions of factors that support change}

Youth marginalised by truancy, excluded from classrooms, and subjected to changes in school policy without consultation, report that they require support to change. Research suggests three areas in which support may happen: fostering collective responsibility; establishing inclusive environments; and providing assistance to recommence attending class.

\section{Fostering collective responsibility}

The concept of "fostering collective responsibility" in relation to preventing truancy refers to the respectful positioning of students, and the implementation of studentcentred and culturally responsive pedagogies to foster student engagement in learning, student autonomy, and the strengthening of home-school relationships.

A study of thirty-nine youth with a history of truancy who were interviewed in South and East Los Angeles suggests that schools have an opportunity to prevent truancy in four ways (Gase, De Forrest, Perry, \& Kuo, 2016):

- promoting school engagement and providing culturally relevant and meaningful learning tailored to student interests and experiences;

- responding to truancy more effectively (for example, early interventions that establish clear boundaries and consequences);

- addressing the root causes of truancy (i.e., family turmoil and mental health issues); and,

- strengthening staff and parent relationships.

As noted by Gase et al. (2016), these practices increase parents' capacity to understand school structures and enable resources to be used more effectively to support 
youth reduce their truancy behaviour. In particular, this study suggests that studentcentred approaches help diminish truancy.

Two further studies support the notion that certain practices diminish truancy (Cavanagh et al. 2012; McHugh, et al., 2013). Young people who truant report that when they co-construct behaviour expectations with their teachers, they are able to maintain a positive sense of self, their relationships with teachers are positive, and they experience autonomy (McHugh et al., 2013). This consultation, respect, and inclusion of students' viewpoints contrasts to students in previously mentioned studies, who experienced disrespectful social relationships, exclusion and unsafe learning environments (Reid \& McCallum, 2014; Strand, 2014; Syrjäläinen et al., 2015). In New Zealand, Cavanagh et al. (2012) gathered data from interviews with Māori students and teachers, classroom observations, and researcher reflections to investigate what mainstream schools were doing to create an ethic of care for minoritized students in dominant culture schools. Developing a school-wide culture for minoritized students was important; effective culturally responsive approaches build trust and respectful relationships, repair wrongdoing and acknowledge students as culturally located beings. The McHugh et al. (2013) and Cavanagh et al. (2012) studies suggest that there is a positive impact when teachers sustain culturally responsive practices, support marginalised student functioning and create a culture of inclusivity in classrooms. These are protective factors against previously mentioned exclusionary practices (Dahl, 2016; Pless, 2014; Strand, 2014) and work towards diminishing truancy.

Explicit teacher expectations also support youth functioning in the classroom. For example, Lewis et al., (2012) claim that specific teacher behaviours are required to convince youth to accept responsibility for their behaviour and avoid blame for their exclusion. Students excluded from class report that teachers should explain why the exclusion is necessary and warn and punish students before excluding them. Teachers should also hold a follow-up conversation that highlights the impact of the students' 
misbehaviour on classmates and avoid just 'telling them off". As a result of teachers' implementation of such strategies, excluded youth perceived that instead of setting out on a slippery slope of exclusion and underachievement, they would be successfully reintegrated into their classes and would more likely accept that their misbehaviour has an impact on their peers. They also felt that they would take more responsibility for their actions if teachers themselves behaved reasonably to them (Lewis et al., 2012). Teacher intentional professional behaviour appears to be a precursor for excluded youth accepting responsibility for their misbehaviours as well as increasing the opportunities for their re-inclusion and achievement.

In addition, evidence exists that youth gain autonomy when they are consulted respectfully. For example, DaCosta (2006) advocated for a more viable student-centred approach, such as student involvement in decision-making regarding the co-design of school uniforms to enhance student ownership. She claims that as early as possible, youth must learn to think about others empathetically, respond caringly to what others think and feel, and find thoughtful and responsible solutions to problems. In other words, when teachers position youth respectfully to share power, they experience autonomy.

The research in this section suggests that the actions of teachers - consultation with students, inclusion of students in decision-making, blame avoidance, explanations for discipline, and other intentional teacher behaviours - contribute to collective responsibility and students gaining a sense of autonomy. This respectful treatment of youth reduces problems associated with identity struggles that occur in classrooms.

\section{Establishing inclusive environments}

The concept of "establishing inclusive learning environments" relates to the support provided to excluded students to help them develop a sense of belonging to school. It includes the experience of acceptance and connection to others, and the development of self-efficacy, autonomy and feeling valued. 
Evidence exists that teachers who establish and monitor classroom environments through inclusive teaching and learning approaches provide a context that supports meaningful learning. For example, from a content analysis of 280, 7th and 9th Grade students' essays about a safe school day, Syrjäläinen et al. (2015) drew the conclusion that youth associated caring by their teachers with feelings of safety, joy, well-being, trust, and empathy. The youth wanted inclusive approaches such as acceptance of difference and building positive teacher-student relationships. Under these conditions, youth reported they would be able to build trust, receive support, and experience closeness with others. Syrjäläinen et al. also associated inclusive teaching with the establishment of collective responsibility and the development in students of a sense of belonging.

Similarly, culturally responsive practices improve the dynamics in the classrooms and enhance opportunities for meaningful learning. For example, according to five 14-15 year-old secondary students, who participated in focus group discussions and individual interviews (Reid \& McCallum, 2014), the use by teachers of contextual learning connected to the students' lives acknowledged meaningfully the cultural capital that they possessed. This relevant contextual learning helped establish the conditions necessary for inclusivity and encouraged the youth to develop educational, social and vocational goals that were aspirational.

In another case study in Australia, O’Donovan, Berman, and Wierenga (2015) used feedback from students, parents, a principal, and a community collaborator to investigate "enabling spaces" (p. 645). These alternative learning opportunities, situated outside school classrooms in spaces within the school setting, supported previously excluded students to participate in practical, hands-on building projects. In these enabling spaces students were supported to explore respectful relationships, to foster a sense of belonging, and to develop self-efficacy. O'Donovan et al. report that time and 
space allocated for previously excluded students to connect with others contributed to meaningful learning occurring.

Similarly, in a study conducted in England (Stahl \& Dale, 2013), the opportunity for students to engage in music making outside the classroom provided a meaningful school context with positive experiences. This opportunity supported 12 white working class 14-16 year-old interviewed boys from Years 9-11 to change their identities from failures because of truancy, to achievers because they were inspired to attend. They were able to persevere because they did not associate failure with loss of status, and the supportive music-learning environment helped them to recognise that their skill base was improving. In addition, the context of an inspiring supportive, inclusive learning environment provided a place for them to attend. They experienced relationships that were positive and equal. Outside of class, the boys chose work that inspired them, their peers recognised them as successful, and their identities changed. Positive relationships, equal status, peer approval, and inspiring contexts for learning are the features of inclusive learning environments that support truant youth to participate in learning and to experience success.

All of the studies in this section (O'Donovan, et al. 2015; Reid \& McCallum, 2014; Stahl \& Dale, 2013; Syrjalainen et al., 2015) suggest that relevant, meaningful, purposefully designed curriculum, privileges youths' cultural capital and positions them favourably to achieve academically. Youth who truant claimed that they needed to be safe, connect with others, and be seen as successful, in order to belong at school and achieve.

\section{Providing assistance for students to recommence attending class}

The concept "providing assistance for students to recommence attending class" refers here to the nature of the social and emotional support that youth who truant need to foster their attendance at school. 
Specific approaches provide support for youth to change. For example, youth in the study by Syrjäläinen et al. (2015) recommend that teachers prevent student bullying, build positive teacher-student relationships, accept difference, and encourage closeness. In this way, collective responsibility is emphasised and every student receives the necessary support to feel a sense of belonging. Similarly, Delgado, Ettekal, Simpkins, and Schaefer (2016) report that when students were nominated as a friend by peers and experienced the perception that they were amongst friends, their sense of belonging to school was enhanced. The study suggests that safe learning environments and close reciprocal relations between students promote school belonging.

However, based on analysis of data from 1,458 8th graders' questionnaires, school records and test scores, Hallinan (2008) reports that, “it is teachers' support more than youth friendships that increased youth liking of school" (p. 281). Hallinan concluded that when teachers provided social and emotional support to students through care, respect and praise, they strongly influenced students' attachment to school (Hallinan, 2008). This argument is supported by data from a previously mentioned study of immigrant Hmong girls (Edinburgh et al., 2013). Runaway girls were motivated to return home and try to change because of factors such as missing their younger siblings. However, these girls needed culturally relevant, youth-centred support in order to reunite with their families. What seems apparent is that youth want support to reconcile differences with others. This support involves the positioning of youth as culturally located beings, having friends, experiencing closeness to others, being accepted, respected and praised, and feeling safe.

The preceding discussion indicates that across different countries, student perspectives on truancy provide insight into the impact of deficit adult thinking in terms of labelling, stereotyping, and imposed positioning. This imposed negative identity contributes to youth exclusion and marginalisation. Youth perceive other school circumstances, such as unsafe learning environments, uninteresting curriculum, lack of 
attention from teachers and others, and social rejection as contributing to diminished confidence and personal insecurity in classrooms. Youth understand they need support, care, reciprocity of relationships, peer approval and equal status to promote school belonging and attendance.

\subsection{Literature review: Summary}

The review of literature in this chapter has selectively focused on two broad sources of evidence about truancy and excluded youth:

- Historical trends in the causal description and interpretation of truancy behaviour, including an update on the initial literature consulted for this research;

- "Findings-driven" literature that relates to the emerging theorisation from the grounded theory analysis of the data gathered in this research.

The literature under the first of these sources highlights that truancy is a complex problem, both internationally and nationally in countries with compulsory school attendance policies. Young people who truant neither fit in nor cope with expectations of staff in schools. Historical labelling of the child was problematic because the blame was mainly attributed to characteristics of the child (e.g., "bad", "dull”, "stubborn", "phobic") while contributions to the problem of truancy from the home, the school, and the students' peers were assigned limited influence. In line with deficit theorisation, the task was seen as one of fixing the child's attitude and behaviour, not one of changing the contextual elements of schooling and the home that contributed significantly to the truancy behaviour. The child who truanted was positioned as an outcast, was excluded, and subsequently marginalised. However, towards the end of the $20^{\text {th }}$ Century, the importance of home and school-based causes became more widely recognised in the literature. For example, school contextual factors such as bullying from other students, negative labelling from teachers, insensitivity of teachers to 
students' needs, boring lessons and ineffective pedagogy, and seemingly (at least to the student) irrelevant curriculum, were all identified as motives or reasons for students to absent themselves from school.

The current situation in New Zealand is that truancy is associated with school decile, school type, gender, and ethnicity, but these factors interact in ways that yield a complex picture of truancy behaviour. For example, truancy amongst Māori boys is greatest in mainstream classes but lowest in immersion schools, suggesting the importance of embedding education within the cultural context of students and drawing more effectively upon their cultural capital.

While the needs of youth who truant are still not widely recognised, there is increasing evidence that when youth experience inclusive teaching and learning, a positive school climate, a caring approach from teachers, positive teacher-student relationships, and co-operative and supportive classroom practices, truancy diminishes. However, the literature also suggests that increased effort from schools and family, further follow-up on the progress of youth in schools, and increased resourcing to combat truancy (in particular for low decile schools) is required in the New Zealand context.

The second review of literature ("findings-driven" in relation to the grounded theory analysis of data collected in this research) gathered data on students' perspectives on truancy, students excluded from classrooms, and students subjected to changes in school policy without consultation.

The analysis of the studies reviewed in this research, in relation to the theoretical concepts and codes emerging from the analysis of the data (see Chapter 4), suggest three areas that make sense of the underlying progression perceived as present in the study: positioning of students who truant; youth perceptions of factors that lead to truancy; youth perceptions of factors that support change. 
The findings in relation to each of these areas generally reinforce many of the ideas summarised from the historical analysis of the truancy literature. In relation to the positioning of youth who truant, students experienced entrenched stereotyping and a sense of marginalisation in their time with teachers, in their ability to achieve, and their feelings of self-worth and safety. Consequently, many youth who truant sought alternatives to school, such as peer group friendships and membership, in order to gain self-esteem, social status, and an identity based on "belonging". In relation to youth perceptions of causes of truancy, the research reviewed suggests that lack of positive social relationships with teachers and peers, and circumstances within the classroom and school (meaningless learning, school policies, bullying, loneliness, mistrust of teachers, and perceived teacher attitudes) reduce students' sense of autonomy and feelings of selfworth, consequently affecting engagement and achievement. In relation to factors that youth feel support positive change for them, teaching and school practices that foster collective responsibility for tackling truancy (i.e., involving teachers, students, peers, parents, and other relevant persons) are important for underpinning behavioural change. In addition, specific teacher behaviours such as clear and respectful communications with students in relation to expectations and rules, and teaching practices that are inclusive of all students (e.g., respecting cultural differences and knowledge) all impact positively on students' re-engagement with school and subsequent success.

The three areas of the progression described above have been depicted in outline form in Figure 2.1 (below). The relationship has been portrayed as two overlapping ellipses, with the overlap represented by "positioning of students". The reason for this is that "positioning of students" seems to be a core element of both the other two areas; hence it is depicted in the overlap. Negative positioning of students is evident in youth perceptions of causes of truancy. Positive positioning of students links with youth perceptions of factors that support students' sense of belonging at school and a change away from truancy behaviour. Whether this is the best depiction of the relationship 
between the three themes will not be pursued at this point; at the moment Figure 2.1 should be seen as an initial analysis of the literature that will be further considered in relation to the grounded theorisation as later research to be undertaken.

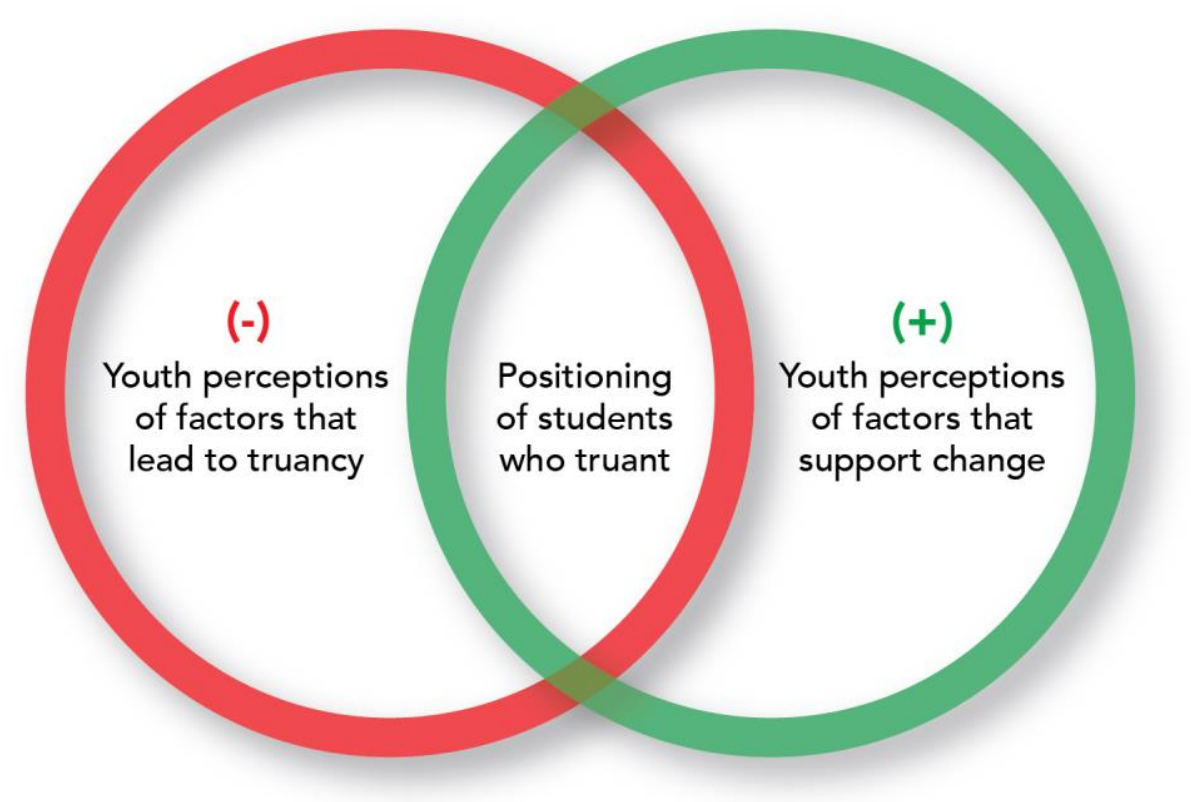

Figure 2.1 Positioning of students who truant

In relation to these data, the review of the literature suggests a number of questions that this research should consider. The main question is:

How do secondary school students in New Zealand construct meaning from their experiences of truancy?

This question breaks down into five sub-questions:

1. In what ways do the experiences of these students, and the challenges they face, contribute to their decision to attend class or not?

2. How do New Zealand girls and boys position themselves when they truant classes?

3. In what ways do youth manage the complexities and consequences of truancy?

4. How, and under what circumstances, are New Zealand youth able to reintegrate in class after persistent truanting? 
5. In what ways do secondary school students' perceptions of truancy provide insights into addressing and solving truancy problems in New Zealand secondary schools? 


\section{CHAPTER 3}

\section{METHODOLOGY}

\subsection{Introduction}

In the literature review in chapter two, I indicated a paucity of research regarding youth perspectives of truancy compared to other stakeholders (e.g., school staff, relevant community members, and parents). This project was designed to help fill this gap in understanding about truancy. In this chapter, I explain and justify the research design that draws on the use of Grounded Theory methodology and tells the story about my analysis of student data.

\subsection{Research aim and question}

The aim of the research was to learn about how a sample of thirteen students experienced their world of truancy and how they interpreted the social aspects of their personal, school and home circumstances. I wanted to understand their behaviours as participants understood them, and to identify a social process that accounted for most of the similarities and variations in the reported behaviour. To fulfil this purpose, I stayed close to the data, was reflexive, and gained an understanding of the participants through our conversations and my interpretation of their stories. By creating a safe space where these youth were encouraged to speak, I listened, recorded, interpreted data, discovered and understood what was problematic for the participants in the study.

This research was a study of truancy in naturalistic settings without intervention (in this instance three schools and an activity centre), and focused on description and interpretation (Cohen, Manion, \& Morrison, 2000). For this reason, I used qualitative, interpretative, contextual research with a grounded theory approach. The main question was, "how do secondary school students in New Zealand construct meaning from their experiences of truancy?" This question involved five sub-questions (see Literature Review, Section 2.4). 


\subsection{Justification of research design}

In the human and social sciences, paradigms assist understanding of phenomena (Creswell, 1999) and stories told by people are a common way of capturing the phenomena. The three most common ways of telling stories about social worlds are normative (often referred to as quantitative), interpretative (often referred to as qualitative), and mixed methods research (Denzin \& Lincoln, 2005; Cohen et al., 2000).

Qualitative researchers are fascinated with how people position themselves in situations, how they make sense of the inhabited space through factors such as social roles, symbols, and rituals (Berg, 2009), and the meaning people assign to these lived experiences (Davidson \& Tolich, 2003). They gather ideas about the people's interactions and the flow of events to encounter new insights or view old experiences in a new light and provide understanding of our surrounding world (Davidson \& Tolich, 2003). Thus, the intention of qualitative research is to scrutinise various social situations and the individuals who occupy them, and to apply systematic practices to discover answers to questions (Berg, 2009). Often the data collected and analysed consist of interview transcripts, documents, artefacts, video recordings, field notes used to record the researcher's and participants' experiences in social action, and researcher personal reflections (Saldana, 2011).

In contrast, normative (quantitative) research takes its philosophical basis from a positivist frame of reference. The world is seen from an objectivist viewpoint, that is, the world exists and is able to be objectively described free from the perceptions and beliefs of the researcher. The aim is to discover the norms, patterns and laws that govern people's behaviour. The approach uses manipulations or interventions to test hypotheses and generate theories. The design focuses on carefully worked out procedures and rules that test a theory composed of variables, using statistical analysis to ascertain the truth of predicted generalisations (Denzin \& Lincoln, 2005; Creswell, 1994). 
Often research that uses quantitative data also uses additional data of a qualitative nature to triangulate with, or further explain, statistical findings. Such an approach is generally labelled as "mixed methods" research. As noted by Creswell (1994), this approach adds complexity to the design by mixing aspects of both quantitative and qualitative paradigms in many or all of the methodological stages of the project. Green, Carcelli and Graham (1989) similarly note that there are several purposes for using a mixed methodological design (e.g., triangulation, elaboration of results, and extending the breadth of the enquiry). Creswell (1994) suggests that this research paradigm moves between inductive and deductive models of thinking, so the researcher needs strong content knowledge of both the quantitative and qualitative paradigms.

I selected qualitative methodology because my goal was to understand, explain and interpret the social reality of truancy from participant perspectives. Qualitative interpretative studies aim to discover how different people interpret events, situations, and actions (Cohen et al., 2000). Qualitative methodology was well suited for the present study for revealing insights into truancy and how it unfolds. This type of research argues for contextuality rather than generalisability, and meaning obtained from text symbols and images rather than from analysis of numbers. I sought to understand and make sense of truancy within the current context of New Zealand schooling.

\subsection{Personal subjectivity}

Knowledge is open-ended and social reality is characterised by complexity (Cohen et al., 2000). The world of truancy exists but people interpret truancy in different ways (see Literature Review, Section 2.2.2). Qualitative research involves the subjectivity of the researcher, who is encouraged to declare her/his positioning. This includes the values and objectives s/he brings to the research and reflection on how these will influence the research project (Ratner, 2002). Ratner suggests that subjectivity influences every aspect of a study (e.g., the choice of topic and the nature of the methodology selected). 
Likewise, Isakson and Boody (1993) state that our biases are an inescapable part of the research process and that rather than apologise for them, we should instead give as full an account of them as we can. They suggest that individuals recognise things in unique ways and that it is the distinctive view of the researcher that makes the research. Peshkin (1988, p. 21) states, "untamed subjectivity mutes the emic voices" - the perspectives of the "insiders", my participants - and suggests that all researchers need to actively seek out their own subjectivity. To gain an emic perspective requires me to view the world of truancy as the young people who truant view it. This is managed through the process of gathering, scrutinising, and writing up the data, and avoiding the "thwarting biases that subjectivity engenders" (Peshkin, 1988, p. 21). Sipe and Ghise (2004) note that "All coding is a judgement call", because we bring "subjectivities, our predispositions, [and] our quirks" (pp. 482-3) to the process of investigation. Within any qualitative research project, therefore, it is important that the researcher outlines their background and interests. Then the reader of the research has some idea of the lenses through which the participants' experiences were examined.

However, as noted by Ratner (2002), because the subjectivity of the researcher compromises her/him from knowing the objectivity of the examined world, researchers need to include processes that test the trustworthiness of their interpretations. In considering this, and with the support of my supervisors, I reflected on my positioning. I acknowledged how this influenced my interpretation of the data, and my supervisors monitored my subjectivity closely. As Saldana (2016) suggests, my supervisors functioned as "rigorous examiners and auditors to my analysis" (p. 37). I recognise that my values shaped the directions of my research into truancy (see Section 1.5).

\subsection{Grounded theory methodology}

Grounded theory (GT) is a methodology that is well suited for studying processes (Charmaz, 2009); it is used to conduct social research that is qualitative, exploratory, and small-scale in nature by scrutinising the perspectives of participants (Denscombe, 
2010). The goal of GT is to discover a new theory that emerges from analysis of the data gathered from participants rather than interpreting the data in relation to prior conceptions that may be based in literature, or in the preconceived beliefs held by the researcher. GT develops a rigorous theory by applying systematic procedures (Thistoll, Hooper, \& Pauleen, 2016). There are three key components of GT (Glaser \& Strauss, 1967):

- constant comparison of new data with previously coded fragments of data to test and refine existing interpretations and ascertain the coherence between categories and their properties;

- theoretical sampling, that is, purposefully selecting further participants to provide data that will clarify interpretations that are linked to gaps or ambiguities in the emerging theory; and

- theoretical saturation, that is, the point in the process of GT where the emerging theory has reached stability, that is, no further data are needed.

Theoretical sampling, inductive analysis, and constant comparison of new data with emerging theory occur during concurrent data gathering and analysis (Bryant \& Charmaz, 2007). The theory that develops from this process explains "an educational process of events, activities, actions and interactions that occur over time" (Creswell, 2005, p. 396), and "grounds the researcher's final theorising in the participant's experiences" (Mills, Bonner \& Frances, 2006, p. 27). However, the historical development of GT has not been without disagreement amongst the different proponents of this approach to qualitative analysis of data (Heath \& Cowley, 2004).

\subsubsection{The history of Grounded Theory}

Glaser and Strauss (1967) is recognised as the foundational work on GT. They argued for the need to combat the subordinate status of qualitative research at that time, when research was mainly deductive and used a coding scheme that was developed before 
data were coded (Kelle, 2007). However, Glaser and Strauss argued that a new theory could not be generated using deductive reasoning. Previously, qualitative research analysis also involved collecting the data then analysing it. Glaser and Strauss (1967) suggested a new approach - a constant comparative method - where data were gathered and analysed concurrently with joint use of theoretical sampling to develop an integrated theory (Glaser \& Strauss, 1967). Together these processes added rigor to the data coding processes by emphasising simultaneous involvement of data collection and analysis, the construction of analytical codes from the data, and the use of constant comparison at each stage of analysis (Glaser, 1992). Glaser and Strauss (1967) extended an invitation to other researchers to publish "their own methods for generating theory" (p. 8) developed systematically from data.

Four stages of constant comparative analysis were identified by Glaser and Strauss (1967): “(1) comparing incidents applicable to each category, (2) integrating categories and their properties, (3) delimiting the theory, and (4) writing the theory" (p. 105). This was an emergent process that involved each stage transitioning into the next over time. Earlier stages continued to operate until saturation of the data became evident. However, according to Schatzman (1991) there were problems inherent in the "classical" version of GT proposed by Glaser and Strauss. He suggested their work lacked the necessary structure to articulate the analytical process involved in defining and interpreting data that led to theory development. In other words, Schatzman thought that the establishment of a theory was insufficient unless the analytical processes leading to the generation of the theory were soundly based and explicit.

Differences in beliefs about GT developed over the years that caused Glaser and Strauss to dissolve their research partnership (Douglas, 2003). Their differences related in particular to coding procedures. Glaser focused on emergence, discovery and inductive theory generation, whereas Strauss argued for the use of a social worlds/arenas framework to examine the active role of people who live in the social life under study. 
Strauss consequently formed a new research partnership with Corbin. Strauss and Corbin $(1994,1998)$ advanced the emphasis on context in GT, through the use of multiple coding procedures and comparative techniques that assisted researchers to consider the contexts of their research. Glaser (1992) criticised Corbin and Strauss' work, highlighting that the forced nature of their data analysis and preconceived ideas were problematic in relation to the emergence of theory and theoretical sensitivity. He claimed that this way of working placed an over-emphasis on research techniques, which reduced the theoretical sensitivity of the researcher. Allen (2010) also criticised Corbin and Strauss' (1990) work; specifically the vague nature of definitions and unclear details about how to conduct grounded theory. In addition, Mills, Bonner and Francis (2006) argue that Strauss and Corbin's work $(1990,1998)$ draws too much on their variety of techniques "in the act of theory development" (p. 29), thus implying that theories are constructed rather than discovered.

After Strauss died, Corbin modernised the method (Corbin \& Strauss, 2009). She favoured detailed, analytical procedures rather than emphasising comparative methods that characterised earlier GT (Corbin \& Strauss, 2009). However, Clarke (2005) acknowledged that although these were appropriate directions to follow, the idea of context was flawed. She suggested that the focus should be on the conditions present in the situation. Charmaz (2014) also criticised Strauss and Corbin's work, specifically the underlying assumptions and verification. Despite these criticisms, Corbin and Strauss' work has informed graduate programmes and students worldwide (Charmaz, 2006).

Over the following decades, GT underwent other modifications. GT evolved and changed into three different versions. The "distinct genealogy" (Morse, 2009, p. 16) of GT that developed included a form of dimensional analysis (Schatzman, 1991), situational analysis (Clarke, 2005) and constructivism (Charmaz 2006). Charmaz's GT is now the most widely followed. 
Dimensional analysis (Schatzman, 1991), similar to classical GT, did not just focus on a single basic process but aimed to discover the meanings of all the interactions involved in a given situation (Kools, McCarthy, Durham \& Robrecht, 1996). Schatzman (1991) delayed constant comparison until a larger bank of dimensions was named and their properties identified. Schatzman then used an explanatory matrix to determine their importance until saturation was reached. These components shaped the actions and/or the interactions of the situation and provided different interpretations of meaning. Dimensional analysis addressed the perceived challenges of undisclosed analytical operations and assisted novice researchers through analysis and interpretation.

Situational analysis (Clarke, 2008; Clarke \& Friese, 2007) emphasised that the situation itself was a key unit for analysis. Clarke introduced three forms of mapping situational, social words, and positional - to analyse the relations, social and institutional dimensions, and the issues in the situation of inquiry respectively. This methodological innovation addressed researcher analytical paralysis at those times when the researcher studied the collected data, but did not know how or where to begin (Clarke \& Friese, 2007). Thus, situational analysis provided scaffolding between GT's close study of data and the larger changes in the current world achieved by considering researcher positioning and reflexivity, focusing on participant voice and acknowledging the complications of social life (Bryant \& Charmaz, 2007). Clarke's clear theoretical rationale helps justify her new way of dealing with GT changes (Allen, 2010).

The relationship between the researcher and the participant are different in constructivist and classical GT approaches. Classical GT researchers took an observer stance that separated the researcher from the participants, imperfectly perceiving an authentic reality (Lincoln \& Guba, 2000), whereas constructivist grounded theory researchers (Strauss \& Corbin, 1990, 1994, 1998) were committed to a reciprocal relationship, working in partnership with participants in two ways. Firstly, during 
interviews researchers constructed meaning from the knowledge produced together, and secondly, constructivist GT researchers reconstructed participants' stories into GT.

Strauss and Corbin $(1990,1994,1998)$ were the first to acknowledge researchers as constructors of meaning, which was a result of interpreting participants' stories in GT. However, Charmaz $(2006,2011)$ was the first researcher to explicitly identify this approach as constructivist grounded theory. Her focus on maintaining participants' presence was achieved by two strategies; using their words during analysis and using a creative writing strategy that communicated how participants constructed their worlds.

Charmaz also sought multiple perspectives and provided a method of critical enquiry and theorising that promoted social justice; the method focused on power, inequality and marginality (Charmaz, 2017). This method was contextually located in the time, place, and culture being researched (Charmaz, 2006). This is because no two people, places, contexts or times are the same (Misco, 2007). Constructivist GT encouraged researchers' reflexive practices when interpreting the participants' perspectives (Charmaz, 2014). This social interaction approach emphasised the researchers' interactions with participants to construct a theory (Charmaz, 2006). Personal, social, and historical conditions surround the experience, so the emerging theory is positioned in the context it is created from (Charmaz, 2011).

All of these various GT versions have one common goal: to promote critical thinking about the chosen research (Clarke \& Friese, 2007). They also provided useful techniques for gathering, managing, analysing, and conceptualising data (Charmaz, 2009). GT then, is an iterative process of coding cycles involving careful attention to the process of developing a theory (Charmaz, 2006). The different types of codes used during the data analysis process - for example, open, selective and theoretical coding (Saldana, 2016; Glaser, 1992) - are interrelated with theoretical memo writing. Questions that emerge when analysing and thinking about data, guide further data 
collection. As Charmaz (2006) states: "As grounded theorists, we study our early data and begin to separate, sort and synthesize the data through qualitative coding" (p. 3).

GT is a rigorous methodological procedure that analyses data for process and action - not topics - to understand social processes (Charmaz, 2014). One approach for understanding the social world is to notice and make sense of its patterns and thereby capture life's principles and necessities within that setting (Saldana, 2011). Hence, the intent and result of data analysis is to identify, and convey to others, fresh observed and uncovered understandings gained about human circumstances (Saldana, 2011). The extensive debates about the different versions of GT have helped to establish GT as a rigorous qualitative research method.

\subsubsection{Grounded Theory's relevance to privileging student voice}

Student voice and experience as a source of knowledge, has developed over time. Awareness of student voice emerged in the 1990s, identifying students as people whose opinions mattered (Fullen, 1991), promoting them as active participants (Ruddick \& Flutter, 2004), and the honouring and repositioning students to influence school reform (Fielding, 2001). Bourke and Loveridge (2018) identify the initial phase as a wave of uncritical enthusiasm. However, subsequently more critical commentary emerged. Fielding (2004), for example, claimed that student voices could be misrepresented, and proposed involving children as co-researchers as one approach to address this issue. Cook-Sather (2006) challenged researchers to stop viewing students as consumers of knowledge, and to regard student voice as a necessary factor for change to occur. An example of change at this time was evident when students' views of the curriculum were considered, students were given control over their learning processes and achievement levels improved dramatically (Briggs, 2007). Lewis (2010) reviewed the dominant focus of student voice as a moral crusade and highlighted the need to be more transparent in raising awareness of how students' voices (and silences) were reported. Mockler and Grounsdwater-Smith (2015) also claimed that student voice work was 
sometimes a dividing practice; the voices of confident, articulate students, who thrived in the system were selected, documented and heard and this research was not representative of the marginalised or culturally diverse students. Thomson (2011) concurred, suggesting that often students perceived as difficult, were not invited to speak about what they thought. Currently there is a call for student voice to be acted on for radical change in the system; if we ask students about their experiences and their knowledge, action on student voice must follow (Bourke \& Loveridge, 2018).

This research project addresses this challenge in two ways. Firstly, the use of grounded theory as a means to build a theoretical model of truancy based on students' voices; and secondly, post-thesis, an ethnodrama based on student voices in the thesis will provide an opportunity for student actors to perform the messages of the research participants to their community for audience members to take action upon. Concerning the first challenge, there are some critiques of student voice research that need further consideration.

Grounded theory is theory that is "grounded" in data drawn from those who are close to the issue being examined (Glaser, 2007); in this case drawing on data from student voice privileging students' experiences and knowledge about truancy. According to Chadderton (2011), researchers generate data through their own involvement and various researchers will produce dissimilar data from the same participants. This is because each researcher is distinct due to, for example, his or her age, gender and socio-economic background. The presented story is filtered by the researcher's values and beliefs. The explicit account of my positioning in chapter one made some of these transparent. I used the strategy of peer critique through supervision, constantly checking my interpretation, and I sought to privilege the voices of the marginalised. I listened to underrepresented voices.

I positioned student voice at the centre; kept the analytical process close to the data; and honoured young people as active participants, shaping and managing their 
lives. Through substantive theory, I presented another reality of truancy as this theory developed from student's own words. The notion of "authentic voice" ignores the various, changing experiences of young people and the complexity of their background (Chadderton, 2011). She also argues that "discourses shape and produce [voice] ... the subject is the author of the discourse she speaks ... Subjectivity can never be totally understood or captured" (p 76). Hence, when students offered a perspective that was represented as their essential unmediated self, I needed to be aware that their voice was discursively constructed. It is also important to note that throughout this thesis I have used words such as"alleged", "perceived" and "believed" when highlighting student' experiences of youth in the truancy debate. This is not to claim that students' experiences were not "believable", or that there may be another way of accounting for their behaviour. Rather, it is a strategy to respect teachers: to acknowledge that their perspective is not included in this thesis, and to ensure that I do not attribute any blame to teachers for the events that students' report.

Grounded theory was an open-ended inquiry method that provided analytical guidance and engagement for understanding student voice. I constantly compared incidents of data, analytical questions emerged from the data and eventually I used academic literature as data to develop the substantive theory. This process of privileging student voice using grounded theory methodology supported me to compare similarities and differences, so I did not focus on a single reality.

\subsection{Approach taken for this study}

The approach I took closely aligned with a compilation of different versions of GT (Charmaz, 2006; Glaser, 1992; Glaser \& Strauss, 1967). This was because the nature of my relationship with participants changed during the research process. Initially, I looked upon the interviews and participants as data, however, as my confidence grew, and after seven interviews, the relationships with participants developed. 
My analysis, coding and memo writing commenced concurrently with data collection, and theoretical sampling influenced further data collection (Glaser and Strauss, 1967). I coded from the data to find an emergent GT and did not intentionally engross myself in the literature until categories emerged from the data (Glaser, 1992). Charmaz's CGT (2006) influence was evident in emphasising the social context and my own reflexivity. GT supported me to connect with the participants and to the research. I listened to youth perceptions about their experiences of truancy and focused on the social process that was problematic for them in this study - how they came to truant. This approach supported me to identify student actions and interactions in the school context and generate a substantive theory directly from the data. In order to understand this social process, I used aspects of classical grounded theory (Glaser \& Strauss, 1967; Glaser, 1978, 1992; 1998) - constant comparison, and theoretical sampling (see Section 3.7) - to represent the reality of some youth who truant in New Zealand schools. I made this choice because classical GT is best suited to areas where little is known about the social processes (Hunter, Keady, Casey, Grealish, \& Murphy, 2016). In keeping with classical GT, there were two main sources of data in this research: field data (notes) and interview data (notes, recordings and transcriptions). In addition, although gaps in the literature were a reason for the selection of GT, where relevant literature existed, this was used to support that data gathered in the field. In line with Glaser's position, academic literature in effect became another source of data. The process was iterative: I moved back and forth between, data gathering, coding, memoing and theorising (Glaser \& Strauss, 1967).

\subsection{Pilot study}

A pilot study, according to Jairath, Hogerney and Parsons (2000), is a "small sample study" (p. 92) that is conducted before a larger scale version of the study. It is "a preliminary visit to the field" (Sampson, 2004, p. 386). The function of a pilot study is to provide a starting point; to pre-test the achievability of gathering data; implement the 
proposed methods and procedures to inform an effective research design; and to gain an awareness of the impact of events, people and situations on the continuity of the research process and decision making (Nunes, Martins, Zhou, Alajamy, \& Al-Mamari, 2010). The results, therefore, indicate in advance the challenges, weaknesses and achievability of the proposed research (Teijlingen \& Hundley, 2001). A further consideration is an appropriate sample size for the main research, an issue that has been debated in the literature (see Hertzog, 2008). However, for the present study, the final sample size was determined by the needs of theoretical sampling (see Section 3.7).

\subsubsection{Initial objectives of the pilot study}

Nunes et al. (2010) argue the need for novice GT researchers to introduce pilot studies prior to conducting a GT process. This is a necessary step to provide the novice researcher with training in conducting interviews, for acquiring "contextual sensitivity" (p. 74) early in the research process, and for gaining experience in GT procedures and techniques.

In keeping with these ideas, after obtaining ethical approval (Appendix 1) I conducted a pilot study to try out different research strategies and tools, to gain familiarity with youth who truant, and to provide information to suggest an initial sample size for gathering data. The pilot study also helped me identify an ethical process for engaging in conversation with participants about their experiences of truancy. The initial intention of the pilot study was to investigate the experiences of those closest to truancy: deans, parents, Resource Teachers of Learning Behaviours (teachers qualified to work closely with children with special needs), and youth who truant. I conducted two interviews per group of participants. However, it became evident that student perceptions were poignant, relevant, and sufficient for the study. Consequently, I decided to interview only youth who truanted for the main study. I recruited two boys, one from a school contact and one via a friend who knew a parent of a youth who truanted. 
I invited the two students to read, complete and comment on a questionnaire, information sheet and consent form, and trial the use of drawings to engage students in a conversation about truancy. The intent was to use the questionnaire (Appendix 2) to recruit students from schools in which I would conduct the main research project and to identify the reasons that contributed to Year 10 students in the NZ context truanting school. I developed the questionnaire in consultation with literature and my supervisors; the wording and order of the questions were tested. The youth understood what I was asking and were able to answer questions without clarification. I asked students to draw a picture that represented what truancy meant to them and, at the same time, take part in an interview, which was audio recorded. The answers of the first participant were monosyllabic; it was challenging to elicit responses. As noted by Harvey-Jordon and Long (2001), the limitations of brief answers, along with background noise, time constraints, and interruptions are pitfalls in conducting interviews. I therefore considered how I would modify my introduction and initial disclosure about why I was investigating youth's experiences of wagging. Before interviewing the second youth, I told a personal, relevant story (about my teaching and maternal experiences of truancy) to build rapport, prior to the interview. The nature of his responses improved; he offered more detail, asked for clarification and established eye contact. Both interviews were analysed to see if the drawing and open-ended interview questions supported students to reveal their stories. Neither pilot study participants, nor the data, were included in the main study, as I wanted to recruit participants in the main study who were all responding to questions for the first time and that participation was experienced as a voluntary process (further explained below).

\subsubsection{Contribution of pilot to main study}

At the beginning of this project, I knew little about truancy, youth who truanted, the dynamics they experienced and the circumstances that influenced these experiences. 
Likewise, I knew little of how to gain access to youth who truanted. The pilot study provided important learning opportunities about what was occurring within truancy.

Findings from the pilot study influenced the main research project. A conversation with my first supervisor challenged me on two points: I had not maintained researcher autonomy; and I did not know if adults coerced youth who truant to participate in my research. The school contact person identified a young man to participate. I was not present when she recruited him. His body language, monosyllabic answers and lack of eye contact during the interview indicated his unease with participation. This lead to my unease. On reflection with my supervisor, I understood I had lost control of the recruitment process; given my power to the staff member and compromised the student in the process. One dilemma in social research is the conflict that may emerge between showing respect for the autonomy of the participants and the need for the researcher to maintain autonomy over decisions related to the design and conduct of the research (Hammersley \& Traianou, 2014). At this time, I paused to consider this tension and the wise decision required in these circumstances. Consequently, I considered how to maintain ownership of the process and maintain an ethical approach when recruiting participants. I decided to use the questionnaire and design a poster as another option to recruit participants. This placed the onus on participants to take action and choose to be involved in the project.

The pilot study highlighted the need for one other further amendment. One student in the pilot study did not complete a drawing so I decided to respect future participant choices to complete drawings about their truancy experiences. I did not use this data gathering method in the main study as the first four participants declined the invitation to draw. Another finding of this pilot study was that youth who truant would be hard to find and interview. I thought about how I might build rapport when interviewing participants so they would feel sufficiently comfortable to share with me their experiences, feelings and attitudes about truanting class. At this stage of the 
research process, I was naïve concerning the complexities of GT, especially coding, refining, and conceptualisation.

\subsection{Selection of schools and recruiting participants}

The recruitment process was complex. Youth who truant school were hard to find because they were not attending school regularly, and possibly because being truant affected their dignity (as discussed in the Literature Review, Sections 2.2.1 and 2.3.1). Access to schools and identification of key contact people were challenging, time consuming, and required careful consideration. This was due to three factors: effective gatekeeping; ensuring that I, and others, followed an ethical process that respected youths' choices to participate in the research; and maintaining researcher autonomy within the school system.

I approached staff in five settings and gained access to four. I contacted schools, either because they publicly acknowledged that their school was addressing truancy, or I had an established relationship with a community member, who was able to assist access. The nature of relationships are central to access and the consequent conduct of the research (Reeves, 2010). Duke (2002) claims that access is easier when researchers have personal contacts within the population on site (people, who were gatekeepers, both helped and hindered my access to schools). Reeves (2010) claims that access is dependent on the gatekeeper's approach to caring for people on site and their perceptions of the validity and value of the research. Their versions of reality may have a positive or negative impact on the research project (Berg, 1999). They can either prevent access, stopping the project before it begins (Berg, 1999), or they can have local knowledge, influence and power that they use to validate and accept the project. However, gatekeepers may only refer participants they approve of (Sixsmith, Boneham, \& Goldring, 2003). Although gatekeepers, for example, secretaries, did not block my entrance into schools, they did slow the process down by initially screening calls to the 
principals. I managed these dynamics by being persistent and following up on initial face-to-face contact. I made reminder phone calls; I referred to previous contact dates; I explained the value of student participant research and recruiting from their school; and I was respectful at all times. Persistence, patience and politeness were researcher traits contributing to successful entrance to schools.

The four urban schools in this study varied in nature. School A is a coeducational Year 9-13 school of ethnically diverse students. School B is a coeducational Year 7-13 state school that celebrates diversity and community. In School C, a Year 9-13 co-educational school, students do not wear uniforms. School D, one of the fourteen Activity Centres in New Zealand, provided an alternative education designed to meet the social and academic needs of Y9-11 students who had disengaged from their host mainstream school. The four participants transferred to this activity centre from their host school. These four schools were situated in two different cities in New Zealand.

It took time and patience to recruit the thirteen participants, seven girls and six boys, who presented with persistent and unexplained absences from class. When eventually I gained access to participants, I recruited them individually. Table 3.1 offers an account of this recruitment sequence. 
Table 3.1 Recruitment sequence

\begin{tabular}{|c|l|l|l|}
\hline $\begin{array}{c}\text { Stage of } \\
\text { Process }\end{array}$ & \multicolumn{1}{|c|}{ School } & \multicolumn{1}{|c|}{$\begin{array}{l}\text { Participants } \\
\text { Pseudonyms }\end{array}$} & \multicolumn{1}{|c|}{ Purpose } \\
\hline Stage 1 & School A, City 1 & $\begin{array}{l}\text { Christina and } \\
\text { Courtney } \\
\text { Sob, John, Becky, } \\
\text { Tyrone and Amy }\end{array}$ & $\begin{array}{l}\text { Recruit youth who lack } \\
\text { belonging and truant. } \\
\text { To recruit youth } \\
\text { returning to school after } \\
\text { truanting. }\end{array}$ \\
\hline Stage 2 & School C, City 2 & $\begin{array}{l}\text { Julie, Rose Amy and } \\
\text { Christina. } \\
\text { Amy transferred } \\
\text { schools }\end{array}$ & $\begin{array}{l}\text { Comparing experiences } \\
\text { of students who return } \\
\text { to school after truanting. }\end{array}$ \\
\hline Stage 3 & $\begin{array}{l}\text { School C, City 2 } \\
\text { School B, City 2 }\end{array}$ & $\begin{array}{l}\text { Julie } \\
\text { Bob }\end{array}$ & $\begin{array}{l}\text { Finding data about } \\
\text { particular "thin" } \\
\text { categories. }\end{array}$ \\
\hline Stage 4 & Activity Centre 1, City 1 & No participants & $\begin{array}{l}\text { To elicit data about } \\
\text { youths' experiences; } \\
\text { both inside and outside } \\
\text { the classroom. }\end{array}$ \\
\hline Activity Centre 2, City 1 & $\begin{array}{l}\text { TM, Michael, James, } \\
\text { Decity }\end{array}$ & \\
\hline
\end{tabular}

Senior management and counsellors across three secondary schools and one activity centre in New Zealand identified these students as the most frequent truants in their schools (see Table 3.2 later) and indicated that their absences were unexplained.

As indicated in Table 3.1, there were four stages of recruitment. The purpose of stage 1 was to recruit youth who truant, to look for a new school site, to find youth experiencing a lack of belonging at school, and to recruit youth returning to school after truanting. Although I gained new information about truancy that supported the development of the idea of "truanting in class", I needed to understand the factors contributing to participants' successful return to class. The purpose of stage 2 was to compare experiences of four students to understand the support and guidance required to return to school after truanting. The analysis of these interviews provided more information about emerging categories contributing to theory building. I recruited participants during stage 3 to find data about under-represented categories. I interviewed two participants a second time to develop understanding of participants' attitudes when caught truanting. The properties and dimensions of a construct were now rich, identifying the need for me to interview a different group who would provide data regarding the gaps in under-represented categories. Consequently, I recruited 
participants from a new site; an activity centre. Finally, during stage 4, I recruited four participants to elicit data about perceived challenges in class; to understand the nature of relationships established outside of class during times of truancy; and to identify what happened whilst truanting. Accordingly, I considered the issue of sampling, deciding which youth to select and who would best represent the wider group of youth who truant school in New Zealand (Cohen et al., 2000). I asked questions about participants' experiences in the mainstream school compared to experiences in their activity centre.

Theoretical sampling (Glaser \& Straus, 2017, Charmaz, 2014) was the key strategy used to recruit participants and gain specific knowledge. According to Butler, Copnell and Hall (2018), theoretical sampling involves three different data gathering techniques: looking for new, different sites; developing new interview questions that emerge from the analysis; and purposefully selecting new samples of participants to develop specific characteristics of categories identified in earlier analysis. Similarly, Ying and McClain (2015) identify theoretical sampling as involving a process of concurrent data collection, coding, and analysis, followed by decisions that relate to the nature of the next participants who should be interviewed, and where these participants could be found. In line with both Butler et al. and Ying and McClain, I adopted theoretical sampling for this research. In addition, I included memo writing to complement and inform further my decisions relating to the nature of the data to be gathered next and which participants to involve (Glaser \& Strauss, 1967).

Although I used three strategies to recruit students, only two were successful. I posted 140 questionnaires to School B for staff to distribute to students, who were not required to identify themselves on the forms. These questionnaires provided an opportunity for Year 10 students to disclose anonymously if they truanted, identify causes for such behaviour, and indicate if they wanted to participate. As only five completed questionnaires were returned, and one parent did not give permission for her child to participate, this strategy was not repeated to recruit participants from other 
schools. However, I successfully recruited participants through two strategies: a poster, displayed in strategic locations, such as the counsellor's waiting room in schools, and snowball sampling (Cohen \& Arieli, 2011; Vogt, 2005; Watters \& Biernacki, 1989). The poster (Appendix 3) contained my photograph, described the research, invited youth to participate, and identified the person for students to contact to express their willingness to participate in the research. It was only then that I phoned to arrange a time for an interview, if the identified staff member had not already done so.

I recruited one participant through snowball sampling (Cohen et al., 2000), or chain referral sampling (Cohen \& Arieli, 2011), a method used to find participants in social networks by one participant volunteering the name of another in an on-going process of referrals (Vogt, 2005). Snowballing sampling is an effective methodology regarding the recruitment of hard-to-reach marginalised populations who shield themselves from public attention (Watters \& Biernacki, 1989). Potentionally, social network limitations may exist with this methodology; for example, it excludes possible participants because they do not belong to the social network in question, or because gatekeeper bias may restrict who is contacted (Cohen \& Arieli, 2011). This selection bias may occur because the gatekeepers may have reasons for referring someone to the researcher that is not made explicit.

There was only one occasion in an activity centre when recruitment was unsuccessful. I visited this centre, different from the one in the study, and talked to students. I explained my research, invited them to participate, and distributed my poster. A student eager to participate approached myself and the liaison teacher as I was leaving but the parent did not return the consent form. The liaison teacher contacted the parent, and although the father promised to sign, after two reminders I thanked the teacher and withdrew from the idea of conducting research in that school.

Despite taking care to build rapport, including having participants member check my interpretations of their data (discussed later in Section 3.9), three participants 
(Becky, John, and Tyrone) "disappeared" between interviews for different reasons. Becky became more involved in drug use (personal maternal communication); a disconnected telephone prevented contact with John; and Tyrone relocated to another city (personal paternal communication). In addition, Courtney declined the invitation for a second interview (personal maternal communication).

Details of the thirteen recruited participants are shown in Table 3.2. As indicated, four participants did not discuss their family circumstances, seven lived in single-parent families, and two participants lived with their birth parents. Two girls lived separately from their siblings. Two of the three girls who exited school were from single-parent families. Four participants (three girls and one boy) experienced mental illness; the three girls all exited school. Four participants (three girls and one boy) disclosed they were involved in drug and alcohol consumption; one boy was on suspension from an activity centre, one boy attended school regularly, one girl left school at 16, and one girl continued to truant classes. 
Table 3.2. Participants in the study

\begin{tabular}{|c|c|c|c|c|c|}
\hline $\begin{array}{l}\text { Participant } \\
\text { pseudonym }\end{array}$ & Age & $\begin{array}{l}\text { School } \\
\text { \& class }\end{array}$ & Living conditions & Additional details & II \\
\hline Christina & 14 & $\begin{array}{c}A^{*} \\
\text { Year } 9\end{array}$ & $\begin{array}{l}\text { Lived with mother, who was an } \\
\text { invalid on a sickness benefit. Her } \\
\text { sister lived with their father. }\end{array}$ & $\begin{array}{l}\text { Christina's parents separated when she } \\
\text { was } 5 \text {. She identified herself as suffering } \\
\text { from anxiety and although transferring to } \\
\text { another school between interviews, she } \\
\text { exited school. }\end{array}$ & 2 \\
\hline Courtney & 13 & $\begin{array}{c}A^{*} \\
\text { Year } 9\end{array}$ & $\begin{array}{l}\text { Lived with her mother, brother } \\
\text { and sister. }\end{array}$ & $\begin{array}{l}\text { Courtney did not mention her father. } \\
\text { She returned to school in response to } \\
\text { threatened parental prosecution. }\end{array}$ & 1 \\
\hline Bob & 14 & $\begin{array}{c}\mathrm{B}^{*} \\
\text { Year } 9\end{array}$ & $\begin{array}{l}\text { Lived with his mother, one } \\
\text { brother and one sister. Bob was a } \\
\text { middle child. His father lived in } \\
\text { another city. }\end{array}$ & $\begin{array}{l}\text { Bob returned to school in response to } \\
\text { threatened parental prosecution. }\end{array}$ & 2 \\
\hline John & 14 & $\begin{array}{c}B^{*} \\
\text { Year } 10\end{array}$ & $\begin{array}{l}\text { Lived with his mother and three } \\
\text { brothers on a domestic purposes } \\
\text { benefit. }\end{array}$ & $\begin{array}{l}\text { John lived in overcrowded living } \\
\text { conditions. His brother was epileptic. }\end{array}$ & 1 \\
\hline Becky & 14 & $\begin{array}{c}\mathrm{B}^{*} \\
\text { Year } 10\end{array}$ & $\begin{array}{l}\text { Lived with her mother and older } \\
\text { brother, whilst sister lived with } \\
\text { father. }\end{array}$ & $\begin{array}{l}\text { Becky did not show up for an arranged } \\
\text { second interview. Her mother reported } \\
\text { Becky as using drugs. }\end{array}$ & 1 \\
\hline Tyrone & 14 & $\begin{array}{c}B^{*} \\
\text { Year } 10\end{array}$ & $\begin{array}{l}\text { Lived with his mother and } \\
\text { younger sister. }\end{array}$ & $\begin{array}{l}\text { Tyrone identified himself as depressed. } \\
\text { Between interviews, he moved with his } \\
\text { mother and sister, to attend school in } \\
\text { another city. }\end{array}$ & 1 \\
\hline Amy & 14 & $\begin{array}{c}\mathrm{B}^{*} \\
\text { Year } 10\end{array}$ & $\begin{array}{l}\text { An only child living with her } \\
\text { mother }\end{array}$ & $\begin{array}{l}\text { Although transferring to another school } \\
\text { between interviews, Amy began } \\
\text { wagging again. }\end{array}$ & 2 \\
\hline Julie & 18 & $\begin{array}{c}C^{*} \\
\text { Year } 13\end{array}$ & $\begin{array}{l}\text { She did not discuss family } \\
\text { circumstances. However, she } \\
\text { explained her parental } \\
\text { intervention: sending her to live } \\
\text { with her uncle in another city. }\end{array}$ & $\begin{array}{l}\text { Julie took a year out due to personal } \\
\text { trauma, re-enrolled in year } 11 . \text { In year } \\
13 \text { she received three top Visual Arts } \\
\text { Prizes. She went on to university study. }\end{array}$ & 2 \\
\hline Rose & 17 & $\begin{array}{c}C^{*} \\
\text { Year } 12\end{array}$ & $\begin{array}{l}\text { Lived with her parents. Her } \\
\text { brother lived independently. }\end{array}$ & $\begin{array}{l}\text { Rose suffered from a history of family } \\
\text { violence, self-harm and depression. She } \\
\text { tranferred schools but exited the } \\
\text { second school. }\end{array}$ & 1 \\
\hline Decity & 15 & $\begin{array}{l}\text { D* } \\
\text { Activity } \\
\text { Centre }\end{array}$ & $\begin{array}{l}\text { She did not mention family } \\
\text { circumstances. }\end{array}$ & $\begin{array}{l}\text { Decity began wagging in year } 9 . \text { She } \\
\text { was involved in drug and alcohol use } \\
\text { when she left School D at } 16 .\end{array}$ & 2 \\
\hline James & $\begin{array}{l}\text { Not } \\
\text { given }\end{array}$ & $\begin{array}{l}\text { D* } \\
\text { Activity } \\
\text { Centre }\end{array}$ & $\begin{array}{l}\text { He did not mention family } \\
\text { circumstances. }\end{array}$ & $\begin{array}{l}\text { James began wagging in year } 8 . \mathrm{He} \\
\text { attended School D regularly. }\end{array}$ & 2 \\
\hline Michael & $\begin{array}{l}\text { Not } \\
\text { given }\end{array}$ & $\begin{array}{l}\text { D* } \\
\text { Activity } \\
\text { Centre }\end{array}$ & $\begin{array}{l}\text { He did not mention family } \\
\text { circumstances. }\end{array}$ & $\begin{array}{l}\text { Michael transferred to School D for } \\
\text { continual wagging and dope smoking. } \\
\text { He attended the Activity Centre } \\
\text { regularly. }\end{array}$ & 2 \\
\hline TM & $\begin{array}{l}\text { Not } \\
\text { given }\end{array}$ & $\begin{array}{l}\text { D* } \\
\text { Activity } \\
\text { Centre }\end{array}$ & $\begin{array}{l}\text { He lived with parents and two } \\
\text { brothers. His father was the } \\
\text { leader of a gang. }\end{array}$ & $\begin{array}{l}\text { TM began wagging in Year } 9 \text {. Sent to } \\
\text { School D for breaking school rules, } \\
\text { defiance, continual wagging and dope } \\
\text { smoking. Was due to go before the } \\
\text { Board of Trustees for trespass of } \\
\text { previous school the day of his second } \\
\text { interview. }\end{array}$ & 2 \\
\hline
\end{tabular}

* Site (School or Activity Centre) coding

II Number of interviews 
I wish to acknowledge that because of challenges faced when recruiting these participants - challenges finding them, the desire to maintain participant and researcher autonomy, and perceived need to establish rapport and build trust - I neglected to identify participants' ethnicity. As I did not wish to assume and incorrectly identify participants' ethnicity, this aspect of their demographics is not itemised in the table.

\subsection{Concurrent data collection and analysis}

This section provides an account of the strategies, tools and instruments I used for collecting and analysing data, how I used these, and what I achieved. Individual interviews, field notes, and memo writing provided evidence of conversations and observations of youth's experiences of truancy in four New Zealand schools.

\subsubsection{Strategies, tools and instruments}

Successful interviewing is reliant on the relationship established between the researcher and the participant (Woolner, Thomas, Todd, \& Cummings, 2009). According to Fontana and Frey (2005) the most common form of interviewing involves face-to-face spoken exchange. They suggest when two or more participants are interviewed their interactions lead to "the creation of a collaborative effort" (p. 695). The key here is the active nature of the process (Holstein \& Gubrium, 1995) that leads to a contextually bound and mutually created story. The purpose of interviewing then, is not just to relay facts, but to obtain participants' analyses of what happened (Gubrium \& Holstein, 2002) and how they are interpreting the situation (Taylor, 1996). It is through interviews in qualitative research that we explore participants' perceptions, experiences and attitudes to understand why they act in particular ways (Harvey-Jordan \& Long, 2001). Walliman (2001) suggests that all participants in interviews (including interviewers) create believable accounts of their worlds; in this way participants may be viewed as "meaning makers" (Gubrium \& Holstein, 2002, p. 83). Although interviews may produce rich data, responses are related to a particular participant at a particular time but days later 
that same person may report altered facts (Harvey-Jordan \& Long, 2001). However, as interviews are the most prevalent method of data generation in international youth research (Loveridge, 2010) this was the method I selected.

In order to see the circumstances from participants' perspectives and capture truancy activities and meanings applied to them, the researcher should establish rapport and a sense of trust with the participants from the outset of the research (Loveridge, 2010). Denzin and Lincoln (2005) also acknowledge the importance of this strategy, claiming that because understanding is the focus of interviewing, researchers need to be empathetic, see the situation from the participants' perspectives, and avoid imposing their own academic viewpoint. The focus in this research was on accessing and representing the participants' world by listening to, and hearing, participant voices. Trust was essential to ensure that what was reported was honest and true to participants' experience in the situation, and that the data collected were authentic. I established a rapport and built trust by taking time to: explain who I was, discuss what the interview would be about, ask participants to choose a pseudonym, and invite them to give me information to illustrate who they were.

The interviews assisted me to follow up hunches, probe complexity, and understand how youth responded to truancy. Fontana and Frey (2005) state that it is much more difficult than initially anticipated to ask questions and get answers. Nevertheless, interviews are a powerful tool used to privilege students' voices regarding their experiences and concerns (Heath, Brooks, Cleaver, \& Ireland, 2009). One-on-one interviews are ideal for participants who are articulate, confident, and keen to share their ideas (Creswell, 2005). However, in some instances, this was not the case when I interviewed youth who truant. They initially presented as not forthcoming, cautious and without confidence. Therefore, taking time to get to know them, explaining the rationale for the research and establishing rapport, provided the support for them not to be nervous and hesitant about sharing their experiences. As noted by Harvey-Jordan and 
Long (2001), when participants struggle to answer questions, or only provide short answers, the relevance of the study needs to be explained so they feel they can make a valuable contribution. The interview process went well; the first interview with each participant was exploratory, and their responses sharpened the focus of my research questions (Strauss \& Corbin, 1994).

I purposefully selected two writing strategies - field notes and memos - to support my observations and develop understanding of events, situations and impressions that occurred in the field and in the data. Although Mulhall (2003) provides guidelines for observational data gathering, historically there has been little guidance on the information to include in field notes (Phillippi \& Lauderdale, 2018). These researchers claim that field notes, the written records of researchers' observations, support them to record their perceived interactions and impressions in the environment, identify biases and provide the context for future analysis. There are also differing approaches to the form of field notes. Unlike authors who used labels to categorise field notes (Hammersley \& Atkinson, 2002; LaCompte \& Preissle, 1993), Glaser (1998b) emphasised the process to increase the researcher's awareness of the subtext in conversations during concurrent data collection and analysis.

According to Mulhall (2003), researchers use unstructured field notes in interpretative paradigms to understand cultural behaviours. She claims that context and co-construction of knowledge between researchers and participants is significant, unlike quantitative data, where observations are structured and focus on pre-defined behaviours. As I interviewed participants, I listened to their stories and explored how they managed their choices, how these choices affected their learning and their relationships with others in classrooms, and how they viewed their consequent choices and truancy experiences. I recorded comments post-interview and wrote field notes as soon as possible after the interviews; I understood the urgency in writing regular and prompt field notes (Denscombe, 1998) to capture participants' perspectives accurately 
and gather authentic data. Field notes were used here to support the data gathered from listening to the stories of youth who truant. In order to maintain confidentiality of the field notes, I prepared these more fully off site when I was alone. Montgomery and Bailey (2007) also wrote their field notes off site but their rationale was different; they did not want to disrupt the telling of the participants' stories.

Memos by contrast (see Appendix 4), are an in-the-moment reflection that documents the meaning and ideas about codes and their interconnections as well as researcher' thinking processes that are related to the growing theory (Glaser, 1998b). Memoing provides the analytical space to reflect, follow hunches and reactions, and better articulate ideas (Locke, 2003). Engaging and recording intellectual conversations about the data supports the researcher to move away from description into interpretation (Creswell, 1994). Memo writing, according to Glaser (1992), provides opportunities to write up ideas as they emerge during the processes of "constantly comparing, coding and analysing" (p. 108). This practice changes the way we look at each stage of creating an emerging theory. Saldana (2016) refers to memo writing as a "generating method" (p. 242) for developing a code or category. Memo writing supported me to form an idea, develop it, check it, and generate theory. This included identifying my next steps, recognising patterns and properties, and distinguishing between major and minor codes and categories. Memo writing supported me to track analytical processes; for example, I scrutinised my subjectivity and noticed insights and analytical ideas as they occurred during data collection and analysis. Saldana (2016) notes that descriptive titles assist the researcher to group related memos (participants, category development, and abstracting categories). I added descriptive titles to memos.

To ensure the credibility of this investigation, immediately following transcription of each interview I emailed participants their transcripts and asked them to confirm that the transcription was an accurate recording of our conversation. Where possible, given participant availability, I followed up with a phone call and I checked 
that they were happy with the content of the transcript. In this way, I checked the accuracy of what participants actually said and identified that the descriptions resonated with their experiences (Birt, Scott, Cavers, Campbell, \& Walter, 2016). It was only when each participant confirmed their interview as accurate, I began data analysis. I chose not to use computer software programmes for managing data. I focused my mental energy on the data, not technology; I stayed close and manually coded to become very familiar with the data (Saldana, 2016).

\subsubsection{Sorting and ordering the data}

The data coding was a complex process that involved four steps: (1) Forming initial impressions; (2) structuring my analysis; (3) constantly comparing participants' experiences; and (4) abstracting ideas and developing theory. This systematic procedure for analysing the data gathered, provided the necessary structure for me to manage, organise and analyse the data. This is exemplified in Table 3.3.

The initial impressions phase began with meeting and interviewing participants. During the structuring analysis phase, I ordered data into grids and used open and in vivo coding and gerunds - "ing" words - (Glaser, 1978) to label the data, identify actions, and detect processes (Glaser, 1992). By constantly comparing the similarities and differences in youth perspectives in phase 3, categories and their properties emerged. Researchers develop common labels for multiple incidents by sharpening and clarifying their observations about what is happening in the data (Locke, 2003). Finally, in phase 4 , I used academic literature as data to assist the development of a theory. Glaser (2007) claims that everything is data and GT is a method that uses data of any type. During this final phase I searched for, wove in, and constantly compared literature. I used literature to support or challenge my claims. 
Table 3.3 Sorting and ordering the data

\begin{tabular}{|c|c|c|c|}
\hline Steps in the process & Structures used & $\begin{array}{l}\text { Rationale for } \\
\text { approach }\end{array}$ & Other influences \\
\hline $\begin{array}{l}\text { Step One: } \\
\text { Initial impressions }\end{array}$ & $\begin{array}{l}\text { I sent interview sound files to the } \\
\text { transcriber. When transcripts } \\
\text { returned, I checked they were an } \\
\text { accurate recording of our } \\
\text { conversation and verified this } \\
\text { with the participants. I read the } \\
\text { transcripts several times. The } \\
\text { transcribed interviews assisted me } \\
\text { to familiarise myself with the } \\
\text { data, notice the words and ideas } \\
\text { participants used to explain their } \\
\text { actions and experiences of } \\
\text { truancy. }\end{array}$ & $\begin{array}{l}\text { I used an inductive } \\
\text { method of analysis, } \\
\text { grounded in the data that } \\
\text { provided an explanation } \\
\text { for truancy from a student } \\
\text { perspective }\end{array}$ & $\begin{array}{l}\text { I was interested in } \\
\text { developing a process } \\
\text { theory that fits the } \\
\text { situation, works in } \\
\text { practice, considers } \\
\text { sensitively the perspectives } \\
\text { of youth who truant, and } \\
\text { potentially represents the } \\
\text { complexities found in the } \\
\text { process. }\end{array}$ \\
\hline $\begin{array}{l}\text { Step Two: } \\
\text { Structuring my analysis }\end{array}$ & $\begin{array}{l}\text { I used analytical grids to } \\
\text { systematically order the data into } \\
\text { segments. This structure assisted } \\
\text { me to identify participants' } \\
\text { actions, interactions, and the } \\
\text { activities that occurred over time. } \\
\text { I used open and in vivo coding } \\
\text { and gerunds to refine my ideas } \\
\text { and move from segment to } \\
\text { segment and from segment to } \\
\text { category, allocating a label as a } \\
\text { short description of each data } \\
\text { segment. }\end{array}$ & $\begin{array}{l}\text { I wanted to stay close to } \\
\text { the data and privilege } \\
\text { student voice - an } \\
\text { identified gap in the } \\
\text { literature. I wanted the } \\
\text { emerging information to } \\
\text { guide the research } \\
\text { process. I looked for } \\
\text { clues in the data about } \\
\text { what data to collect next, } \\
\text { then re-entered the field } \\
\text { to gather additional } \\
\text { information. }\end{array}$ & $\begin{array}{l}\text { I designed analytical grids } \\
\text { to reflect on my practice. I } \\
\text { identified what I wanted to } \\
\text { know; and gathered more } \\
\text { data to explore and fill out } \\
\text { these codes. I produced } \\
\text { new understandings. } \\
\text { I asked myself, what am I } \\
\text { discovering? Do I want to } \\
\text { pursue these discoveries? } \\
\text { Where can I gain the data? } \\
\text { Who will I interview now? }\end{array}$ \\
\hline $\begin{array}{l}\text { Step Three: } \\
\text { Constantly comparing youths, } \\
\text { experiences }\end{array}$ & $\begin{array}{l}\text { I compared codes across } \\
\text { interviews as I coded each new } \\
\text { transcript. I cut the grid into } \\
\text { strips and constantly compared } \\
\text { incident with incident, incident } \\
\text { with category, and category with } \\
\text { category to observe multiple } \\
\text { similarities and diversities in the } \\
\text { data. } \\
\text { During this three-tiered process, } \\
\text { my supervisors read and } \\
\text { scrutinised the grids, challenged } \\
\text { the use of particular labels, looked } \\
\text { for overlaps and inconsistent use } \\
\text { of labels }\end{array}$ & $\begin{array}{l}\text { I wanted to stay close to } \\
\text { the data and ground the } \\
\text { categories in the data. I } \\
\text { wanted to follow } \\
\text { hunches, ideas and } \\
\text { thoughts, collapse codes } \\
\text { and explore them to } \\
\text { understand participants' } \\
\text { experiences of truancy at } \\
\text { a deeper level. }\end{array}$ & $\begin{array}{l}\text { Focused and process } \\
\text { coding supported me to } \\
\text { scrutinise similarities and } \\
\text { differences between } \\
\text { incidents and reveal } \\
\text { subcategories of a given } \\
\text { category and their } \\
\text { relationship to other } \\
\text { categories. } \\
\text { Categories were identified } \\
\text { and used so I understood } \\
\text { the process. Data provided } \\
\text { new wording for emerging } \\
\text { research questions }\end{array}$ \\
\hline $\begin{array}{l}\text { Step Four: } \\
\text { Abstracting ideas and } \\
\text { developing theory }\end{array}$ & $\begin{array}{l}\text { The goal was for a theory to } \\
\text { emerge from the data. I } \\
\text { connected categories and } \\
\text { emerging theory, and discussed } \\
\text { the relationship among them. } \\
\text { Theoretical coding focused my } \\
\text { investigation towards discovering } \\
\text { a core category that identified the } \\
\text { main problem of concern for } \\
\text { participants. } \\
\text { I wrote memos and drew } \\
\text { diagrams to integrate and refine } \\
\text { the ideas to support theory } \\
\text { construction. }\end{array}$ & $\begin{array}{l}\text { I wanted the theory to fit } \\
\text { the realities of each } \\
\text { participant, as well as } \\
\text { having relevance to the } \\
\text { settings of practitioners } \\
\text { and researchers. } \\
\text { I wanted to identify and } \\
\text { select a core category that } \\
\text { was central, related to all } \\
\text { other categories, and } \\
\text { appeared logically, } \\
\text { consistently and } \\
\text { frequently in the data. }\end{array}$ & $\begin{array}{l}\text { I wrote out the storyline } \\
\text { that interconnected the } \\
\text { categories. I ordered my } \\
\text { theoretical ideas: Sorting } \\
\text { through personal memos } \\
\text { that elaborated on ideas } \\
\text { about the data and coded } \\
\text { categories. } \\
\text { I used relevant literature as } \\
\text { data to develop a theory } \\
\text { that explained a basic } \\
\text { social process of wagging. }\end{array}$ \\
\hline
\end{tabular}

In phase 1, Christina was the first participant interviewed. I took time to get to know Christina before beginning to record her responses to the interview questions. I introduced myself fully and talked with her until she seemed at ease in the situation. 
This successful strategy was adopted as a consistent approach with other participants. I scribbled notes straight after the interview and wrote them up as field notes later. I chose to minimise transcription errors by employing a professional transcriber. Whilst waiting for the transcripts, I listened to the voice recordings of the interviews. I noticed that I missed opportunities to open up the conversation. I was thinking about the next question rather than being in the moment, listening attentively, and asking questions to clarify what Christina was telling me. I recognised that I needed to find a solution (see Table 3.5 below).

When interview transcripts were returned, I read them repeatedly, checking them for accuracy of punctuation and mistyped words but only needed to make minor changes. For example, I added words in brackets to show how Christina's response related to the research question:

It's [learning is] complicated at times but it's [learning is] a challenge and it makes me want to go to get better so I really like maths. (Christina, interview one)

I also noted explanation marks that emphasised words. Eason, McComish, and Greenberg (2000) claim that when a transcriber pays attention to such detail, it is easier for the researcher to analyse data. I then highlighted the text that I noticed (in italics below):

cause like now that the seniors have left, she [my best friend] was going away soon so I'm kind of like by myself. (Christina, interview one)

In addition, I highlighted sections of text and added first response notes in brackets (in italics below):

and then, [when I return to class after truanting], I get into trouble for not attending and it's just horrible. I get into trouble because the teacher says you have not been here, like blaming me, bit yeah. I feel really bad. \{Returning to class after wagging is not a pleasant experience for Christina\}. (Christina, interview one)

These strategies were used to ensure that the meaning was not lost when I placed the identified incidents into a grid ready for analysis, that I remembered what first struck 
me in the interview, and what I perceived to be the interactions with others that affected participants. During this cycle, I read and re-read participant transcripts to familiarise myself with what the participants were saying, immersed myself in the data, and noticed the words and ideas they used to explain their actions and experiences of truancy. Clark (2005) acknowledges that it is important to spend time "digesting and reflecting" (p. 84) on data before coding.

During the second step of analysis - structuring my analysis - I split the data by initially marking incidents manually on the transcribed interviews and using grids to systematically order the data into segments ready for analysis. The grids recorded the participant's name in the first column, and the transcript-segment in the middle column. I wrote open codes in the third, right hand side column.

\section{Table 3.4 Data analysis grid}

\begin{tabular}{|l|l|l|}
\hline \multicolumn{1}{|c|}{ Participant } & \multicolumn{1}{|c|}{ Transcript } & \multicolumn{1}{|c|}{ Open code } \\
\hline Christina & $\begin{array}{l}\text { I understand that you've been choosing not to } \\
\text { attend school; how often has that happened in } \\
\text { the past? I usually wag like once a day. Like one } \\
\text { class or two }\end{array}$ & wagging habit \\
\hline Christina & $\begin{array}{l}\text { What makes you decide not to go to class? The } \\
\text { kind of teachers make you decide not to go to } \\
\text { class. But then kind of I feel that class isn't } \\
\text { important, }\end{array}$ & $\begin{array}{l}\text { prioritising } \\
\text { specific } \\
\text { classes }\end{array}$ \\
\hline Christina & $\begin{array}{l}\text { then it's like I really need to realise that every } \\
\text { class that I choose not to go to like, it does affect } \\
\text { me }\end{array}$ & $\begin{array}{l}\text { choosing not } \\
\text { to go }\end{array}$ \\
\hline
\end{tabular}

As evident in Table 3.4, the data were fragmented segment by segment and a phrase labelled each incident of the data. The aim was, as Strauss suggests, "to produce concepts that seem to fit the data" (p. 32). I looked for "topics of interest contained in the data" (Kelle, 2007, p. 209) and simultaneously summarised and accounted for each segment of the data (Charmaz, 2006). These grids supported me to focus attention on specific data. I labelled and compared incidents before I wrote memos that recorded my responses to what I observed in the data. Open coding was the first step of theoretical analysis (Glaser, 1992). This structure assisted me to identify participants' actions, 
interactions with others, as well as the activities that occurred over time. During this phase, the four iterations of open coding of transcripts assisted me to label the data and compare them for similarities and differences (Glaser, 1978). Comparing while labelling supports the researcher to develop a common name for multiple incidents by sharpening and clarifying the observations about what is happening in the data (Locke, 2003). Early in this stage of analysis, I sometimes used in vivo codes because words extracted from participant voice in the data kept me close to their perspectives, honoured their voices (Charmaz, 2006), focused the analysis on issues that were important to the participants, and recognised how these issues connected to one another (Elliot \& Jordan, 2010). This iterative process took time and, although experiencing feelings of insecurity because there were many codes and no coat hangers in view, I stayed open to possibilities in the data. During the structuring phase of analysis, the revising of codes improved their fit to the data and captured and condensed meanings and actions (Charmaz, 2006). This concurs with Glaser's (1978) notion of emerging fit; that new data which challenges conceptual development must be included and the researcher must be prepared to modify generated concepts.

After coding each interview, I wrote a memo to track the process of examining small chunks of data, to describe what I saw in the data, and to write about how I related to the participants and their experiences of truancy, in order to develop my analytical thinking (see Appendix 4). As Locke (2003) notes, memos support researchers to conduct an iterative analysis that captures ideas and develop lines of thought about what is happening in the data. I used headings to structure this analysis and describe: (1) the inferences I made from the data; (2) what codes emerged from the data; (3) what I wanted to clarify; (4) what literature supported these findings; (5) what I wanted to know now; and (6) what general questions emerged from the data. Memos are the researcher's impressions of important conversations and issues observed in the data (Cho \& Lee, 2014). 
During this phase, I reflected on the quality of my research processes. To do this, I designed a three-column grid to structure my analysis. This strategy supported me to reflect on missed opportunities in the interview that I was analysing. I considered what I needed to change in order to improve my thinking in the moment when present with participants and trying to encourage them to tell me about their experiences of truancy. Butler et al. (2018) categorise this form of theoretical sampling as adapting interview questions. They claim that new questions form the direction of the investigation. I used the most frequently occurring codes to group data into categories, and then I framed new questions to gain further understanding of developing categories and the relationship between them. A three-column grid (Table 3.5 below) noted the questions asked in the first column, what I needed to follow up on in the middle column, and identified future potential questions in the third column.

Table 3.5 Questioning analysis grid

\begin{tabular}{|l|l|l|}
\hline \multicolumn{1}{|c|}{ Question } & $\begin{array}{c}\text { What is mentioned } \\
\text { that requires follow } \\
\text { up }\end{array}$ & \multicolumn{1}{|c|}{ Potential question } \\
\hline $\begin{array}{l}\text { What makes you decide not to go to } \\
\text { class? }\end{array}$ & $\begin{array}{l}\text { She mentions that it } \\
\text { is the kind of teachers } \\
\text { that influenced her to } \\
\text { truant class }\end{array}$ & $\begin{array}{l}\text { In the previous interview, you } \\
\text { mentioned that the nature of } \\
\text { teachers influenced you to not } \\
\text { to attend their class. Why was } \\
\text { this? }\end{array}$ \\
\hline $\begin{array}{l}\text { Are there any other subjects that you } \\
\text { like? }\end{array}$ & $\begin{array}{l}\text { Music is Christina's } \\
\text { 'sweet' escape. }\end{array}$ & $\begin{array}{l}\text { When you say music is your } \\
\text { sweet escape, what are you } \\
\text { escaping from, and why? }\end{array}$ \\
\hline $\begin{array}{l}\text { What makes you decide not to go to } \\
\text { class? }\end{array}$ & $\begin{array}{l}\text { Class is not } \\
\text { important }\end{array}$ & $\begin{array}{l}\text { In your previous interview } \\
\text { you claimed that you felt class } \\
\text { was not important, why was } \\
\text { this? }\end{array}$ \\
\hline
\end{tabular}

I noticed two strengths in my analysis: our conversations were on topic and the nature of the questions changed from "what" and "how" questions to "why" questions. This approach influenced the way I conducted future interviews

Data analysis requires a researcher to be "open to possibilities" (Creswell, 1999, p. 153) when coding, comparing codes, and noticing contrasts. During step 3 in this cycle of analysis - constantly comparing participants' experiences - I compared 
incidents of data with other incidents, segments with category, and category with category, to observe the many similarities and differences in the data (see Appendix 5). Elliott and Jordan (2010) claim that this is an important step because by looking for the links between incidents and concepts and between the different concepts, the researcher ensures that concepts account for all incidents in the data. I assessed what was happening in the data and identified new information to confirm its relationship to what other participants said. This involved four strategies: cutting and rearranging lines of data with the same coding; undertaking constant comparison; writing up memos; and creating diagrams.

For the first strategy, the grids, which contained lines of data, were cut into strips and placed on the same page as other segments labelled with the same codes. I compared these segments to ensure that I was labelling similar activities, interactions and actions with the same codes. I made necessary modifications when I discovered discrepancies in my analysis. Glaser and Strauss (1967) claim that generating properties of a category begins with comparing incidents. I regularly stopped to compare aspects of the data and made meaning of what was there and wrote memos. The number of codes decreased as I moved between levels of analysis.

As I compared the new data to previous data, different levels of codes, corresponding to different levels of theory (e.g., categories and sub-categories) developed. After interviews with four young people, the core category around which other categories evolved, was identified (Chiovitti \& Piran, 2003). This core category was central to the theory, and appeared frequently in the data (Glaser \& Strauss, 1967). It is also important to note that this process iterated back and forth between data collection and on-going analysis until each category reached saturation (Charmaz, 2014). That is, when I decided that additional data would not provide new information or insights to further develop the categories or explain their properties (Charmaz, 2006), I ceased the process. 
The relationships between and within categories that emerged from the data were examined (Chiovitti \& Piran, 2003). Thus, the various ways that categories needed refining and developing were recognised (Strauss, 1987). This emerging information guided the process. For example, as indicated in Table 3.5, data provided new wording for further questions. When I allocated space between groups of interviews to transcribe and view my data, the opportunity was provided to identify aspects for further investigation (Appendix 6); this increased my awareness of the data (Davidson \& Tolich, 1999). Memo writing aided my reflection (see Section 3.8) and provided an opportunity to stop coding, think, ask questions, critically reflect on what I had observed and what was coded in the data, and capture my thoughts about what I could elaborate on. This reflective process is illustrated in the following memo.

\section{Table 3.6 Category development: Constant comparison involving another sweep of the data, November 2013}

It is evident through the comparative analysis process that the code "disengaged from school" identified as a starting point to wagging requires rethinking. Talking about a starting point insinuates that this was an event; however, youth are in a process of "disengaging from learning". I notice that I had coded several incidents "disengaging from school", however when I read these comments again, I see that youth are talking about school work, which also provided another reason for coding these incidents as "disengaging from learning". Today I also changed the code "teachers are the main deal" to "disengaging from teachers" for three reasons: (1) I am concerned that this is a judgmental statement; (2) I am making assumptions; and (3) that I am imposing an idea on the data that is not actually based in the experiences of youth who truant. This category relates to "disengaging from learning" in some way.

When reading text coded "making the change", it appears that these circumstances are contributing to, or facilitating, the opportunity for youth to change their wagging behaviour. It appears that in these instances youth are experiencing pathways out of truancy. This belongs to another category at a later stage of the process. I need more data to understand what supports and what inhibits their return to class.

This constant comparative analysis of the data is supporting me to refine categories and make further appropriate changes over the next scoping of the entire data. I am beginning to discover the relationships between categories!!

During the fourth and final stage - abstracting ideas and developing theory theoretical coding, academic literature, diagrams, memo writing, and the writing-up of ideas contributed to the development of theory. During this process, I was "sensitive to the underlying meaning of the data" (Thistoll et al., 2016, p. 620). I developed sufficient 
"theoretical sensitivity" (Glaser 1978) to read, interpret and assign meaning to the data. This was achieved by conducting a preliminary literature review for my proposal, constant comparison of data, the development of many open, selective and theoretical codes, conceptualising patterns within the data, relating categories to one other, and integrating the theory. Table 3.7 (later) illustrates this process.

Theoretical codes were "conceptual connectors" that supported me to identify the categories and the "relationships between their properties" (Glaser, 1992, p.38). Theoretical coding assisted me to find the bigger picture and account for all the categories and codes identified at this point in the process. Glaser (1978) describes this stage as the weaving of the fractured story back together again. Literature was analysed to clarify, elaborate, and modify the emerging concepts (Lo, 2016). The generation of this process theory was an interplay of both inductive and abductive reasoning (Kelle, 2007). I constantly compared data to develop codes, categories and constructs (Appendix 7). Once the theory emerged, I associated preliminary findings to further clarify, explain and elaborate emerging concepts (Lo, 2016). I used literature as a triangulation strategy to validate my theory. During this process, I focused on discovering the main construct that identified the major problem of concern for participants.

By using literature as data, and identifying the relationship of the literature to each category, I was able to note its influence on theory construction (Chiovitti \& Piran, 2002). Throughout this stage, I conducted member checking with participants. To enhance credibility, I took ideas back to participants for confirmation of whether they aligned with their experiences (Charmaz, 2006). I asked some of them to read the initial codes that were emerging and see if they recognised my descriptions as their own (Beck, 1993). I discussed this in further detail in Section 3.9 below. In summary, the fourth step in the data gathering and analysis process involved abstracting ideas by writing and sorting memos and developing theory. This final step in the process related to theory 
development and literature was used to validate findings (Strauss \& Corbin, 1990). At

this point, analysis concluded and I finalised the framework.

\section{Table 3.7 Abstracting ideas towards theory development}

Core Category: Merging codes and abstracting theoretical ideas
In order to identify and select a core category that was central to the theory, that relates
to all other categories and that appeared frequently in the data, I examined the
contributing codes from what youth identified as happening in the classroom when
they disengaged from teachers, peers and learning. They were physically present but
absent from what was happening around them in terms of interactions with others and
learning. I grouped the codes according to participant interactions with others, their
feelings and their responses to the task. I listed codes under headings, before gathering
my thoughts and writing about what the participants were saying.

Disengaging from teachers

\begin{tabular}{|c|l|}
\hline \multicolumn{1}{|c|}{ Headings } & \multicolumn{1}{c|}{ Codes } \\
\hline Teacher behaviours & $\begin{array}{l}\text { Teacher frustration, teachers being } \\
\text { angry, teacher being harsh, teacher } \\
\text { laying down the law, being treated } \\
\text { unfairly, being growled at, being told } \\
\text { off, grilling from teacher, getting into } \\
\text { trouble, being judged, favouring other } \\
\text { students, not noticing youth in class and } \\
\text { blaming them }\end{array}$ \\
\hline Participant needs & $\begin{array}{l}\text { Lacking help, needing help, lacking } \\
\text { care, being invisible and wanting } \\
\text { attention. }\end{array}$ \\
\hline
\end{tabular}

\section{Observations}

Youth who truant were not enjoying their teachers' behaviours. They perceived that they were on the receiving end of their teacher's anger, harsh judgements, blame and frustration. Their perception of unfair treatments resulted in them resenting their teachers. Youth perceive that they needed more academic support and care. They were not experiencing positive interactions with teachers; they were being growled at, treated unfairly, and being ignored. They appeared to be lacking attention. At times youth appeared invisible in class. When they were unnoticed, it was an unpleasant experience, which caused them to disengage from teachers. They were physically present but now - as a consequence of their perceived sense of marginalisation in the class - appeared to be absent in relation to their teachers. They were "wagging-inclass". I have just identified a main concept around which categories cluster!

Throughout analytical activity (covering all stages), constant comparison of data supports researchers to discover categories, identify their properties, understand the relationship between categories, extend the categories to abstraction (Appendix 7), and integrate and arrange categories with the framework (Locke, 2003). Glaser and Straus 
(1967) claim that this comparative process delimits the theory on two conceptual levels - the categories and theoretical framework. There is conceptual reduction when categories develop sufficiently for their properties and dimensions to be accounted for, and when the theory solidifies as major modifications diminish (Locke, 2003). This stage-orientated process theory outlines the sequence that characterises how participants truant over time and the processes that move them from one stage to another.

\subsection{Ensuring the trustworthiness/validity of the research findings}

The aim of this study was to understand the world of truancy from a student perspective. Due to the subjective nature of qualitative research, Eason et al. (2000) maintain that it is the researcher's responsibility to design and implement rigorous approaches that ensure the results are trustworthy. In this section I present the criteria that I used to establish the trustworthiness of this research along with the strategies that I employed to address these criteria and ensure research rigor.

The concept of trustworthiness in qualitative research is the equivalent of validity in quantitative research (Cresswell, 2009). Both concepts focus on fitness for purpose - that the research has been designed and carried out in a way that is appropriate for answering the research question(s). A qualitative study is trustworthy if it gives confidence that: the design is sound and uses appropriate methods of data collection and analysis; gives rich or thick description of the research site and processes that have been used; and provides evidence that interpretations are based in the data and reasonable (Creswell, 1999). These qualities are important if the research is to resonate with readers and have future impact on policy and practice. In relation to GT, Strauss and Corbin (1990) note that trustworthiness and the quality of GT relates to the " ... rigor in the coding and research process, quality of concepts, systematic relatedness amongst concepts, conceptual density, range of variations and specificity, significance of theoretical findings and theoretical sensitivity" (pp. 18-19). According to Lincoln and 
Guba (1995) trustworthiness in qualitative research is established through considering the concepts of credibility, dependability, confirmability, transferability, and authenticity. It should be noted that there is a degree of overlap in the meanings of these concepts; in addition, many practices or strategies that are adopted for the conduct of qualitative research usually contribute evidence for several of these criteria.

\section{Credibility}

Different writers in the field of education (Carpenter, 1995; Charmaz, 2006; Cohen et al., 2000; Lincoln \& Guba, 1995; Miles \& Huberman 1994), variously identify some or all of the following as important elements of credibility: evidence of attention to detail; suspension of interpretations until the data have spoken; member checking; appropriate use of triangulation; peer debriefing; and negative case analysis. All of these processes have been illustrated in previous sections of this chapter. For example, in relation to the first and second elements of credibility, twenty individual interviews provided rich information about participants' truancy experiences and constant comparative analysis and theoretical sampling led to an iterative process that explored truancy in depth. These analytical procedures align closely with classical grounded theory methodology. At all stages, interpretations were based in the data, subjected to various processes of development and confirmation through constant comparison and further collection of data until a substantive theory emerged (Glaser \& Strauss, 1967). This social process contributes to our understanding of social problems, links directly to the data, is embedded in the context, and reflects the lives of the participants (Morse, 2009).

In relation to member checking, I compared the emerging theory against participants' meanings of truancy. At times, I used their actual words in the coding. As I progressed through this process of developing the theory, I invited participants to comment on, and verify my choice and development of codes. This was to ensure that these codes represented accurately what the participants stated. I checked that available participants agreed and believed that this was a true representation of their ideas. Birt et 
al. (2016) describe this approach as member checking because it explores whether results resonate with participants' experiences. Although this was a rigorous process, there was a tension regarding the expectation of constant reality checking with participants. In some cases, it was too demanding of their time and too intrusive; not all youth verified the research. However, to enhance credibility of this research, during second interviews I talked to Julie, Bob, Amy, and Christina about my findings. This was as Beck (1993) explains, to see if they recognised my descriptions as their own.

The above approach also gives clear evidence of triangulation - using the data from different students to build a coherent theory about truancy - by marshalling data so that codes and categories represented what was in common amongst students and what distinguished some students' experiences from others (e.g., those who reintegrated into school and those who exited). As noted by Kohl (2012), using the same method gathered over time also achieves triangulation, in this instance interviews. In addition, data from academic literature was used to complement and/or supplement data from interviews and other research strategies. These approaches indicate that the rigorous coding and research process confirmed the systematic relatedness of the concepts (Strauss \& Corbin, 1990).

Peer debriefing took place at regular intervals with my supervisors who challenged my analytical processes and the interpretations I made from the data. Negative case analysis is a strategy to prevent personal bias in analysis and is demonstrated by the recognition of data that did not conform to the full sequence of the theory that emerged (Kolb, 2012). Negative case analysis led to the need to distinguish between students who reintegrated into school and those who exited. This is explained more fully in Chapter 4 with reference to the current findings.

\section{Dependability}

Dependability refers to the faith that can be placed in the data because of the checks that have taken place to ensure that the data accurately reflects the beliefs, intentions, or 
actions of participants (Cohen et al., 2000). In qualitative research, this is achieved in different ways depending on what part of the data is being checked. Returning interview transcripts to interviewees (member checking) is an example of checking the accuracy of the data recorded. When observations are being made, checking that a second researcher agrees with the observations and subsequent coding of a sample of data by the first researcher is an example of a practice that enables greater faith to be ascribed to the data (Guba, 1981). More generally, evidence that the researcher has followed practices that have been found in the literature to be effective (that is, following "good" research practices), along with rich or thick descriptions of the conduct of the research (processes can be audited), help provide evidence that the data and subsequent interpretations can be depended on for being accurate (Creswell, 1999). All steps of the research process were systematic, flexible, and dynamic (Lo, 2016). Clearly, some of the evidence that is described above for assessing credibility also double up in supporting the dependability of the data that have been gathered. Eason et al. (2000) claim that investment in the research process and paying careful attention to each step of the research process provides a larger degree of confidence in the research.

\section{Confirmability}

Confirmability is a concept closely aligned to dependability. If a finding is replicated either internally through the research, or separately (externally) through a replication study, then evidence for confirmability exists (Cohen et al., 2000). The first draws upon processes such as member checking, peer debriefing, and triangulation of perceptions from different participants (Creswell, 1999). The previous paragraphs identify evidence for confirmability “within” the current research. For example, I used participants' quotes when depicting emerging categories, thus providing confirmatory evidence of interpretations and findings. This approach confirmed the systematic relatedness amongst concepts (Strauss \& Corbin, 1990). However, replication studies are hard to carry out within qualitative research because the phenomenon under investigation may 
change over the course of the study, the setting and/or events may be unique, or the focus of the research is very local (Charmaz, 2006). Grounded theory cannot be duplicated as the researcher, the time, and the population are all different (Stern, 2009). The present study is unique in that it focuses on truancy from the perspective of the youth involved rather than from the views of teachers, parents, and administrators. "External" confirmability, for example, of the grounded theory that emerges from the present research, is something that lies ahead for subsequent research to establish (Charmaz, 2011).

\section{Transferability}

One of the main purposes of quantitative research is the aim of generalising findings to the population(s) from which the sample(s) have been drawn (Cohen et al., 2000). Typically this is achieved through the use of randomised sampling techniques so that the samples used can be assumed to be representative of their respective populations. Qualitative research does not require randomised sampling because it is not (usually) attempting to make generalisations to the wider population; it is attempting to describe and interpret what is happening, or what views are held, within a relatively circumscribed situational context (Creswell, 1999). The aim of transferability, rather than generalisability, is what characterises qualitative methodology (Cohen et al., 2000). For this to happen, the researcher must provide rich or thick description to enable readers/users of the research to decide if the results, or other aspects of the research, fit their own contexts (Merrian, 2001). Transferability thus lies in the eyes of the reader (Merrian, 1998; Tashakkori \& Teddlie, 1998). As noted by Glaser (2002), we generate data within a specific place, time, and interactions with others; we cannot generate these data, but we create descriptions and interpretations from the data.

In the present study, the researcher has attempted to provide the research details that should enable readers to decide whether the findings transfer to their own situations. In addition, I approached three stakeholders - a deputy principal, a counsellor, and a 
dean - to verify the trustworthiness of the findings; all three considered that the findings fitted their own context. Other relevant approaches that I used to establish the trustworthiness of this research and enhance transferability were triangulation (Cohen et al., 2000) between emerging concepts and literature on truancy, member checking (Miles \& Huberman, 1994), negative case analysis (Charmaz, 2006; Beck, 1993), and peer debriefing. In addition, I provided a clear audit trail, and declared my role as the researcher.

\section{Authenticity}

The concept of authenticity overlaps with the notions of credibility and dependability. The essential idea is that the research data and interpretations provide an authentic representation of what the participants believe and say and the events that are described within the study. In other words, the readers are convinced that the author was present in the world under investigation, and that s/he understood the participants' perspectives (Locke, 2003). Cohen et al. (2000, p. 108), drawing upon the views of ethnographic researchers, Lacompte and Preissle (1993), identify five aspects of authenticity:

- Fairness: there should be a balanced representation of the realities of all participants

- Ontological authenticity: the findings should advance what is known and provide a more sophisticated understanding

- Educative authenticity: the findings should lead to a greater (wider and deeper) appreciation of the phenomenon under research

- Catalytic authenticity: the findings lead to specific courses of action

- Tactical authenticity: the research should benefit the circumstances of all involved.

I believe that the present study satisfies the first and second of these bullet points. The data were gathered from the perspective of those closest to the truancy 
experience; youth who truant. Many of the processes described above in relation to credibility and dependability focus on ensuring that the participants' voices and circumstances are accurately represented in the data codes and categories that were developed and in the subsequent grounded theory that was produced. The other three categories of authenticity (educative, catalytic, and tactical) largely follow on from the research and involve acceptance of the findings from relevant people in education (e.g., policy makers, teachers, school administrators); this will involve a dissemination strategy of the research that brings the results to the attention of the key people just listed. For the moment, the focus has been on fairness and ontological authenticity.

\subsection{Ethical considerations}

Tracy (2010) identifies the need for researchers to attend to four aspects of ethics when conducting qualitative research: "Procedural", "situational", "relational" and "exiting" (p. 847). I attended to all four aspects during the course of this research project.

The procedural ethics, which I gained from Victoria University Faculty of Education, Wellington (Ethics No. RM19352), included permissions to negotiate informed consent, voluntary participation, privacy, and confidentiality (see Appendix 8). In respect of the latter, individual interviews were recorded and a typist was employed to transcribe them; she was required to complete a confidentiality form. In addition, I declared my intentions to protect participants; they chose pseudonyms and understood my intention to consult with supervisors or counsellors in regards to their disclosure about self-harm or other risks of harm. I also informed them of the potential consequences of my research (e.g., future publications, presentations, and lectures). Tracy argues that when researchers follow these procedures, data that are more credible are gathered. As I was often in the field, on occasions I gave my personal phone number to the participants for two reasons: to obtain names of other potential participants, and to confirm interview times. To be ethically responsible I protected participants' identity 
from disclosure by securing personal data in a password protected computer and a locked filing cabinet in my office.

Tracy (2010) refers to situational ethics as "practices that emerge from a reasoned consideration of a context's specific circumstances" (p. 847). As suggested, I constantly reflected, analysed, and questioned my ethical decision-making and moral goals to ensure that the data were worth exposing. For example, I talked to one participant about whether the trauma experienced should be disclosed; I sought advice about ramifications from a school counsellor, checked several times that the participant gave permission to tell the story, and invited the participant to choose a pseudonym.

Relational ethics required me to implement an ethic of care, to be self-aware, and to consider carefully what I was doing in the field and the consequences of my actions on others. Field notes provide evidence of the care I took:

I took time and used four strategies to establish a rapport: (1) I explained who I was and why I was conducting this research, (2) I discussed what the interview was about, (3) I invited Christina to give me information to illustrate who she was, and (4) I asked her to choose a pseudonym. I remember feeling content during the interview that it appeared to be going better than the previous two pilot study youth interviews. She responded to my non-verbal cues and talked spontaneously. There was an ease before we began the interview. She opened up to me and appeared to be honest and non-hesitant in her responses. I listened carefully to Christina's experiences of truancy. Although a short interview, at the end Christina commented that it had felt very therapeutic.

When I took time to show compassion (e.g., be present in the moment, listen attentively, and pause when what was spoken provided a brave personal disclosure), I was able to connect with the participants. Building trust and rapport with participants, according to Cope (2014), fosters "rich, detailed responses" (p. 90). In taking an empathetic approach, I was assuming the need for youth's well-being (Butler, Copnell, \& Hall, 2018). I also took time to check with participants that the transcribed interview 
represented their comments. I also provided them with a summary of their interview and I shared the findings at an appropriate time if this was possible.

I also carefully considered my responsibility to "exiting ethics" (Tracy, 2010, p. 847). I thought about how the readers might interpret the research and my responsibility regarding the writing-up of the findings and the nature of future presentations. I thought about how I might minimise the readers' misinterpretations of data (e.g., disclosing my positioning by carefully charting my subjectivity).

\subsection{Limitations}

The current study focused on students' perspectives of truancy. Participants were purposefully selected using theoretical sampling, but school attendance records were not used to confirm this selection. However, the data obtained clearly indicated that the participants were suitable as subjects for this research.

The study was restricted to a small sample of thirteen participants within a specific time-frame; although this cannot be considered to be a large sample of students, enough data were obtained to provide theoretical saturation within the confines of grounded theory methodology. In addition, as noted in Section 3.7, three students dropped out of the study for different reasons between the first and second interviews.

The use of self-reported data is both a strength and a limitation. For the purposes of the present research, self-reported data from youth who truant were selected because it dealt with a gap in the literature on truancy. However, as noted by Cohen et al. (2000), the use of self-reported data does not necessarily mean that participants are accurate in their reports or even honest in what they say. As noted in Section 3.9, various processes were used to check the credibility, dependability, and authenticity of the data. The triangulation provided by field notes, written memos, and the use of academic literature as a data source will have, at least to some extent, provided a coherence check on the trustworthiness of the conclusions reached from the self-reports of students. 


\subsection{Conclusion}

In this chapter, I explained and justified the research design: a qualitative, interpretative, contextual study with a classical grounded theory approach to investigate youth's perceptions of truancy. I explained how insights gained from the pilot study improved the main research project. I used a poster to recruit participants; this strategy helped to recruit participants in a respectful and ethical manner. It also helped me retain a sense of autonomy for participants and myself within the school establishment. Attention was paid to the trustworthiness of the research and the use of ethical procedures. The concurrent use of data collection, analysis and theoretical sampling provided opportunities to find and recruit purposefully participants with an acknowledged history of truancy in New Zealand schools. A process theory emerged from data and revealed the main process that these youth experienced. The following chapter - findings and discussion - presents the process theory. 


\section{CHAPTER 4}

\section{FINDINGS AND DISCUSSION}

\subsection{Introduction}

In the previous chapter, I introduced the methodology for this research; how I conducted the simultaneous gathering and analysis of student interviews to produce a process theory of wagging. In this chapter, I begin by introducing participants' perceptions of truancy and the rationale for using the term wagging. I discuss four dimensions of participants' perceptions of truancy in relation to academic literature that contributes to a deeper understanding of the circumstances related to the nature of wagging. These dimensions cover: wagging as habit; wagging as an activity in response to perceived disrespect in class; wagging as an attraction to be with friends; and wagging as a time to be alone. I then introduce a diagram of a process theory of wagging (Figure 4.1) and present in detail each of its components - "wagging-in-class", "leaving", "awakening", and "reincluding" - to demonstrate how the participants' experiences of wagging inform each part of the process theory.

\subsection{The nature of wagging}

This section begins by explaining the use of the term wagging as a common description for truancy (Section 4.2.1), moving on to the discussion of the nature of wagging that reveals four dimensions in the experiences of students (Sections 4.2.2 to 4.2.5 respectively).

\subsubsection{Wagging as a common term for truancy}

As reported in international studies, youth refer to truancy by different names. For example, in the USA "playing hooky", "skipping class", or "ditching" are common expressions (Spencer, 2009; Dahl, 2016; Gase et al., 2016); and in the UK, "bunking off" and "dodging" are other examples of terminology for the concept of wagging (Wilson et 
al., 2008). In a number of New Zealand studies, youth have used the term wagging (e.g., Hawke \& Hill, 2003; Bobillier, 1976) when describing their experiences of unexplained absence from school. Youth in different cultural contexts use different terms for their truancy behaviour. For example, participants in the present study used a variety of names instead of the word truancy, including, "bunking", "hanging around", "gapping it", "time out", and "wagging". They used slang to talk about their wagging behaviour but wagging was the predominantly used expression:

I usually wag like once a day, like one class or two. (Christina)

Like usually I didn't even turn up to school. Usually I would wag a whole day and just walk around school doing nothing. (Decity)

I think I probably only went to only a couple of classes in the first term. I wagged a lot. (Julie)

I was wagging about nearly every day basically, or four times a week, and I would wag like three classes, then go to two classes. (TM)

Wagging was a term used to explain a perceived common event that occurred in particular situations at particular times. Although most participants in this study understood that wagging was, or had been, a regular occurrence in their lives, they perceived wagging as selective absence from classes, whole day non-attendance, as well as chronic non-attendance. Wagging was described in a variety of ways:

... purposefully not coming to school. (Amy)

... taking time out. (Tyrone)

... not going to class for whatever reason. (Julia)

... just hanging around, doing nothing. (Courtney)

Participants recognised wagging as an intentional absence that occurred at a particular point in the day. Although they understood they were intentionally disobeying school rules, there was little evidence to indicate that they thought it a serious matter, until threat of parental prosecution (see Section 4.6.1). Intentional absence from class was symptomatic of wagging. 


\subsubsection{Wagging as habit}

The development of wagging as habit highlighted the formation of wagging as involving behaviour that began and progressed over time. When participants wagged, it began with specific subjects:

Maths, social studies, don't like them at all. I just suck at them so then I don't try, then I get bored so I don't go. (Becky)

I just hated science; it was so hard. So I just started wagging that first and then it went to maths 'cause I'm not good with numbers. And then it went to some of the tech classes and that kept on going on and on then I just started wagging them all. (TM)

Before youth wagged a particular subject, there was a progression of withdrawal from participation in class (see Sections 4.4.1 - 4.4.5). The participants' motivation to learn, or even attempt to learn, diminished due to their thinking about how much they did not like the subject, that it was challenging, and something they could not master. This negative thinking that learning was beyond their capability contributed to participants' commencement of wagging behaviour. Once begun, their wagging gained momentum and escalated until participants experienced chronic levels of unexplained absence.

A longitudinal study by Chen, Culhane, Metraux, Park, and Venable (2016) investigated unexplained absence data in schools to ascertain truancy patterns. Their analysis yielded five distinct truancy subgroups - "very low", "low", "declining", "rising", and "chronic" (p. 1070) - as well as the characteristics of the challenges students faced within these distinct groupings. The principal finding from this study was that most students in the "very low", "low", and "declining" groups continued to show low or reducing levels of truancy over the year. However, students in the "rising" group experienced increasing absences over the year, and those in the "chronic" group increased further to represent the group of most concern in relation to attendance. Similar to the latter two groups in the Chen et al. study, participants' in the present research showed increased vulnerability over time associated with diminished 
motivation to learn, followed by the commencement of wagging from classes and then from school altogether.

Some of the participants reported that they did not actually commence wagging until the third year of secondary school but then their absences rapidly increased to a high level.

I never bunked in year 9. (Rose)

I never bunked, year 9 and 10. It was only when I got to year 11; I barely ever went. (Julie)

It is also possible that different organisational structures within schools

contributed to the opportunity and intentionality of wagging:

It [wagging] started off when I was second year at Intermediate: year 8 like most of the day. That was, I would go to school, get marked on the roll and as soon as that happened, I would leave class and wag school. It took them quite a while to discover that I wagged. (James)

Participants in the present research understood school routines; for example, James (above quote) recognised attendance in an intermediate school as a temporary necessity for the purpose of roll taking and the possibility of then wagging the entire day without detection. In contrast at secondary school level, participants typically progressed into their wagging behaviour from one subject to another until becoming an established habit.

Of relevance is a US report on absenteeism by Balfanz and Byrnes (2012). These writers claim that chronic absenteeism before detection can be disastrous. Attendance leads to success whereas non-attendance impacts negatively on standardised test grades and school completion or drop out. These researchers group chronic absence into three broad categories, reflecting the aspects of the present research. They distinguished between students who "cannot attend" (e.g., because of home responsibilities, the need to work, or illness), who "will not attend" (avoidance of bullying, harassment and embarrassment in an unsafe school environment), and who "do not attend" (the students and their parents see little value in school); the latter group of students prefer to be involved in other activities and report little or no deterrents 
being implemented for truancy. According to Balfanz and Byrnes, the first month of absenteeism from school can predict an entire year of poor attendance. For the present research it seems that in some instances undetected wagging was problematic; it also contributed to wagging becoming a chronic habit for all participants.

\subsubsection{Wagging as response to perceived disrespect in class}

Two main forms of disrespect were commonly described by participants, one involving a sense of social injustice arising from actions of teachers and peers, the other involving acts of bullying from other students. In relation to the first, participants identified instances of what they felt was unfair treatment, creating a sense of being ostracised:

He never told me I needed to fix the errors; I didn't know they were there. Or he would lose my work and then I just stopped going after a while. (Rose)

She (teacher) was mean, just standing there and being really like, telling you full on what is what, usually growling at you. (Christina)

When I was new to class they teased me, they swore at me and called me names. I didn't want to go. They just, they're mean. (Courtney)

I was just seen as a loser pretty much, the little druggie and everyone looked down their noses at [me] and no one took me seriously. They wrote me off as a loser and that was it. No one really cared, so there was no point going to school. (Julie)

Most participants perceived school as a negative experience. They interpreted judgmental approaches and disrespect from both teachers and peers as a lack of care. When participants felt that their status was lower than their teacher and peers, they interpreted unmet learning needs as unacceptable and chose to leave class to avoid continued disrespect. According to Almquist and Brannstrom (2014), within the social world of the peer context of the classroom, social power relates to one's ability to influence peers' attitudes and behaviours and gain control. Students' status in class affected their social power, available support, and later adult outcomes. Similarly, some participants in this study lacked autonomy for a reason; they were unable to influence their peers due to lack of social power, status, control and support. Wagging occurred in response to this lack of power and autonomy in the classroom. 
In relation to reported bullying from peers, participants included both verbal (putdowns) and physical acts as examples of disrespect:

We're protecting ourselves from just anything and bullies, anything that comes at me. (TM)

Some people just judge you, judge you by your looks. They were mean, always mean. Threatening. They smashed me. It hurt. (James)

We just made our little group so we can protect ourselves against anything that comes at us. We used to just beat up all the bullies 'cause they used to pick on all our mates, our mates who weren't even that strong, we used to beat up the bullies ... (Michael)

Three participants, all males from the activity centre, were aware of the possibilities of confrontation and consequent hurt by physical or mental abuse in a mainstream school. The last response from Michael identifies that some participants viewed bullying as a problem requiring collaborative force, dominance, and revenge in order to reclaim social status and resolve the issue on participants' own terms. Findings from on-line surveys (Goldweber, Waasdorp, \& Bradshaw, 2013) suggest that students who initiate retaliatory fights were concerned about personal safety, lacked belonging in their school-bullying environment, bullied others, and contributed to the bullying problem in their schools. Similarly, when some participants in this study were bullied, their motivation was retaliation and revenge; however, it was also in response to the desire to protect their friends.

\subsubsection{Wagging as an attraction to be with friends}

Most of the participants identified that wagging was an attraction that enabled them to be with their friends.

It was fun while I was doing it [wagging] because school's boring. I'd rather be out with my mates having fun. (Bob)

I can do whatever I like when I wag: more fun I reckon. (Decity)

I just feel better than being in class 'cause it's fun being with friends. (Becky)

Some participants enjoyed the freedom that wagging their class provided. They variously remarked that when wagging, time with friends provided entertainment, 
enjoyment, a distraction from wasting time in class, and opportunities to feel good personally. This is similar to the Swedish students in Warne, Snyder and Gillanders' (2013) student-perspective research, which provides insights into what needs to change for participants to enjoy being in class and to not leave. For example, youth in their study felt like outsiders who were disconnected from others when they were in class. These researchers claimed that youth identified motivational factors that improved their health and well-being in class. Youth identified three needs they wanted from teachers: (1) to notice and respect them, which included teachers establishing positive expectations; (2) to facilitate events so students could connect with others, feel safe, make good decisions and obtain shelter within a supportive learning environment; and (3) to facilitate restorative approaches to enhance school success and well-being. Considering the findings of Warne et al. (2013) and the present study, it is evident that participants needed teachers to facilitate events in ways that would support them to connect with others and participate in interesting class activities. Students needed a supportive learning environment to experience a sense of enjoyment and belonging in class.

It is also clear that sometimes participants wanted a change from classroom routines to unwind with company and feel important to and liked by others. In these moments, participants recognised that being with friends when wagging was meaningful, because wagging alliances provided opportunities to feel good, relax together, and participate in exciting activities. The participants connected with others outside class by walking, resting, eating and smoking marijuana.

Well I just used to tell them [my friends] come for a walk and yeah go for a session and we would all go cruise. They're the boys, like I connect with them, just going for strolls, cruising. Yeah we're pretty close, kick back, eat food, get stoned. (TM)

I know they want my time and company, and that makes me feel good. (Rose)

It more relied on my friends, what they were going to do, and if I was keen to go along. (Amy)

When we kicked back we relaxed and smoked a little bit of dope. (Michael) 
Whenever we go down the mall we always go into Countdown we just take like chocolates, drinks, chips and that just for something to eat. Nah, we [never got caught] never have. Just, I don't know how though. (Michael)

As noted in these comments, being with friends contributed to staying away from school and, sometimes, becoming involved in criminal activity. Undetected criminal activities contributed to the maintenance of wagging behaviour. In a US study, Henry (2010) found that many students engaged in drug use whilst wagging; unsupervised, unstructured time spent with peers created a setting conducive to pushing boundaries of unacceptable behaviours. Unstructured time due to lack of adult supervision, was also a risk factor for drug use and pushing boundaries of unacceptable behaviours in this study.

\subsubsection{Wagging as a time to be alone}

While sometimes, wagging related to communal activity, at other times wagging was a solitary activity:

I was just like didn't see any purpose of it, just school was nothing, didn't bother, just thought, didn't see myself having a future cause the amount of drugs and that I was doing. I was drinking every single night until I blacked out and when I came to, I'd just pick up another drink. (Julie)

I choose not to go. Other people don't influence me. If I don't want to be surrounded by people I just want to be in my own space. (Christina)

I stay at home [in bed] recovering from my [sports] injuries. (John)

I get down, depressed, upset and don't want to really do anything, just rather sit in bed and lay there, have time to think. I just need time out. (Tyrone)

Hopelessness, need for personal space, recovery time, and feeling down, interfered with the ability of the participants above to sustain normal school routines and were reasons for them to wag class alone. Although they perceived that being alone was a choice that provided time out in a private space to manage what was bothering them, they avoided negative experiences in their lives if possible. Of relevance, is an Australian study investigating students' perspectives of wellbeing. Woodman (2005) claimed that students sought out space to "engage with the non-cognitive aspects of experience" 
(p. 91). Unlike school, students chose these spaces to be in the present to deal with the challenges they faced that related to overload, family circumstances, and the constant burden of the future. They mostly talked about well-being in relation to the present and the future, rather than the past. So instead of avoidance, time out provided a space to be in the here and the now and was part of students' well-being. Linking with Woodman's findings, participants took time out to be present, in the here and now, and to be responsible for, and look after, their own well-being, often in difficult family circumstances. As Christina explains:

My sister does not live in the same house as me. She lives at her boyfriend's but stays with Dad, who lives alone. He does not help me. Every time I have to ask to see him. I am his kid. He should want to see me and let me come over, no matter what. He is not there for me. (Christina)

\subsubsection{Summary of students' perspectives on wagging}

In summary, this section first explained the term wagging, as used variously in the literature; participants used the term to explain a common event that occurred in particular situations at particular times, involving intentional disregard of school rules and intentional absence from class. This behaviour established and progressed over time. Wagging was a habit; an activity in response to perceived disrespect in class; an attraction to be with friends; and a time to be alone. Lack of detection contributed to wagging becoming established as a habit. More specifically, wagging activity related to the disrespect that participants alleged was perpetrated by either or both peers and teachers. They also sensed a lack of power and autonomy in the classroom; consequently, by voting with their feet they achieved a sense of relief and gained control over a threat to their well-being. Most participants sought connections with others who wagged, although a few preferred to be on their own. Some participants engaged in unlawful activities during wagging. 


\subsection{A process theory of wagging: Overview}

In the following section, I present a process theory of wagging, which introduces each of the four multi-dimensional constructs and their components in detail (sections 4.4 to 4.7). This sequence, regarding participants" "wagging-in-class", "leaving", "awakening", and "reincluding" in class, offers an explanation of how wagging occurs. These four multi-dimensional constructs provide insights into the nature of the relationships, dynamics, and circumstances that students' perceive as contributing to their choice to leave class and wag. Figure 4.1 sets out the process theory of wagging in diagrammatic form. In brief, "wagging-in-class" was a response of participants to negative aspects of the classroom environment, covering the relationship dynamics with teachers and peers, and obstacles affecting learning. "Leaving" communicates the dynamics involved in the choice of participants to leave class without permission and identifies obstacles at school or at home that participants try to avoid. "Awakening", emphasises the significant moments that influence participants to consider the negative outcomes of wagging, re-evaluate and change their behaviours and attitudes. Lastly, "reincluding" highlights the restorative approaches, circumstances and support required to assist students to turn back to school and succeed. 


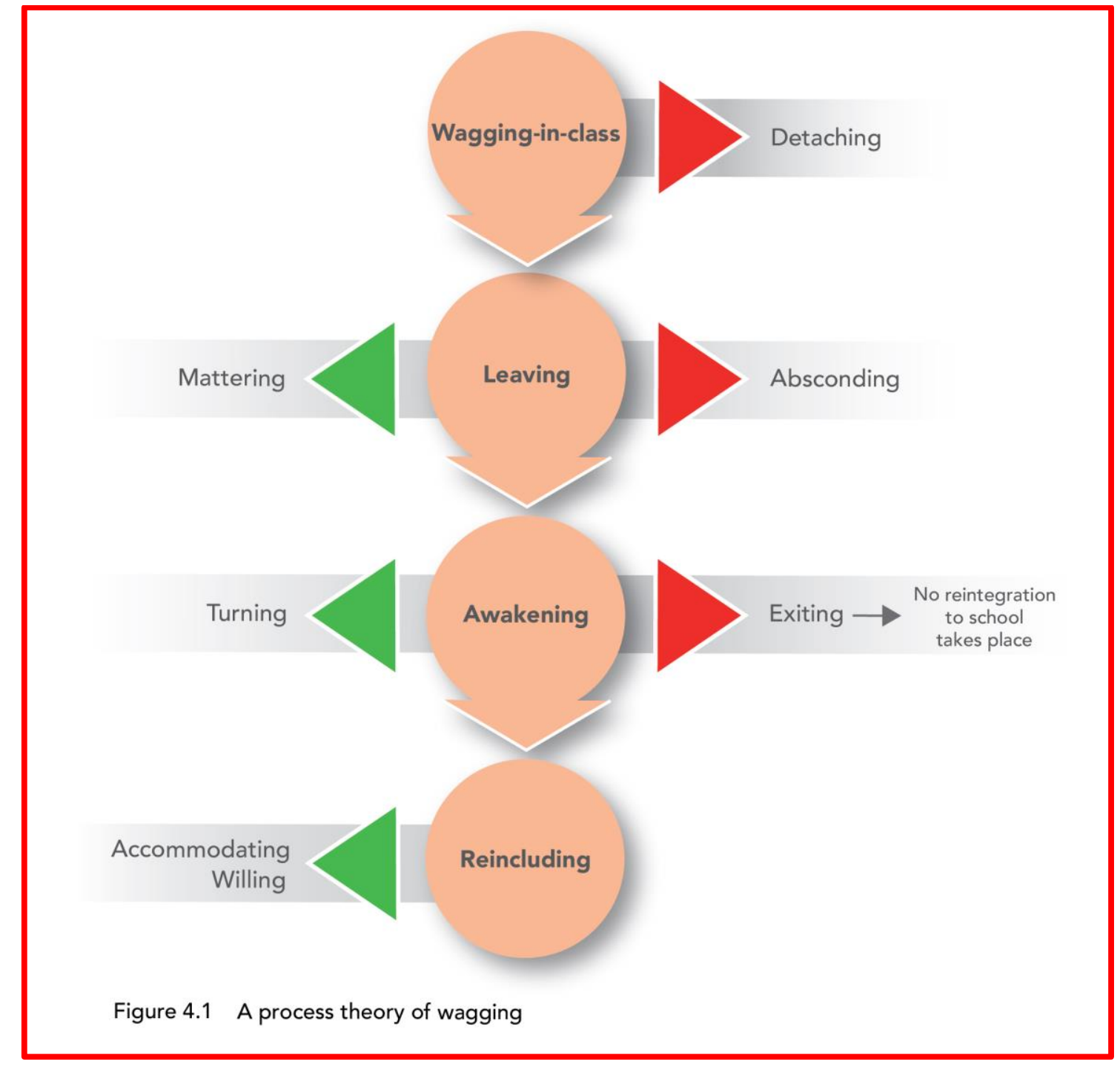

\subsection{Process theory of wagging: Stage 1 - Wagging-in-class}

\subsubsection{Introduction to Wagging-in-class}

The process of wagging began inside classrooms. Wagging-in-class consists of three components: detaching from teachers; detaching from classroom peers; and detaching from learning. The term detaching is used to describe participants' responses to the classroom environment as well as a state of being. Wagging-in-class was about participants being physically present but not participating due to one or more of the following: lost motivation; isolation; invisibility; lack of academic support; triggered negative emotions; perceived student-teacher conflict, disrespect and disinterest; and 
challenging home circumstances. Participants were physically present but so detached that they typically saw no point in being there; no learning was occurring:

I know what it's like to look at the work and say I can't do this so it's easier just to talk to my friend and make the time go faster than actually doing the work and every minute drags on. So like my [subject] teacher doesn't seem to care and he doesn't take notice. He is not very observant so it is quite easy to wag during that class. (Amy)

The participants wanted to be involved in their learning but challenged whether they received the necessary support to do so. Wagging-in-class highlighted their responses to alleged unfair treatment when facing difficult and unresolved challenges in the classroom. When wagging-in-class participants experienced emotional, social or personal detaching, they became dissatisfied and/or disinterested in response to what they believed was happening.

Similar constructs to wagging-in-class identified in the literature are "mental truanting”, known as one of the many ways estrangement manifests in schools (Harber, 2008), and "hidden dropout" (Rosenblum, Goldblatt, \& Moin, 2008; Sultana, 2006; Lifshitz, Noam, \& Habit, 1998), referring to students being marked present on the roll but not visible in relation to learning and instruction. Makarova and Herzog's (2013) survey of 1,186 immigrant students' in Swiss primary schools suggests that hidden dropout refers to students experiencing diminished attention in lessons and becoming disengaged during class. Their findings indicate that for primary students, their attitude, academic achievement, and peer and adult relationships are important aspects explaining hidden dropout.

In their report of 14-18 year old dropout rates Lifshitz et al. (1998) refer to the phenomenon of hidden dropout as involving students who physically missed many hours or days of classes. Rosenblum et al. (2008) used Lifshitz et al.'s (1998) definition of hidden dropout when they conducted a questionnaire study to compare 60 irregular attendees among 14-18 year old immigrant adolescents in Israel with 28 regular attendees. Apart from this discrepancy in relation to in-class and absent from class 
behaviours, the studies by Rosenblum et al. (2008), Sultana (2006), and Lifshitz et al. (1998) are consistent in their acknowledgement of hidden dropout as the first stage in the process of dropping out from school. In the present study, wagging-in-class was the first stage in the process of truancy; although participants were attending class, they were progressively detaching from their teachers, peers and from learning.

\subsubsection{Detaching from teachers}

Detaching from teachers refers to the tenuous and deteriorating bond between teachers and participants; it involves a disconnectedness that inhibits interactions and academic support over time and causes participants' internal withdrawal from teachers. At times, during this first stage of the process, participants detached from their teachers when reacting to observed teacher inattention. When left waiting, participants said that they felt unsupported, and their academic learning needs were overlooked by teachers. As a reaction to the identified injustice, participants believed they were being rejected. Detaching in this instance was about the participants feeling excluded and less important or inferior to other students in class. When detaching, they saw themselves as becoming separated from teachers; they also felt socially and emotionally isolated in class, and experienced reduced motivation to learn and a diminished sense of belonging to class. As evident in the following quotes, this detachment from teachers was manifested by participants' lack of interest, withdrawing from what was going on in the class, and the beginning of their separation from the social and learning environment:

$\mathrm{He}$ is too busy trying to get these girls on this side of the room to actually at least do something. He is too busy helping someone else, giving them so much attention that he barely notices that your hand goes up, so you are there for 20 minutes and your hand gets tired so you just put it down and give up. (Amy)

I used to have to do it all on my own and I just wanted a helping hand and I never got it. So, it kind of made me give up hope. Everyone asks [for help] but it is up to the teacher if they are busy or what they are doing so it's kind of like, you are the last option for them. (Christina)

Although these participants were beginning the process of detaching from the class activities, they found it unsettling to be invisible in class. They needed support and 
regarded themselves as not prioritised. Such interactions had influence when the task could not be completed without teacher assistance and resentment built as the teacher attended to others. Bergin and Bergin (2009) suggest that attachment provides security, a sense of worth and the motivation to explore new ideas. However, dependency on teachers for academic success, along with the reported inattention to their academic needs, was often challenging for participants. The pressure imposed on them by these circumstances, resulted in participants taking recognised teacher behaviours personally leading to heightened insecurity and diminished motivation to learn:

When I wasn't getting any attention from [the teacher] in [subject name], I would be overly sad with maybe over thinking about, because I didn't used to get noticed that well. (Christina)

Sometimes in class I wouldn't get attention and if I don't get attention like no one's listening to me, I want to do something, like leave. (Decity)

Of relevance here from the literature is a study by McNeely and Falci (2004). Their study was based on two student surveys that investigated adolescent-school connectedness and identified that students were more likely to do better academically when they received teacher support that they saw as caring and fair. Similarly, youth in the study by Gase et al. (2016) reported lack of one-on-one academic attention and teachers not caring as negative aspects of the school environment. In the present study, participants identify several factors as contributing to their understood tenuous and deteriorating bond with teachers. These include lack of academic support, isolation, and strong emotional responses to felt injustice:

I was somewhat jealous; she [teacher] made me feel like I wasn't good enough and it wasn't fair because I needed help and [student name] didn't. Some teachers can be quite biased. Like have their favourites or they like boys more than girls or something. [Name] was like that, so was [name] the [subject] teacher. (Rose)

My teacher's unfair and unreasonable, she treats all us kids differently. It's usually just me that gets told off. If I don't understand, I don't get help. She just says I'm dumb. It's one of the times that I felt like the teachers were taking people's sides. (Becky) 
When participants' learning needs were unmet, they noticed and resented observed unfairness. Some of the participants believed that their teachers were unjust when they prioritised others in class and teachers' personal opinions about different students influenced choices to provide assistance. All of these experiences contributed to youth who truant detaching from teachers. Hallinan's (2008) study investigating the determinants of liking school, suggests that teenagers have strong intuition regarding justice. They judge their teachers' approaches to applying school rules and policies in classrooms, and when teachers are fair and compassionate, students feel respected. This is in keeping with my findings where teachers were seen as unfair causing feelings of disrespect and inferiority. Students' experiences of exclusion and unmet learning needs, and the consequent surfacing of their insecurities, were barriers to their participation in class. The following participants' comments capture some of the feelings that they felt:

If they have students that do really well, and then the ones that weren't doing so well, they just didn't care about them; and they are the people that need the most help. (Rose)

I get scared, like if I am not good at work. Others are usually quite clever at work and teachers talk to them. It's embarrassing. Makes me feel kind of mad. (Courtney)

The participants professed that opportunities to learn in the classroom were inequitable; they identified themselves as being not as important as others. They recognised teachers as being selective, providing care to those already advantaged in the classroom and leaving them to struggle alone. Osterman (2000) suggests that when students perceive teachers as supportive, they are secure in their teacher-student relationship. They are willing and able to engage, and become more bonded to school. However, the participants developed a perception that teachers did not accept them, and they were consequently defensive or ill at ease in the classroom, contributing to their detaching from teachers. The research of McHugh et al. (2013) about identified barriers inhibiting positive student-teacher relationships in the classroom provides further insight. The success of supportive teacher-student relationships is attributed to the 
frequency of interactions, the duration or length of the relationships, authentic and genuine intentional reaching out by the teacher, and connecting and care for student well-being by the teacher to support relationship development. In other words, students consider that such teachers signal a feeling of care towards them when they approach and engage them in conversation about their day, concerns, and needs. However, participants in this study considered that they had not received quality attention.

Some participants also considered that their teachers were not only unsupportive but also unkind and hostile. This occurred, for example, when participants were disciplined for off-task behaviour while not necessarily receiving academic assistance to attempt set tasks.

Some of them [teachers] were a bit harsh and they'd pick out all the like little things I'd do: like what I'm wearing, like if I had correct shoes. (Decity)

The [subject name] teacher was rude, everybody hated her. I am not the only one - she was nasty to me. We just had a massive personality clash and she just didn't want to help me at all. (Rose)

A review of disaffected youth (Furlong, 1991) identified that demands placed on already emotionally vulnerable students become the focus of conflict. Participants resented the conflict created when they perceived teachers as being rude and petty. Given that approval from teachers fosters students' confidence and inspires them to persevere and achieve (Hallinan, 2008), circumstances such as those identified above by participants contributed to their emotional detachment from teachers. In addition, Gase et al. (2016) claim that relationships with teachers are fundamental to students' decisions as to whether to wag or not; when students do not like teachers and feel unwelcome, personal conflict in class contributes to this decision. This sense of conflict within participants and the associated perception of teachers' disrespect and disinterest in their learning, clearly contributed to the detachment from teachers and the consequent wagging-in-class.

Wagging-in-class also concealed the need for help with a task that was too difficult to attempt alone: 
That work was too hard; or like you do not want to do it. The teacher will be teaching, like helping everyone but like if I put my hand up and I don't get attention I was like oh no I'm going to walk out the door. (Decity)

Sometimes I am challenged, but sometimes it's too much challenge and I can't finish it. That makes me sad, 'cause the teacher doesn't help. I found school depressing and just wanted to be alone. (Tyrone)

These comments suggest that participants were ready to learn but classroom events affected their motivation and caused detachment from the teacher and the task when they did not receive the academic support they needed. The participants felt disempowered and unable to do anything to change the situation; they did not feel part of the class. The findings of Cavanagh et al. (2012) are relevant here. They investigated Māori students' perspectives about their relationships with teachers. Students in their study wanted teachers to care for both their well-being and their learning. Classrooms that were inclusive were typified by acceptance of individual and cultural differences. Therefore, when students experience such care, when teachers foster and support caring peer and teacher relationships, students feel a sense of belonging, feel safe, and experience meaningful participation. The participants in the present study ascertained that they were not receiving the necessary support and encouragement from teachers to feel part of what was happening in class.

In summary, participants detached from teachers because of their negative perceptions of teachers' behaviours towards them. These suppositions included the prioritisation by teachers of other students' learning needs, and participants receiving unjust treatment and inadequate academic support.

\subsubsection{Detaching from peers}

Detaching from peers was similar to detaching from teachers, in that it represented another tenuous and deteriorating bond. The participants disconnected from peers to avoid shame and peer judgement. Disconnectedness separated participants from others, caused exclusion from activities, and evoked a sense of unworthiness, difficulty interacting with peers, and further isolation in the class environment: 
I didn't really get along with much people in the class because they didn't get along with me. (James)

Because I feel like they'll think I'm dumb or something. Sometimes, I don't want to ask a question because I'm scared like they'll be like, why are you asking that? (Christina)

Participants recognised that they could not form harmonious relationships with some students in class, and felt uncomfortable and fearful. They were not relaxed in class. Murphy-Graham et al. (2014) investigated how trust could be fostered. When students experienced beneficial, positive collaborative learning, peers assisted other students to learn. Students developed confidence when they knew peers would not judge their ideas and when they trusted that their peers would not humiliate them. As trust built, they could admit to peers that they did not understand the work, and peers assisted them to learn. Trust was a learned capacity as peer relations focused on cooperation rather than competition. However, the inability of participants in the present study to trust their peers inhibited collaborative learning. The participants were not able to trust peers sufficiently to disclose any difficulties they were struggling with, or to ask for help. Fear of what peers would think and lack of confidence were contributing to these dynamics.

The participants considered the trustworthiness of friends, and understood that establishing supportive relationships was challenging:

I don't trust anyone, every girl and guy. It just spreads, you tell them something and there is just no trust, you think you know someone and they will surprise you. (Christina)

It was like one time I went to school and I got locked in the toilet by my best friend and that really hurt for me because it was a really close friend. And I just don't want to; I hate to fight with people, especially when I am close to them. (Decity)

Breaches of trust influenced friendship and acceptance of others and did not provide the space to sustain positive relationships. In a phenomenological study of five alienated boys' experiences at school, Schulz and Rubel (2011) claimed that to manage their insecurity, distrust and growing fear of failure, these students joined existing 
groups that demonstrated anti-social attitudes and behaviours. As they wanted to fit in and gain a sense of security, rather than being an outsider, they adopted the same behaviours. They remarked it was better to be socially accepted and belong rather than achieve academically. Likewise, at times participants experienced alienation. The participants hesitated to trust others; when peers and close friends betrayed their trust, they were surprised, hurt, reluctant to continue sharing and unwilling to resolve conflict. The participants understood that not everyone was trustworthy and expected friends to be kind and loyal. They thought it unsafe to share personal stories with peers who had broken trust. Two further studies (Hamm \& Faircloth, 2005; Strand, 2015) endorse this claim. Students, who were interviewed to understand their perceptions of truancy, claimed that they felt abandoned and like outsiders because they lacked relationships with classmates and peers (Strand, 2014). Hamm and Faircloth (2005) speculate that students in their study also experienced school as a socially and academically alienating setting due to peer rejection, cliques, and biased and racial peer opinions in the school. However, when students perceived that friends acquired an intimate awareness of the special circumstances in their lives and built support that encouraged self-confidence and perseverance, they felt more successful because their friends cared, understood and valued them (Hamm \& Faircloth, 2005). These findings highlight friendships as central for teenagers to function in school environments in which they feel disengaged and excluded. However, participants in the present study were aware of their inferior status when they experienced confusion due to an imposed negative identity:

At an only girls' school they are very catty and I think because I was really shy. I would say I am not a lesbian and I don't know why it matters if I was one or not. (Rose)

I [was] seen as a little druggie, everyone looked down at me and no one cared. (Julie)

Differing values around sexuality and prejudice created conflict. Given the importance of peer status in the context of relational domains, as identified by LaFontanna and Cillessen (2010), it is of note that the participants in this study were at 
times at the mercy of their peers, as they were judged regarding personal attributes that were unacceptable to that particular peer group:

Then they would start mocking me during classes and the teacher wouldn't do anything. School is pretty unsafe; yes, it sucks. (Rose)

I do not like class when I am scared of being made fun of, or called names and I know the teacher sees them doing it. It makes me want to be by myself, not around other people. (Courtney)

These comments also identify that participants recognised teachers as ignoring, as well as not intervening to change inappropriate peer behaviour. This finding was supported by Gourneau (2012) who conducted a bullying survey and an anti-bullying programme with 500 middle school students. He suggested that verbal bullying results in victims feeling discredited; however, a bystander who steps in and gives the victim reassurance that the behaviour is not acceptable, minimises harmful effects. In this study, such intervention did not occur; the stigmatisation and marginalisation experienced by some participants caused them to feel discredited and prevented them from building trustworthy relationships with peers, as well as teachers. Libbey (2004) suggests that a student's sense of school belonging, which develops in a school social setting, involves positive relationships with peers and adults in the school context and a perception of safety. In San Diego, Wormington, Anderson, Schneider, Tomlinson and Brown (2016) measured the association between peer victimisation, alcohol use, and academic functioning. They found that low student perceptions of school belonging could trigger school truancy. In addition, Ma (2003) suggests that alienation is a reason for student's lack of belonging at school.

In this study, participants wanted to intentionally leave class when they felt unwanted and not valued:

So you just want to get away from everyone so they don't try to care when they actually don't. (Christina)

I'm an over thinker and I was really bad back then so I thought everyone hated me. (Rose) 
If I don't want to be surrounded by people, I just want to be in my own space. You are by yourself and you are left alone from all the bullshit, you don't have to deal with it. (Christina)

Rejection by other students influenced participants' choice to cease engagement with their class peers. Strand (2014) concurs, stating that skipping school ends with students "rejecting or being rejected by school" (p. 273). In order for participants to value others in class, and be valued by others, they needed to experience positive supportive relationships that provided genuine care and stress-free interactions. It was evident that participants assessed these negative school experiences with peers as unsatisfactory. Although from a teacher perspective in an alternative school setting, Haggis (2017) provides insights into the nature of teacher behaviours that are effective in developing positive classroom interactions between students, who have a history of failure, and their peers. Teachers highlight the value of using peers to help one another by providing opportunities for group work, assistance in crisis, and developing social skills through encouraging positive interactions between all students. Collaborating in this way creates a more caring learning environment. Rather than simply being punished, students were encouraged by teachers to think about, and learn from, their mistakes so they would be able to resolve conflict and repair peer relationships. Teaching students to collaborate with peers was critical for encouraging students to invest in their learning.

Similarly, a study by Delgado et al. (2016) identified that when Latino adolescents perceived that they had many friends, they were more likely to feel a sense of belonging and achieve academically. However, when participants in the present study did not have friends in class, they were less likely to belong and achieve. Consequently, lacking friends led to participants detaching from peers, which contributed to waggingin-class. This occurred when participants felt unworthy, did not trust their peers, were discouraged from interacting with friends, and felt unsafe in the classroom due to ridicule from peers. 
Research by Makorova and Herzog (2013) suggested that relationships with pupils in primary schools are important; they invited other researchers to confirm these findings at other school levels. The present study supports their claims; participants' relationships with peers are important in secondary school classrooms, influencing participants' sense of worthiness, and their ability to relate to, and trust, their peers. Peer status influences participants' willingness and ability to fit into classes; this in turn influences their consequential level of connection to learning.

\subsubsection{Detaching from learning}

Participants' detachment from teachers and peers also contributed to their detachment from learning. The term "detaching from learning" refers to the obstacles that participants experienced that inhibited their ability to focus and increased their disconnection from the social and academic aspects of class. Such obstacles include the demanding or boring nature of experiences:

Never been into writing and journals and I find them boring, straight boring. I don't like to do it, I just, I'd rather do something else with my time. (Tyrone)

School's boring ... doing the same thing every day, I can't stand it. (Bob)

Because class gets boring and all you do is just sit and write. (James)

Just thinking of gapping [it] "cause it started getting boring even more. (Michael)

The participants' boredom increased over time due to lesson dissatisfaction and the seemingly irrelevance of material. This aligns with the research of Hawk and Hill (2003), which suggests that students who wagged class often referred to classes as boring; students needed to believe they could learn, improve, and make progress to sustain motivation. Meaningful learning and self-belief were required to engage the participants in this study in learning, which implies that both curriculum content and design required adaptation to suit the specific learning needs of participants. The findings of Tze, Daniels and Klassen (2016) in a meta-analysis of 29 studies involving 19,052 students, support this claim. They examined how boredom related to academic 
outcomes and concluded that attention by teachers to curriculum design and the context of learning helps alleviate boredom, a negative emotion, and in turn improves students' learning.

Although participants' detachment from learning manifested in similar ways to their detachment from teachers and peers, it arose from different experiences, which included curriculum difficulty and subject choice:

Some of the classes will be too low and too high for you. (Becky)

English, essays and stuff I don't get, find them confusing. I've never been an English person. (Tyrone)

The participants experienced personal failure, manifested in their diminished ability to achieve because of their perception that the curriculum was delivered at the incorrect level. Their perceptions varied regarding subject challenges; subjects were regarded as too hard or they disliked the content. This evidence is consistent with the findings of Gase et al. (2016). In their study, students neither enjoyed nor found subjects interesting, and saw classes as pointless, too difficult, or insufficiently engaging due to content and teaching style. These students' experiences frequently intertwined issues that contributed to youth becoming "academically disconnected" (p. 308). School influenced not only students' motivation and desire for learning, but also their decisions to start "skipping class" (p. 312). The participants here also lost motivation to engage with learning, detaching from learning when the lack of stimulation, or insurmountable challenges, influenced their ability to do the work. It was easier for some participants to detach when they did not feel challenged by the material or able to concentrate.

For one student, thoughts about difficult family events contributed to her not being able to engage:

She would physically attack me when she was drunk and she wouldn't remember the next day. During that time that was all I would think about during the day. I would be thinking about my mum and dad and my brother. My brother just left the house because he didn't want to be around it [mother hitting her] so I didn't really have him, I couldn't talk to dad because he was in denial about it. (Rose) 
Home circumstances in this instance were so challenging that thoughts of family consumed the day, impaired Rose's ability to concentrate on class work and contributed to her wagging-in-class. Historically, truancy research highlights home circumstances as a contributing factor to students' wagging (e.g., Fogelman et al., 1980; Teasley, 2004), but few studies highlight the specific impact of negative home circumstances on students' ability (or inability) to concentrate and focus on learning in class. However, a US police department study (Gill, Gottfredson, \& Hutzell, 2016) that used a trauma informed framework to support youth in challenging environments, offers insights regarding the support required for students suffering from direct exposure to violence and other risk factors such as chronic truancy. Effective strategies to help mitigate the effects of community violence on school students, involved collaboration, problem solving, and direct referral of vulnerable youth to case management and services. Officers who were able to establish a safe and secure environment for students, provided "gap bridging" (p. 556), involving home visit support between schools, students and their families. This helped build trustworthy relationships including the modelling of supportive, patient, and youth orientated approaches. The officers possessed a good understanding of the school's wider community and were able to provide support that improved outcomes for the students. These findings suggest that participants such as those suffering from trauma due to violence in their homes require specific support. They need to be identified and receive support from empathetic, patient adults, who can visit their homes and are able to establish safe and secure environments that improve students' capacity to focus and concentrate on schoolwork.

\subsubsection{Wagging-in-class: Summary}

For students at risk of truancy, wagging-in-class serves the function of controlling detachment from teachers, of managing perceived isolation from friends, and the concealment of work that is either too difficult or insufficiently challenging, and the 
concealment of challenging home/life circumstances. Wagging-in-class is the first stage of the process of wagging from class and school.

\subsection{Process theory of wagging: Stage 2 - Leaving}

\subsubsection{Introduction to Leaving}

"Leaving" is the second stage of the process theory of wagging, and a construct consisting of two components: "absconding" and "mattering". Leaving is a term used to describe participants' explicit choices to remove themselves from class. They wanted to have control, to be somewhere else, doing something more enjoyable:

[I'd] just get up and go. (Decity)

I mean like the decision's mine to wag. (Christina)

There was no point; and going to school was just a waste I'd rather be off doing other things. (Tyrone)

I would just leave; get up and walk out. (Michael)

Sometimes I just walked out as soon as I could; I would leave class. (James)

I wanted to get out of class. (Julie)

In leaving, the participants indicated that school did not matter, although some acknowledged that it was a bad decision:

Its [wagging's] very bad but then it's like the decision's yours, it's your life, your decisions, like no one can stop you from being who you are. (Christina)

Usually I'd like school but it will be my subject but yeah I'd just do the wrong decisions, wrong choice [and wag]. (Decity)

A few times I actually was a bit scared when I did not go to class. Like I know what I was doing was wrong. (Amy)

Participants understood that wagging was a reasonable response to intolerable circumstances. They were aware they should not be leaving even though they found the classroom circumstances, initially at least, stressful. They were determined to leave, took responsibility and left classes. Dahl (2016) concurs in part. In her research, truancy was identified as "selective ditching" (p. 127). Students selected some classes to truant but not others, and socialised with friends, visiting their houses and sharing meals. In these particular circumstances, the participants in this study were similarly selective, did 
what they wanted to do, chose to participate when activities were meaningful, and avoided situations and activities they saw as challenging:

That's when I choose [my] time out zone and go sit over there alone. (Tyrone) I am not going to lie, not going to class and going to the mall instead was definitely way better because some of the teachers were arseholes. (Rose)

I'd have to run away from the teachers, Mr [teacher name] will be running after me. (Decity)

She [the teacher] called me helicopter all the time, took my hat off me, never gave it back and that's why I hated her. I never went to her classes. (TM)

I didn't even think about it, I just knew I didn't want to be there, I just didn't enjoy it, absolutely hated it, just couldn't bear the thought of being in school. It was just horrible. (Julie)

The participants were determined to leave class. Escaping was a preferred option to experiencing anxiety and stress and being in class with teachers and peers who they disliked. Strand (2014) claims that students identified school conflict and atmosphere as "forces beyond their control" (p. 267) and reasons for truancy, which is upheld in my study. The two components within this construct, absconding and mattering, further explain the dynamics within which such circumstances occurred.

\subsubsection{Absconding}

The term "absconding" refers to the personal choice made by participants to actually leave class without permission and get away from teachers, peers, and recognised problems in class. Absconding was motivated by an immediate need to get away and to engage in a preferred, pleasurable activity. The participants walked away, in the main, for the same reasons they wagged in class; the subject did not hold their interest, the class was not a place where they could relax and enjoy learning, and the learning environment was non-inclusive. The participants wanted to be safe; they missed opportunities to connect with their out-of-school friends. In addition, some were trying to cope with difficult family circumstances that were stressful and abusive, a finding also reported by Raval (2012) who noted that leaving may be prompted by an interpersonal conflict with an important adult in the family. 
As previously established, teachers are important adults in participants' school lives, so the perceived conflict experienced between participants and some teachers in classrooms, diminished productivity, and increased aversion to learning, all contributed to participants considering and deciding to abscond. The participants left class for other reasons as well; because they wanted to avoid trouble, they wanted to feel better, they wanted to take a break because they wanted to be alone, and they wanted to avoid bullying and injustice. The following comments illustrate these reasons:

I'd just say, when I have time out [wag] I like to be alone, sit down, think, and then once I've had enough time out I come back. (Tyrone)

I wanted to just relax and just be free [so I bunked]. (Rose)

Some of them [peers] I was bloody getting into fist fights and mostly I just decided to walk off. I didn't want to get kicked out so I just walked out so I didn't get into any trouble; but I still did. I got stood down. (Michael)

For Tyrone and Rose, leaving class was an attempt to self-manage the need for personal space in order to think, relax and feel free. For Michael, leaving class was an attempt to keep out of trouble with peers; to look after himself. He understood what behaviours incurred suspension, and he thought about consequences when making a choice to leave class, and understood the implications of this action. For many participants the most challenging circumstances that contributed to their absconding were the incidents of physical and verbal aggression that occur at school:

I got pushed down a set of concrete stairs and landed in mud, the teacher didn't do anything because I was white. I did not want to go to school. It was just emotional and people would make up lies about me. (Rose)

I loved it at home, just fun but at school it just felt unsafe "cause when my older brother left and everyone started bullying me so yeah. (Michael)

The participants recognised the climate in their schools as a climate characterised by physical and verbal aggression, stress, and as being an unsafe place to be. Although peers took advantage of quieter participants, older siblings provided protection against bullies. The participants wanted to escape identified physical and verbal bullying when they viewed themselves as unprotected by teachers. This is in accord with Attwood and Croll's (2006) research conducted with young people who had 
been persistent truants. One young woman in their study claimed she stopped attending school when she saw teachers as not supporting her in relation to bullying problems that she experienced. Similarly, participants here did not want to be in a place that they felt as unsafe; their experience of injustice, racism and prejudice influenced their desire to abscond. In their review regarding the effects of friendships, peer support and socially marginalising experiences on student engagement, Juvonen, Espinoza and Knifsend (2012) investigated how and when teenage friends were important. They suggested that friends provide social support but belonging to school promotes engagement. Teenagers may be forced to totally avoid school due to distressing concerns regarding being ridiculed and bullied. Accordingly, such negative social experiences with classmates influence rejected teenagers to seek the company of other disengaged students. Teenagers who are socially alienated from friends do not fit in and are disengaged are more at risk of school dropout, a conclusion supported in this study. Because of unsafe environments, the participants struggle to stay in class. Absconding also served the function of dealing with social rejection and there were times when unacceptable attention also motivated participants to abscond. They understood injustice, and disapproved of recognised unethical behaviour.

At times, participants tested boundaries, and resisted school rules and norms. Although findings from DaCosta's (2006) research cannot be generalised, they provide further insight. She suggested that students feel suffocated because school policy prevents them from exerting personal clothing choice. In relation to noncompliance of school policy, students (especially males) rated teachers as using the uniform policy as an unfair selective screening tool for delinquency. They also felt unfairly targeted and labelled as troublemakers, which created hostility. The participants openly broke school rules and rebelling was a strategy used to be different:

I like used to wear a jersey and a school jersey over top. So yeah, I just said "I still got it on". (Michael) 
They said that you have a detention but I've not shown up to several detentions and I've gotten away with it so they're not really that strict. (Amy)

Prioritising pleasure also contributed to the absconding of participants from school. This occurred when participants left class to be with friends and to do something they viewed as better than being in class:

Then sometimes I just didn't want to go to class because I couldn't be bothered and I just wanted to go shopping and other stuff. (Rose)

Well I just used to tell them [my friends] to go for a session [smoke marijuana] and we would all go cruise. (TM)

Like usually I would get on the piss after school or skip school and go get on the piss yeah bad habits. I don't know [why I enjoyed drinking] like just to get on the buzz, like have fun, feeling better, and like having a break. (Decity)

Participants also followed others' lead to wag. They understood that skipping school to drink was wrong but wanted to participate in preferred outside-class activities, a finding supported by Gase et al. (2016). They found that youth "ditched classes" (p. 308) because truancy experiences were more enjoyable and meaningful than attending. The participants here perceived shopping, cruising, smoking marijuana, and drinking alcohol as meaningful activities worth wagging class for and more meaningful than attending class and dealing with disapproval.

Most participants were comfortable with the idea of wagging and others identifying them as young people who wagged. They were relaxed, secure and enjoyed the reputation of belonging to this outside-class group:

It wasn't that bad to be known as someone that wagged because I didn't care what they said. I knew that there were other students out there getting told that they wagged. (James)

Bottrell (2007) claims that when young people negotiated and adapted to social worlds, they gained status, belonging, empowerment, support and loyalty from outsideschool youth networks. These gains were not experienced in school, and outweighed any negative reputation associated with the network. Showing off and the display of violence and assertive anti-school attitude aimed to satisfy participants' needs to oppose 
what was happening; to show their disapproval and unacceptance of other people's actions towards them.

And then I started getting into heaps of fights and then that, started doing graffiti at the high school, did a few things, broke the cameras. I started getting in, into mean as trouble just showing off. (TM)

In summary, absconding from peers and teachers without permission served the function for participants of opting-out from obstacles they faced. This gave them the space to think, time to improve the way they were feeling, opportunity to participate in more enjoyable activities, a place to find support, status and belonging, and to overcome disapproval of what was happening in class.

\subsubsection{Mattering}

The term "mattering" explains the enjoyable shared experience that provided opportunities for participants to form close relationships, develop a sense of community, and receive the support they needed to overcome the restlessness and obstacles they experienced in classrooms. That is, the participants were accepted for who they were; they felt important to others and found a safe place to belong when absconding. Feelings of being wanted and accepted were key dynamics of experiencing mattering. Rosenberg and McCullough (1981) coined the term mattering and through it identified three key components - awareness, importance and reliance. Mattering acknowledges that the person is there and that someone cares enough about her/him so that $\mathrm{s} / \mathrm{he}$ is able to ask for help. For mattering to exist, all of these components must be present. Most of the participants who absconded formed a social group, and helped one another. Within the group, norms of justice, loyalty, mutual respect and support operated:

Like being accepted and them laughing at your jokes makes you feel good and I know they want your time and your company that makes you feel good. And you are not getting that in class. (Rose)

I just feel restricted in class. It was fun when I was wagging; meeting new people all the time and being able to talk to new people. I relaxed, I felt free when I wagged. (Bob) 
The experience of mattering meant that participants encountered positive peer interactions that created safe places where they were able to explore what it was like to be someone who was important to others; someone who wagged and someone who belonged in that world of truancy. The participants perceived wagging as rewarding, giving value that their school experience was not providing. Unlike classroom experiences, when participants wagged their peer interactions were positive, welcoming and fun, and contributed to them feeling better about themselves. This was significant given that previously the participants experienced vulnerability in school. Of relevance, Syrjalainen, Jukarainen, Varri and Kaupinmaki (2015) conducted a narrative case study and within the theme of "practices and procedures to build safety" (p. 64) reported that students associated safety with joy, well-being, trust, empathy, and caring. When the participants here wagged, they received care and compassion from outside-class friends; and experienced consequent trust, safety, belonging and acceptance. According to Jones, Audley-Pitorowski and Kiefer (2012), meaningful social interactions and friendships perform a vital part in well-being, and being with and supported by outsideclass friends improved the well-being of participants:

I got attention from them that I wasn't getting from classmates. (James)

I wasn't getting bullied or that and I was actually talked to properly. They weren't swearing at me or anything or telling me to F off. (Michael)

When people invite me out and say I want you to come, it's like me, you really want me. That's what I get like when people invite me out. (Rose)

Being with outside-class friends offered an alternative to previous stressful classroom experiences; here, peer relationships were positive, mindful of others' feelings, respectful, protective and inclusive. The participants were included and accepted for who they were. Friere et al. (2009) investigated how students constructed their identities and the consequent impact on decisions regarding school and education. When students experienced negative personal assessments or reactions from other students about themselves, it was challenging to negotiate who they were in their school 
community. In relation to the present study, to manage this situation, maintain psychological well-being, and to make sense of their own experiences, participants used the strategies of dropping out and truancy to engage in other communities and renegotiate their own identities. The participants valued inclusion in this group of outside-class friends. The rewards received from friendship bonds formed outside of class, and the opportunities these bonds afforded, contributed to their decisions to sustain wagging. Mattering to outside-class friends allowed participants to be at ease, to re-examine who they were, and to contribute to their identity formation. Participants could not achieve a sense of belonging in the same way in class:

Because I found some friends that I could tell my secrets to, that I could rely on, they were honest and they weren't disrespectful. The good thing is when they don't judge you. (James)

I think people who bunk are really just unloved and rejected: uncared for. I think because I wasn't so used to people liking me, I ended up bunking to get that feeling of being wanted. I think that is what happened to me. (Rose)

When you get to wag, you wag with your friends and just catch up with your mate; just two boys regularly. I've known them ever since I was in primary school. It was just that I could connect with them. We could just hang out. Connecting is when you just get along with the person. You just connect and you just know that you're friends from then on. (James)

It feels better to be loved than to have qualifications, like having lots of money does not bring you happiness. Having lots of friends and people who love you brings you happiness. Some people need it more than others so they do anything they can to fit in and try to be cool so they get the sense of feeling loved. (Rose)

A clear contrast emerged between inside and outside-class relationships. Peer social rejection in class contributed to a need to belong and experience peer approval. The participants connected with outside-class friends to meet these needs. This was possible as expectations were neither imposed, nor judgements made. Participants valued being together. They perceived outside-class friends as confidants who respectfully shared intimate, honest ideas. They committed to one another outside of class and maintained trustworthy peer relationships; they received friendship and acceptance. In order to belong, the participants in fact prioritised caring and mattering over learning. Cohen and Prinstein (2006) and Laursen, Hafen, Kerr and Stattin (2012) 
suggest that higher-status peers are agents of socialisation; such peers are often advantaged by superior social skills, and consequently influence others to wag. By being respectful, responding to kindness and being part of a positive social experience with peers who chose to wag, many participants received recognition. They moved from being invisible and rejected in class to being visible and accepted amongst outside-class friends. Absconding provided a place to belong, support for developing their identity in relation to others, and opportunities to explore and understand what it was to be included, noticed, independent, emotionally intimate, and cared for. Friendships mattered, were more important than attending class, and also afforded some participants a sense of "being cool":

I thought I was very cool when I bunked. As ridiculous as it sounds I thought I was so cool when I didn't go to class and people would be like, oh you coming to class, and I'd be like, no I'm going to go to the beach. (Julie)

They'd be like, oh my gosh, they'd be like, so cool, like that's naughty. Just know that it's trying to fit in and trying to just be cool. (Julie)

The participants gained status amongst outside-class friends by not conforming to school rules and norms and enjoyed the sensation of being cool. The term being cool acknowledged those who truant as a group of outsiders who were viewed negatively by others in their school community, experienced alienation in class, and were part of a social group conforming to their own group norms for the sake of being accepted for who they are. Bottrell (2007) concurs, suggesting that the youth network in her study offered belonging, support and empowerment that was understood as unavailable at school. The participants chose such a group to be empowered and become accepted members. This membership was more successful than when in the classroom because participants experienced peer esteem and close relationships. Being cool contributed to them mattering and compensated for previous unpleasant classroom experiences:

I wasn't with the people who wanted to start fights with me. I would be with the bros that would always want to kick back. (Michael)

They would like shout me fish and chips and then I would shout the next day and leave class. I hang out with them in the weekends and that too; so they're like my main people. (Decity) 
[We talked about] Just boy stuff, like whatever came to our mind. Just about what us boys do and what makes us different to girls and what, you know, stuff like that. (James)

Outside-class friends did not hurt others' feelings. They talked, confided, and relaxed. The participants enjoyed socialising, reciprocated hospitality and shared financial resources. They participated in unguarded conversations about important aspects of being adolescents and prioritised peer friendships, loyalty, and kindness instead of attending class. Being accepted by the group was so important that the consequences of wagging were not considered as important as being in the moment. The participants therefore turned to peers for acceptance and validation and experienced tightness or security in the group when they wagged. In short, they bonded. Newman, Lohman and Newman (2007) confirm that feelings of connection are important to group belonging; that being proud of one's group and being a valued group member are two aspects contributing to emotional well-being. Connecting to one another promoted a sense of belonging. LaFontana and Cillessen (2010) suggest that by defying school rules, prioritising friendships and bonding, students succumb to peer norms and gain peer favour. The participants in the present study thought that peer preference and the desire for the company of peers was more important than being in class. Being secure and accepted by outside-class friends provided support; the peer group acted like a close, caring, functional family. The participants were able to do what they valued together, were present in the moment, and felt they mattered when they were with friends outside of class. They felt wanted, valued, better about themselves, proud to belong to their group, talked about what was important, and experienced improved status and personal well-being. The peer group provided a purpose to participants; a context to explore and discover who they could trust, and who they were as people:

It [the group] was just like a family. It's just like we were like besties and if anyone wanted to do something to one another and all of us will just rock up and do something to them, just talk to them about it, so that's just basically like just a family to us. (Michael) 
If I don't like [people] I am not going to want to sit in a class with them. That is why being outside with only people you like, is better than being in class with people you don't. (Bob)

They laugh at your jokes, include you, and talk to you, just being there: they want you to go with them and hang out with them. (Rose)

Like if some random (guy) came up behind me and hit me, they would jump and hit them. ... and that and if one would ditch we'd all ditch; so there's, there's no proof that we were hanging out or anything so it was low-key as. (Michael)

[Outside class friendships were prioritised over learning] because I wouldn't have friends. I'll be lonely if I didn't have friends and school would be boring. (James)

Being with peers provided participants with a place to be at ease and safe. A place that alleviated uncertainty and mistrust. For participants lacking positive peer relationships in the classroom, school was lonely and boring (James), unfriendly (Bob) and unsafe (Michael). When participants experienced positive peer relationships, they reported being part of a family (Michael) and being connected and included (Rose). It was possible for participants to experience positive peer relationships, but not in the classroom where, as previously noted, most experienced peer social rejection. It is interesting that outside of class, the participants found support, care and diminished alienation, which increased their motivation to wag.

Studsrod and Bru (2011) investigated peer socialisation practices and noted that most students acknowledged levels of emotional support. Even though few students reported peers as "school obstructive" (p. 168), there was a strong association between frequent class absence, poor work habits, intention to quit school, and school alienation. Positive peer relations improved motivation for continued education, less school alienation and fewer intentions to quit school, indicating that having supportive peers at school is important.

These findings have ramifications for this study as Studsrod and Bru suggest that positive peer relationships influence young peoples' ability to sustain attendance. Participants reported improved peer relationships and bonding outside of classrooms, indicating the significance of these "wagging" relationships. These peer friendships 
were important; they eradicated loneliness, and provided a safe place to explore how having a positive peer relationship, mattered. Being included by peers, and being cool, meant more than 'being together'. It also included being emotionally available and being important and mattering to one another. The satisfaction gained from existing 'in the moment', being 'present' in the group, being social, experiencing inclusion, and protecting friends, was decidedly more meaningful than the risk of being caught wagging.

\subsubsection{Leaving: Summary}

In summary, peer support and care allowed the participants to matter, and to be who they wanted to be. Group membership, although not based on blood, provided connections in a way that was representative of a family of loyal friends; within this family, participants experienced a sense of mattering to other family members. This peer bonding, occurring outside the classroom, was a strong influence for reinforcing participants' continued wagging. Being part of these families gave the participants the necessary support, care and friendship to feel better about themselves, and helped them feel secure from the sensed bias and exclusion in classrooms. When participants relaxed, they were free to be who they wanted to be and gained status. Despite the participants benefitting from outside-class experiences in the ways outlined, eventually there came a time when most young people in this study experienced an "awakening" that caused them to reconsider what they were doing.

\subsection{Process theory of wagging: Stage three - Awakening}

\subsubsection{Introduction to Awakening}

The third construct in the process theory of wagging, "awakening", consists of two components: "turning" and "exiting". The term awakening is used to explain defining moments, times when participants came to the realisation that there was no future in 
wagging. This positioning evoked significant change in their behaviour and attitudes and these changes reshaped participants' future directions:

It's [wagging] stupid cause it got me nowhere. (Michael)

It's [wagging] dumb and just people being lazy ... it was just me being an idiot. Like just not even thinking about what's going to happen in the future. (Bob)

I feel a bit dumb because I didn't do that much work in high school. (Decity)

Making my family proud and that, not just being, I was just a disgrace really. (Julie)

Although wagging previously offered participants in-the-moment enjoyable experiences, they understood that wagging was not only shameful to their family but also impacted on their future opportunities. In awakening, participants understood that wagging was no longer a viable option; that chances for success at school were minimal because they wagged.

When people have the ability to act and make their decisions, they have agency. However, structures - for example, gender, socio-economic circumstances, and religion - determine or limit people and their decisions (Evans, 2007). Bounded agency explains the ways that barriers and contexts in situations shape young people's decisions and aspirations (Hamilton \& Adamson, 2015). Bounded agency is an active, socially situated process, guided by both young people's experiences and their imagined likely prospects and with the potential for change (Evans, 2002). In a comparative study in two locations in two European Countries, Evans (2007) aimed to advance the discussion about beliefs and values associated with life-chances that occur under different structural and cultural conditions. She examined 640 young peoples' transition behaviours in four labour markets. The East German young people, who due to given circumstances, needed to "invent new scripts and routines for themselves" (p. 90), attributed failure to themselves as individuals. This was also the case for the participants in this study who, as indicated in the quotes above, gave reasons for their failure that related to themselves as individuals. 


\subsubsection{Turning}

"Turning" is a term used to describe the events and behaviours that happened when either other people in participants' lives applied interventions that signalled that participants' behaviour was unacceptable and change was expected, or when circumstances changed and students received the support they needed to turn from wagging and attend class. Prior to these defining moments, participants with challenging lives were breaking school and/or societal rules. There were three outcomes when participants persisted in wagging; (1) changing locations and/or schools; (2) transfer from the mainstream school to an activity centre; and (3) putting parents at-risk of prosecution. When participants dabbled in illegal societal activities (shoplifting, underage drinking and smoking marijuana), family members intervened out of concern for their children's future.

Turning involved reassessment of behaviour. When participants understood the changes required, they accepted responsibility. In the process of turning, participants were not only required to change their view of wagging, but also needed to reconcile differences between their reputation as failures and their emergent positive sense of identity, now willing to turn from wagging behaviours and return to attending class regularly. The experience of turning was different for different participants in this study. Some participants turned when they relocated (Julie, Christina, Rose), some turned when they received family support to change (Amy, James, Julie), a few participants turned because they did not want to place their parents at-risk of prosecution (Bob, Courtney), whereas an opportunity for a fresh start contributed to others' turning (TM, Decity, James, Michael).

Some participants experienced a change in location or school:

I spent seven months in another city at my uncle's orchard. He did not muck around; he pretty much was like, you're here to work, so get to it. It was so hard. (Julie) 
Since I moved schools, I actually try. I really want to succeed: to really try to get somewhere. I am going to class every day - it's been two weeks. (Christina)

In my new school I tried to fit in. I tried to be cool so I got that sense of feeling loved. (Rose)

It was not an easy option for some participants to move to a new setting. Clear expectations, desire to achieve and personal needs motivated them to change. They made an effort to fit in, adjust and manage their challenging new circumstances, and turn. Whereas, in other circumstances, a few participants identified intentional parental guidance and concern as influencing their turning:

So I wasn't allowed to use the computer or I wasn't allowed to be in the living room or something. I had to stay in my room. I was grounded; I wasn't allowed to hang with friends and I just really got like tired of that. (Amy)

My mum cared about me wagging "cause she used to growl at me all the time. She caught me at home one time, then got tough. She stopped me going out with my mates in the weekend. (James)

Participants like James and Amy appreciated their parents stepping in and demonstrating they cared for them. They described their parents as acting in two ways; (1) protecting them from the long-term impact of their behaviours; and (2) providing a safe place for them to reflect on what they had done. The nature and importance of the intervention mattered in this defining moment when young people reassessed their actions. Grounding facilitated "turning" and social isolation in a safe space provided an opportunity for participants to reflect alone without distractions and consider what was happening. When parents set explicit high expectations for change, they guided these participants into action. Interactions with friends were important and denial of contact so distressing, that these participants reconsidered their actions, which fostered turning and change. When the participants' choices and actions were limited by their parents, they changed their behaviours and began to attend school again.

Although there is no academic literature to support or contest the impact of parental discipline on students' truanting behaviours, it is interesting to note Amy's 
comments regarding the nature of the discipline she experienced when grounded by her mother:

I changed because my mum supported me. She was punishing me so there was a consequence but she was doing it fairly, it was absolutely fair. So after she was absolutely fair, I understood. Yeah, she taught me how. I don't know, it's like a give and take situation. Yeah I definitely decided to change. (Amy)

Amy recognised that her mother was being fair, providing support, and Amy was adamant that her mother's actions were justified. Amy awakened and, with her mother's guidance, began to think about the future and realise that things needed to change. In part, Amy had the opportunity to think independently in a safe place provided by her mother, which facilitated Amy to turn from shoplifting and truanting.

Further evidence provides insights into the nature of family support and guidance required to intervene, break the cycle of problem behaviours such as drug use and truancy, and to deal with the experience of personal trauma:

My uncle owns an orchard up there and he had me work there every day. If I didn't work well enough on the orchard, it was, nah, off you go, go to bed. [If I did work I] get rewarded at the end of the day by being able to have a beer and have dinner and watch a movie. (Julie)

The consistent action of Julie's uncle over time provided the support and guidance needed to awaken and turn. When Julie separated from things familiar, and spent every day working under close adult supervision in a safe, structured environment conducive to thinking and exhaustion, a turning occurred. Her changed attitudes and behaviours, and response were indicative of this repositioning:

Coming down off the drugs that I'd been on, not being able to drink, and I think just being away from everything. Getting away from the people I was around, and no access to drugs and alcohol, just totally coming out of where I was. (Julie)

Withdrawal was not just associated with detoxification, but also with a physical distance from people, and the denial of access to drugs and alcohol. Family took action; they provided a safe place for Julie to withdraw, recover and be clean from drugs. This action facilitated the desire for change. 
During turning, family created a new set of conditions that supported Julie to realise what she wanted to do:

He wouldn't let me talk to anyone. I started thinking about what I was going to do with my future; just thinking about what I like doing. What do I need to do to get there; then working through, sort of ticking off the things I needed to do to get to where I wanted. (Julie)

The positive experience of being active, productive, sleeping well, and being away from friends, provided Julie with time to think clearly and see what she wanted to do prior to leaving school. Family support and thinking time empowered Julie to adjust and discover a new way forward for herself.

A Canadian study by Tavernier and Willoughby (2012) collected data on turning points experienced in the lives of 418 adolescent students. The turning points for students identified by the researchers suggested two main types of meaning making in narratives written by the adolescents: lessons and insights. Lessons referred to learning about socially acceptable ways of behaviour; insights provided a worldview change that altered attitudes towards life. In relation to Julie in the present study, an awakening being removed from a harmful situation to withdraw from alcohol and drugs - was an essential, initial step of her meaning-making process. It involved lessons and subsequent insights that changed her attitude and behaviour in relation to drugs and provided an opportunity to adjust and be drug free.

The evidence here also shows that "turning" participants worked hard to improve relationships with parents and teachers:

And I tried really hard and I was attending classes and I was doing really well at home so I was allowed all my privileges back. (Amy).

Although turning was not always easy, small things could make a difference. One parent reinforced the effort that one young person made to attend class by giving her privileges back, whereas in another instance, the reinforcement of chocolate for attending class worked:

Treats stop students wagging. Chocolate. Since I started going to classes I've been getting chocolate. That's why I'm going to class (Courtney) 
When participants decided to change their perspective of wagging behaviour, the desire and determination to achieve replaced previous attitudes and beliefs about wagging. By thinking about factors contributing to mistakes as well as making the effort to change, participants managed to recognise that changing behaviour was worthwhile. Adults' actions supported participants to see a new pathway forward. School and home life were easier as a result.

Aaltonen (2012) examined transitions and future aspirations of youth, whose recollections of school concerns were unpleasant. The "anti-school disgruntlement" (p. 227) identified by youth conveyed their sense of abandonment by the school. The "hostile and uncaring" (p. 230) school culture and student-teacher relationships contributed to this alienation. Some youth, reluctant to talk about past and future experiences, were not confident decision-makers; knowing neither how, nor why, to change. Youth were required to reconstruct a different self between their past misbehaving self and their more current self (Aaltonen, 2012).

In the process of turning, participants in the current study needed to reconstruct themselves, which involved thinking about and reconciling differences between their previous self-perception as a failure and their emergent positive sense of identity, as manifested by their willingness to turn from wagging to attending class regularly. Factors that contributed to the process of turning included a willingness to change attitudes and beliefs about wagging, the development of a determination to achieve, the acknowledgement of factors that contributed to wagging, the positive recognition and feedback provided by parents and their rewards, a willingness to make an effort, and the learning that resulted from thinking about the situation. All of these things contributed to a reconstruction of participants' sense of identity, and a growing desire to change:

I have to come now, but I have to get my classes moved up for and the only way Miss will do that [is] if I come to school. But I gave her [my tutor] my word I'd come and I'm not going to like disrespect her by getting what I want and then just leaving again. (Bob) 
It was just completely coming out of this situation where I was and really just realising what was important. So, coming off all the alcohol and the drugs, that was the first thing, and the second thing was, to be frank, getting up off my arse and actually doing something, which was working on the orchard. (Julie)

Like today my mates wanted me to come with them but I had to come [to school] which was hard to get here. But I'm over that stuff because, that's just a waste of her time. (Bob)

Even when I was like really, really sick and should have [been tucked] up in bed I still went. Even when I was sick I was like, I have to go. I'd just tell [everybody] to stay away from me. (Julie)

These comments indicate that turning facilitated a change in priorities. The participants valued attendance over friends and the opportunity to think carefully, reevaluate, and understand the importance of decisions they made during these defining moments. They also reconsidered actions and changed their attitudes towards previously detrimental habits. Their thinking changed. In the case of Julie, when she was moved to a different location, she experienced being active, and productive so the distance from previous people and places supported her to come to think about what was important to her and identify new priorities. Bob overcame the challenge of conforming to peer behaviour, focused on himself, and did what was best for him. These participants began to respect their new teachers in their different schools and realised the importance of keeping promises. For Bob it was about his relationship with his tutor so he did not want to harm it. Because they received support from many adults, attitudes towards teachers and school improved. They understood it was better to attend school. These participants prioritised the desire to achieve to such an extent that they adjusted attitudes, connected to learning, became motivated, and developed a newfound confidence and determination to attend and succeed. Successful turning in these defining moments required adults to take action; to create a new set of conditions that acknowledged and gave serious attention and support to the challenges young people faced. This provision of support empowered participants to focus on themselves, think about changing priorities and discover a new pathway forward. 
Although quite different in relation to social and cultural context, the study by Edinburgh et al. (2013) of Hmong immigrant adolescent girls also emphasises the importance of relationships in influencing behavioural change. As noted earlier, these girls ran away and returned home repeatedly. During this time, whilst on the run, some girls experienced both sexual assault and sexual exploitation. Relationships, family and recognition were the three external factors that motivated their desire to change. Girls were motivated to return home because of the strong desire to see younger siblings they missed. They were motivated to change and stop truanting because of the connections they had to friends and to school. They understood what they needed to engage with to do well at school and were motivated to find work and earn money because they wanted to support family and pay bills. Finally, the girls changed because others wanted them to, but also the girls wanted recognition from significant adults when they managed to change their behaviour.

Much of this behaviour is congruent with the findings of the current research and indicates the importance of supportive respectful relationships in influencing the expected change for young people to turn and attend school again. Further factors influencing participants in this study to realise what was important and to decide to return to school, included promised placement in higher classes, participants themselves working hard, and participants respecting school staff and adults taking action. Participants' connections with staff and schoolwork increased their connection to school. School began to matter to them. A pro-active attitude to achieve was a driver for this change. Turning allowed participants to gain clarity about what was required to reengage with learning.

Another defining moment occurred when some participants awakened to the seriousness of the situation and wanted to protect their parents from the threat of prosecution:

But I had to come [else] my mum's going to get a criminal record for something that's not her fault. It's just like, I feel bad for getting my mum in 
trouble when she's done nothing wrong and she's actually been trying to get me to come to school and it was just me being stupid. (Bob)

'Cos yeah if you do it [wag] too much you can get taken off your parents and that so yeah, that's, that's just the stupid thing about it. And I wouldn't want that to happen, nah, no one would. (Michael)

I guess if you don't want to get taken off your parents; you might want to start going to class. (Courtney)

The involvement of the police heightened both parental disapproval of wagging and these participants recognition that their actions (wagging) could also damage others, particularly family. These three participants blamed themselves and felt obliged to make the transition to recommencing school attendance. They valued family; they did not want their parents blamed for something they did, and they could not bear separation from them. Gase et al. (2016) found that the threat of parent incarceration resulted in students changing their behaviour because they were afraid. Although not fearful, participants in this study experienced a defining moment when they acknowledged that they did not want to be removed from parents. Although we cannot predict the longterm outcomes for these younger participants, it is evident that they compromised in this defining moment and stopped wagging when significant adults nudged them back to attending school again. Loyal family relationships and empathy for parents motivated these participants to turn from wagging. These features of turning enabled participants to change their wagging behaviours.

An opportunity for a fresh new start is the final significant factor that influenced turning for other participants:

I just didn't feel like I learned anything there ... I just wanted to be top man over there. Then I got shipped over here [activity centre].I got more attention, like help. Now I do all the work. (TM)

Like, here is better for me. Yeah, it's better than the last school. I just like having one on one times, not on my own, getting help to figure it out. Here is easier. (Decity)

I just needed help with my work; like here, in this school [activity centre], the teachers ask me how I have been, they help me and they ask me what I need. They talk to me. (James) 
It's changed now; I'd rather be here than there. Sometimes they show me how to answer. Then I can go through the whole thing; check if they're all goods or not. (Michael)

Classroom experiences changed significantly for the four participants when they transferred from a mainstream school to an activity centre. These comments capture the sense of struggle these participants had in mainstream school. In contrast, in the setting of the activity centre, their needs were being met and they responded by making the effort to attend school. Activity centre participants also seem to be appreciative of relationships with teachers. These four students were visible to teachers; they received academic support from teachers and teachers shared knowledge with them through clear lines of communication. Their relationship with both learning and teachers changed. Teacher academic support enabled them to engage in learning, work independently, complete tasks and achieve. The defining moment of the fresh start improved activity centre students' connections with staff and schoolwork and, along with the academic support provided during this time, contributed to their turning from truancy to attending school regularly. The experience of these four participants highlighted the powerful role that a setting, such as an activity centre, provided to break the cycle of wagging (which was in part their response to coping with mainstream schools not recognising their struggle and their learning needs) and refocus on learning.

Findings from the New Zealand research of Sanders, Munford and Boden (2018) provide insights regarding the impact of positive adult interactions with youth and the resulting development of hope and their journeys toward better futures. Five hundred and ninety three, 12-17 year old vulnerable youth were interviewed as part of a longitudinal mixed methods study to investigate how they made sense of their experiences, gained control and the support and resources that they used to make these transitions. Time proved to be an important factor in the accounts of youth experiences with social workers, who made a difference in these young people's lives. These significant adults invested time to establish caring, respectful relationships, build trust, 
and listen and understand about how past experiences impacted youth behaviours and youth abilities and strengths. They also took time to provide the emotional and practical support necessary for youth to face the challenges in their environments. Social workers supported youth to develop belonging, make their needs known and keep themselves safe. These trustworthy adults supported youth to "enact agency and to take control of their circumstances" (p. 629). This meant that youth experienced agency; with the help of social workers, youth were able to reflect, make sense of their circumstances, take control and open up positive ways forward.

These findings (Sanders et al, 2018) have ramifications for my study as these researchers claim that positive relationships with significant adults provide opportunities for vulnerable youth to trust, take part in decision-making, have influence in their environment, address challenges they face and find positive future pathways. During the defining moments of awakening and turning experiences of vulnerable youth in my study, participants who transferred to the activity centre claimed that positive relationships with adults provided the safe space to address learning challenges they faced in mainstream, and find a different, successful pathway to learning in this new school. In this fresh start, these participants experienced an opportunity to turn from their wagging behaviours back to attending class regularly and achieving academically.

When considering the nature of defining moments, it is interesting to note the contrasts between adult actions. Firstly, when adults caught participants in illegal activities, adults were in control; participants were limited in choice and forced to change. Secondly, when participants wanted to protect their parents from the threat of prosecution and adults nudged them back to school, the youth felt bad and obliged to transition back to re-attending school. Finally, participants who transferred to an activity centre took advantage of the new start, seized the opportunity to change and awakened to a new connection to school. During this process, when both awakening and turning occurred, participants were able to think about their behaviours, re-evaluate, and gain 
clarity about what was required to change. Awakening then was only possible when participants thought about consequences, wanted the outcomes, were willing to change, and possessed the motivation to respond to the clear boundaries that adults implemented.

Relationships also played an important role in young people's turning, in particular their interactions with adults in this process. It took timely adult interventions and intentional adult support and guidance to achieve the awakening and turning of young people. However, when participants' actions were determined by their parents' actions and they were forced to change their behaviours, these young people experienced bounded agency. Conversely, when a few participants seized an opportunity for a new start, and adults provided academic support and guidance for change in participant positioning, these positive relationships facilitated change. In contrast to the previously mentioned vulnerable youth, the nature of change that occurred during turning was a different experience due to the nature of the adult's actions.

In the activity centre, positive adult relationships facilitated a change in participants' desire to attend, a change in their ability to learn, a change in their ability to be present and share ideas with others, and their preference to enjoy a smaller space to learn and achieve. Because of these positive interactions with the significant adults in this activity centre, these four participants had more choice and experienced a less bounded sense of agency.

\subsubsection{Exiting}

"Exiting" is the term used to explain circumstances when participants lacked sufficient adult support to build positive relationships, when they did not accept school rules and when they were unable to change attitudes and behaviours towards attendance. Consequently, they were involved in leaving school. Although most of these 
participants changed schools, continued to wag, wanted to give up, or were facing potential expulsion, they were following the pathway of leaving school.

A few particular girls still struggled to attend even though they understood that there was a need for change:

I just keep ignoring pieces of paper to say I have to go see my Dean but she found me and said I was not allowed to wag. You have like ten detentions. I already had ten and I hadn't been attending them either so I had twenty detentions that I had to finish. I think I had the record for the most lates in a year. (Amy)

I gap it, but like I need I need to do better, like actually try. (Decity)

Then I just screamed at her, I screamed that I am not going to get a punishment for returning back to class. She called my mum and I was stood down again. When I came back to school they tried putting me on a clean slate but I still wagged and then left that school. (Amy)

These two girls understood the challenges they faced with attending school. Ignoring the problem did not make it go away for Amy, whereas Decity understood that an effort was required for her to change. Although adults paid attention to Amy, she did not report these interactions as supportive. A defining moment - a teacher's response to Amy returning to class - was challenging. Amy was unable to navigate re-entry to class, trust her teacher, and seize the offer for a clean slate and return to attending school regularly. Inability to open up, to be ready and willing to participate and accept help, indicated that there may have been an association between personal troubles and wagging. Particular assistance from adults to address the underlying causes of wagging was required for these girls to change.

A case study by O'Donovan, Beman and Wierenga (2015) introduces a conceptual framework, "enabling spaces" (p. 645), to explore respectful relationships for those youth at risk of leaving school early. These inclusive learning opportunities, based on the principles of connection, control, and meaning, provide youth facing exclusion with opportunities for inclusion by focusing on building respectful relationships. Connection was achieved through establishing positive relationships and building a "hands on learning" (p. 648) experience in which students participated in 
purposeful practical tasks that related to their lives. During this time, perceptions of marginalised youth changed, and their sense of belonging developed which contributed to their increased connectedness to people and place. Previously, students were disconnected from learning; they were passive onlookers in class due to irrelevant content for learning and/or prior absence that made it hard for students to catch up. A shift in self-perfection from being a failing marginalised person to someone who had something valuable to offer their community improved students' sense of self-worth. Hands on learning education redefined youths' school experiences. They were safe in a place with people who nurtured relationships, consequently they achieved and gained respect for self and others and were able to choose to either continue with school or pursue an apprenticeship. Building respectful relationships and belonging are protective factors against marginalised student's exclusion from school. Amy and Decity needed connection to people, place, and meaningful contexts of learning in order to belong, engage, achieve and stay attending school.

Despite a fresh start in other schools, two participants did not sustain turning:

I think today I'm gonna get stood down. That was for going over to the high school when I am not. allowed. I didn't like it when I heard that my mate done it with my woman. I started nutting out. I like, I just got angry, started swearing. I took off over there. I didn't care. But now, I'm gonna get stood down. (TM)

I didn't want to be a failure. I am tired of people making me feel horrible. Every day is shit; every day is too much. I just want to get away from everyone, everything at school. I was thinking that could get me away from all the stupid drama and stuff and that's why I dropped out to do a trip and do work. (Rose)

These two participants reported alienation and distress due to hostile environments and loss of trust in people. They also understood why they might be exiting and were able to rationalise their actions, which were shaped by strong emotions. Even though TM understood that what he did was wrong, when hearing about the betrayal from ones he cared about, he did not think about the consequences of his actions. Rose was dissatisfied, worn down and estranged from both people and place. Although the conflict she felt between her perceived lack of teacher care and of her 
unwanted failure contributed to Rose's inability to continue to be in a situation she found unbearable, she took initiative. School was not a good experience for her, so she was proactive in making the decision at the age of 17 to move on with her aspirations to gain work and travel. Due to TM's missed opportunity to act and change, his continuation with education was tenuous and, similar to the other participants who exited; there was no mention of adult support previously identified as necessary for participants to change.

A study by Bersani and Chappie (2007) involving a longitudinal survey of youth and their mothers over three time points (1994, 1998, and 2000), provides insight regarding how particular events in participants' lives may contribute to them exiting school. The aim of their research was to ascertain the factual nature of how school failure operated as an adolescent turning point. They suggested that dropping out of school may be perceived as an adolescent "pivotal turning point" (p. 385) because of its strong relationship with later adult outcomes, such as diminished employment opportunities, an increased crime trajectory, and reduced life opportunities. In other words, dropping out risks what Bersani and Chappie (2007) refer to as "accumulative disadvantage" (p. 385). Lack of detection of negative turning points involving anger and dissatisfaction have not provided an opportunity for early intervention and staff and family missed an opportunity to minimise the potential pathway leading to later disadvantage for TM and Rose. Disrespecting school rules and returning to a previously attended school, and estrangement from both people and place placed these participants at-risk of exclusion and in a position of permanently exiting.

However, another participant considered that his poor well-being required quiet, stillness, and space from others:

They didn't want me to get involved with them in class. They know I hate that type of stuff, when people show off. That's when I want to be alone and take time out. So I find a place to sit alone in the park when others have gone back to class. (Tyrone). 
Due to this self-perception of being unpopular with peers, Tyrone preferred solitude. However, he made the choice to cope with his state of mind and sense of wellbeing. His intentional self-removal from class was a pro-active strategy for being safe, managing reported annoyance, and experiencing peace of mind. Tyrone exited this school. His father later reported that his parents had re-enrolled him in another school in another city.

Stories from the "margins" about youth negotiating difficulties highlight the doubt and uncertainty students feel (Pless, 2014). These turbulent times in school are associated with academic difficulties, bullying, social rejection, fewer opportunities regarding post-compulsory education, and experiences of dropout. According to Pless, current educational policy and pathways to the workforce position such youth as failures, who feel disappointment and vulnerability due to the inferior positioning they experience. Students were unable to achieve regular pathways from school to employment. In the present study, participants also told stories about their experiences of being in the margins of the New Zealand education system. They also experienced drop out. A turbulent time for Tyrone was associated with social rejection. Heightened sensitivity, desire for solitude, and avoidance of insincerity, were drivers for him to be alone in school and contributed to his exiting. For other participants, inability to trust teachers, accept help, alienation, estrangement from people and place, and breaking school rules were other contributing factors to exiting school.

\subsubsection{Awakening: Summary}

In this study, both adults and participants themselves contributed to the awakening of participants who were truanting; if truancy behaviour was to stop, both adults and the participants acted in the defining moments that contributed to the stage of awakening. In some circumstances, adults signalled disapproval and imposed consistent, appropriate, timely responses, which influenced participants to change their attitude and behaviours. Participants found this hard and an effort was required to change. In other 
instances, teachers provided academic support and guidance to re-engage in learning and for participants to make decisions to improve attendance. These activity centre participants were striving to change: they were on the pathway of changing their 'scripts'. In these circumstances, participants experienced a less bounded sense of agency. Conversely, those students who exited school had decided that school was not an environment they wanted to be in, nor was it meeting their needs. It is noteworthy that unlike the students who turned, students who exited did not report having supportive adults to provide control, guidance, and encouragement.

\subsection{Process theory of wagging: Stage 4 - Reincluding}

\subsubsection{Introduction to Reincluding}

"Reincluding" refers to the circumstances and support necessary for participants to make a positive change after their awakening and to transition back to attending school regularly again. Reincluding contains two components; "accommodating" and "willing" which indicate successful transitioning of students into regular school attendance and developing a sense of belonging in class. Reincluding is an existing concept in the language of returning long-term absentee students to mainstream education (Thomas, 2015). Thomas suggested the possibility of coining the term "reinclusion" (p. 191) for two reasons. Firstly, reincluding reflects schools' willingness to accommodate students, which he maintains is foundational to success. Secondly, reincluding suggests disadvantaged students no longer suffer exclusion from education. As noted earlier, participants in the present study perceived teachers as contributing to their failure to achieve and consequent exclusion at school (see Section 4.4.4). However, whilst in the reincluding stage, participants received social and academic support, care, and respect and were motivated to change, attend school again, and experience a successful outcome. Reincluding highlighted participants' responses to 
inclusion from teachers and peers; when reincluded in class, participants experienced contentment, visibility, academic success, and belonging to a place.

\subsubsection{Accommodating}

The term "accommodating" is used to describe the nature of teacher and peer interactions and the social structures that supported participants to stop wagging. Participants recognised that the support from teachers was different from peer support. In their new schools, teachers provided meaningful content and contexts for learning, and dedicated more time to attend to their needs. Participants found teachers were taking time to notice, know and listen to them, time to address their academic and personal needs, and time to scrutinise their attendance. In their new schools, time spent developing relationships with peers and building trust meant that participants felt sufficiently comfortable to talk about difficulties they were experiencing with learning, and they received the necessary support to understand what to do and consequently succeed in learning. Following awakening and turning, the nature of social structures required for participants to further change were a sense of connectedness to learning and enhanced enjoyment of school:

I absolutely love [School B]. I never, ever could imagine a better school for me ... I can't pinpoint exactly what it is about School B but just everything, I love everything about this school.... I looked forward to class every single day and yeah, it was completely, completely different, and just so happy there, you know. I just absolutely, absolutely love it; I can't imagine a better school for me. (Julie)

[Now I am] just succeeding in different things. Like achieving, achieving my work, finishing off my maths that I never even used to fucken' look at, we just used to look at it and draw a big black power fist on them. Now I'm writing numbers. (TM)

Here I get like all the attention 'cause there's not that much kids, like being in a small environment is better for me and like yeah it's better than the last school. (Decity)

They help you with your work, they make sure you get what you need and they also pay attention to you and it's not that easy to wag here. (James)

A variety of outcomes occurred for participants. One girl and one boy (Courtney and Bob) awoke, turned and returned to their same school. Different 
approaches taken by different teachers, contributed to participants' improved, regular attendance. Although four girls (Christina, Amy, Rose, and Julie) awoke, turned and transferred to another school, two exited, one began wagging occasionally, whilst one sustained attendance in the long-term. Four students (Decity, TM, James, and Michael) transferred to an activity centre. Although they all awoke and turned, one exited on her 16th birthday, one was waiting to attend a potential expulsion meeting with the Board of Trustees, and two were attending regularly and achieving. Contact was lost with one girl (Becky) and two boys (John and Tyrone) between interviews, although in the case of Tyrone, information provided by his father indicated that he was now attending school regularly in another city. For many participants who attended a new school, they found that difficulties disappeared, and that everything about this school was different. Consequently, they adapted and prospered. Previous time spent in class had been solitary and unproductive.

Attendance at a new activity centre or an inclusive secondary school with intimate classroom environments, supported participants to connect with learning, experience improved attendance, and make progress in learning. These participants found that their experiences changed as they received academic support; they felt safe, stayed in class and were motivated to attend. Teachers' behaviour defined and maintained classroom roles and circumstances necessary for inclusive classrooms. According to these participants when teachers noticed them, cared, and set clear boundaries, wagging was no longer necessary.

Although providing a teacher perspective, Frelin's (2015) case study highlights the complexities of teachers developing and maintaining relationships with secondary students who have experienced failure. The aim of Frenlin's research was to identify factors contributing to social and academic success by interviewing a teacher with a reputation for successfully turning round students who experience failure. This teacher took time and engaged in deliberate relational practices to ensure success for these 
students. She initially welcomed students into the school, which included making the second chance opportunity explicit, explaining career options in discussion with a guidance counsellor, and holding in-depth confidential, individual interviews with other teachers present. In addition, discussion with the students obtained information about their short and long-term goals, peer conflict, and sensitive life issues. The teacher in Frenlin's study purposefully listened, joked and laughed at herself, indicating to students that she rated what they said as important. She developed closeness in order to observe when students lacked motivation to work so she could resolve the situation. She intentionally set out to improve students' negative self-image and repair the damage caused by past teachers by creating a different school atmosphere. She encouraged students to participate in joyful, immediate learning, read and discussed books, and applied what they learnt to practice. School was a smaller, safe, fair place. She was committed to improving the educational experiences of each student.

The finding of Frenlin's case study indicate that teacher intentionality is a core ingredient contributing to failing students' social and academic success. In this study, participants are motivated to attend when teachers purposefully took time to be present, notice students, create a relaxing context, build trust and show respect and care. These deliberate relational practices restored participants' "mana" (personal power) and opened a space for them to be safe and present in class and matter to others. Transition back to class was possible because teachers behaved respectfully to students. Teachers accommodated to the needs of the students, evident when their intention to include students in person was explicit; they met participants' academic needs, and encouraged positive peer relations. When these conditions were present, participants began to experience success and learning became positive and transformative. Accommodating provided motivation for students to be psychologically present and participate in learning. Teachers' accommodation to the previously excluded participants' needs 
facilitated reincluding: teachers played an important role as mentors by modelling positive interactions and establishing positive classroom climates.

Sometimes other adults within the school had a role to play in accommodating participants' needs. In the present study, counsellors provided a positive experience and a safe place for participants to talk:

It helps to know there is someone there. A counsellor is kind to me; respectful and listens. People try to offer help and it's up to them whether they take it, or whether they don't. (Christina)

I started seeing a counsellor and it's starting to help: I'm more open. (Tyrone)

It's kind of like you know there is always going to be someone at the Counsellor's Office when others might not have time for you. (Christina)

The participants understood that receiving assistance was their choice. Someone being there was reassuring. Participants needed to know that people were available and accessible to them. They recognised that teachers were not always available to help them with problems, consequently specialist help from counsellors was necessary to meet their emotional needs. One-on-one time with counsellors provided a positive experience and supported participants to see things differently. Participants recognised from meetings that they mattered and that their opinions were important when counsellors listened to them. Assistance, in the form of kindness and attentiveness, built trust, encouraged openness and reassurance, and provided participants the continued support necessary for change.

What is clear from both the literature and the present study is that adults provide a way forward when truanting students experience collaborative approaches that are free from judgment and blame. In these instances, trust builds between adults and students. Participants in this present study valued others listening, offering expert advice, and respecting them. Participants clearly preferred adults' encouragement, and attention to their needs rather than an approach based on strict or harsh discipline. Accommodating in this context provides an opportunity for teachers to think about changes they can make in relational practices; moving from a punitive to an inclusive ideology. In those 
instances of reinclusion teachers indicated explicitly that participants mattered and attending class became the preferred activity. It was also very clear that participants understood what was needed to stop them wagging:

Knowing more about what was going on in student's lives would help and I think teachers and staff need to discuss giving a helping hand. (Christina)

I think people should have treated me better, I just think that people have no respect for one another, I think sometimes people forget. (Rose)

Maybe they need to try and find a friend in that class or try to fit in. (Christina)

People have no respect for one another. I think what would help is just having someone to stick up for them whether it's a friend or whether it's a teacher that won't take it. Just someone that has your back is what everyone needs. (Rose)

In class, these girls were vulnerable and sensitive to others' attitudes and recognised that classmates disrespected one another. They also recognised the importance of supportive friends in class. If friends were not in class, participants found alternative ways to fit in, which required a conscious effort. Participants understood that they needed acceptance, better treatment, and protection.

Reid and McCallum (2014) examined the aspirations of disengaged, underachieving secondary students living in poverty. The study aimed to explore participants' perspectives of their community and these influences on future aspirations. By participating in focus group and individual interviews, taking photographs, and mapping their past, present and future journey, students were supported to view place as a lens to make sense of themselves, their community, the social structures that shaped their world, and how their world fitted into this community. Teachers with strong trustrelationships played an important role in influencing students' capacity to aspire, and to connect to significant people and places in their community. The rigorous, relevant, meaningful learning that connected to students' life worlds, built the cultural capital necessary for future aspirational attainment. In relation to the present study, it was clear that participants needed opportunities to connect to people and the classroom context in meaningful ways. They needed to be accepted and experience strong trust-relationships with teachers. 
In summary, accommodating functioned to support participants to share, provided the circumstances to encourage participants to be the best they could be, and alleviated their vulnerability in the classroom so that they participated and developed future aspirations. When these aspects were fulfilled, participants experienced reincluding. The features of accommodating were: Dedication of teacher time to participants, strong trust-relationships between teachers and participants and between peers and participants, emotional support from counsellors, and safe inclusive classrooms with well-established routines. Under these conditions participants were respected, felt secure, experienced social and academic support, and belonged as valued class members.

\subsubsection{Willing}

The term "willing" is used to describe student readiness, desire and determination to overcome previous challenges, and the underlying factors that provided the impetus to make the necessary changes to stop wagging. When participants had a reason to change and understood what they needed to do to make it happen, "willing" occurred:

The future ahead of me has changed my life [going to school] just seeing all those people succeeding and getting great careers and stuff. [I realised that] if I don't change then I won't get anywhere in the future. (James)

If you don't get a good education you're either going to wind up on the street, prison or no job. I don't want to live on the street, live off a low wage or something. I want a good life. If I have a family in the future; I want a good life for them too. (Tyrone)

[It's worth getting an education] so you can get a job and some money and a house, a car and a wife. (Michael)

Thinking about their future influenced participants to consider change. Noticing people succeeding, the importance of career opportunities, the desire for material possessions, and the reality of understanding the challenges of a life without education, influenced participants' future aspirations. They recognised life without a good education as full of hardships and crime, and wanted more out of life for themselves and future families. Witnessing others' achievements and their desire for a good life, 
material possessions, and personal hope for the future were aspects of willing needed for change.

Findings from a reintegration programme evaluated by Tootill and Spalding (2000) provide insight. This special school programme was designed to prepare, support and integrate 26 students with emotional and behavioural difficulties into full-time mainstream education, and offered a "clean slate" (p. 113) opportunity. Although students broke away from negative feelings and experiences, they faced challenges when adapting to their new school. It was hard for these students to attend school on time with their completed homework and with the appropriate equipment to participate in learning. Lack of independence and organisational skills made students conspicuous; they annoyed new teachers. Despite this, 21 of the students experienced successful reintegration. There were specific key factors that contributed to this change. These were the establishment of effective communication and links between schools, a coconstructed action plan, and trial and part-time placement in the new school. These students experienced welcoming teachers and peers, effective classroom management, and support supplied by the accompanying re-integration teacher. The trial placement provided transition time for the students to develop understanding of expectations and routines as well as new curriculum learning opportunities, as some subjects were not available in special schools. Although participants in the present study did not experience trial part-time placement or receive support from an accompanying previous teacher, they still received the necessary help in class to complete tasks; the positive atmosphere encouraged them to attend.

In the present study, hope and/or a sense of agency was a necessary factor for participants to be willing to change so that they experienced reincluding:

They need to think that everything's going to be ok, even if they don't, they need to think that. (Christina)

Just myself realising that I needed to start changing. (James) 
But I got there and I said to all my teachers, right so I want to be an art teacher, to do that I want to pass Level 1, 2 and 3 with merit endorsement at least, preferably with excellence and I want to get excellence in all my folios. (Julie)

When some participants knew what they wanted to do and understood how to get there, these participants developed a sense of agency and they gained purpose. By imagining and positioning themselves in the future, some participants were able to envision future educational achievement, including the possibility of achieving excellence. Julie told teachers she wanted to achieve. Willing required hope and imagination, positive thinking, future direction, scaffolding, accepting teacher support, and peer acceptance. The thought of achieving was motivating. However, finding motivation to change, required participants to understand that it was in their best interests to take offered help. As noted earlier, the participants who reincluded all had adult support.

Research also suggests that there can be attitudinal change when the curriculum is meaningful and accessible; in such instances, students can reposition themselves, moving from perceptions of under-achievement to experiencing success. For example, a small case study (Stahl \& Dale, 2013) explored 14-16 year old boys' involvement in extra-curricular music at school. This music club, a place on the margins at school, was the centre of learning for these boys. Boys valued this meaningful learning experience, evident particularly in one boy's change in attitude and behaviour. He stopped persistent truancy for a day a week to attend. When outside class and choosing learning that interested them, these boys perceived they could develop their skill level. Their peers regarded these boys as successful. Previously disengaged boys in the classroom experienced the transformational potential of this meaningful context for learning, which changed their identities from failures in the classroom to successful learners outside class. The boys repositioned themselves from their place in the margins to accepting the social structures of school life. 
To reposition themselves after truanting class, participants in this study needed to experience purpose, meaningful context for learning, self-belief, and peer approval. These conditions influenced participants to develop the willingness to be open to change and experience reinclusion in class:

I should have been learning. Nah yeah I could have been learning ages ago, but yeah now I want to learn. (TM)

My Year 10 exams were like only a couple of weeks away so I stopped [wagging]. (Bob)

I don't wag class anymore. I tell a teacher where I'm going. I listen to what I've been told by the school. (James)

Although it was up to participants to change their attitude towards wagging cessation, school life was difficult to manage without assistance from teachers. The participants wanted to change. When participants were ready and eager to learn, understood the significance of missed opportunities, felt regret or made the decision to change, they co-operated with teachers and attended school again. By taking responsibility and acknowledging their part in wagging, students developed the desire to achieve and the willingness to make the required changes.

These findings are similar to another study that provided mainly an adult perspective (Thomas, 2015). The mixed methods research investigated how both teachers and students play active roles in student reintegration. Thomas analysed pupil tracking data and information from questionnaires, and conducted individual interviews with educational practitioners to investigate successful student reintegration. The aim of the study was to investigate the key influences in individual student situations regarding successful reintegration when students transitioned from "pupil referral units" (p. 188) to mainstream schools in Wales. Educators perceived that students had a large responsibility for achieving successful integration by exhibiting a positive attitude, showing desire to reintegrate, accepting school rules and the support offered by the school, and implementing strategies identified prior to the transition. However, they also claimed that teachers influenced student ability to reintegrate to mainstream after time 
away. Staff willingness to advocate, care and listen to students' perspectives, were factors perceived as crucial to successful reintegration.

Participants in the current study also needed staff to listen in order for them to sustain the changes they were willing to make. Teacher planning and support was crucial for successful reinclusion and for participants to stop wagging, communicate and listen to teachers. Mutual respect, teacher advocacy, care and reciprocal listening were indicators of reincluding occurring in the classroom:

I had teachers actually say like I'm looking forward to seeing this when it's finished and that they just really care and they get so involved and excited and just keep pushing you. ... I wanted to make them proud. (Julie)

Things are better. I get help now. She [the teacher] comes to me and checks out my work. She asks me what I need help with and shows me what to do. We work it out together. (Michael)

These participants saw teachers in their new schools as supportive and were impressed by the teachers' attitudes and willingness to collaborate with them. Direct, articulate communication between teachers and participants contributed to participants' ability to change. Having a vision and communicating that vision to teachers clearly contributed to participants' willingness to change.

Research by Freire et al. (2009) involving students with high rates of truancy and failure, aimed to understand students' perspectives of being labelled as problematic and the consequent meaning they made of those experiences. When these students focused on images of themselves and their future, it permitted them to give alternative meaning to their non-participation experiences within the school. Clarity regarding career pathways and the qualifications required, provided students with an opportunity to find the motivation to envision success and engage teachers to support them to change their self-perception from a failure to a potential achiever.

The participants in the present study understood what they were doing when they truanted but did not always know how to change. Adult guidance was required to change participants' positioning from failures to achievers. Willingness was evident 
when participants identified future aspirations, communicated their vision and enlisted teacher support. This willingness was a crucial step in the reinclusion of participants in class. Willingness to change then served three functions for participants: to further develop hope, to create the necessary desire and determination to overcome previous challenges, and to find pathways forward that provided opportunities for them to envision success and attend class again.

\subsubsection{Reincluding: Summary}

Participants experienced reincluding when teachers dedicated time to them, facilitated the development of trusting relationships and established safe, inclusive learning environments. Under such conditions, participants also experienced change; they developed hope, overcame previous challenges, envisioned success, and attended class again. It was through the accommodating role of teachers and the subsequent willingness of participants to make changes, that students engaged in reinclusion to school and experienced the shift in identity from failure to achiever.

\subsection{Chapter summary}

In this chapter, I presented the findings of this research relating to students' perspectives regarding the nature of wagging and the proposal of a process theory of wagging comprising four stages: wagging-in-class, leaving, awakening, and reincluding. Wagging began in class when participants detached (switched off) from teachers, peers and learning. Over time, participants increasingly acted on their feelings and left class to manage perceived isolation in the class, to conceal their work on content or tasks that were either difficult or insufficiently challenging, or to conceal life circumstances that were challenging.

Outside of class, most participants connected with others who wagged, received support, care and friendship, which (at least temporarily) permitted them to be who they wanted to be, gain status, and matter to others. However, some participants wagged 
class to be on their own, to find space where they could think and feel free from the negativity that they felt surrounded them at school or at home.

Eventually most experienced an awakening due to early, effective adult interventions, causing them to reconsider what they were doing. Participants developed strong consciences, took responsibility, turned, and embraced the opportunity to change. However, specific circumstances and support were required to implement these changes. To stop wagging, participants needed positive teacher and peer interactions and changed social structures that were accommodating to their needs; otherwise, they exited class.

During the final stage of the process of change - reinclusion into school and learning - participants identified future aspirations, communicated their vision and enlisted or accepted teacher support. Such participants changed their school identity from failure to achiever through their willingness to change; they became engaged in learning as a consequence of teachers being accommodating and inclusive of them. 


\section{CHAPTER 5}

\section{CONCLUSION: CONTRIBUTION, METHODOLOGICAL REFLECTIONS, AND IMPLICATIONS}

\subsection{Introduction}

In the previous chapter, I presented a process theory of wagging using grounded theory to investigate youths' perceptions of truancy. Youth wagged to avoid reported personal trauma and challenging home and school-based circumstances. For these youth, wagging from school was purposeful and lacked effective punishment; it provided an opportunity to avoid criticism and blame from teachers for their actions, and it provided relief from the marginalisation and isolation that youth experienced in class.

In this chapter, I begin by acknowledging the contributions this theory makes to truancy scholarship. I then conduct a brief methodological critique of the study, identifying strengths, weaknesses, limitations, and implications, and finally make recommendations for future research and draw conclusions.

\subsection{Contribution to knowledge}

The current study emerged from an aspiration to make recommendations on the basis of greater understanding of the truancy experiences of youth. Grounded theory is well suited to describing and understanding behavioural processes that relate to people's experiences (Charmaz, 2009). This qualitative study provides an original process theory of wagging that identifies the four stages involved in wagging as: wagging-in-class; leaving; awakening; and reincluding. It makes an original contribution to understanding the nature of wagging as a process and what students and adults need to do to stop the process happening, or to shortcut that process. It also contributes knowledge about truancy in terms of the nature of wagging, causes of truancy, relationship pedagogy, repositioning of youth who truant, the experience of mattering, and the reinclusion of students into class after wagging. 


\subsubsection{Nature of wagging}

Student perceptions regarding the definition of wagging are relatively new in the longstanding definitional debate in truancy research. Participants in this study used the term wagging to explain a common event that occurred in particular situations at particular times, and involved intentional disregard of school rules and intentional absence from class. Youth explained wagging in new ways: as a habit; an activity in response to perceived disrespect in class; an attraction to be with friends; and a time to be alone. Students claimed that lack of detection contributed to wagging becoming established as a habit.

\subsubsection{Causes}

Historically, numerous reasons for truancy were categorised in terms of individual, home and school-based influences. This doctoral research delves deeper into these factors, illuminating particular individual situations, providing a deeper understanding of the dynamics present therefore informing the development of the process theory. The young people detailed experiences regarding the impact of family violence on the ability to concentrate in class, and the impact of personal trauma as precursors to their process of truanting. During this time, in these different contexts, their decisions to leave class were influenced by circumstances they found intolerable; when they lacked power and autonomy. When some participants in this study experienced bullying, their motivation was retaliation and revenge as well as a desire to protect their friends. These experiences provide insights into the reasons underlying truancy and how they contribute to the various pathways participants were influences to take. Wagging meant that students took time out from class without permission from teachers to overcome the attribution of blame, isolation, and the marginalisation that they felt at school. They also sensed a lack of power and autonomy in the classroom; consequently, by leaving class they achieved a sense of relief and gained control over a perceived threat to their wellbeing. 
Participants recognised that the classroom climate was at times prohibitive to regular attendance: feeling unwelcome; experiencing particular personal and home circumstances that are challenging; and the consequences of all of these, namely, experiencing anxiety and depression. As noted by the Ministry of Education (2017), students cannot achieve to their potential when they feel unsafe in class. Before they can learn, they need to feel they belong, be treated with respect, and trust that teachers will be sensitive to challenging circumstances in their lives that directly affect their capacity to sustain engagement at school. During this first stage of the process theory, participants' detachment from teachers, peers and learning highlight the challenges faced in the initial stage of the process. They reported that they needed emotional and social support as well as academic support from teachers. They also advised teachers to provide opportunities for them to work with friends, to share ideas, to obtain support for their learning, and to have learning conversations that support them to understand the set tasks. Participants also recommended that students who were silent in class, be noticed and receive attention. Participant recommendations highlight the significance of relationships in this process theory of wagging.

\subsubsection{Relationship pedagogy}

Although relationship pedagogy (Bishop, 2010; Bishop \& Berryman, 2006; Bishop et al., 2003) is a well-established field of research in education, this study provides significant insights into aspects related specifically to young people who truant. Previously, the quality of teacher-student relationships and the interactions between teachers, students and peers in classrooms were identified as causal factors of truancy. The findings of this study indicate that detachment was the main problem that youth faced in classrooms and contributed to their wagging in class. Youth responded to negative aspects occurring in their personal lives, in classrooms, and at home by detaching from teachers, peers, and learning, and then by leaving class. 
Participants signalled that teachers needed to focus on building positive relationships so that students knew they mattered to someone, and that people cared about their academic achievement. The literature indicates that positive teacher-student relationships are essential for sustained student engagement (e.g., Hunter, Brinkworth, \& Harris, 2013); and that positive relationships may be the single most important ingredient for promoting youth development and well-being (Pianta \& Allen, 2008). Relationships between teachers and students and their peers shape the social climate in schools (Allodi, 2010). To maintain care in the classroom the roles of both the teachers and students need consideration. Noddings (2012) provides insights, claiming that care ethics involve two dynamics: (1) that teachers listen, observe and be receptive to the students' needs, and respond positively to those identified needs without hurting others in their care; and (2) that students respond in a way that indicates the teacher's care is received. Noddings argues that without such a response there is no caring relationship. Furthermore, she states that caring for others in classrooms is intentional, out of inclination and love, and dependent on empathetic and sympathetic emotions for its motivation.

At the core of an ethic of care then is attention, which by its nature involves being receptive and requires teachers to put aside what they are doing, to be open, and to listen to what students are going through. Likewise, when teachers are kind, forgiving, and understanding of students' feelings, are not hostile towards them, and recognise their abilities and interests, they demonstrate that they are noticing students (Lumpkin, 2007). When teachers prioritise such caring, students become more actively interested and think about their learning; this is essential if learning is to be enjoyable, important, and provide opportunities for students to build confidence in their ability to do well (Lumpkin, 2007). As noted by Wentzel (1997), students pay more attention during class to teachers whom they perceive as caring. Similarly, Tarabini, Jocovkis, and Montes (2018) report that students acknowledge their teachers as playing an 
important role in their growing engagement at school. These researchers found that lack of teacher expectations and the lack of academic, social and emotional support (as reported by students) diminished the students' opportunities for educational success and achievement. Collectively, all of the above studies and the participant data in this research indicate that students who wag need to know that care and support are available and that this care and support can be trusted for responding sensitively and discretely to the hardships they are facing.

Teacher kindness was also a factor that some students identified as important for their relationship with teachers. Norwegian research (Krane, Ness, Holter-Sorensen, Karlsson, \& Binder, 2017) supports this finding. These researchers report that students identified recognition, helpfulness, care, and academic support as evidence of teacher kindness and claim that positive teacher-student relationships promote student wellbeing and attendance. An associated finding was that participants felt the need to connect with teachers, to be confident that they (the students) were visible, and to trust teachers to help them. However, trust extended beyond the actions of teachers to also include the forming of supportive relationships with peers to enhance both collaboration and learning.

Of relevance is a study of Māori students in New Zealand (Berryman, Eley, \& Copeland, 2017), which provides further clarification of the importance of interactions in classrooms. They suggest that a foundational element of respectful interactions is the teacher's knowledge of who students are, their whānau and cultural background, and the particular knowledge that this background provides them. The encouragement of students to develop their abilities requires this understanding so that new conversations can take place that support the students to look ahead and make relevant future decisions. Teacher-student rapport, then, opens spaces in classrooms for learning conversations that benefit students who are at risk of leaving or who, having taken the 
path to truancy, are in need of trust and support to equip them with the skills and confidence to reintegrate into school.

"Noticing" is another important concept in relationship pedagogy. It is not a new construct in teaching and learning, as evidenced from research in both science and mathematics education (Barnhart \& van Es, 2015; Sherin, Jacobs, \& Phillipp, 2011). Ball (2011) claims that noticing is part of life and human sense making and that in noticing, teachers observe and come to understand students' ideas. Youth indicated that they wanted to matter to their teachers, to be visible to them, and to be acknowledged and welcomed in class even if they had previously wagged. These findings highlight that youth advocated for a more caring approach from teachers; they required opportunities to build trust, disclose what was happening in their lives, and receive sufficient support to feel safe to return to class and take responsibility for their wagging.

\subsubsection{Repositioning}

Truancy research indicates that students who truant understand their marginal positioning at school (Bottrell, 2007), the delegation of responsibility to them for their behaviours (Aaltonen, 2012; Friere et al., 2009; Pless, 2014), and the labelling as "outcasts" they receive as a result of being stereotyped (Strand, 2015). However, the present research identifies new knowledge relating to how participants repositioned themselves when they wagged class. This discussion of repositioning highlights three ideas: the places youth inhabited; the nature of their interactions with peers; and the characteristics of the group they established outside class.

The theory suggests that two forms of positioning occurred when youth wagged classes. During this time, participants occupied both private and public places. A minority of participants preferred to be alone; solitude provided these youth with an opportunity to use personal space to take time to think, adjust, and manage negative emotions related to anxiety and/or depression. Other youth looked for, and found, a social group. Participants who found a social group perceived that this community 
functioned cohesively through positive inter-relationships. Within these groups, they reported that justice, loyalty, mutual respect, and support functioned. Consequently, they repositioned themselves to overcome their previous status as failures and outsiders and became successful members of a group representative of a family of loyal friends. When they wagged, participants recalled that interactions were mostly positive, welcoming, friendly, protective, and inclusive. In these instances, participants reported that they experienced acceptance, care, support, unguarded conversations, and improved status. They had fun in the group, were visible, mattered, and belonged to this close group in a created safe place. However, there were occasions when interactions were not positive; for example, an incident was reported which involved a few participants moving as a group to implement social justice that was perceived as absent in classrooms and took revenge for prior bullying.

\subsubsection{Mattering and its implications}

In relation to the present research, the notion of mattering emerged as a new concept in truancy research. The social groups established outside the classroom when students wagged provide insights regarding what might be required for these participants to belong in class. The concept of "mattering" suggests possible teacher actions that might diminish incidents of future wagging. Youth acknowledged that their interactions with others in their social group supported them to be present, emotionally available, important, and matter to one another. They bonded with peers and being present in their chosen inclusive places was a preferred, pleasant alternative to attending class. Here, they reported trusting others, consequently alleviating insecurity and mistrust and experiencing diminished alienation. These loyal friends met needs that were previously unfulfilled in classrooms, even though sometimes the students' behaviours crossed social or legal boundaries (e.g., shoplifting and smoking marijuana). This new knowledge identifies components for outsider students to be positioned positively in classrooms and matter to others. The interviews with young people in the urrent study 
provide guidance on how teachers might support them to be present, participate and stay in class. These include creating safe learning environments, facilitating positive teacher and peer relationships and addressing bullying in class. Students wanted to be safe, treated fairly, accepted, bond with others they could trust, and belong. Participants needed teacher support to stay in class. It appears that teacher observational skills and behaviours make a difference. Participants wanted to feel welcome in class; they wanted teachers to see them, to be respectful and kind, and to talk to them. Participants wanted teachers to know and understand them as individuals; to understand the challenges they faced. When they were struggling, they wanted teachers to provide the necessary academic support to succeed and to refer them to adults who provide the emotional support they need. They wanted to be motivated to learn. Participants wanted teachers to design meaningful, stimulating learning that was relevant to their lives. They wanted their learning to matter. They wanted to matter to their teachers and their peers.

\subsubsection{Reintegrating into schooling after wagging}

The study reveals how students required timely interventions to gain insights into their mistakes, to put things right, and to receive adult support and acceptance from peers. The findings extend truancy scholarship with regard to the circumstances occurring in New Zealand mainstream schools that supported participants to reintegrate in class after wagging.

Some participants claimed that they were not receiving the support they needed to encourage them to return to the classroom. They understood that wagging meant that they missed learning and that this added to the struggle they had to understand work when they returned to class. However, the anticipation of being blamed for their absence when they returned to class was a large obstacle to overcome on their own. Given the participant data and the findings of Tarabini et al. (2017) that teachers' negative attitudes towards students greatly influence their bad performance, it is clear that teachers' positive attitudes and support are important for welcoming students back 
to class and helping them build success and satisfaction in their learning. However, to ensure this transition is possible, youth who wag also require an attitude of "willingness to change". The participant data suggest that the support of a significant adult, not necessarily a teacher, is important for helping students develop a positive and determined attitude to engage with school. These additional findings offer insights into effective approaches to manage and promote school attendance in New Zealand schools.

\subsection{Methodological reflections}

This research was designed and implemented to examine the social world of truancy in four New Zealand schools from a student perspective. The intention was also to build an original process theory by examining the similar and different experiences of students in order to identify the main issues they faced and their responses to these. The accounting scheme developed by Glaser and Strauss (1967) is implicit in many of the procedures developed in the current research relating to establishing the trustworthiness of the findings (credibility, confirmability, dependability and transferability). As explained in Chapter 3 (Section 3.9), during the research process I used conventional grounded theory methods of data collection - constant comparison and theoretical sampling - that led to an iterative process in line with the work of Glaser and Strauss (1967). Critical to the iterative process used here has been the practice of providing rich or thick descriptions of contexts, procedures, and decision-making (Glaser, 2002; Stern, 2007). I argue, therefore, that the design and conduct of the research satisfies all four criteria of trustworthiness - credibility, confirmability, dependability and transferability.

In relation to credibility, the research has employed techniques of triangulation (e.g., relating literature to participant data), peer debriefing (e.g., challenges provided my supervisors), member checking (e.g., participants confirming their interviews), and negative case analysis (e.g., giving full recognition to the data of students who did not return to school). In relation to confirmability and dependability, the provision of thick

description also supports the potential for other researchers to replicate aspects of the 
present study in relation to contextual elements that are similar between the current and their contexts. The thick description also allows readers the opportunity to conduct an audit trail analysis of the research process and answer the question: has the researcher followed well established practices in conducting qualitative and grounded theory research?

The question of transferability of findings is one that can only be answered by readers who have the opportunity to examine the applicability of the research to their own contexts or to contexts that they have experienced in their lives. However, it is important in this respect to understand the distinction between theories that are "substantive" in nature and those that attain the status of "formal" (more comprehensive) explanations of events, actions or behaviours. As noted by Glaser and Strauss (1997) substantive theories represent the results of research of a limited nature, for example, research conducted on a small group and/or in a narrowly defined context. Such theories are transferable but not generalisable. In contrast formal theories are derived from the build-up of understanding from the integration (cross analysis) of a wide range of research studies such that greater applicability can be assigned to the resultant theory; this does not imply that a formal theory is full generalisability (such as a law) but its contextual basis and theoretical explanation of the underlying process is deepened and widened. Glaser and Strauss (1967) maintain that even with formal theories there is a need to maintain connections between the constant comparative method of analysis and theory generation and these connections need to be explicit.

The process theory of wagging as derived here - youth who wag class or school in New Zealand - is grounded in research in one particular area, specific to a particular group or situation; it therefore fits with the notion of substantive rather than formal theory (Glaser 1978, 2005; Glaser \& Strauss, 1967; Patton, 2002; Strauss \& Corbin, 1998). However, as Glaser and Strauss (1967) propose, the substantive theory derived here is a strategic link to the later generation of a formal theory. The substantive theory 
here is original, but it only represents the beginning of research that might over time build a more formal theorisation of truancy behaviour across a wider range of educational contexts.

\subsubsection{Summary of strengths}

The research presents an original process theory that identifies and explains a process of wagging in four New Zealand secondary schools. This process theory is grounded in student data with clearly explained contextual boundaries. The rigorous methodology of constant comparison and theoretical sensitivity has ensured conceptual density, integration, and clarity (Glaser \& Strauss, 1967). As previously argued this theory adds to truancy scholarship.

\subsubsection{Limitations}

In Section 3.11 limitations of this research were discussed. While I have no intention of repeating these earlier reflections, there is one aspect of the process theory that I now wish to acknowledge. I recognise that the process theory of wagging does not focus systematically on specific cultural aspects of the lives of participants who wagged classes. Research related to the use of culturally responsive pedagogies in classrooms show that teachers' commitment to social justice significantly sharpens their capacity for addressing oppression and racist attitudes (Villegas, 2007). As already noted, the purpose of an inductive process, grounded in student data, is not to focus on individual student experiences but rather to build a process theory that examines the similar and different experiences of students in order to identify the main issues they face and their responses to these. Cultural influences are an important element of the similarities and differences that students experience. We also know that students' cultural background (class and ethnicity in particular) contribute to differential outcomes in education. I acknowledge that questions designed to ask participants about the cultural aspects of their lives did not emerge during the concurrent data collection and analysis process. While this is clearly a limitation of the design, there is scope for including cultural 
considerations in further research. To address this limitation, I recommend spending time clarifying the meaning of culture in relation to youth who truant, identifying data relating to this, and I would take time to gather more in depth background information for each participant.

\subsection{Implications of the findings for policy and practice}

School leaders, counsellors, and teachers play an important role in understanding the magnitude of the truancy problem in their schools and further developing inclusive approaches that promote student well-being and achievement. The participant data relating to the fourth stage of the process theory of wagging identifies administrative and teaching practices that have been effective in the lives of the students who became re-included in school and learning. In the case of students in activity centres, the reinclusion of students was perhaps assisted by a lower student-teacher ratio, enabling stronger teacher-student bonds to be formed. However, the data relating to the first and second stages of the process theory of wagging (wagging-in-class and leaving) indicate that there are circumstances that contribute to participants disengaging from teachers, peers and learning, leading to students leaving class without permission. The evidence here concurs with the views of the Children's Commissioner (2018a) who argues that the unique needs of marginalised students are not being satisfactorily met in New Zealand schools. While the data in this research cannot be generalised to the wider New Zealand context (it is for readers to decide whether the results transfer to their own contexts), there are findings that policy makers and school administrators/teachers should reflect on in relation to their own work. The following four suggestions are proposed here to promote reflections on themes that this research has identified:

1. Build teacher-student rapport and school connectedness

2. Monitor student attendance

3. Review school systems to foster inclusiveness and student attendance 
4. Provide a strong focus on inclusiveness within teacher education and professional development programmes.

\subsubsection{Build teacher-student rapport and school connectedness}

Findings indicate that positive relationships with teachers, peers, and family promote wagging cessation. Positive supportive relationships provide genuine care and stressfree interactions. Genuine care also supports students who wag to be present and at ease, develop the skills to meet challenging academic requirements, and improve their sense of belonging to school. Libbey (2004) claims students' relationships with teachers, and the interactions between students influence their ability to develop self-sufficiency and emotional regulation in the classroom. Student-teacher relationships are also an important element in the research reported earlier by Bishop and Berryman (2006), Pianta and Allen (2008), Bishop (2010), Hunter et al. (2013), and Berryman et al. (2017).

Associated with the notion of teacher-student rapport is the concept of school connectedness. McNeely and Faci (2004) state that school connectedness combines a student's perceptions of safety, social support, belonging, and engagement, and is a protective factor against students detaching from teachers, peers, and learning. The findings of the present research concur with McNeely and Faci's findings; the evidence here is that relationships in classrooms are important to students' sense of belonging and connectedness to both class and school.

Four strategies have the potential to strengthen students' participation in class activities so that they stop wagging-in-class, develop a sense of belonging, and connect to class, school and home. The strategies cover actions by teachers and/or other relevant adults in schools as well as communications between home and school.

- Focus on improving the social climate in classrooms so that students feel visible and respected, and that all interactions send the message that students who wag are welcome back in class. 
- Address deficit thinking towards these students so that the consequent attribution of blame recognises the wider factors that inhibit students' willingness to attend school.

- Demonstrate through consistent, demanding, and kind practices, that students who wag still matter, and that understanding of learners' strengths and blocks is a priority for providing meaningful contexts for students' learning.

- Acknowledge positively students' engagement and achievements so that they are encouraged to reintegrate and learn after wagging.

The Ministry of Education's (2017) suggestions for strengthening student well-being and success are worthy of consideration in relation to the above strategies. As the Ministry notes, student well-being, mental health, and learning are connected. Positive feelings, optimism, and satisfaction with learning characterises students' well-being in school. In addition, effective pastoral care, guidance and counselling promotes students' well-being and success by reducing psychological discomfort and stress; this in turn improves students' engagement, retention, and achievement (Ministry of Education, 2017). In addition, reciprocal interpersonal relationships are at the core of student engagement, and are fundamental to preventing truancy (Pianta, Hamre, \& Allen, 2012). It follows that positive student-teacher and student-student relationships are necessary for students who wag to overcome their low commitment to school work.

\subsubsection{Monitor student attendance}

Findings from both the literature and the participant data indicate that lack of detection contributes to wagging becoming an established habit in schools; early intervention is necessary to address the challenges some students confront in attending school. Spencer (2009) recommends that student attendance should be monitored from the time a student enters school in their first year in order to identify frequent absences, possible issues, achievement progress, and potential barriers to success. If difficulties emerge at any 
time, a prompt response to a student's individual needs and circumstances should be made.

Spencer also recommends that a comprehensive effort be made in relation to resourcing so as to address intentional non-attendance and to increase school completion rates. As Spencer notes, it is important to address these "red flags" (p. 317) and improve attendance, school completion, and future employment outcomes in order to reduce the long-term cost to society.

As evidenced within the small sample of 13 students in the present research, the problems most students faced were not simple or easily solved. The students who reintegrated did so because someone (or some people) provided the time, support and guidance to reinforce a willingness to try again. The adults involved (teachers and others) acted purposefully, took the time to understand a student's circumstances, and built rapport and trust. The prompt recognition of attendance problems and subsequent actions are central to future success for students who wag; an ambulance at the bottom of a cliff is not the kind of support that sends a strong signal of care and attention to a student in need of help earlier in the process.

Cook-Sather (2010) argues for the reconceptualisation of responsibility taken for developing student accountability. She emphasises a relational process; creating environments where students - despite existing constraints - can be active, engaged and feel safe in a shared learning experience. This requires reciprocity as students and teachers are both learners and teachers (Ministry of Education, 2007). However, section 4.2.2 in this thesis outlines the tenuous and deteriorating bond between teachers and youth who truant. As a positive supportive relational process is a precondition to becoming willing to engage and learn (Cook-Sather, 2010), change is required in classrooms. If we consider Cook-Sather's and the findings from this study, it appears that teachers have a vital role in this relational process: to provide academic and emotional support, care and respect, to facilitate positive peer relationships and to 
provide equitable opportunities to learn. These relational components are necessary for youth who truant to be empowered, motivated, attach to their teachers and peers, to feel part of the class, belong and experience agency.

\subsubsection{Review school systems to foster inclusiveness and attendance}

There are also implications from this study for school leaders, teachers, school counsellors, and parents relating to inclusive teaching and social practices that support and promote student well-being. At one level, most schools will already have established and implemented a strict and comprehensive policy on inclusion. An important element is that all school leaders should support teachers, counsellors, other staff, and parents to enhance their ability to listen and see problems when they arise, to intentionally establish and maintain safe learning and home environments, and to set expectations for respectful interactions in their classrooms and homes. All students should be provided with social and academic support, and all students should be noticed so that their interactions in class and outside ensure that they experience a safe school and home environment emotionally and physically. Students who wag should be recognised as students who need particular support in relation to inclusion; this involves recognising a student's immediate problems, acting strongly in a time of crisis, and involving staff and family in these conversations. Students who wag may also need to be referred to specialist services (e.g., psychologists, social workers, and family agencies) to deal with severe or long-term difficulties. A school's policy on inclusion is a central element in promoting a positive academic, social and behavioural climate in schools. The point here is that a school's policy on inclusion is something that requires ongoing reflection and constant vigilance in its application. In addition, strong whānauschool, teacher-student, and student-student relationships are required to support students to attend.

Four principles underpin the United Nations Convention of the rights of the child: (1) non-discrimination; (2) best interests; (3) life, survival, and development; and 
(4) voice of the child to guarantee that children flourish, prosper and thrive (UNCRC, 1989). The current policy development in New Zealand concentrates on vulnerable children and youth (Office of Children's Commissioner, 2018a). The core services of OrangaTamariki, Ministry of Children (n.d.) are consequently undergoing positive change to fulfil this focus. Their new emphasis is on prevention and early intervention that aims to have fewer children moving through the system to State care. By preventing vulnerability the system will move from focusing on crisis response to addressing underlying factors and strengthening families to provide children with loving, stable homes. Similarly, the role of the Children's Commission in Aotearoa (New Zealand) is to advocate for children and young people, uphold their rights, and support them to have a say in the policies and services that affect them. The Children's Commissioner's Office (2018a) has engaged with tamariki (children) and rangatahi (youth) in Aotearoa to ensure their voices contribute to national and educational priorities introduced in January, 2018 (Children's Commissioner, 2018a). This study aligns with and affirms these foci, with the possibility of these youth who truant being heard and considered, thus contributing to developing policy. Specifically, this study identifies a process that may inform teachers, educators, and policy makers to move from focusing on a crisis response to an early intervention approach, which will aim to have fewer youth truanting school. This recommendation is supported by a recent study (uncovered after the write-up of Chapters 2 and 4), which asks for early intervention "as a form of truancy prevention" (Bruce, 2018, p. 39).

\subsubsection{Recommendations for teacher professional learning}

Teacher education programmes are increasingly giving attention to inclusiveness, reflecting the content of the Graduating Teacher Standards (Education Council of New Zealand, n.d.), in particular, the focus on diversity and building relationships with students. However, this research indicates the need for more attention to some of the practical ways that both pre-service and in-service teachers can be assisted to help 
support marginalised students in their schools. This requires that pre-service education programmes address specifically inclusiveness as a major theme running through the different courses student teachers undertake, and that inclusiveness is treated as a significant component of the practical assessment of these future teachers. Similarly, professional development and learning opportunities should be available for in-service teachers, both as postgraduate coursework provided by tertiary institutions and as school-based provision so that a "whole-school" approach can be fostered and implemented with full support from all staff. In relation to the latter point, school leaders should acknowledge and encourage teachers with exemplary practice to provide professional advice and learning to colleagues.

Key insights about progress and achievement (Children's Commissioner, 2018b) indicate that learning environments impact on young people's well-being; they need to feel comfortable, be happy, and have trusting relationships to learn. Therefore, students who wag should be recognised as students who need particular support in relation to inclusion; this involves recognising a student's immediate problems and acting strongly in a time of crisis. Students who wag may also need to be referred to specialist services (e.g., psychologists, school counsellors, social workers, and family agencies) to deal with severe or long-term difficulties. A school's policy on inclusion is a central element in promoting a positive academic, social, and behavioural climate in schools. The Office of the Children's Commissioner suggest a way forward, stating that when making decisions for young people, we need to purposefully and deliberately incorporate their views to inform policy.

\subsection{Recommendations for future research}

Participants in this research felt safe to speak and share their perceptions; my role was to listen and record. Now I offer an opportunity to family, educators, policy makers, researchers, and wider community members to consider the relevance of this research to 
their own situations. This may provide an opportunity for coordinated action that will promote transformative change in the learning and living contexts of young people who truant school. This will give these youth the support they need to move from the margins, where they are perceived as failures, back to class so they are included, willing to learn, and experience success.

The findings of this study highlight further research possibilities. Firstly, it is my intention to apply for funding to conduct an arts-based collaborative project - an ethno-drama - to disseminate the results of this study and to heighten awareness of the dangers of wagging to students and the community. An ethno-drama provides a way to interact with data and learn about the realities of participants' experiences (Fels, 2012), in this case in an oral account of participants' perspectives of truancy. It is my intention to develop and script scenes about truancy from my doctorate, work with students to dramatise them, and perform this ethno-drama in a volunteer school in the Wellington region which identifies as having a truancy problem. Key community stakeholders students, parents, teachers, deans, counsellors, principals, community church leaders, the mayor, politicians, and policy makers - will be invited to attend and then participate in a discussion about truancy in their community to identify preferred solutions. Their responses to this ethno-drama, their ideas about how community members may plan to act (or not), and the potential to work in multi-disciplinary teams in this community will be undertaken as an evaluation study as well as providing information for identifying future research.

Secondly, because this research involved particular students in a very limited range of school settings, further studies are needed to replicate the design features of the present research in other contexts in order to confirm, modify, extend or challenge the process theory of wagging that has emerged from this research. In addition, research using a different design, such as a mixed methods quantitative and qualitative survey of different stakeholders (administrators, teachers, parents, and students), along with 
gathering and analysing observations of teachers' practices, could be undertaken to examine particular provisions, practices, and values that are effective in preventing or reducing student wagging. A different research approach, building on the knowledge gained from the present study, is likely to add to our understanding of the phenomena of wagging and how it may be prevented or at least significantly reduced.

Thirdly, the findings of this research identified that students who wag progressively detach from teachers, peers, and learning. Therefore, other areas of related educational research, such as attachment theory (Bergin \& Bergin, 2009; Riley, 2010) and students' funds of knowledge (Hogg, 2011; Rodriguez, 2013) should be examined for building a bigger and more connected picture of why students wag and what strategies seem likely to improve attendance and learning. Research in these areas may help to potentially build on the data and findings of this study and contribute to improving teacher relationships with students who wag.

In addition, a future "Funds of Knowledge" (FoK) investigation that involves ethnographic research with students and their families about their culture may inform teacher intentional behaviours in the classroom in relation to youth who wag. In this way, knowledge and skills culturally developed and that evolve from life experience outside the school setting (FoK) are valued and built on within the school setting (Hogg, 2011; Rodriguez, 2013).

Fourthly, a study could be undertaken of resilient students - those who attend class and achieve despite experiencing difficult life and educational challenges - to identify if there are particular characteristics or behaviours that typify their ability to engage with school and learning. The study might include classroom observations and follow-up interviews to investigate the reasons for the success of such students. In identifying the nature of resilient students, and the contributing factors to their success, we may understand what factors, circumstances, and attributes are required to build the 
capacity of students who wag so they may overcome barriers contributing to their absence and low level of participation in classes.

\subsection{Conclusion}

This qualitative study investigated the process that occurred when participants wagged class in four New Zealand schools and provides an original process theory of wagging. The findings of the study showed that detaching was the main problem that youth faced in classrooms and contributed to the behaviour described here as wagging-in-class. Participants responded to negative aspects occurring in classrooms by detaching from teachers, peers, and learning. Progressively, they chose to remove themselves and abscond from class to overcome these obstacles.

Wagging meant that youth took time out from class without permission from teachers to overcome the attribution of blame, isolation and marginalisation that they felt at school. Wagging meant that most of the students in the study repositioned themselves from their perceived failure status as an "outsider" from school to one of gaining acceptance from caring friends and experiencing security in being who they wanted to be within these inclusive outsider groups. Alternatively, sometimes a smaller group of students chose to remain in isolation when wagging, not seeking or obtaining outsider group support. In relation to all participants, wagging meant that youth required timely interventions to gain insights, make an effort to change, receive adult support and acceptance from peers, change their attitudes and behaviours, and make decisions to improve attendance. Such youth were able to make positive changes after their awakening. Experiencing these changed conditions meant that students were able to transition to attending school again and re-engage in learning. When unable to change, youth exited school; they perceived that their opportunities to succeed in class, and in their future, were limited due to their experienced failure status and mental health 
related issues. Such students also lacked the adult support to facilitate the attitudinal change they needed. 


\section{REFERENCES}

Aaltonen, S. (2012). Subjective orientations to the schooling of young people on the margins of school. Young, 20(3), 219-235.

doi.org/10.1177/110330881202000301

Allan, G. (2003). A critique of using grounded theory as a research method. Journal of Business Research, 2(1), 1-10.

Allodi, M.W. (2010). The meaning of social climate of learning environments: Some reasons why we do not care enough about it. Learning Environments Research, 13(2), 89-104. DOI https://doi.org/10.1007/s10984-010-9072-92-9

Almquist, Y. B., \& Brännström, L. (2014). Childhood peer status and the clustering of social, economic, and health-related circumstances in adulthood. Social Science and Medicine, 105(2014), 67-75. doi.org/10.1016/j.socscimed.2014.01.011

Alvita, N. (2006). Thoughts on literature review and grounded theory. The Grounded Theory Review, 5(2-3), 35-41.

Attwood, G., \& Croll, P. (2006). Truancy in secondary school pupils: Prevalence, trajectories and pupil perspectives. Research Papers in Education, 21, 467-484.

Andrew, T. (2006). The literature review: A response to McCallin. The Grounded Theory Review, 5(2-3), 29-33.

Baker, M. L., Sigmon, J. N., \& Nugent, M. E. (2001). Truancy reduction: Keeping students in school. Juvenile Justice Bulletin. NCJ-188947. Washington, DC: USA: Office of Juvenile Justice and Delinquency Prevention, Department of Justice.

Baleinakorodawa, L. (2009). Causes of truancy from mainstream education for a group of Pasifika students enrolled in alternative education (MA thesis). Auckland University of Technology, NZ. Retrieved from http://aut.researchgateway.ac.nz/bitstream/10292/786/3/BaleinakorodawaL.pdf

Balfanz, R., \& Byrnes, V. (2012). The importance of being in school: A report on absenteeism in the nation's public schools. The Education Digest, 78(2), 4-9.

Baskerville, D. (2009a). Navigating the unfamiliar in a quest towards culturally responsive pedagogy in the classroom. Teaching and Teacher Education, 25(3), 461-467. 10.1016/j.tate.2008.11.015 
Baskerville, D. (2009b). A youth offender said: I liked acting and devising a scene because it is about cars. Drama NZ e-Journal, 2.

Beck, C. T. (1993). Qualitative research: The evaluation of its credibility, fittingness, and auditability. Western Journal of Nursing Research, 15(2), 263-266. doi.org/10.1177/019394599301500212

Bell, A. J., Rosen, L. A., \& Dynlacht, D. (1994). Truancy intervention. Journal of Research and Development in Education, 27(3), 203-211.

Berg, B. L. (2009). Qualitative research methods: For the social sciences. Boston, USA: Allyn \& Bacon.

Berg, J. A. (1999). Gaining access to under-researched populations in women's health research. Health Care for Women International, 20(3), 237-243. doi.org/10.1080/073993399245737

Bergin, C., \& Bergin, D. (2009). Attachment in the classroom. Educational Psychology Review, 21(2), 141-170. doi.org/10.1007/s10648-009-9104-0

Berlak, A. (1996). Teaching stories: Viewing a cultural diversity course through the lens of narrative. Theory into Practice, 35(2), 93-101. doi.org/10.1080/00405849609543708

Berryman, M., Eley, E., \& Copeland, D. (2017). Listening and learning from rangatahi Māori: The voices of Māori youth. Critical Questions in Education, 8(4), 476494.

Bersani, B. E., \& Chappie, C. L. (2007). School failure as an adolescent turning point. Sociological Focus, 40(4), 370-391. doi.org/10.1080/00380237.2007.10571316

Birt, L., Scott, S., Cavers, D., Campbell, C., \& Walter, F. (2016). Member checking: A tool to enhance trustworthiness or merely nod to validation? Qualitative Health Research, 26(13), 1802-1811. doi.org/10.1177/1049732316654870

Bishop, R. (2011). Te Kotahitanga: Kaupapa Māori in mainstream classrooms. In C. Sleeter (Ed.), Professional development for culturally responsive and relationship-based pedagogy (pp. 23-46). New York: Peter Lang.

Bishop, R., \& Berryman, M. (2006). Culture speaks: Cultural relationships and classroom learning. Wellington, NZ: Huia.

Bishop, R., \& Glynn, T. (1999). Culture counts: Changing power relations in education. Palmerston North, NZ: Dunmore Press. 
Bishop, R., Berryman, M., Tiakiwai, S., \& Richardson, C. (2003). Te Kotahitanga: The experiences of year 9 and 10 Māori students in mainstream classrooms. Wellington, NZ: Ministry of Education.

Blackburn, L. (1993). Heads hit at parks over "fun days out". Times Educational Supplement, $4028(1), 8$.

Bobillier, C. W. (1976). Truancy in New Zealand (MA thesis). Victoria University of Wellington, NZ.

Bottrell, D. (2007). Resistance, resilience and social identities: Reframing 'problem youth' and the problem of schooling. Journal of Youth Studies, 10(5), 597-616. doi.org/10.1080/13676260701602662

Bourke, R. \& Loveridge, J. (2018). Students' voice shifting the gaze from measured learning to the point of learning. In R., Bourke \& J., Loveridge. (Eds.). Radical collegiality through student voice: Education, Experience, Policy and Practice. Singapore: Springer.

Briggs, C. L. (2007). Curriculum collaboration: A key to continuous program renewal. The Journal of Higher Education, 78(6), 676-711. doi:http://dx.doLorg/1O.13S3/jhe.2007.0036

Broadwin, I. T. (1932). A contribution to the study of truancy. American Journal of Orthopsychiatry, 2, 253-259. doi.org/10.1111/j.1939-0025.1932.tb05183.x

Brown, F. (1934). The truant child. School and Society, 6(40), 772-773.

Bruce, J. (2018). Dis/Engagement in secondary schools: Towards truancy prevention. Christchurch, NZ: Teorahau. Retrieved from www.teorahou.org.nz

Bryant, A., \& Charmaz, K. (2007). Introduction: Grounded theory research. In A. Bryant \& K. Charmaz (Eds.), The Sage handbook of grounded theory (pp. 31-57). London: Sage.

Butler, A. E., Copnell, B., \& Hall, H. (2018, in print). The development of theoretical sampling in practice. Collegian. doi.10.1016//j.collegn.2018.01.002.

Carpenter, R. D. (1995). Grounded theory research approach. In H. Streubert \& R. Carpenter (Eds.), Qualitative research in nursing: Advancing the humanistic imperative (pp. 145-161). Philadelphia, USA: J.B. Lippincott.

Catalano, R. F., Hawkins, J. D., Wells, E. A., Miller, J., \& Brewer, D. (1991). Evaluation of the effectiveness of adolescent drug abuse treatment, assessment of 
risks for relapse, and promising approaches for relapse prevention. International Journal of Addiction, 25(9A-10A), 1085-1140.

doi.org/10.3109/10826089109081039

Cavanagh, T., Macfarlane, A., Glynn, T., \& Macfarlane, S. (2012). Creating peaceful and effective schools through a culture of care. Discourse Studies in Cultural Politics of Education, 33(3), 443-455. doi.org/10.1080/01596306.2012.681902

Chadderton, C. (2011). Not capturing voices: A poststructural critique of the privileging of voice in research. In Czerniawski, G., \& Kidd, W. (Eds.). The student voice handbook: Bridging the academic/practitioner divide. Bingley, UK: Emerald.

Charmaz, K. (2006). Constructing grounded theory: A practical guide through qualitative analysis. London: Sage.

Charmaz, K. (2011). Grounded theory methods in social justice research. In N. K. Denzin, \& Y. S. Lincoln (Eds.), The Sage handbook of qualitative research (pp. 359-380). Thousand Oaks, CA: Sage.

Charmaz, K. (2014). Constructing grounded theory ( $2^{\text {nd }}$ ed). Thousand Oaks, CA: Sage.

Charmaz, K. (2017). The power of constructivist grounded theory for critical inquiry. Qualitative Inquiry, 23(1), 34-45. doi.org/10.1177/1077800416657105

Chen, C. C., Culhane, D. P., Metraux, S., Park, J. M., \& Venable, J. C. (2016). The heterogeneity of truancy among urban middle school students: A latent class growth analysis. Journal of Child and Family Studies, 25(4), 1066-1075. doi.org/10.1007/s10826-015-0295-3

Children's Commissioner. (2018a). He manu kai matauranga: He tirohanga Māori: Education matters to me; Experiences of tamariki and rangatahi Māori. Wellington, NZ: NZSTA.

Children's Commissioner. (2018b). Education matters to me: Progress and achievement. Wellington, NZ: NZSTA.

Children's Commissioner. (2018c). Education matters to me: Engagement. Wellington, NZ: NZSTA.

Chiovitti, R. F., \& Piran, N. (2003). Rigour and grounded theory research. Journal of Advanced Nursing, 44(4), 427-435. doi.org/10.1046/j.0309-2402.2003.02822.x 
Cho, J. Y., \& Lee, E. (2014). Reducing confusion about grounded theory and qualitative content analysis: Similarities and differences. The Qualitative Report, 19(32), 120.

Claes, E., Hooghe, M., \& Reeskens, T. (2009). Truancy as a contextual and schoolrelated problem: A comparative multilevel analysis of country and school characteristics on civic knowledge among 14 year olds. Educational Studies, 35(2), 123-142. doi.org/10.1080/03055690802470258

Clark, T., Smith, J., Raphael, D., Jackson, C., Denny, S., Fleming, T., Ameratunga, S., $\&$ Crengle, S. (2010). Kicked out of school and suffering: The health needs of alternative education youth in New Zealand. Youth Studies Australia, 29(4), 1017.

Clarke, A. (2005). Situational analysis: Grounded theory after the postmodern turn. Thousand Oaks, CA: Sage.

Clarke, A. (2009). From grounded theory to situational analysis: What's new? Why? How? In J. Morse, P. Stern, J. Corbin, B. Bower, K. Charmaz, \& A. Clarke (Eds.), Developing grounded theory: The second generation (pp. 194-233). London: Routledge.

Clarke, A., \& Friese, C. (2007). Grounded theorizing using situational analysis. In A. Bryant \& K. Charmaz (Eds.), The Sage handbook of grounded theory (pp. 363397). London: Sage.

Cohen, G. L., \& Prinstein, M. J. (2006). Peer contagion of aggression and health risk behavior among adolescent males: An experimental investigation of effects on public conduct and private attitudes. Child Development, 77(4), 967-983. doi.org/10.1111/j.1467-8624.2006.00913.x

Cohen, L., Manion, L., \& Morrison, K. (2000). Research methods in education (5 ${ }^{\text {th }}$ ed.). New York: Routledge Palmer.

Cohen, N., \& Arieli, T. (2011). Field research in conflict environments: Methodological challenges and snowball sampling. Journal of Peace Research, 48(4), 423-435. doi.org/10.1177/0022343311405698

Coldman, C. (1995). Truancy and the curriculum. In D. O'Keefe \& P. Stoll (Eds.), Issues in school attendance and truancy. London: Pitman.

Cook-Sather, A. (2006). Sound, presence, and power: "Student voice" in educational research and reform. Curriculum Inquiry, 36(4), 359-390. 
Cook-Sather, A. (2010). Students as learners and teachers: Taking responsibility, transforming education and reducing accountability. Curriculum Inquiry, 40(4), 555-575. doi.org/10.1111/j.1467-873X.2010.00501.x

Cope, D. G. (2014). Methods and meanings: Credibility and trustworthiness of qualitative research. Oncology Nursing Forum, 41(1), 89-91. doi.org/10.1188/14.ONF.89-91

Corbin, J. M., \& Strauss A. L. (2008). Basics of qualitative research: Techniques and procedures for developing grounded theory. Thousand Oaks, CA: Sage.

Corbin, J. M., \& Strauss A. L. (2014). Basics of qualitative research: Techniques and procedures for developing grounded theory ( $3^{\text {rd }}$ ed.). Los Angeles, CA: Sage.

Creswell, J. W. (1994). Research design: Qualitative and quantitative approaches. Thousand Oaks, CA: SAGE Publications.

Creswell, J. W. (2005). Educational research: Planning, conducting, and evaluating quantitative and qualitative research ( $2^{\text {nd }}$ ed.). Upper Saddle River, NJ: Pearson.

Creswell, J.W. (2009). Designing a qualitative study: Qualitative, quantitative and mixed methods approaches ( $3^{\text {rd }}$ ed.). Thousands, CA: Sage.

DaCosta, K. (2006). Dress code blues: An exploration of urban students' reactions to a public high school uniform policy. Journal of Negro Education, 75(1), 49-59.

Dahl, P. (2016). Factors associated with truancy: Emerging adults' recollections of skipping school. Journal of Adolescent Research, 31(1), 119-138.

doi.org/10.1177/0743558415587324

Dalziel, D., \& Henthorne, K. (2005). Parents'/carers' attitudes towards school attendance. (Research Report, RR 618). Nottingham, UK: Taylor Nelson Sofres.

Darmody, M., Smyth, E., \& McCoy, S. (2008). Acting up or opting out? Truancy in Irish secondary schools. Educational Review, 60(4), 359-373. doi.org/10.1080/00131910802393399

Davidson, C., \& Tolich, M. (1999). Social science research in New Zealand: Many paths to understanding. Auckland, NZ: Pearson Education.

Davidson, C., \& Tolich, M. (2003). Social science research in New Zealand: Many paths to understanding. Auckland, NZ: Pearson Education.

Davies, D., \& Lee, J. (2006). To attend or not attend? Why some students choose school and others reject it. Support for Learning, 21(4), 204-209. 
doi.org/10.1111/j.1467-9604.2006.00433.x

Delgado, M. Y., Ettekal, A. V., Simpkins, S. D., \& Schaefer, D. R. (2016). How do my friends matter? Examining Latino adolescents' friendships, school belonging and academic achievement. Journal of Youth and Adolescence, 45(6), 1110-1125. doi.org/10.1007/s10964-015-0341-x

Dembo, R., Wareham, J., Schmeidler, J., Briones-Robinson, R., \& Winters, K. C. (2016). Differential effects of mental health problems among truant youths. The Journal of Behavioral Health Services \& Research, 43(3), 402-427. doi:http://dx.doi.org.helicon.vuw.ac.nz/10.1007/s11414-014-9435-6

Denny, S., Robinson, E., Utter, J., Grant, S., Milfont, T., Grengle, S., Ameratunga, S., \& Merry, S. (2011). The association of truancy behaviours and school environments among a nationally representative sample of adolescents. Journal of Adolescent Health, 59(5), 555-561. doi.org/10.1016/j.jadohealth.2016.07.012

Denscombe, M. (1998). The good research guide: For small-scale social research projects. Philadelphia, USA: Open University Press.

Denscombe, M. (2010). The good research guide: For small-scale social research ( $^{\text {th }}$ ed.). Buckingham, UK: Open University Press.

Denzin, N. K., \& Lincoln, Y. S. (2008). Strategies of qualitative inquiry. California: Sage.

Denzin, N., \& Lincoln, Y. (2005). The Sage handbook of qualitative research. California: Sage.

Dey, I. (1993). Qualitative data analysis: A user-friendly guide for social scientists. London: Routledge.

Donn, M., Bennie, N., \& Kerslake, J. (1993). Who's not here? Working towards keeping 'absentee students' at school. Wellington, NZ: Ministry of Education.

Dougherty, J. W. (1999). Fastback: Attending to attendance. Bloomington, USA: Phi Delta Kappa Educational Foundation.

Douglas, D. (2003). Inductive theory generation: A grounded theory approach to business inquiry. Electronic Journal of Business Research Methods, 2(1), 47-54.

Duke, K. (2002). Getting beyond the "official line": Reflections on dilemmas of access, knowledge and power in researching policy networks. Journal of Social Policy, 36(1), 39-59. 
Eason, K. L., McComish, J. F., \& Greenberg, R. (2000). Avoiding common pitfalls in qualitative data collection and transcription. Qualitative Health Research, 10(5), 703-707. doi.org/10.1177/104973200129118651

Edinburgh, L. D., Garcia, C. M., \& Saewyc, E. M. (2013). It's called "going out to play": A video diary study of Hmong girls' perspectives on running away. Health Care for Women International, 34(2), 150-168. doi.org/10.1080/07399332.2011.645962

Education Act (1989). No 8 (as at 31 March, 2018). Public Act Contents - New Zealand: Part 3.

Education Counts. (2017). Students attending schools regularly. Retrieved from www.educationcounts.govt.nz.

Education Counts. (2018). Students attending schools regularly. Retrieved from www.educationcounts.govt.nz.

Education Government New Zealand (n.d.). Special purpose units (activity centres, teen parent units, other). Retrieved from http://www.education.govt.nz/

Education Government New Zealand (n.d.). retrieved from https://parents.education.govt.nz/secondary-school/your-child-atschool/making-sure-your-child-attends-school/

Elliott, N., \& Jordan, J. (2010). Practical strategies to avoid the pitfalls in grounded theory research. Nurse Researcher, 17(4), 29-40. doi.org/10.7748/nr2010.07.17.4.29.c7922

Evans, K. (2007). Concepts of bounded agency in education, work, and the personal lives of young adults. International Journal of Psychology, 42(2), 85-93.

Evans, K. (2002). Taking Control of their Lives? Agency in Young Adult Transitions in England and the New Germany. Journal of Youth Studies, 5(3), 245-269. DOI: $10.1080 / 1367626022000005965$

Fallis, K. R., \& Opotow, S. (2003). Are students failing school or are schools failing students? Class cutting in high school. Journal of Social Issues, 59(1), 103-119. doi.org/10.1111/1540-4560.00007

Farrington, D. P. (1980). Truancy, delinquency, the home, and the school. In L. Hersov \& I. Berg (Eds.), Out of school: Modern perspectives in truancy and school refusal (pp. 49-63). Chichester: Wiley.

Fels, L. (2012) Collecting data through performative inquiry: A tug on the sleeve, Youth Theatre Journal, 26(1), 50-60. DOI: 10.1080/08929092.2012.678209 
Fergusson D. M., Swain-Campbell, N. R., \& Horwood, L. J. (2002). Outcomes of leaving school without formal educational qualifications. New Zealand Journal of Educational Studies, 37(1), 39-55.

Fielding, M. (2004). Transformative approaches to student voice: Theoretical underpinnings, recalcitrant realities. British Educational Research Journal, 30(2), 295-311.

Fielding, M. (2001) Students as radical agents of change, Journal of Educational Change, 2(3), 123-141.

Fine, M., \& Rosenberg, P. (1983). Dropping out of high school: The ideology of school and work. Journal of Education, 165(3), 257-272. doi.org/10.1177/002205748316500304

Fogelman, K., Tibbenham, A., \& Lambert, L. (1980). Absence from school: Findings from the National Child Development Study. In L. Hersov \& I. Berg (Eds.), Out of school: Modern perspectives in truancy and school refusal (pp. 25-48). Chichester: Wiley.

Fontana, A., \& Frey, J. H. (2005). The interview: From neutral stance to political involvement. In N. Denzin \& Y. Lincoln (Eds.), The Sage handbook of qualitative research ( $3^{\text {rd }}$ ed., pp. 695-729). Thousand Oaks, CA: Sage.

Freire, S., Carvalho, C., Freire, A., Azevedo, M., \& Oliveira, T. (2009). Identity construction through schooling: Listening to students' voices. European Educational Research Journal, 8(1), 80-88. doi.org/10.2304/eerj.2009.8.1.80

Frelin, A. (2015). Relational underpinnings and professionality: A case study of a teacher's practices involving students with experiences of school failure. School Psychology International, 36(6), 589-604. doi.org/10.1177/0143034315607412

Fullen, M. (1991). The meaning of educational change. New York: Teachers College Press.

Furlong, V. J. (1991). Disaffected pupils: Reconstructing the sociological perspective. British Journal of Sociology of Education, 12(3), 293-307. doi.org/10.1080/0142569910120302

Galloway, R. (2007). Character in the classroom: A report on how New Zealand's changing social values are impacting on student behaviour and how schools can meet new challenges. Alexandra, NZ: Foundation for Character Education. 
Galloway, R. A. (1995). Home-schooled adults: Are they ready for college? Educational Research, 24(7), 13-27.

Garry, E. M. (1996). Truancy: First step to a lifetime of problems. Washington, DC: USA Department of Justice.

Gase, L. N., DeFosset, A., Perry, R., \& Kuo, T. (2016). Youths' perspectives on the reasons underlying school truancy and opportunities to improve school attendance. The Qualitative Report, 21(2), 299-320.

Geiger, S. G. (1941). Truancy: A symptom of a conflict between the child and his environment. Federal Probation, 5(2), 22.

Gentle-Genitty, C., Karikari, I., Chen, H., Wilka, E., \& Kim, J. (2015). Truancy: A look at definitions in the USA and other territories. Educational Studies, 41(1-2), 6290. doi.org/10.1080/03055698.2014.955734

Gill, C., Gottfredson, D., \& Hutzell, K. (2016). Can school policing be traumainformed? Lessons from Seattle. Policing: An International Journal of Police Strategies and Management, 39(3), 551-565.

Glaser, B. G. (2007). All is data. Grounded Theory Review: An International Review, 2(2007), 6.

Glaser, B. (1978). Theoretical sensitivity. Mill Valley, CA: Sociology Press.

Glaser, B. G. (1992). Emergence vs forcing: Basics of grounded theory. Mill Valley, CA: Sociology Press.

Glaser, B. G. (1998a). The future of grounded theory. Qualitative Health Research, 9(6), 836-845.

Glaser, B. G. (1998b). Doing grounded theory: Issues and discussion. Mill Valley, CA: Sociology Press.

Glaser, B., \& Strauss, A. (1967). The discovery of grounded theory: Strategies of qualitative research. New York: Aldine.

Glaser, B. G. (2002). Conceptualization: On theory and theorizing grounded theory. International Journal of Qualitative Methods, 1(2), 23-38. doi.org/10.1177/160940690200100203

Glaser, B. G. (2006). The roots of grounded theory. An International Review, 5(2/3), 110. 
Gleeson, J. P. (1996). Kinship care as a child welfare service: The policy debate in an era of welfare reform. Child Welfare, 75(5), 419.

Goldweber, A., Waasdorp, T. E., \& Bradshaw, C. P. (2013). Examining the link between forms of bullying behaviors and perceptions of safety and belonging among secondary school students. Journal of School Psychology, 51(4), 469-485. doi.org/10.1016/j.jsp.2013.04.004

Gourneau, B. (2012). Students' perspectives of bullying in schools. Contemporary Issues in Education Research, 5(2), 117-126. doi.org/10.19030/cier.v5i2.6929

Green, J. C., Carcelli, V. J., \& Graham, W. F. (1989). Toward a conceptual framework for mixed-method evaluation designs. Education Evaluation Policy and Analysis, 11(3), 255-274. doi.org/10.2307/1163620

Guba, E. G. (1981). Criteria for assessing the trustworthiness of naturalistic inquiries. Educational Communication and Technology Journal, 29(1981), 75-92.

Gubrium, J., \& Holstein, J. (2002). Handbook of interview research: Context and method. Thousand Oaks, CA: Sage.

Haggis, D. (2017). Influencing positive outcomes for troubled youth. Contemporary Issues in Education, 10(3), 1-6. doi.org/10.19030/cier.v10i3.9978

Hall, C. (2005). Outcomes based approaches to aid evaluation: Some concerns. In K. Sanga, C. Chu, C. Hall, \& L. Crowl (Eds.), Re-thinking aid relationships in Pacific education. Wellington: Victoria University of Wellington \& Suva: Institute of Education, University of the South Pacific.

Hallinan, M. T. (2008). Teacher influences on student attachment to school. Sociology of Education, 81(3), 271-283. doi.org/10.1177/003804070808100303

Hamilton, M G., \& Adamson, E. (2013) Bounded agency in young carers' lifecoursestage domains and transitions, Journal of Youth Studies, 16(1), 101-117, DOI: 10.1080/13676261.2012.710743

Hamm, J. V., \& Faircloth, B. S. (2005). The role of friendship in adolescents' sense of school belonging. New Directions for Child and Adolescent Development, 76(5), 61-78. doi.org/10.1002/cd.121

Hammersley, M., \& Atkinson, P. (2002). Ethnography: Principles in practice (2 ${ }^{\text {nd }}$ ed.). London: Routledge. 
Hammersley, M., \& Traianou, A. (2014). Foucault and research ethics: On the autonomy of the researcher. Qualitative Inquiry, 20(3), 227-238.

doi.org/10.1177/1077800413489528

Harber, C. (2008). Perpetrating disaffection: Schooling as an international problem. Educational Studies, 34(5), 457-467. doi.org/10.1080/03055690802288445

Harvey-Jordan, S., \& Long, S. (2001). The process and the pitfalls of semi-structured interviews. Community Practitioner, 74(6), 219-221.

Hawk, K., \& Hill, J. (2003). Achieving is cool: What we learned from the AIMHI Project to help schools more effectively meet the needs of their students. Wellington, NZ: Ministry of Education.

Heath, S., Brooks, R., Cleaver, E., \& Ireland, E. (2009). Researching young people's lives. Los Angeles: Sage.

Heath, H., \& Cowley, S. (2004). Developing a grounded theory approach: a comparison of Glaser and Strauss. International Journal of Nursing Studies, $41(2), 141-150$.

Heilbrunn, J. Z. (2007). Pieces of the truancy jigsaw: A literature review. (An Initiative of the Colorado Foundation for Families and Children: White paper). Retrieved from www.schoolengagement.org.

Hertzog, M. A. (2008). Considerations in determining sample size for pilot studies. Research in Nursing and Health, 31(2), 180-191.

Hogg, L. (2011). Funds of knowledge: An investigation of coherence within the literature. Teaching and Teacher Education, 27(3), 666-677.

doi.org/10.1016/j.tate.2010.11.005

Hogg, L. (2013). Applying funds of knowledge in a NZ high school: The emergence of team-based collaboration as an approach ( $\mathrm{PhD}$ thesis). Victoria University Wellington, NZ.

Holstein, J., \& Gubrium, J. (1995). The active interview. Thousand Oaks, CA: Sage.

Hunter, A., Keady, J., Casey, D., Grealish, A., \& Murphy, K. (2016). Psychosocial intervention use in long-stay dementia care: A classic grounded theory. Qualitative Health Research, 26(14), 2024-2034.

doi.org/10.1177/1049732316632194 
Isakson, M., \& Boody, R. (1993). Hard questions about teacher research. In L. Patterson, C. Santa, K. Short, \& K. Smith. (Eds.), Teachers are researchers: Reflection and action (pp. 26-34). Newark, DE: International Reading Association.

Jairath, N., Hogerney, M., \& Parsons, C. (2000). The role of the pilot study: A case illustration from cardiac nursing research. Applied Nursing Research, 13(2), 9296. doi.org/10.1016/S0897-1897(00)80006-3

Jensen, J. (1967). Incidence of truancy. Wellington, NZ: Joint Committee on Young Offenders.

Jensen, J. (1968a). Truancy in Auckland. Wellington, NZ: Joint Committee on Young Offenders.

Jensen, J. (1968b). Truancy in New Zealand schools. Wellington, NZ: Joint Committee on Young Offenders.

Jonasson, C. (2011). The dynamics of absence behaviour: Interrelations between absence from class and absence in class. Educational Research, 53(1), 17-32. doi.org/10.1080/00131881.2011.552233

Jones, L. P., Harris, R., \& Finnegan, D. (2012). School attendance demonstration project: An evaluation of a program to motivate public assistance teens to attend and complete school in an urban school district. Research on Social Work Practice, 12(2), 222-237. doi.org/10.1177/104973150201200202

Jones, M. H., Audley-Piotrowski, S. R., \& Kiefer, S. M. (2013). Relationships among adolescents' perceptions of friends' behaviors, academic self-concept, and math performance. Journal of Educational Psychology, 104(1), 19-31. doi.org/10.1037/a0025596

Juvonen, J., Espinoza, G., \& Knifsend, C. (2012). The role of peer relationships in student academic and extracurricular engagement. In S. L. Christenson, A. L. Reschly, \& C. Wylie (Eds.), Handbook of research on student engagement (pp. 387-401). New York: Springer.

Kahn, A. J. (1951). Who are our truants? Federal Probation, 15(1), 35-40.

Kahn, J. H., \& Nursten, J. P. (1962). School refusal: A comprehensive view of school phobia and other failures of school attendance. American Journal of Orthopsychiatry, 32(4), 707-718. doi.org/10.1111/j.1939-0025.1962.tb00320.x 
Kearney, C. A. (2002). Identifying the function of school refusal behaviour: A revision of the School Assessment Scale. Journal of Psychopathology and Behavioural Assessment, 24(4), 235-245. doi.org/10.1023/A:1020774932043

Kelle, W. (2007). "Emergence" vs "forcing" of empirical data? A critical problem of grounded theory reconsidered. Historical Social Research, 32(19), 133-156.

Keppens, G., \& Spruyt, B. (2016). Towards a typology of occasional truancy: An operationalisation study of occasional truancy in secondary education in Flanders. Research Papers in Education, 33(1), 121-135. doi.org/10.1080/02671522.2015.1136833

Kerslake, J., \& Lang, D. (1998). Attendance, absence and truancy in New Zealand schools 1996. Wellington, NZ: Ministry of Education.

Kerslake, J., Lang, D., \& Bennie, N. (1997). Truancy action survey: A survey of truancy action undertaken in schools. Wellington, NZ: Ministry of Education.

Kilmister, P., \& Baxter, B. (2002). Tracking truants in Wanganui: Social work now. The Practice Journal of Child, Youth and Family, 21(2002), 4-9.

Kohl, H. (1994). I won't learn from you! Thoughts on the role of assent in learning. Rethinking Schools, 7(1), 16-19.

Kolb, S. M. (2012). Grounded theory and the consistent comparative method: Valid research strategies for educators. Journal of Emerging Trends in Educational Research and Policy Studies, 3(1), 83-86.

Kools, S., McCarthy, M., Durham, R., \& Robrecht, L. (1996). Dimensional analysis: Broadening the conception of grounded theory. Qualitative Health Research, 6(3), 312-330. doi.org/10.1177/104973239600600302

Krane, V., Ness, O., Holter-Sorensen, N., Karlsson, B., \& Binder, P. (2017). You notice that there is something positive about going to school: How teachers' kindness can promote positive teacher-student relationships in upper secondary school. International Journal of Adolescence and Youth, 22(4), 377-389. doi.org/10.1080/02673843.2016.1202843

Kuser, W. L. (1916). Truant children. The Survey, 37(13), 366.

LaCompte, M. D., \& Preissle. J. (1993). Ethnography and qualitative design in educational research ( $2^{\text {nd }}$ ed.). San Diego: Academic Press. 
LaFontana, K., \& Cillessen, A. H. N. (2010). Developmental changes in the priority of perceived status in childhood and adolescence. Social Development, 19(1), 130147. doi.org/10.1111/j.1467-9507.2008.00522.x

Laursen, B., Hafen, C. A., Kerr, M., \& Stattin, H. (2012). Friend influence over adolescent problem behaviors as a function of relative peer acceptance: To be liked is to be emulated. Journal of Abnormal Psychology, 121(1), 88-94. doi.org/10.1037/a0024707

Lewis, A. (2010). Silence in the context of "child voice". Children \& Society, 24(1), 14-23.

Lewis, R., Romi, S., \& Roache, J. (2012). Excluding students from classrooms: Teacher techniques that promote student responsibility. Teaching and Teacher Education, 28(6), 870-878. doi.org/10.1016/j.tate.2012.03.009

Libbey, H. P. (2004). Measuring student relationships to school: Attachment, bonding, connectedness, and engagement. Journal of School Health, 74(7), 274-283. doi.org/10.1111/j.1746-1561.2004.tb08284.x

Lifshitz, C., Noam, G., \& Habib, J. (1998). The absorption of Ethiopian immigrant. Youth, a multi-dimensional perspective. Jerusalem, Israel: JDC-Brookdale Institute, The Centre for Children and Youth.

Lincoln, Y., \& Guba, E. (1985). Naturalistic inquiry. Beverley Hills, CA: Sage.

Little, L. F., \& Thompson, R. (1983). Truancy: How parents and teachers contribute. School Counsellor, 30(4), 285-291.

Lo, C. O. (2016). Literature integration: An illustration of theoretical sensitivity in grounded theory studies. The Humanistic Psychologist, 44(2), 177-189. doi.org/10.1037/hum0000029

Loader, M. (2014). Attendance in New Zealand schools 2013. Wellington, NZ: Ministry of Education.

Loader, M., \& Ryan, T. (2010). Attendance in New Zealand schools in 2009. Wellington, NZ: Ministry of Education.

Loader, M., \& Ryan, T. (2012). Attendance in New Zealand schools 2011. Wellington, NZ: Ministry of Education.

Locke, K. (2003). Grounded theory in management research. Thousand Oaks, CA: Sage. 
Loveridge, J. (2010). Involving young people in research in secondary school settings. In J. Loveridge (Ed.), Involving children and young people in research in educational settings. Wellington, NZ: Ministry of Education.

Lumpkin, A. (2007). Caring teachers the key to student learning. Kappa Delta Pi Record, 43(4), 158-160. doi.org/10.1080/00228958.2007.10516474

Lyons, R. G. (2016). Addressing school refusal through effective school, family and community-based Intervention. University of England. All Theses and Dissertations. Retrieved from htttp://dune.une.edu/thesis.57

Ma, X. (2003). Sense of belonging to school: Can schools make a difference? The Journal of Educational Research, 96(6), 340-349. doi.org/10.1080/00220670309596617

MacDonald, R., \& Marsh, J. (2004). Missing school educational engagement, youth transitions, and social exclusion. Youth and Society, 36(2), 143-162. doi.org/10.1177/0044118X04265156

Makarova, E., \& Herzog. W. (2013). Hidden school dropout among immigrant students: A cross-sectional study. Intercultural Education, 24(6), 559-572. doi.org/10.1080/14675986.2013.867603

Malcolm, H., Wilson, V., Davidson, J., \& Kirk. S. (2003). Absence from school: A study of its causes and effects in seven LEAs. (The SCRE Centre, Research Report No. 424). Glasgow, Scotland: University of Glasgow.

Mallari, M., \& Loader, M. (2013). Attendance in New Zealand schools 2012. Wellington, NZ: Ministry of Education.

Martin, V. B. (2006). The relationship between an emerging grounded theory and the existing literature: Four phases for consideration. The Grounded Theory Review, $5(2-3), 47-50$.

Maynard, B. R., McCrea, K. T., Pigott, T. D., \& Kelly, M. S. (2013). Indicated truancy interventions for chronic truant students: A Campbell systematic review. Research on Social Work Practice, 23(1), 5-21.

doi.org/10.1177/1049731512457207

Maynard, B. R., Salas-Wright, C. P., Vaughn, M. G., \& Peters, K. E. (2012). Who are truant youth? Examining distinctive profiles of truant youth using latent profile analysis. Journal of Youth and Adolescence, 41(12), 1671-1684. 
McCallin, A. M. (2006). Grappling with the literature in a grounded theory study. Contemporary Nurse, 15(1-2), 61-69. doi.org/10.5172/conu.15.1-2.61

McCray, E. D. (2006). It's 10 am: Do you know where your children are? The persisting issue of school truancy. Intervention in School and Clinic, 42(1), 30-33. doi.org/10.1177/10534512060420010501

McElwee, E. W. (1931). A study of truants and retardation. Journal of Juvenile Research, 15, 209-214.

McHugh, R. M., Horner C. G., Colditz J. B., \& Wallace, T. L. (2013). Bridges and barriers: Adolescent perceptions of student-teacher relationships. Urban Education, 48(1), 9-43. doi.org/10.1177/0042085912451585

McIntyre-Bhatty, K. (2008). Truancy and coercive consent: Is there an alternative? Educational Review, 60(4), 375-390.

McNeely, C., \& Falci, C. (2004). School connectedness and the transition into and out of health-risk behavior among adolescents: A comparison of social belonging and teacher support. Journal of School Health, 74(7), 284-292. doi.org/10.1111/j.1746-1561.2004.tb08285.x

Merrian, S. (1998). Qualitative research and case study applications in education. San Francisco: Jossey-Bass.

Miles M., \& Huberman A. (1994). Qualitative data analysis: A methods sourcebook. Beverly Hills, CA: Sage.

Mills, J., Bonner, A., \& Francis, K. (2006). The development of grounded theory. International Journal of Qualitative Methods. 5(1), 1-10. Retrieved from http://creativecommons.org/licenses/by/2.0.

Ministry of Education. (2005). Attendance, absence and truancy in New Zealand schools in 2004. Wellington, NZ: Author.

Ministry of Education. (2006). Attendance, absence and truancy in NZ schools in 2006: Preliminary report. Wellington, NZ: Author.

Ministry of Education. (2007). The New Zealand Curriculum for English-medium teaching and learning in years 1-13. Wellington, NZ: Learning Media.

Ministry of Education. (2010). Improving attendance: Case management of truancy and the prosecution process. Wellington, NZ: The New Zealand Government. 
Ministry of Education. (2011). Attendance matters: Guidelines for implementing an elective attendance management plan. Wellington, NZ: The New Zealand Government.

Ministry of Education. (2014). Inclusive practice for secondary schools: Ideas for school leaders. Wellington, NZ: New Zealand Government. Retrieved from www.education.govt.nz

Ministry of Education. (2017). The Ministry of Education annual report for year ended 30 June. Wellington, NZ: The New Zealand Government.

Ministry of Education. (2018). New Zealand Schools Attendance Survey: Term 2, 2017 results. Wellington, NZ: The New Zealand Government.

Misco, T. (2007). The frustrations of reader generalizability and grounded theory. Alternative considerations for transferability. Journal of Research Practice, 3(1), $1-11$.

Mockler, N., \& Groundwater-Smith, S. (2015). Engaging with student voice in research, education and community: Beyond legitimisation and guardianship. Switzerland: Springer International Publishing.

Montgomery, P., \& Bailey, P. H. (2007). Field notes and theoretical memos in grounded theory. Journal of Nursing Research, 29(1), 65-79. doi.org/10.1177/0193945906292557

Morris, M., \& Rutt, S. (2004). Analysis of pupil attendance data in excellence in cities (EiC) areas: Interim report. (London: HMSO Research Report No. 657, National Foundation for Educational Research).

Morse, J. (2009). Tussles, tensions, and resolutions. In J. Morse, P. N. Stern., J. Corbin, B. Bowers, K. Charmaz, \& A. Clarke (Eds.), Developing grounded theory: The second generation (pp. 13-20). London: Routledge.

Mulhall, A. (2003). In the field: Notes on observation in qualitative research. Journal of Advanced Nursing, 41(3), 306-331. doi.org/10.1046/j.1365-2648.2003.02514.x

Murphy-Graham, E., \& Lample, J. (2014). Learning to trust: Examining the connections between trust and capabilities friendly pedagogy through case studies from Honduras and Uganda. International Journal of Educational Development, 36(4), 51-62. doi.org/10.1016/j.ijedudev.2014.01.001 
National Centre for School Engagement. (2007). Pieces of the truancy jigsaw: A literature review. An initiative of the Colorado Foundation for Families and Children 303 E. Retrieved from www.schoolengagement.org

New Zealand Government. (2016). New Zealand education system overview. Wellington, NZ: Ministry of Education. Retrieved from http://www.education.govt.nz/assets/Uploads/NZ-Education-System-Overviewpublication-web-format.pdf

New Zealand Government (n.d.). NZ-Education-System-Overview.

https://www.education.govt.nz/assets/Uploads/NZ-Education-System-Overviewpublication-web-format.pdf

New Zealand House of Representatives. (1995). Report of the education and science committee: Inquiry into children in education at risk through truancy and behavioural problems. Wellington, NZ: Research Division, Ministry of Education.

Ng, L. (2007). Attendance, absence and truancy in New Zealand schools in 2006. Wellington, NZ: Ministry of Education.

Nielson, A., \& Gerber, D. (1979). Psychosocial aspects of truancy in early adolescence. Adolescence, 14(54), 313-326.

Nilsson, M., Ejlertsoon, G., Andersson, I., \& Blomqvist, K. (2015). Caring as a salutogenic aspect in teachers' lives. Teaching and Teacher Education, 46, 51-61.

Noddings, N. (2012). The language of care ethics. Knowledge Quest, 40(4), 52-56.

Norton, P. L. (1934). Teamwork for the wayward child. Journal of Criminal Law and Criminology, 25(3), 434-437.

Nunes, M. B., Martins, T. J., Zhou, L., Alajamy, L.M., \& Al-Mamari, S. (2010). Contextual sensitivity in Grounded theory: The role of pilot studies. The Electronic Journal of Business Methods, 8(2), 73-84.

O’Donovan, R., Beman, N., \& Wierenga, A. (2015). How schools can move beyond exclusion. International Journal of Inclusive Education, 19(6), 645-658.

doi.org/10.1080/13603116.2014.961686

OECD. (2015). Are education and skills being distributed more inclusively? Education indicators in focus, No. 32. Paris: OECD. Retrieved from http://dx.doi.org/10.1787/5js0bsgdtr28-en.

Oranga Tamariki, Ministry of Children (n.d.) https://www.orangatamariki.govt.nz/ 
Osterman, K. F. (2000). Students' need for belonging in the school community. Review of Educational Research, 70(3), 323-367. doi.org/10.3102/00346543070003323

Ovink, S. (2011). “This ain't my school!” Criminality, control, and contradictions in institutional responses to school truancy. Qualitative Sociology, 34(1), 79-99. doi.org/10.1007/s11133-010-9181-x

Peshkin, A. (1988). In search of subjectivity: One's own. Educational Research, 17(7), $17-21$.

Phillippi, J., \& Lauderdale, J. (2018). A guide to field notes for qualitative research: Context and conversation. Qualitative Health Research, 28(3), 381-388. doi.org/10.1177/1049732317697102

Pianta, R. C., \& Allen, J. P. (2008). Building capacity for positive youth development in secondary school classrooms: Changing teachers' interactions with students. In M. B. Shinn \& H. Yoshikawa (Eds.), Towards positive youth development: Transforming schools and community programs (pp. 21-39). New York: Oxford University Press.

Pianta, R. C., Hamre, B. K., \& Allen, J. P. (2012). Teacher-student relationships and engagement: Conceptualizing, measuring, and improving the capacity of classroom interactions. In S. Christenson, A. Reschly, \& C. Wylie (Eds.), Handbook of research on student engagement (pp. 365-386). Boston, MA: Springer.

Pless, M. (2014). Stories from the margins of the educational system. Journal of Youth Studies, 17(2), 236-251. doi.org/10.1080/13676261.2013.815700

Prescott, P. A., \& Soeken, K. L. (1989). The potential uses of pilot work. Nursing Research, 38(1), 60. doi.org/10.1097/00006199-198901000-00015

Ratner, C. (2002). Subjectivity and objectivity in qualitative methodology. Forum: Qualitative Social Research, 3(3), 16-20.

Raval, V. V. (2012). Fight or flight? Competing discourses of individualism and collectivism in runaway boys' interpersonal relationships in India. Journal of Social and Personal Relationships, 30(4), 410-429.

doi.org/10.1177/0265407512458655

Ravet, J. (2007). Enabling pupil participation in a study of perceptions of disengagement: Methodological matters. British Journal of Special Education, 34(4), 234-242. doi.org/10.1111/j.1467-8578.2007.00484.x 
Redmond, A. (2018). Rare truancy prosecution a case of "last resort". Stuff. Retrieved from https://www.stuff.co.nz/education/105363770

Reeves, C. L. (2010). A difficult negotiation: Fieldwork relations with gatekeepers. Qualitative Research, 10(3), 315-331. doi.org/10.1177/1468794109360150

Reid, A., \& McCallum, F. (2014). 'Becoming your best': Student perspectives on community in the pursuit of aspirations. Australian Educational Researcher, 41(2), 195-207. doi.org/10.1007/s13384-013-0133-9

Reid, K. (1985). Truancy and school absenteeism. London: Hodder \& Stoughton.

Reid, K. (1999). How to stem the tide of truancy (British schools). Times Educational Supplement, Oct 8, Issue 4345, p. 27.

Reid, K. (2004). The views of head teachers and teachers on attendance issues in primary schools. Research in Education, 72, 60-76. doi.org/10.7227/RIE.72.5

Reid, K. (2006). An evaluation of the views of secondary school staff towards school attendance issues. Oxford Review of Education, 33(3), 303-324. doi.org/10.1080/03054980600775557

Reid, K. (2008). The causes of non-attendance: An empirical study. Educational Review, 60(4), 345-357. doi.org/10.1080/00131910802393381

Reid, K. (2010). Finding solutions to reduce truancy. Research in Education, 84(1), 118. doi.org/10.7227/RIE. 84.1

Reid, K. (2012). The strategic management of truancy and school absenteeism: Finding solutions from a national perspective. Educational Review, 64(2), 211-222. doi.org/10.1080/00131911.2011.598918

Reynolds, D., \& Murgatroyd, S. (1977). The sociology of schooling and the absent pupil: The school as a factor in the generation of truancy. In H. Carroll (Ed.), Absenteeism in South Wales: Studies of pupils, their homes and their secondary schools. Swansea, UK: University Press.

Richman, J. (1906). The incorrigible child. Educational Review, 31(May), 484-506.

Riley, P. (2011). Attachment theory and the teacher student relationship: A practical guide for teachers, teacher educators and school leaders. New York: Routledge.

Roache, J. L., \& Lewis, R. (2011). The carrot, the stick, or the relationship: What are the effective disciplinary strategies? European Journal of Teacher Education, 34(2), 233-248. doi.org/10.1080/02619768.2010.542586 
Rodriguez, G. M. (2013). Power and agency in education: Exploring the pedagogical dimensions of funds of knowledge. Review of Research in Education, 37(1), 87120. doi.org/10.3102/0091732X12462686

Rohrman, D. (1993). Combating truancy in our schools: A community effort. NASSP Bulletin, 77(549), 40-45. doi.org/10.1177/019263659307754906

Rosen, L. A., \& Dynlacht, D. (1994). Truancy intervention. The Journal of Research and Development in Education, 27(30), 203-211.

Rosenberg, M., \& McCullough, B. (1981). Mattering: Inferred significance and mental health among adolescents. Research in Community and Mental Health, 2(1994), $163-182$.

Rosenblum, S., Goldblatt, H., \& Moin, V. (2008). The hidden dropout phenomenon among immigrant high-school students: The case of Ethiopian adolescents in Israel - A pilot study. School Psychology International, 29(1), 105-127. doi.org/10.1177/0143034307088506

Ruddick, J., \& Flutter, J. (2004). How to improve school: Giving pupils a voice. London, UK: Continuum.

Rudduck, J. \& Demetriou, H. (2003) Student Perspectives and Teacher Practices: the transformative potential, McGill Journal of Education, 38, 274-288.

Ryan, T., \& Loader, M. (2012). Attendance in schools 2011. Wellington, NZ: Ministry of Education.

Saldana, J. (2011). Fundamentals of research: Understanding qualitative research. New York: Oxford University Press.

Saldana, J. (2016). The coding manual for qualitative researchers $\left(3^{\text {rd }}\right.$ ed.). Arizona: Sage.

Sälzer, C., Trautwein, U., Lüdtke, O., \& Stamm, M. (2012). Predicting adolescent truancy: The importance of distinguishing between different aspects of instructional quality. Learning and Instruction, 22(5), 311-319. doi.org/10.1016/j.learninstruc.2011.12.001

Sampson, H. (2004). Navigating the waves: The usefuleness of a pilot in qualitative research. Qualitative Research, 4(30), 383-402.

doi.org/10.1177/1468794104047236 
Sanders, J., Munford, R., \& Boden, J. (2018). Improving educational outcomes for atrisk students. British Educational Research Journal, 44(5), 763-780.

Schatzman, L. (1991). Dimensional analysis: Notes on an alternative approach to the grounding of theory in qualitative research. In D. R. Mains (Ed.), Social organisations and social process (pp. 303-314). New York: Aldine De Gruyter.

Schooling Analysis Unit. (2015). Attendance in New Zealand schools 2014. Wellington, NZ: Ministry of Education.

Schooling Analysis Unit. (2016). Attendance in New Zealand schools 2015. Wellington, NZ: Ministry of Education.

Schooling Analysis Unit. (2017). Attendance in New Zealand schools 2016. Wellington, NZ: Ministry of Education.

Schulz, L., \& Rubel, D. (2011). A phenomenology of alienation in high school: The experience of five male non-completers. Professional School Counselling, 14(2011), 286-298.

Sipe, L. R., \& Ghiso, M. P. (2004). Developing conceptual categories in classroom descriptive research: Some problems and possibilities. Anthropology and Education Quarterly, 35(4), 472-485. doi.org/10.1525/aeq.2004.35.4.472

Sixsmith, J., Boneham, M., \& Goldring, J. (2003). Assessing the community: Gaining insider perspectives from the outside. Qualitative Health Research, 13(4), 578589. doi.org/10.1177/1049732302250759

Sleeter, C. E., Bishop, R., \& Meyer, L. (2011). Professional development for culturally responsive and relationship-based pedagogy. In C. Sleeter (Ed.), Professional development for culturally responsive and relationship-based pedagogy (pp. 163178). New York: Peter Lang.

Smith, G. H. (2012). The politics of reforming Māori education: The transforming potential of kura kaupapa Māori. In H. Lauder \& C. Wylie (Eds.), Towards successful schooling (pp. 73-88). London: Routledge.

Smith, M. (2004). Edinburgh study of youth transition and crime. Edinburgh, Scotland: University of Edinburgh.

Sommer, B. (1985). What's different about truants? A comparison study of eighthgraders. Journal of Youth and Adolescence, 14(5), 411-422. 
Spencer, A. M. (2009). School attendance patterns, unmet educational needs, and truancy: A chronological perspective. Remedial and Special Education, 30(5), 309-319. doi.org/10.1177/0741932508321017

Split, J., Vervoort, E., \& Verschueven, K. (2017). Teacher-child dependency and teachers' sensitivity predict engagement of children with attachment problems. School Psychology Quarterly. Advance online publication. Retrieved from http://dx.doi.org./10.1037/spq000215

Stahl, G., \& Dale, P. (2013). Success on the decks: Working-class boys, education and turning the tables on perceptions of failure. Gender and Education, 25(3), 357372. doi.org/10.1080/09540253.2012.756856

Stern, P. N. (2009). In the beginning Glaser \& Strauss created grounded theory. In J. Morse, P. Stern, J. Corbin, B. Bowers, K. Charmaz, \& A. Clarke. (Eds.), Developing grounded theory: The second generation (pp. 24-29). Walnut Creek, CA: Left Coast Press.

Strand, A. M. (2014). 'School - no thanks - it ain't my thing': Accounts for truancy: Students' perspectives on their truancy and school lives. International Journal of Adolescence and Youth, 19(2), 262-277. doi.org/10.1080/02673843.2012.743920

Strauss, A. (1987). Qualitative analysis for social scientists. Cambridge, UK: Cambridge University Press.

Strauss, A., \& Corbin, J. (1990). Basics of qualitative research: Grounded theory procedures and techniques. Newbury Park, CA: Sage.

Strauss, A., \& Corbin, J. (1994). Grounded theory methodology: An overview. In N. Denzin \& Y. Lincoln (Eds.), Handbook of qualitative research (pp. 273-285). Thousand Oaks, CA: Sage.

Strauss, A., and Corbin, J. (1998). Basics of Qualitative Research - Techniques and Procedures for Developing Grounded Theory ( $\left.2^{\text {nd }} \mathrm{ed}\right)$. London, Sage Publications

Strauss, A., \& Corbin, J. (2008). Basics of qualitative research: Grounded theory procedures and techniques. Newbury Park, CA: Sage.

Strickland, V. P. (1998). Attendance and grade point average: A study (Report No.SP038147). East Lansing, MI: National Centre for Research on Teacher Learning. (ERIC Document Reproduction Service No. ED423224) 
Studsrød, I., \& Bru, E. (2011). Perceptions of peers as socialization agents and adjustment in upper secondary school. Emotional and Behavioural Difficulties, 16(2), 159-172. doi.org/10.1080/13632752.2011.569401

Suddaby, R. (2006). From the editors: What grounded theory is not. The Academy of Management Journal, 49(4), 633-642. doi.org/10.5465/amj.2006.22083020

Sultana, R. G. (2006). Facing the hidden drop-out challenge in Albania. Evaluation report of Hidden Drop-out Project Piloted in basic education in 6 prefectures of Albania, 2001-2005. Retrieved from www.unicef.org/albania/HDO_new_eng_2006.pdf.

Syrjäläinen, E., Jukarainen, P., Värri, V., \& Kaupinmäki, S. Y. (2015). Safe school day according to the young. Young, 23(1), 59-75. doi.org/10.1177/1103308814557399

Tarabini, A., Jacorkis, J., \& Montes, A. (2018). Factors in educational exclusion: Including the voice of youth. Journal of Youth Studies, 21(6), 836-851. doi.org/10.1080/13676261.2017.1420765

Tashakkari, A., \& Teddlie, C. (1998). Mixed methodology: Combining the qualitative and quantitative approaches. Thousand Oaks, CA: Sage.

Tavernier, R., \& Willoughby, T. (2012). Adolescent turning points: The association between meaning-making and psychological well-being. Developmental Psychology, 48(4), 1058-1068. doi.org/10.1037/a0026326

Tawhai, V., \& Gray-Sharp, K. (2011). Always speaking: The Treaty of Waitangi and public policy. Wellington, NZ: Huia.

Taylor, P. (1996). Doing reflective practitioner research in arts education. In P. Taylor (Ed.), Researching drama and arts education: Paradigms and possibilities. London; New York: Routledge Falmer.

TeAra (n.d.) TeAra Stories. Retrieved from www.teara.government.nz

Teasley, M. (2004). Absenteeism and truancy: Risk, protection, and best practice implications for school social workers. Children \& Schools, 26(2), 117-128. doi.org/10.1093/cs/26.2.117

Teijlingen, E. R., \& Hundley, V. (2001). The importance of pilot studies. Art and Science Clinical Research, 16(4), 33-36. doi.org/10.7748/ns2002.06.16.40.33.c3214 
Thistoll, T., Hooper, V., \& Pauleen, D. (2016). Acquiring and developing theoretical sensitivity through undertaking a grounded preliminary literature review. Quantity and Quality, 50(2), 619-636. doi.org/10.1007/s11135-015-0167-3

Thomas, D. V. (2015). Factors affecting successful reintegration. Educational Studies, 41(1-2), 188-208. doi.org/10.1080/03055698.2015.955749

Thompson, G., \& Bell, J. (2011). Mired in the shadows: Quiet students in secondary schools. Discourse: Studies in the Cultural Politics of Education, 32(3), 399-413. doi.org/10.1080/01596306.2011.573256. Bingley, U.K.: Emerald.

Thomson, P. (2011). Coming to terms with "voice". In Czerniawski, G., \& Kidd, W. (Eds.). The student voice handbook: Bridging the academic/practitioner divide. Bingley, UK: Emerald.

Tootill, R., \& Spalding, B. (2000). How effective can reintegration be for children with emotional and behavioural difficulties? Support for Learning, 15(3), 111-117. doi.org/10.1111/1467-9604.00159

Tracy, S. J. (2010). Eight "big-tent" criteria for excellent qualitative research. Qualitative Inquiry, 16(10), 837-851. doi.org/10.1177/1077800410383121

Trustees of Boston University. (1907). The root of truancy. The Journal of Education, 65(13), 348.

Tyerman, M. (1958). A research into truancy. British Journal of Educational Psychology, 28(3), 217-225. doi.org/10.1111/j.2044-8279.1958.tb01451.x

Tyerman, M. (1968). Truancy. London: University of London Press.

Tze, V. M. C., Daniels L. M., \& Klassen, R. M. (2016). Evaluating the relationship between boredom and academic outcomes: A meta-analysis. Educational Psychology Review, 28(1), 119-144. doi.org/10.1007/s10648-015-9301-y

Urquhart, C., \& Fernandez, W. (2006). Grounded theory method: The researcher as blank slate and other myths. ICTS 2006 Proceedings, 31. Retrieved from https://aisel.aisnet.org/icis2006/31

Vaughn, M. G., Maynard, B. R., Salas-Wright, C. P., Perron, B. E., \& Abdon, A. (2013). Prevalence and correlates of truancy in the US: Results from a national sample. Journal of Adolescence, 36(4), 736-776.

doi.org/10.1016/j.adolescence.2013.03.015 
Veenstra, R., Lindenberg, S., Tinga, F., \& Ormel, J. (2010). Truancy in late elementary and early secondary education: The influence of social bonds and self-control: The Trails Study. International Journal of Behavioural Development, 34(4), 302310. doi.org/10.1177/0165025409347987

Verschueren, K., \& Koomen, H. (2012). Teacher-child relationships from an attachment perspective. Attachment and Human Development, 14(3), 205-211.

doi.org/10.1080/14616734.2012.672260

Villegas, A. M. (2007). Dispositions in teacher education: A look at social justice. Journal of Teacher Education, 58(5), 370-380.

doi.org/10.1177/0022487107308419

Vogt, W. P. (2005). Dictionary of statistics and methodology: A nontechnical guide for the social sciences. London: Sage.

Walker, D., \& Myrick, F. (2006). Grounded theory: An exploration of process and procedure. Qualitative Health Research, 16(4), 547-559.

doi.org/10.1177/1049732305285972

Walliman, N. (2001). Doing your research project: A step-by-step guide for the first time teacher. London: Sage.

Wang, X. (2018). Treaty of Waitangi. Advances in Social Sciences Research Journal, $5(2), 138-142$.

Warne, M., Snyder, K., \& Gillander, G. K. (2013). Promoting an equal and healthy environment: Swedish students' view of daily life at school. Qualitative Health Research, 23(10), 1354-1368. doi.org/10.1177/1049732313505914

Watters, J. K., \& Biernacki, P. (1989). Targeted sampling: Options for the study of hidden populations. Social Problems, 36(4), 416-430. doi.org/10.2307/800824

Webber, R. (2003). Editor's comments: Theoretically speaking. MIS Quarterly, 27(3), iii-xii.

Wentzel, K. R. (1998). Social relationships and motivation in middle school: The role of parent teachers and peers. Journal of Educational Psychology, 90(2), 202-209. doi.org/10.1037/0022-0663.90.2.202

Williams, H. D. (1927). Truancy and delinquency. Journal of Applied Psychology 11(4), 276. doi.org/10.1037/h0073589 
Wilson, V., Malcolm, H., Edward, S., \& Davidson, J. (2008). Bunking off: The impact of truancy on pupils and teachers. British Journal of Educational Research, 34(1), 1-17. doi.org/10.1080/01411920701492191

Woodman, D. (2003). Responsibility and time for escape: The meaning of well-being to young Australians. Melbourne Journal of Politics, 29, 82-95.

Woolner, P., Thomas, U., Todd, L., \& Cummings, C. (2009, September). How do visually mediated encounters differ from traditional interviews? Paper presented at the first International Visual Methods Conference, Leeds, United Kingdom.

Wormington, S. V., Anderson, K. G., Schneider, A., Tomlinson, K. L., \& Brown., S. A. (2016). Peer victimisation and adolescent adjustment: Does school belonging matter? Journal of School Violence, 15(1), 1-21.

doi.org/10.1080/15388220.2014.922472

Wuest, J. (1995). Feminist grounded theory: An exploration of the congruency and tensions between two traditions in knowledge discovery. Qualitative Health Research, 5(1), 125-137. doi.org/10.1177/104973239500500109

Yingling, J., \& McClain, M. B. (2015). Snowballing, sampling and grounded theory, and theoretical sampling: Roles in methamphetamine markets. London: Sage.

Yonezawa, S., \& Jones, M. (2007). Using students' voices to inform and evaluate secondary school reform. In D. Thiessen \& A. Cook-Sather (Eds.), International handbook of student experience in elementary and secondary school (pp. 681709). The Netherlands: Springer.

Zhang, M. (2003). Links between school absenteeism and child poverty. Pastoral Care in Education, 21(1), 10-17. doi.org/10.1111/1468-0122.00249 


\section{APPENDIX 1}

ETHICS APPROVAL (p. 72)

From: Clare Howard on behalf of Education Ethics

Sent: Wednesday, 11 July 2012 2:39 PM

To: Delia Baskerville

Subject: RE: Ethics application SEPP/2012/24 RM19352

\section{Dear Delia}

RE: Ethics application SEPP/2012/24 RM19352

I am pleased to advise you that your ethics application 'Underneath the skin of truancy in schools' with the required changes, has been approved by the Victoria University of Wellington Faculty of Education Ethics Committee. Please note that the approval for your research to commence is from 11/07/2012.

Once your approval letter has been signed it can be picked up from the main reception at the Faculty of Education or if you prefer it can be sent to you, please let me know.

Regards

Clare Howard

Clare Howard- Faculty Office Administrator

Phone +64-4-463 9777

Faculty Administration \& Services, TE312

Faculty of Education

Victoria University of Wellington

Donald St, Karori, Wellington 6012

PO Box 17-310, Karori, Wellington 6147

New Zealand 


\section{APPENDIX 2 \\ QUESTIONNAIRE (P 73)}

\section{VICTORIA UNIVERSITY OF WELLINGTON \\ Te Whare Wananga o te Upoko o te Ika a Maui}

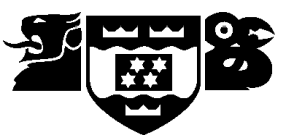

Underneath the skin of absence in schools

\section{NAME:}

\section{Your attendances at school}

Please put a cross on the line in the following statements to show what happens for you.

(a) How often do you bunk school?

\begin{tabular}{cccccccccc}
$\begin{array}{c}\text { Not at } \\
\text { all }\end{array}$ & \multicolumn{4}{c}{} & \multicolumn{4}{c}{ Sometimes } & \multicolumn{3}{c}{ Often } \\
\cline { 2 - 11 } & 1 & 2 & 3 & 4 & 5 & 6 & 7 & 8 & 9 \\
\hline
\end{tabular}

(b) I often bunk school because I am looking after my younger brothers and sisters

\begin{tabular}{ccccccccccc}
$\begin{array}{c}\text { Not at } \\
\text { all }\end{array}$ & \multicolumn{1}{c}{ Sometimes } & & Often \\
\cline { 2 - 11 } & 1 & 2 & 3 & 4 & 5 & 6 & 7 & 8
\end{tabular}

(c) I often bunk school because I do not get on with my teachers

\begin{tabular}{c|cccccccccc}
$\begin{array}{c}\text { Not at } \\
\text { all }\end{array}$ & \multicolumn{1}{c}{ Sometimes } & & Often \\
\cline { 2 - 10 } & 1 & 2 & 3 & 4 & 5 & 6 & 7 & 8 & 9
\end{tabular}

(d) I often bunk school because I am being bullied at school

\begin{tabular}{cccccccccc}
$\begin{array}{c}\text { Not at } \\
\text { all }\end{array}$ & \multicolumn{9}{c}{ Sometimes } \\
\hline 0 & 1 & 2 & 3 & 4 & 5 & 6 & 7 & 8 & 9
\end{tabular}

(e) I often bunk school because school work does not interest me

\begin{tabular}{c|ccccccccc}
$\begin{array}{c}\text { Not at } \\
\text { all }\end{array}$ & \multicolumn{1}{c}{ Sometimes } & & Often \\
0 & 1 & 2 & 3 & 4 & 5 & 6 & 7 & 8 & 9
\end{tabular}

(f) Other reasons I bunk school are

(g) I would attend school more often if ....... 


\section{APPENDIX 3}

\section{RECRUITMENT POSTER (p. 79)}

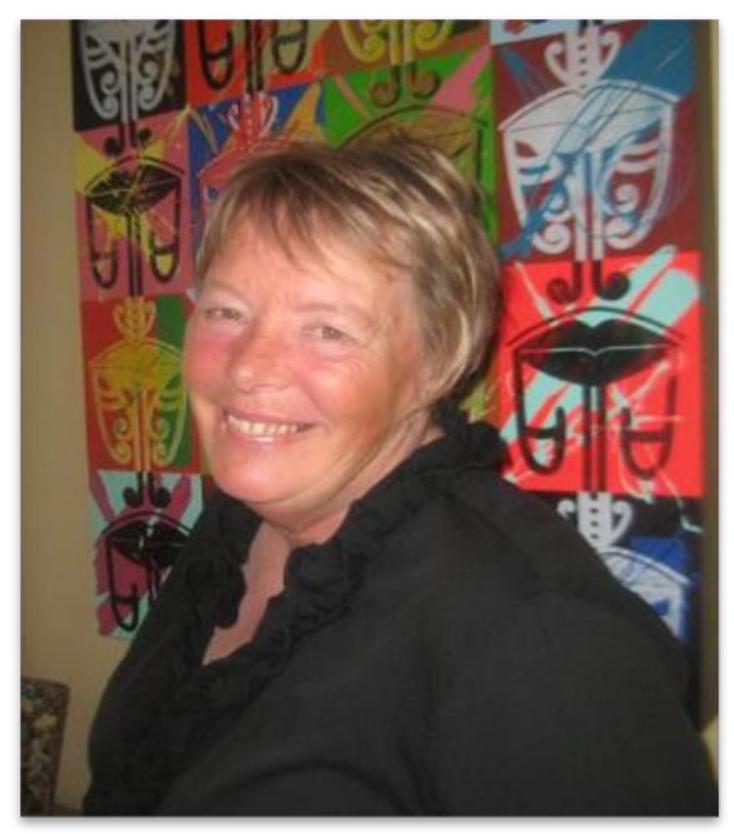

$\mathrm{Hi}$, my name is Delia; I am a $\mathrm{PhD}$ student at Victoria University. I am really interested in hearing your story about why you choose not to go to school. My own boys did not always attend school. I want to understand what young people want to change about going to school.

If you are interested in talking to me about why you chose not to go to school please tell your school counsellor.

N.B There were three versions of this poster; each version identified different staff members as the people for students to contact if they were interested in the research. These people included the school counsellor, the dean or the deputy principal. This person also provided me with access to the school. 


\section{APPENDIX 4 \\ EXAMPLE OF MEMO WRITING AFTER READING TRANSCRIPT (pp. $85 \&$ pp 90)}

School is the main setting Christina highlights in her interview and she describes her interactions with peers and with teachers both in and outside the classroom. She claims her peers are a positive influence; she describes them as amazing, enjoys their company; does not have to worry about anything and can be herself when she is with them. However, Christina states that peers can be a negative influence when youth do not fit in or feel they are not good enough to belong. Christina's interactions with teachers in the classroom setting are positive when; (1) Christina finds learning challenging and wants to get better at Maths; (2) teachers make you want to go to class; (3) class feels important; (4) someone cares; and (5) she has friends.

However, Christina also explains her contact with teachers in the classroom setting can be negative. These interactions occur when: (1) learning is hard; (2) she gets into trouble with her teacher for not attending; (3) her teacher attributes her bunking behaviour to her inability to understand the work; (4) she feels she cannot ask for help; (5) she does not like the teacher; and (6) she feels alone.

Christina does not mention contact with immediate family, or any connection between family and peer experiences. She understands she needs to change her attitude and behaviour, but there appears to be barriers to Christina achieving this. She thinks getting into trouble with teachers is horrible; she feels bad when blamed; she does not want to deal with the punishment her teacher imposes; she lacks friends and feels isolated in class, and decides to wag. For Christina the punishment for attending class (in trouble and feeling bad) influenced her choice to wag. She believes her teacher does not know what is going on in her life, and that she is depressed.

I wonder if knowing what is going on in her life would help the teacher to show more empathy and support Christina in her learning; I notice that Christina may choose not to go to class if she does not like the teacher or the task set. Christina appears to be avoiding punishment imposed by the teacher. She also claims that students need selfconfidence, positive attitude and friends to belong to a class; and that they cannot change truancy by themselves. She suggests students need support to change their drug and alcohol use, their "cool" attitude towards truanting and their motivation to attend and engage with learning. Christina argues that students do not understand the consequence of their behaviour until it is too late for them to do what they want to do in 
the future. She believes if she had support from someone who cares and was willing to help her in bad situations, she would feel happy with learning and going to class. It appears that Christina's decision to truant is influenced by interconnected issues. Christina mentions that everyone has a sweet escape; hers is music.

\section{What codes emerged from the data?}

So many open codes emerged from this interview. They included - choosing (12); helping (10); belonging/not (6); trying (7); taking responsibility (6); being alone (4); changing (4); prioritising (3); escaping (3); feeling down/bad (3); nature of friends (3); not noticing young people in class (3); getting in trouble (2); wanting space (2); camaraderie (2); worrying (not) (2); being my/yourself (2); willing to learn (2); thinking positive (2); needing (2); feeling scared (2); being held back (2); complying (2); drugs (2); habit (1); enjoying subjects (1); missing out (1); blaming (1); feeling happy (1); being motivated (1); feeling inadequate (1); being judged (1); being unmotivated to learn (1); feeling observed (1); getting attention (1); hiding feelings (1); fitting in (1); being cool (1); being punished (1); running away (1); and teacher having power (1).

\section{What do I want to clarify/ know now?}

I want to learn more about classroom dynamics and teacher/student relationships and their impact on students' truancy. For example: what is it about class that does not allow students to socialise or get together with friends? I want to know more about: students' sense of belonging, their relationships with teachers and how these contributing factors affect students' motivation to truant. Also, I want to know what causes students to feel down; how does depression relate to their choice to truant? I can therefore neither consider the influence of interactions in reciprocal relationships between family, friends and school nor fully understand the impact of truancy on her social development. I may need to consider questions to elicit such data in future interviews.

\section{What related general questions emerge from the data?}

- In your previous interview, you claimed that class isn't important, why is that?

- What is it about class that does not allow you to socialise or get together with friends?

- What are you doing, or thinking about, to pass time in class?

- What needs to change for you to belong in class?

- Why do you think teachers blame students for truanting class? 
- What difference would it make for you if teachers got to know you better and understood the circumstances you struggle with outside class?

- When you say music is your sweet escape what does that mean?

- You talked about life being a battle in your last interview; what did you mean by that?

- What causes you to feel down?

- What is it about people that you need to get away from them?

- In your last interview you explained you were happy outside class because you were with your friends, and what you got from them seemed to make up for what was lacking in class. Would you explain what you meant by this?

- You mentioned being alone several times in your last interview. Please tell me more, about what being alone means to you

- What made you realise that you need to have a different perspective on life, that you need to try and attend class?

- What support did you get to attend class again?

- In what ways do circumstances at home impact on you attending class? 


\section{APPENDIX 5}

EXAMPLE OF SIMILARLY LABELLED INCIDENTS OF DATA (p. 92)

\begin{tabular}{|c|c|c|}
\hline Name & Incident & Open code \\
\hline Bob & Maths is interesting & liking subject \\
\hline John & I like English and maths & liking subject/s \\
\hline Tyrone & $\begin{array}{l}\text { I have always just been into maths and } \\
\text { science, two of my favourite subjects. Others } \\
\text { would be music and engineering, like hands } \\
\text { on things to do }\end{array}$ & liking subject/s \\
\hline Becky & $\begin{array}{l}\text { Drama and like music and stuff and English } \\
\text { are okay and science. I love science }\end{array}$ & liking subject/s \\
\hline Julie & $\begin{array}{l}\text { It was the art classes; it was always art really, } \\
\text { even since primary school, art was always the } \\
\text { class I enjoyed the most }\end{array}$ & liking subject \\
\hline Christina & I enjoyed maths & liking subject \\
\hline Tyrone & $\begin{array}{l}\text { I enjoyed mostly maths and science; stuff to } \\
\text { do with chemistry, some physics, [and] maths } \\
\text { with geometry, something like that. }\end{array}$ & liking subjects \\
\hline Courtney & $\begin{array}{l}\text { I find science interesting and computers. [I } \\
\text { think] it's about the new things. }\end{array}$ & liking subject/s \\
\hline cky & $\begin{array}{l}\text { [I like those subjects] I'm just interested in } \\
\text { them. }\end{array}$ & Liking subjects \\
\hline
\end{tabular}

Note to self: There appears to be a link between subjects that students enjoy the most, being interested and learning new things. I wonder if there is a link between enjoying subjects and success in the classroom. 


\section{APPENDIX 6}

\section{IDENTIFYING ASPECTS FOR FURTHER INVESTIGATION (p. 93)}

\begin{tabular}{|c|c|}
\hline Success in the classroom & Disengaged from school \\
\hline $\begin{array}{l}\text { Julie loves everything about school: she is } \\
\text { happy at this school and could never imagine } \\
\text { a better school for her }\end{array}$ & $\begin{array}{l}\text { Something is holding Christina back from } \\
\text { learning. She does not want to learn. She } \\
\text { thinks loud students get attention }\end{array}$ \\
\hline Julie looks forward to class every single day & $\begin{array}{l}\text { Courtney does not like being round some } \\
\text { people when doing the school work }\end{array}$ \\
\hline $\begin{array}{l}\text { Amy enjoys her option subjects because she } \\
\text { got to choose what she wanted to do }\end{array}$ & $\begin{array}{l}\text { Courtney stopped going to school, just got } \\
\text { boring }\end{array}$ \\
\hline Becky wants to do the subjects she likes & $\begin{array}{l}\text { Tyrone finds a subject uninteresting when he is } \\
\text { not into it }\end{array}$ \\
\hline $\begin{array}{l}\text { John enjoys his chosen subjects and his native } \\
\text { tongue }\end{array}$ & $\begin{array}{l}\text { Courtney was motivated to attend school in the } \\
\text { beginning }\end{array}$ \\
\hline $\begin{array}{l}\text { Julie finds class is way less formal; it is } \\
\text { friendly and lovely, and they have open } \\
\text { discussions }\end{array}$ & $\begin{array}{l}\text { In order to come to school, John needs to rest } \\
\text { and wake up early. He finds that hard }\end{array}$ \\
\hline $\begin{array}{l}\text { Julie caches up every Monday: Teachers ask } \\
\text { what she got up to over the weekend }\end{array}$ & $\begin{array}{l}\text { John finds when he has done the work before } \\
\text { he does not want to repeat it }\end{array}$ \\
\hline $\begin{array}{l}\text { Christina wanted to do better when she liked } \\
\text { the subject, when relevant, interesting and } \\
\text { complicated learning. The challenge made } \\
\text { her want to attend. }\end{array}$ & $\begin{array}{l}\text { John gets off task too quick. The work might } \\
\text { be too hard. He thinks bad and just doesn't do } \\
\text { the work. He stops doing the work. }\end{array}$ \\
\hline $\begin{array}{l}\text { Amy really likes the subject and tries her } \\
\text { hardest and gives each class } 100 \%\end{array}$ & $\begin{array}{l}\text { John think negative : he won't be able to catch } \\
\text { up }\end{array}$ \\
\hline $\begin{array}{l}\text { Students enjoy subjects they like doing the } \\
\text { most, their favourite subjects; the ones that } \\
\text { they are interested in; and when they learn } \\
\text { about new things }\end{array}$ & $\begin{array}{l}\text { Bob got behind in his work when he stopped } \\
\text { truanting and returned to work }\end{array}$ \\
\hline $\begin{array}{l}\text { Julie called teachers by their first names: she } \\
\text { realised that they were above her [the teacher } \\
\text { and she was the student] however, first names } \\
\text { made her more levelled. }\end{array}$ & $\begin{array}{l}\text { A class is uninteresting for Becky when she } \\
\text { does not try and then gets bored. She does not } \\
\text { go }\end{array}$ \\
\hline $\begin{array}{l}\text { Because Julie developed a relationship with } \\
\text { her teachers it made her want to succeed more }\end{array}$ & John gets bored easily [I wonder why] \\
\hline $\begin{array}{l}\text { Caring is reciprocal: being there for them and } \\
\text { being there for you }\end{array}$ & Truanting was good while Bob was doing it \\
\hline $\begin{array}{l}\text { Courtney likes playing around with } \\
\text { computers. Her Mum used to be into } \\
\text { computers and Courtney knows a lot through } \\
\text { her. }\end{array}$ & $\begin{array}{l}\text { Julie thinks her friends are crazy truanting } \\
\text { because they will get into trouble }\end{array}$ \\
\hline $\begin{array}{l}\text { Courtney likes science because she gets to } \\
\text { play with everything }\end{array}$ & $\begin{array}{l}\text { Quiet students in class - like Christina - appear } \\
\text { to need support }\end{array}$ \\
\hline Bob does not find some subjects hard & Tyrone finds school boring: straight boring \\
\hline $\begin{array}{l}\text { Bob can do all his subjects with ease except } \\
\text { science. Ease is when you can do the work } \\
\text { without anyone else's help }\end{array}$ & $\begin{array}{l}\text { Bob suggests that it is boring sitting in class for } \\
\text { six hours listening to others speak }\end{array}$ \\
\hline $\begin{array}{l}\text { At her second school Julie experienced } \\
\text { teachers really caring about her }\end{array}$ & $\begin{array}{l}\text { Tyrone claims that teachers are there to help } \\
\text { students not to punish or judge them }\end{array}$ \\
\hline $\begin{array}{l}\text { Teachers were really excited and interested to } \\
\text { see Julie's work. They wanted the class to see } \\
\text { what she had worked on independently over } \\
\text { the weekend and enthusiastically invited her } \\
\text { to show her work }\end{array}$ & $\begin{array}{l}\text { Christina gets into trouble for not attending: she } \\
\text { finds it horrible because the teacher does not } \\
\text { know what is happening in her life }\end{array}$ \\
\hline Teachers were encouraging: they said they so & Becky does not like going to a particular class \\
\hline
\end{tabular}




\begin{tabular}{|c|c|}
\hline Success in the classroom & Disengaged from school \\
\hline looked forward to seeing the work finished & because the teacher is unfair and unreasonable \\
\hline $\begin{array}{l}\text { Because teachers are so involved, Julie feels } \\
\text { she cannot let them down }\end{array}$ & $\begin{array}{l}\text { Bob has been out of class for a while because } \\
\text { he and the teacher had a misunderstanding }\end{array}$ \\
\hline Teachers keep pushing and driving Julie & What the teacher says goes \\
\hline $\begin{array}{l}\text { Because her teachers helped her achieve Julie } \\
\text { wants them to be proud }\end{array}$ & $\begin{array}{l}\text { Christina's teacher blames her for not being } \\
\text { there }\end{array}$ \\
\hline $\begin{array}{l}\text { Becky's teacher is fair, she treats everyone the } \\
\text { same and does not have favourites }\end{array}$ & $\begin{array}{l}\text { John states that sometimes students get smart } \\
\text { back to teachers; and ; students get kicked out } \\
\text { of class }\end{array}$ \\
\hline $\begin{array}{l}\text { Becky's drama teacher is a good teacher: she } \\
\text { does not yell when something goes wrong; if } \\
\text { they do not understand she actually explains it } \\
\text { and does not tell her students "you're dumb" }\end{array}$ & $\begin{array}{l}\text { Christina claims that if she does not like the } \\
\text { teacher she will probably not go to class } \\
\text { because she does not like what the teacher has } \\
\text { set out for her }\end{array}$ \\
\hline $\begin{array}{l}\text { Bob was absent most of the year but still } \\
\text { scored higher marks in the test than most } \\
\text { people. He found everything easy. } \\
\text { [Streaming: placement in cases according to } \\
\text { ability?] }\end{array}$ & $\begin{array}{l}\text { John disclosed that sometimes teachers yell at } \\
\text { students. He observed a boy who made a little } \\
\text { mistake, he put his head down on the table, and } \\
\text { the teacher yelled at him }\end{array}$ \\
\hline $\begin{array}{l}\text { NOTE TO SELF: What am I noticing and } \\
\text { what might I keep an eye out for in upcoming } \\
\text { analysis? }\end{array}$ & $\begin{array}{l}\text { When Amy asked for help, the teacher did not } \\
\text { really try to help her. He said "you either know } \\
\text { it or you don't [teacher power - knowledge] }\end{array}$ \\
\hline $\begin{array}{l}\text { Relevant learning: students engage in subjects } \\
\text { they, are interested in, like, choose \& that are } \\
\text { challenging }\end{array}$ & $\begin{array}{l}\text { Often John hears students say they do not like } \\
\text { the teacher and invite others to truant class }\end{array}$ \\
\hline $\begin{array}{l}\text { Positive learning experiences appear to be } \\
\text { associated with teachers and the nature of } \\
\text { learning }\end{array}$ & $\begin{array}{l}\text { One of Courtney's classes is the hardest to } \\
\text { handle because of bullying }\end{array}$ \\
\hline Students do not appreciate unfairness & Some students are uncontrollable \\
\hline $\begin{array}{l}\text { Students claim that teachers do not notice } \\
\text { quiet students and that teachers get frustrated }\end{array}$ & $\begin{array}{l}\text { Amy thinks that one of her teachers is not } \\
\text { teaching well }\end{array}$ \\
\hline $\begin{array}{l}\text { Positive relationships with teachers motivate } \\
\text { students to engage and they have a reason to } \\
\text { succeed. }\end{array}$ & $\begin{array}{l}\text { In one of Christina's classes, the teacher has } 30 \\
\text { students to teach. She is quiet in class and } \\
\text { suggests that teachers probably do not notice } \\
\text { students like her are there. }\end{array}$ \\
\hline $\begin{array}{l}\text { Students claim that some teachers can be } \\
\text { harsh on them: Students do not like teachers } \\
\text { yelling at them or when they are too harsh. } \\
\text { What does being too harsh mean? }\end{array}$ & $\begin{array}{l}\text { John says that teachers take out their } \\
\text { frustrations on the good kids who sit and get on } \\
\text { with their work. }\end{array}$ \\
\hline $\begin{array}{l}\text { Students who truant appear to be often in } \\
\text { trouble with teachers }\end{array}$ & $\begin{array}{l}\text { Bob thinks that half the teachers do not know } \\
\text { what they are talking about }\end{array}$ \\
\hline $\begin{array}{l}\text { Students perceive that teachers are part of the } \\
\text { reason students disengage from learning and } \\
\text { truant }\end{array}$ & $\begin{array}{l}\text { John suggests that teachers are harsh on } \\
\text { students }\end{array}$ \\
\hline $\begin{array}{l}\text { Students think teachers are not there to punish } \\
\text { or judge. Students find it horrible to be } \\
\text { blamed. }\end{array}$ & $\begin{array}{l}\text { Tyrone suggests that students do not want } \\
\text { students to be harsh on them }\end{array}$ \\
\hline $\begin{array}{l}\text { Students do not like being blamed for not } \\
\text { knowing work when they begin to attend } \\
\text { again }\end{array}$ & $\begin{array}{l}\text { John is in a naughty class: students are always } \\
\text { talking; he is put off his work and ends up } \\
\text { talking to others }\end{array}$ \\
\hline \multirow[t]{4}{*}{$\begin{array}{l}\text { Setting goals supports students to have } \\
\text { direction, work hard and achieve }\end{array}$} & $\begin{array}{l}\text { John saw a real angry student hard out swearing } \\
\text { under his breath. He was whispering }\end{array}$ \\
\hline & $\begin{array}{l}\text { Becky does not get help when she does not } \\
\text { understand the work. She does not like } \\
\text { teachers treating students differently. }\end{array}$ \\
\hline & $\begin{array}{l}\text { Christina thinks that teachers assume students } \\
\text { are all right if they do not make any noise }\end{array}$ \\
\hline & Amy thinks students will get into trouble for \\
\hline
\end{tabular}




\begin{tabular}{|l|l|}
\hline Success in the classroom & \multicolumn{1}{c|}{ Disengaged from school } \\
\hline & not going to one class \\
\hline
\end{tabular}

So how do these dynamics in the classroom compare?

Some students perceive that things affect them negatively in the classroom. Teachers yelling, teachers blaming students, insufficient support to learn, and students not connecting to others.

Some things appear to help students return to class after truanting: Strong connections with others; teachers caring, being excited, passionate and interested; relevant learning inspires students to learn; teachers encouraging positive interactions with peers; setting goals for the future

\section{What do I understand now?}

It appears that many students are not connecting to learning. They do not appear to enjoy specific subjects. They perceive some classes are boring and some as too challenging.

It appears that most students are not connecting with their teachers when they perceive teachers as treating them unfairly, when they perceive that they do not receive sufficient academic support from teachers to learn and when they perceive teachers are judging them.

Some students appear to be alone in class. They do not connect with peers.

It appears that students do not want to be in classes where these dynamics are occurring.

This leaves me wondering about: What happens when youth truant? What experiences make truanting become a habit? 
(Appendix 6: Continued)

\section{Arising topics for clarification and emerging questions}

\section{Hypothesis 1: Sometimes students disengage from learning}

Emerging questions for adding details about "disengaging":

What events contribute to you disengaging from learning?

What support do you need to engage with academic work in the classroom?

What does a teacher being unfair and unreasonable mean?

What happens that switches students off so they do not attend?

\section{Hypothesis 2: Sometimes students are not connecting with others in class}

Emerging questions for adding details about "returning to class":

Why is this happening?

What needs to change so you can connect with others in class?

What academic support do you need when you return to class after truanting?

\section{Hypothesis 3: Students who truant are unhappy in class}

Emerging questions to develop new ideas:

What circumstances cause youth who truant to leave class?

What happens when these youth truant class?

What circumstances make truanting become a habit?

\section{Hypothesis 4: Sometimes teacher behaviours affect youth who truant}

(Note: Sometimes teachers do not notice students sitting quietly in class. Sometimes students do not receive the academic support they need. Sometimes learning is boring, or the work is too challenging. It appears that these circumstances are contributing to students "disengaging" from relationships and learning.)

Emerging questions for member checking:

What do you think about these ideas (hypothesis 4 above)?

In what ways are these experiences a true representation of your experiences?

In what ways are these experiences not a true representation of your experiences?

On occasion, students attend class even though it is not always a positive experience. Is this an experience you understand, and if so, please tell me a story about what happened at that time? 
APPENDIX 7

EXAMPLE OF CODING MECHANISMS THAT LED TO SUBSTANTIVE AND THEORETICAL CODING FOR THE AWAKENING CONSTRUCT (p. 95)

\begin{tabular}{|c|c|c|c|c|}
\hline \multicolumn{2}{|c|}{ Theoretical Coding } & \multicolumn{3}{|c|}{ Substantive Coding } \\
\hline \multirow{2}{*}{$\begin{array}{c}\text { Multi- } \\
\text { dimensional } \\
\text { construct }\end{array}$} & Theoretical Coding & $\begin{array}{l}\text { Tentative } \\
\text { Category }\end{array}$ & $\begin{array}{c}\text { Selective } \\
\text { Coding }\end{array}$ & Open Coding \\
\hline & Conceptualisation & \multicolumn{3}{|c|}{ Substantive Codes } \\
\hline \multirow[b]{2}{*}{ A } & \multirow{8}{*}{$\begin{array}{l}\mathrm{T} \\
\mathrm{U} \\
\mathrm{R} \\
\mathrm{N} \\
\mathrm{I} \\
\mathrm{N} \\
\mathrm{G}\end{array}$} & \multirow[b]{2}{*}{$\begin{array}{c}\text { M } \\
\text { A } \\
\text { K } \\
\text { I } \\
\text { N } \\
\text { G }\end{array}$} & $\begin{array}{l}\text { realising what is } \\
\text { required }\end{array}$ & $\begin{array}{l}\text { taking } \\
\text { responsibility } \\
\text { finding the } \\
\text { motivation } \\
\text { changing attitude } \\
\text { \& behaviour } \\
\text { thinking positive }\end{array}$ \\
\hline & & & needing support & $\begin{array}{l}\text { care \& support } \\
\text { respect for YP } \\
\text { taking wagging } \\
\text { seriously } \\
\text { thinking about } \\
\text { consequences } \\
\text { autonomy }\end{array}$ \\
\hline $\begin{array}{l}\mathrm{A} \\
\mathrm{K}\end{array}$ & & $\begin{array}{l}\mathrm{T} \\
\mathrm{H} \\
\mathrm{E}\end{array}$ & $\begin{array}{l}\text { learning the } \\
\text { lesson }\end{array}$ & $\begin{array}{l}\text { facing the } \\
\text { consequences }\end{array}$ \\
\hline E & & \multirow{7}{*}{$\begin{array}{l}\mathrm{C} \\
\mathrm{H} \\
\mathrm{A} \\
\mathrm{N} \\
\mathrm{G} \\
\mathrm{E}\end{array}$} & $\begin{array}{l}\text { effective } \\
\text { consequences }\end{array}$ & clear boundaries \\
\hline \multirow{6}{*}{ G } & & & getting support & $\begin{array}{l}\text { enabling change } \\
\text { engaged with } \\
\text { teachers }\end{array}$ \\
\hline & & & $\begin{array}{l}\text { ineffective } \\
\text { consequences }\end{array}$ & $\begin{array}{l}\text { managing } \\
\text { wagging better }\end{array}$ \\
\hline & & & $\begin{array}{l}\text { knowing the } \\
\text { pathway }\end{array}$ & planning ahead \\
\hline & & & $\begin{array}{l}\text { engaged with } \\
\text { school }\end{array}$ & positive changes \\
\hline & \multirow{2}{*}{$\begin{array}{l}\mathrm{E} \\
\mathrm{X} \\
\mathrm{I} \\
\mathrm{T} \\
\mathrm{I} \\
\mathrm{N} \\
\mathrm{G}\end{array}$} & & $\begin{array}{l}\text { Ineffective } \\
\text { consequences }\end{array}$ & $\begin{array}{l}\text { missed } \\
\text { opportunities } \\
\text { unaddressed } \\
\text { wagging }\end{array}$ \\
\hline & & & barriers & $\begin{array}{l}\text { inability to } \\
\text { change } \\
\text { feeling bad } \\
\text { socially isolated }\end{array}$ \\
\hline
\end{tabular}


APPENDIX 8

EXAMPLES OF INFORMATION SHEETS AND CONSENT

FORMS (p. 102)

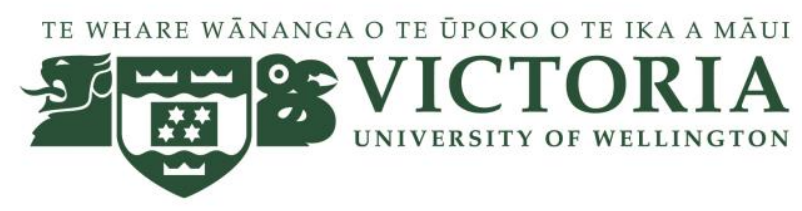

\author{
UNDERNEATH THE SKIN OF TRUANCY IN SCHOOLS: \\ An investigation into participants' perceptions of lived experiences of truancy
}

\title{
PRINCIPAL'S CONSENT FORM
}

Kia ora (name)

My name is Delia Baskerville and I am a Lecturer in the Faculty of Education at Victoria University of Wellington. My PhD proposal has been accepted for a research project titled, UNDERNEATH THE SKIN OF ABSENCE IN SCHOOLS: An investigation into students' perceptions of lived experiences of truancy. I am inviting you to give permission for students from your school to participate in my research project. Please read the information below before deciding whether or not to give permission for them to participate.

\section{What is the aim of the project?}

The aim of the research project is to find out about students' experiences of truancy. I want to gather information through interviews. The information will be used to write a $\mathrm{PhD}$ thesis and used to write a play which will be performed in a school community (date and venue to be confirmed).

\section{What will your students' participation involve?}

Students, if they agree, will be asked questions and they will answer them when I interview them.

\section{Can your students change their mind and withdraw from the project?}

If students decide they no longer want to participate in this research, they can change their minds and withdraw at any time before I begin to analyse the data.

\section{What data or information will be collected and what use will be made of it?}

Student's individual interviews will be audio recorded, transcribed, and analysed. The research findings will be written up as a $\mathrm{PhD}$ thesis and used to write a play which will be performed in a school community (date and venue to be confirmed). The information will also be used for future lectures, conferences, and papers for publication in academic journals. 
Participation will be confidential and students' names will not be used at any time. The audio taped interviews will be destroyed at the end of the project. Participants' transcribed interviews will be kept in secure storage for five years, after which they will be destroyed. Interviews will be shared with my supervisors: Dr. Judith Loveridge (judith.loveridge@vuw.ac.nz $04 \quad 463$ 6028) and $\quad$ Dr. Vivien van Rij (vivien.vanrij@vuw.ac.nz 04463 9706).

If you have any questions about the research please do not hesitate to contact me or my supervisors. If you have any ethical concerns please contact Dr. Allison Kirkman, Chair of the Victoria University of Wellington Human Ethics Committee (Allison.Kirkman@vuw.ac.nz).

I hope my research will help students who do not attend school, attend school, as well as inform strategies for disengaged youth in the future. Thank you for considering giving your permission to conduct this research in this school.

Kind regards,

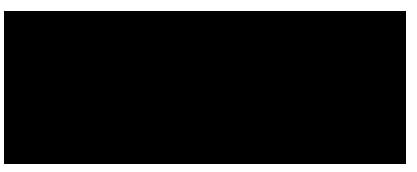

Delia Baskerville

Lecturer

Faculty of Education

Victoria University

PO Box 17310

Karori, Wellington

New Zealand

Phone: 044639639

Email: delia.baskerville@vuw.ac.nz

This research has been assessed and approved by Victoria University Faculty of Education Ethics Committee. (Ethics number RM19352) 


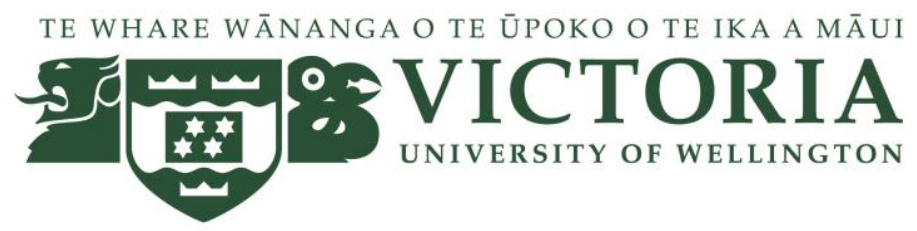

\section{UNDERNEATH THE SKIN OF TRUANCY IN SCHOOLS: \\ An investigation into perceptions of lived experiences of truancy PRINCIPAL'S CONSENT FORM}

Please read the following statements: if you do not want to take part in this research project please leave the form blank and sign your name. If you do want to participate, and you agree with the comments please tick the boxes below and sign the form.

I understand that Delia will not tell people participants' names or the name of our school.

I understand that I have a choice to invite students to take part in this study.

I understand that students will be asked to READ information sheets, complete a consent form, and answering questions in an interview.

I understand that students will be given an opportunity to check their interview transcripts and make changes if they want to.

I understand that the information they give will inform the data gathering process for Delia's $\mathrm{PhD}$ thesis.

I understand that students and deans may change their minds and pull out of the research at any time within two days of the interview.

$\square \quad$ I understand that audio-recorded interviews will be destroyed at the end of the project, and that transcribed interviews will be retained in secure storage for five years, after which they will be destroyed.

I understand that the information gathered from this research may be used for future lectures to University students, conference papers and/or publications in academic journals.

I understand that there is no payment for any individual's participation.

I consent to allow staff and students from my school to participate in this research project. 
Your name:

Date:

Your signature:

This research has been assessed and approved by Victoria University Faculty of Education Ethics Committee (Ethics number RM19352) 


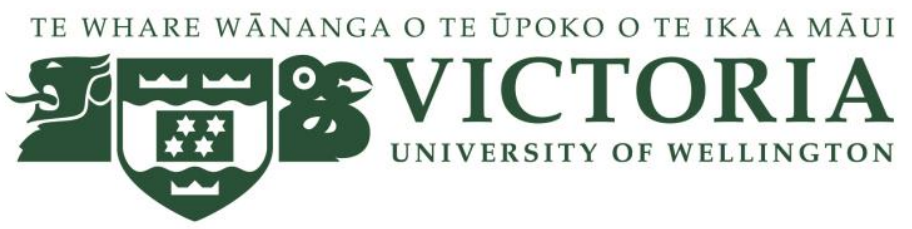

UNDERNEATH THE SKIN OF TRUANCY IN SCHOOLS:

An investigation into perceptions of lived experiences of truancy

INFORMATION SHEET FOR STUDENTS

Kia ora (name)

My name is Delia Baskerville. I am a Lecturer in the Faculty of Education at Victoria University and I am inviting you to participate in my research project for my $\mathrm{PhD}$. We will read the information below together before you decide whether or not you would like to take part.

\section{What is the aim of the project?}

The aim of the research project is to find out about your experiences of truancy. I want to gather information through interviews. The information will be used to write a $\mathrm{PhD}$ thesis and used to write a play, which will be performed in a school community (date and venue to be confirmed).

\section{What will participation involve?}

I will ask you to answer some questions and you will answer them.

\section{Can you change your mind and withdraw from the project?}

If you decide you do not want me to use the information you gave me you can change your mind within two days of our meeting.

\section{What data or information will be collected and what use will be made of it?}

Your answers to my questions will be audio-recorded, written out word for word and read very carefully. The information you give me will help me understand what it is like for students who do not come to school. The information you give me will also be used in lectures to University students, conferences and papers for publication in academic journals to help adults understand what it is like for students who do not come to school.

I will not tell anyone your name at any time. I will keep who you are and what you tell me safe and private. I will look after your answers very carefully. Then they will be destroyed. I hope my research will help students who do not attend school, come to school as well as inform strategies for disengaged youth in the future. Thank you for thinking about my invitation. 
Kind regards

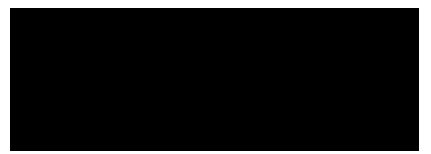

Delia Baskerville

Faculty of Education

Victoria University

PO Box 17-310, Karori, Wellington, New Zealand

Phone: 044639639

Email: delia.baskerville@vuw.ac.nz

People I work with have looked at what I want children to do and think it safe for them to take part. (Ethics number RM19352) 


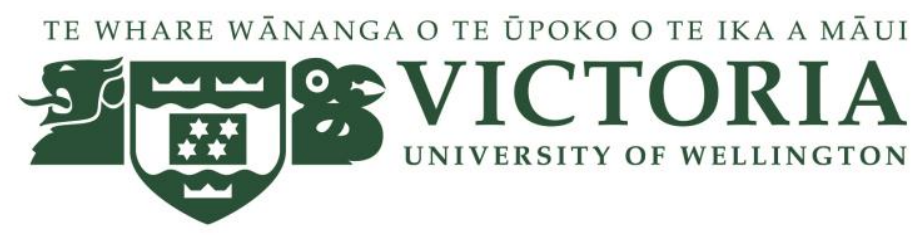

\section{UNDERNEATH THE SKIN OF TRUANCY IN SCHOOLS:}

An investigation into perceptions of lived experiences of truancy STUDENT CONSENT FORM

Please read the following statements: if you do not want to take part in this research please leave the form blank and sign your name. If you do want to participate, and you agree with the comments please tick the boxes below and sign the form.

\section{I understand that Delia will not tell people my name or my school's name}

I understand that I have a choice to take part in this study

I understand, if I want to, I will answer when Delia asks me questions

I understand that I will be given an opportunity to check my written interview and make changes if I want to

I understand that my interview will help adults to understand what it is like for children who do not come to school

I understand that I may decide to change my mind and pull out of the research at any time within two days of our interview.

I understand that audio-recorded answers to my questions will be written out word for word and read very carefully

I understand that the information I give will contribute to Delia's PhD thesis and a play to be performed at a time and place to be confirmed

I agree that my interview may be used in lectures to University students, conference papers and/or publications in academic journals

I understand that if I tell Delia anything that will cause me harm she will support me to seek help and check that I am okay with three days of our interview

I understand that there is no payment for participation

I agree to take part in this research 
Your name:

Date:

Your signature:

People I work with have looked at what I want children to do and think it safe for them to take part. (Ethics number RM19352) 


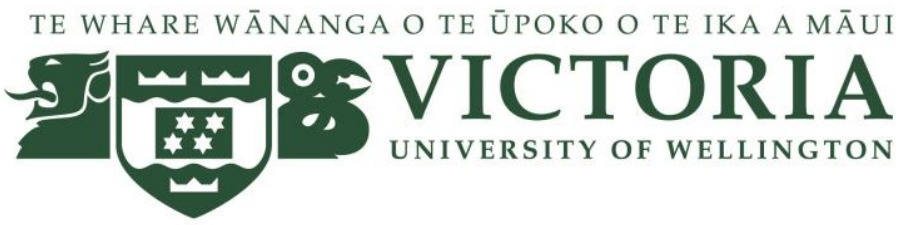

\title{
UNDERNEATH THE SKIN OF TRUANCY IN SCHOOLS: An investigation into perceptions of lived experiences of truancy
}

\author{
INFORMATION SHEET \\ FOR PARENTS/CAREGIVERS
}

Kia ora (name)

My name is Delia Baskerville. I am a Lecturer in the Faculty of Education at Victoria University and I am inviting to give permission for your child to participate in my research project. Please read the information below before deciding whether or not you would like your child to take part.

\section{What is the aim of the project?}

The aim of the research project is to find out about your child's experiences of truancy. I want to gather information through interviews. The information will be used to write a $\mathrm{PhD}$ thesis and used to write a play which will be performed in a school community (date and venue to be confirmed).

\section{What will participation involve?}

Your child will be asked to answer questions when I interview them.

\section{Can my change their mind and withdraw from the project?}

If your chlid decides that they no longer want to participate in the project they can change their mind within two days of our interview.

\section{What data or information will be collected and what use will be made of it?}

Your child's individual interview will be audio-recorded, transcribed, and analysed. The research findings will be used to inform the data gathering process for a $\mathrm{PhD}$ thesis. Their interview will also be used in future lectures to University students, conferences and papers for publication in academic journals. 
Neither your chid's names, nor their school name, will be used at any time and I will protect their identity and any information given to me. The audio-recorded interviews will be destroyed at the end of the project. Transcribed interviews will be kept in secure storage for five years, after which they will be destroyed.

Interviews will be shared with my supervisors: Dr. Judith Loveridge (judith.loveridge@vuw.ac.nz $\quad 04 \quad 463$ 6028) and $\quad$ Dr. Vivien van Rij (vivien.vanrij@vuw.ac.nz 04463 9706). If you have any questions about the research please do not hesitate to contact me or my supervisors. If you have any ethical concerns please contact Dr. Allison Kirkman, Chair of the Victoria University of Wellington Human Ethics Committee (Allison.Kirkman@vuw.ac.nz).

I hope my research will help children who do not attend school come to school as well as inform strategies for disengaged youth in the future. Thank you for considering my invitation.

Kind regards

Delia Baskerville

Faculty of Education

Victoria University

PO Box 17-310, Karori, Wellington, New Zealand

Phone: 044639639

Email: delia.baskerville@vuw.ac.nz

This research has been assessed and approved by Victoria University Faculty of Education Ethics Committee. (Ethics number RM19352) 


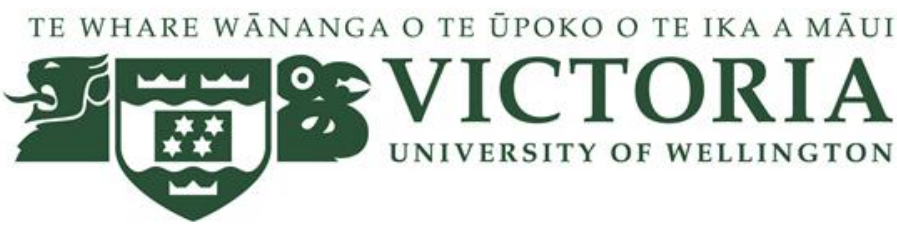

\section{UNDERNEATH THE SKIN OF TRUANCY IN SCHOOLS: An investigation into perceptions of lived experiences of truancy}

\section{CONSENT FORM FOR PARENT / CAREGIVERS OF STUDENT PARTICIPANTS}

Please read the following statements: If you do not want to take part in the study of this research project please leave the form blank and sign your name. If you do want to participate, and you agree with the comments, please tick the boxes below and sign the form.

I understand that Delia will not use my child's name, or his / her school name

I understand that my child has a choice to take part in this research

I understand my child will be interviewed

I understand that my child will be given an opportunity to check the interview transcript and make changes if desired

I understand that the information my child discloses will contribute to a $\mathrm{PhD}$ thesis and a play to be performed at a date and enue to be confirmed

I understand that my child may change their mind and pull out of the research at any time within two days of the interview with Delia

I understand that audio-taped interview transcripts will be destroyed at the end of the project, and that my child's transcribed interviews will be kept in secure storage for five years, after which it will be destroyed.

I understand that this research may be used in future lectures, conference papers and / or publications in academic journals

I understand that there is no payment for any individual's participation

I give permission for my child to participate in this research 
Your name:

Date:

Your signature:

This research has been assessed and approved by Victoria University Faculty of Education Ethics Committee. (Ethics number RM19352) 